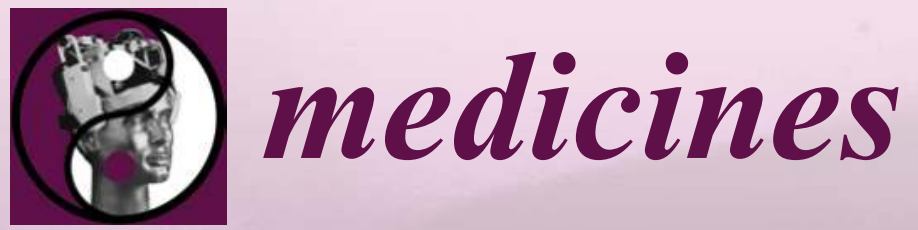

Acupuncture-

Basic Research

and Clinical

Application

Printed Edition of the Special Issue Published in Medicines 
Acupuncture-Basic Research and
Clinical Application 



\section{Acupuncture-Basic Research and Clinical Application}

Special Issue Editor

Gerhard Litscher 
Special Issue Editor

Gerhard Litscher

Medical University of Graz

Austria

\section{Editorial Office}

MDPI

St. Alban-Anlage 66

Basel, Switzerland

This is a reprint of articles from the Special Issue published online in the open access journal Medicines (ISSN 2305-6320) from 2016 to 2018 (available at: http://www.mdpi.com/journal/medicines/ special_issues/acupuncture)

For citation purposes, cite each article independently as indicated on the article page online and as indicated below:

LastName, A.A.; LastName, B.B.; LastName, C.C. Article Title. Journal Name Year, Article Number, Page Range.

\section{ISBN 978-3-03897-234-1 (Pbk)}

ISBN 978-3-03897-235-8 (PDF)

Cover image courtesy of Gerhard Litscher.

Articles in this volume are Open Access and distributed under the Creative Commons Attribution (CC BY) license, which allows users to download, copy and build upon published articles even for commercial purposes, as long as the author and publisher are properly credited, which ensures maximum dissemination and a wider impact of our publications. The book taken as a whole is (C) 2018 MDPI, Basel, Switzerland, distributed under the terms and conditions of the Creative Commons license CC BY-NC-ND (http:/ / creativecommons.org/licenses/by-nc-nd/4.0/). 


\section{Contents}

About the Special Issue Editor $\ldots \ldots \ldots \ldots \ldots \ldots \ldots \ldots$ vii

Preface to "Acupuncture-Basic Research and Clinical Application" $\ldots \ldots \ldots \ldots \ldots$ ix

Gerhard Litscher

Introduction to the Medicines Special Issue on Acupuncture-Basic Research and Clinical Application

Reprinted from: Medicines 2018, 5, 99, doi: 10.3390/medicines5030099 _ . . . . . . . . . . . 1

Gerhard Litscher

Laser Acupuncture Research: China, Austria, and Other Countries-Update 2018

Reprinted from: Medicines 2018, 5, 92, doi: 10.3390/medicines5030092 . . . . . . . . . . . . . 5

Xiaojuan Shang, Luquan Chen, Gerhard Litscher, Yanxia Sun, Chuxiong Pan, Cun-Zhi Liu, Daniela Litscher and Lu Wang

Acupuncture and Lifestyle Myopia in Primary School Children-Results from a Transcontinental Pilot Study Performed in Comparison to Moxibustion

Reprinted from: Medicines 2018, 5, 95, doi: 10.3390/medicines5030095 . . . . . . . . . . . . .

David F. Mayor, Lara S. McClure and J. Helgi Clayton McClure

Individual Differences in Responsiveness to Acupuncture: An Exploratory Survey of Practitioner Opinion

Reprinted from: Medicines 2018, 5, 85, doi: 10.3390/medicines5030085 . . . . . . . . . . . . . 15

Tilo Blechschmidt, Maike Krumsiek and Margarita G. Todorova

The Effect of Acupuncture on Visual Function in Patients with Congenital and Acquired Nystagmus

Reprinted from: Medicines 2017, 4, 33, doi: 10.3390/medicines4020033 . . . . . . . . . . . . 4

David F. Mayor, Lara S. McClure and J. Helgi Clayton McClure

Nonspecific Feelings Expected and Experienced during or Immediately after Electroacupuncture: A Pilot Study in a Teaching Situation

Reprinted from: Medicines 2017, 4, 19, doi: 10.3390/medicines4020019 . . . . . . . . . . . . . 57

Shuo-Ping Tseng, Yu-Ching Hsu, Ching-Ju Chiu and Shang-Te Wu

A Population-Based Cohort Study on the Ability of Acupuncture to Reduce Post-Stroke Depression

Reprinted from: Medicines 2017, 4, 16, doi: 10.3390/medicines4010016 . . . . . . . . . . . . . 79

Masashi Watanabe, Soichiro Kaneko, Shin Takayama, Yasuyuki Shiraishi, Takehiro Numata, Natsumi Saito, Takashi Seki, Norihiro Sugita, Satoshi Konno, Tomoyuki Yambe, Makoto Yoshizawa, Nobuo Yaegashi and Tadashi Ishii

The Pilot Study of Evaluating Fluctuation in the Blood Flow Volume of the Radial Artery, a Site for Traditional Pulse Diagnosis

Reprinted from: Medicines 2016, 3, 11, doi: 10.3390/medicines3020011 . . . . . . . . . . . . 89

Tiaw-Kee Lim, Yan Ma, Frederic Berger and Gerhard Litscher

Acupuncture and Neural Mechanism in the Management of Low Back Pain-An Update

Reprinted from: Medicines 2018, 5, 63, doi: 10.3390/medicines5030063 . . . . . . . . . . . . 98 
James David Adams Jr.

The Effects of Yin, Yang and Qi in the Skin on Pain

Reprinted from: Medicines 2016, 3, 5, doi: 10.3390/medicines3010005

Joana Teixeira, Maria João Santos, Luís Carlos Matos and Jorge Pereira Machado

Evaluation of the Effectiveness of Acupuncture in the Treatment of Knee Osteoarthritis:

A Case Study

Reprinted from: Medicines 2018, 5, 18, doi: 10.3390/medicines5010018 .

Henry Xiao, Christopher Zaslawski, Janette Vardy and Byeongsang Oh

Treatment of Sciatica Following Uterine Cancer with Acupuncture: A Case Report

Reprinted from: Medicines 2018, 5, 6, doi: 10.3390/medicines5010006 . . . . . . . . . . . . 148

Narda G. Robinson

Why We Need Minimum Basic Requirements in Science for Acupuncture Education

Reprinted from: Medicines 2016, 3, 21, doi: 10.3390/medicines3030021 . . . . . . . . . . . . . 152 


\section{About the Special Issue Editor}

Gerhard Litscher, Prof. MSc PhD MDsc, is Head of the Research Unit for Complementary and Integrative Laser Medicine and of the Research Unit of Biomedical Engineering in Anesthesia and Intensive Care Medicine and Chairman of the TCM (Traditional Chinese Medicine) Research Center at the Medical University of Graz, Austria. He is a Doctor of Technical Sciences and Doctor of Medical Sciences and has published more than 220 SCI/PubMed-listed articles. He is the author and/or editor of 16 books and editor-in-chief (e.g., Medicines) and/or editorial board member of more than 35 international journals. Gerhard Litscher is also President of the International Society for Medical Laser Applications (ISLA transcontinental, since 2012) and German Vice President of the German-Chinese Research Foundation (DCFG, since 2014). He is a member of the expert panels of the World Health Organization (WHO) for acupuncture and related fields and is currently honorary or guest professor at 11 top universities and institutions in Asia (www.litscher.info). 



\section{Preface to "Acupuncture-Basic Research and Clinical Application"}

Acupuncture has been used for medical treatment for thousands of years. Using needles, electro acupuncture, moxibustion, or laser stimulation in combination with modern analytical biomedical techniques, it is possible to quantify the changes in biological activities caused by acupuncture.

The bridging between Eastern and Western medicine has been successfully achieved using modern biomedical engineering technologies; the next task is to make the arising possibilities and results beneficial to all patients.

The editor thanks his team members, especially Mrs. Lu Wang, PD Dr.med., and Mrs. Daniela Litscher, Mag.parm. Dr.scient.med., both at the Medical University of Graz, Austria, for their excellent cooperation. In this context, he would also like to thank all the other 44 authors from all over the world for their high-quality contributions to this book.

Above all, the editor wants to thank Mrs. Bonnie Yang, Managing Editor of Medicines, for her valuable support in every respect. Without her continuous support, this book would have never seen the printer's ink. Special thanks also to the publisher MDPI, Basel, Switzerland, especially to Dr. Franck Vazquez and Dr. Martyn Rittman. Within this book, 13 peer-reviewed chapters are summarized. The editor of this book is the corresponding and/or first author of four chapters, one of them in partnership with Chinese colleagues. All articles are PubMed-listed. A short introduction to this book (Medicines Special Issue on Acupuncture-Basic Research and Clinical Application) can be found in the first chapter.

Gerhard Litscher

Special Issue Editor 

Editorial

\title{
Introduction to the Medicines Special Issue on Acupuncture-Basic Research and Clinical Application
}

\begin{abstract}
Gerhard Litscher
Research Unit for Complementary and Integrative Laser Medicine, Research Unit of Biomedical Engineering in Anesthesia and Intensive Care Medicine, and TCM Research Center Graz, Medical University of Graz, Auenbruggerplatz 39, EG19, 8036 Graz, Austria; gerhard.litscher@medunigraz.at; Tel.: +43-316-385-83907; Fax: +43-316-385-595-83907

Received: 3 September 2018; Accepted: 3 September 2018; Published: 4 September 2018

Abstract: This Medicines special issue focuses on the further investigation, development, and modernization of acupuncture in basic research settings, as well as in clinical applications. The special issue contains 12 articles reporting latest evidence-based results of acupuncture research, and exploring acupuncture in general. Altogether 44 authors from all over the world contributed to this special issue.
\end{abstract}

Keywords: acupuncture; moxibustion; myopia; post-stroke; depression; pulse diagnosis; low back pain (LBP); osteoarthritis; uterine cancer; sciatica

This special issue contains 12 articles with different topics in the field of modern acupuncture research (Figure 1).

\begin{tabular}{|c|c|}
\hline Laser & - Litscher G, Editorial \\
\hline Myopia & - Shang X et al. Research \\
\hline Practitionar Opinion & - Mayor D. et al. Research \\
\hline Visual Function & - Blechschmidt T. et al. Research \\
\hline Electroacupuncture Teaching & - Mayor D. et al. Research \\
\hline Post-Stroke Depression & - Tseng S. et al. Research \\
\hline Pulse Diagnosis & - Watanabe et al. Research \\
\hline Low Back Pain & - Lim T. et al. Review \\
\hline Yin, Yang, Qi, and Pain & - Adams J. Review \\
\hline Knee Osteoarthritis & - Teixeira J. et al. Case Report \\
\hline Sciatica & - Xiao H. et al. Case Report \\
\hline Education & - Robinson N. Opinion \\
\hline
\end{tabular}

Figure 1. Topics of the present Medicines special issue.

The editorial “Laser Acupuncture Research: China, Austria, and Other Countries-Update 2018 "contains an overview of the current status of published articles on the subject of laser acupuncture research [1]. 
"Acupuncture and Lifestyle Myopia in Primary School Children-Results from a Transcontinental Pilot Study Performed in Comparison to Moxibustion" [2] is the title of a prospective pilot study in 44 patients aged between 6 and 12 years with myopia. Possible therapeutic aspects with the help of evidence-based complementary methods like acupuncture or moxibustion have not yet been investigated adequately in myopic patients. This study showed that both acupuncture and moxibustion can improve myopia of young patients. Acupuncture seems to be more effective than moxibustion in treating myopia; however further Big data studies are necessary to confirm or refute the preliminary results.

"Individual Differences in Responsiveness to Acupuncture: An Exploratory Survey of Practitioner Opinion" from David Mayor et al. [3] documents patient characteristics that may influence responsiveness to acupuncture treatment, reporting results from an exploratory practitioner survey. Quantitative and qualitative analyses were then conducted. Practitioner characteristics influence their appreciation of patient characteristics. Factors consistently viewed as important included ability to relax, exercise and diet. Acupuncture practitioners may benefit from additional training in certain areas. Surveys may produce more informative results if reduced in length and complexity.

The aim of another study is to examine the short-term effect of visual function following acupuncture treatment in patients with congenital idiopathic nystagmus and acquired nystagmus [4] Therefore an observational pilot study on six patients with confirmed diagnosis of nystagmus was performed. The applied acupuncture protocol showed improvement in the visual function of nystagmus patients and thus, in their quality of life. Further studies are mandatory to differentiate which group of nystagmus patients would benefit more from acupuncture.

Some feelings elicited by acupuncture-type interventions are "nonspecific", interpretable as resulting from the placebo effect, our own self-healing capacities. Expectation is thought to contribute to these nonspecific effects. In the article "Nonspecific Feelings Expected and Experienced during or Immediately after Electroacupuncture: A Pilot Study in a Teaching Situation" the authors describe the use of two innovative 20-item questionnaires in a teaching situation [5]. Cluster analysis suggested the existence of two primary feeling clusters, "Relaxation" and "Alertness". Feelings experienced during or immediately after acupuncture-type interventions may depend both on prior experience and expectation.

Post-stroke depression (PSD) is common and has a negative impact on recovery. Although many stroke patients have used acupuncture as a supplementary treatment for reducing stroke comorbidities, little research has been done on the use of acupuncture to prevent PSD. Within a contribution to this special issue [6] the authors controlled for potential confounders, and it appears that using acupuncture after a stroke lowers the risk of depression.

Radial artery (RA) pulse diagnosis has been used in traditional Asian medicine for a long time. In this article, the authors measured blood flow volume and heart rate variability in the RA and evaluated its fluctuations [7]. It is suggested that fluctuation in the volume at low frequencies of RA is influenced by the fluctuation in velocity; on the other hand, fluctuation in the volume at high frequencies is influenced by the fluctuation in vessel diameter.

In addition to the research articles there are also two review articles included in this special issue $[8,9]$.

Within the last 10 years, the percentage of low back pain (LBP) prevalence increased by $18 \%$. The management and high cost of LBP put a tremendous burden on the healthcare system [8]. Many risk factors have been identified, such as lifestyle, trauma, degeneration, postural impairment, and occupational related factors; however, as high as $95 \%$ of the cases of LBP are non-specific. Acupuncture for LBP is one of the most commonly used non-pharmacological pain-relieving techniques. This is due to its low adverse effects and cost-effectiveness. In this article, the causes and incidence of LBP on global health care are reviewed [8].

The most effective and safe treatment site for pain is in the skin. Another review article discusses the reasons to treat pain in the skin [9]. Pain is sensed in the skin through transient receptor potential 
cation channels and other receptors. These receptors have endogenous agonists (yang) and antagonists (yin) that help the body control pain.

Two case reports are also available [10,11]. Osteoarthritis is a widespread chronic disease seen as a continuum of clinical occurrences within several phases, which go from synovial inflammation and microscopic changes of bone and cartilage to painful destructive changes of all the joint structures. The first case study [10] included two patients with clinical signs of osteoarthritis and diagnosis of medial pain. The results were positive, acupuncture was effective as an alternative or complementary treatment of knee osteoarthritis, with high levels of improvement within a modest intervention period.

For women, gynecological or obstetrical disorders are second to disc prolapse as the most common cause of sciatica. As not many effective conventional treatments can be found for sciatica following uterine cancer, patients may seek assistance from complementary and alternative medicine. Here, the authors present a case of a woman with severe and chronic sciatica secondary to uterine cancer who experienced temporary relief from acupuncture [11].

Last but not least an interesting answer is given: "Why We Need Minimum Basic Requirements in Science for Acupuncture Education" [12]. Acupuncture education for both licensed physicians and non-physicians needs to include science, evidence, and critical thinking.

Funding: This editorial/preface to the different articles received no external funding.

Acknowledgments: The author would like to thank all 44 authors for their valuable contributions to this special issue.

Conflicts of Interest: The author declares no conflict of interest.

\section{References}

1. Litscher, G. Laser Acupuncture Research: China, Austria, and Other Countries-Update 2018. Medicines 2018, 5, 92. [CrossRef] [PubMed]

2. Shang, X.; Chen, L.; Litscher, G.; Sun, Y.; Pan, C.; Liu, C.; Litscher, D.; Wang, L. Acupuncture and Lifestyle Myopia in Primary School Children-Results from a Transcontinental Pilot Study Performed in Comparison to Moxibustion. Medicines 2018, 5, 95. [CrossRef]

3. Mayor, D.; McClure, L.; Clayton McClure, J. Individual Differences in Responsiveness to Acupuncture: An Exploratory Survey of Practitioner Opinion. Medicines 2018, 5, 85. [CrossRef] [PubMed]

4. Blechschmidt, T.; Krumsiek, M.; Todorova, M. The Effect of Acupuncture on Visual Function in Patients with Congenital and Acquired Nystagmus. Medicines 2017, 4, 33. [CrossRef] [PubMed]

5. Mayor, D.; McClure, L.; McClure, J. Nonspecific Feelings Expected and Experienced during or Immediately after Electroacupuncture: A Pilot Study in a Teaching Situation. Medicines 2017, 4, 19. [CrossRef] [PubMed]

6. Tseng, S.; Hsu, Y.; Chiu, C.; Wu, S. A Population-Based Cohort Study on the Ability of Acupuncture to Reduce Post-Stroke Depression. Medicines 2017, 4, 16. [CrossRef] [PubMed]

7. Watanabe, M.; Kaneko, S.; Takayama, S.; Shiraishi, Y.; Numata, T.; Saito, N.; Seki, T.; Sugita, N.; Konno, S.; Yambe, T.; et al. The Pilot Study of Evaluating Fluctuation in the Blood Flow Volume of the Radial Artery, a Site for Traditional Pulse Diagnosis. Medicines 2016, 3, 11. [CrossRef] [PubMed]

8. Lim, T.; Ma, Y.; Berger, F.; Litscher, G. Acupuncture and Neural Mechanism in the Management of Low Back Pain-An Update. Medicines 2018, 5, 63. [CrossRef] [PubMed]

9. Adams, J. The Effects of Yin, Yang and Qi in the Skin on Pain. Medicines 2016, 3, 5. [CrossRef] [PubMed]

10. Teixeira, J.; Santos, M.; Matos, L.; Machado, J. Evaluation of the Effectiveness of Acupuncture in the Treatment of Knee Osteoarthritis: A Case Study. Medicines 2018, 5, 18. [CrossRef] [PubMed] 
Medicines 2018, 5, 99

11. Xiao, H.; Zaslawski, C.; Vardy, J.; Oh, B. Treatment of Sciatica Following Uterine Cancer with Acupuncture: A Case Report. Medicines 2018, 5, 6. [CrossRef] [PubMed]

12. Robinson, N. Why We Need Minimum Basic Requirements in Science for Acupuncture Education. Medicines 2016, 3, 21. [CrossRef] [PubMed]

(C) 2018 by the author. Licensee MDPI, Basel, Switzerland. This article is an open access article distributed under the terms and conditions of the Creative Commons Attribution (CC BY) license (http://creativecommons.org/licenses/by/4.0/). 
Editorial

\section{Laser Acupuncture Research: China, Austria, and Other Countries-Update 2018}

\section{Gerhard Litscher}

Research Unit for Complementary and Integrative Laser Medicine, Research Unit of Biomedical Engineering in Anesthesia and Intensive Care Medicine, and TCM Research Center Graz, Medical University of Graz, Auenbruggerplatz 39, EG19, 8036 Graz, Austria; gerhard.litscher@medunigraz.at; Tel.: +43-316-385-83907; Fax: +43-316-385-595-83907

Received: 15 August 2018; Accepted: 15 August 2018; Published: 20 August 2018

Abstract: This editorial contains an overview of the current status of published articles (pubmed) on the subject of laser acupuncture research. Ordered by country, a rough analysis is carried out.

Keywords: laser acupuncture; research; countries; China; Austria; USA

The number of studies on laser acupuncture listed in SCI and PubMed databases is steadily increasing. Altogether, in PubMed, the most important medical database (www.pubmed.gov), there are over 900 publications on this topic, as of August 2018. Although the practice of laser acupuncture in China still seems to be in its infancy, China occupies the first place for published research in the international scientific ranking. A total of 225 scientific papers on the subject of laser acupuncture with author participation from China were published. If one looks at the details, it is worth noting that 44 articles were produced with the participation of the Traditional Chinese Medicine (TCM) Research Center of Graz (chairman: G. Litscher). In fact, Austria plays a leading role in laser acupuncture, together with China (see Figure 1). In addition, it has to be mentioned that there are about 100 scientific papers published in the Russian language.

\section{Laser Acupuncture - Pubmed Articles}

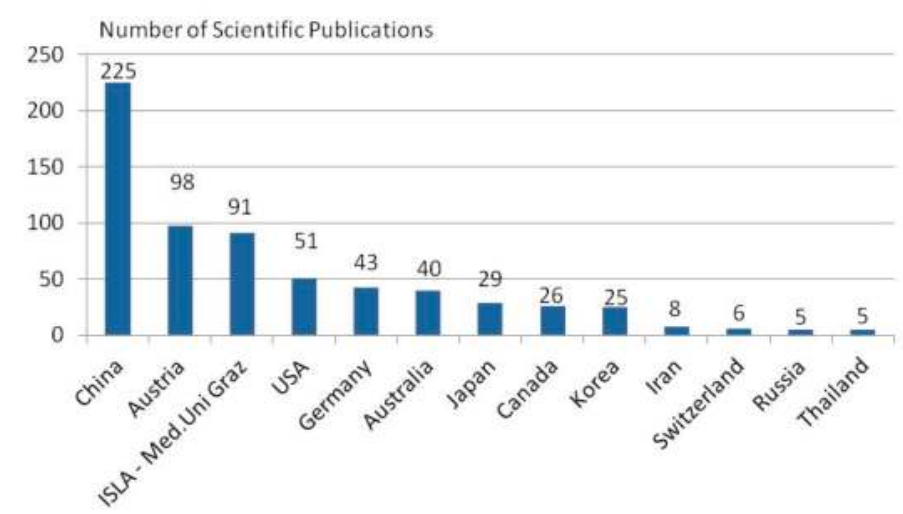

Figure 1. Ranking of countries according to the number of published scientific articles (the majority in the English language) on laser acupuncture.

Remarkable is the fact that the Austrian researchers have published more articles in this study area than the USA and German researchers together. If one goes a bit deeper in this analysis, one recognizes 
that of the 98 published articles from Austria, a very high percentage originates from researchers of the Graz TCM Research Center $(n=91)$. Therefore, it is not an exaggeration to state that Graz has developed into a hotspot for laser acupuncture research and that, together with the representatives of ISLA (International Society for Medical Laser Applications, Germany), it will set the course for future priorities.

One important issue will be the development of automatically individualized dose adjustment in laser acupuncture, which is not currently realizable by any commercially available device. The author of this editorial has repeatedly pointed out in national and international lectures that the ideas for producing such devices are available, but, so far, no company appears to be willing to implement them and build individual device components. It is to be hoped that this implementation will be carried out by industrial partners who recognize the potential of these products, which is supported not only by eminence-based but also by evidence-based research.

At the end of this year (2018), the 4th ISLA Asian conference on Medical Laser Therapy and Regenerative Medicine in Bangkok, Thailand, will take place (see www.isla-laser.org and www.litscher. info). Laser Acupuncture [1-3] is gaining a special boost in Thailand; therefore, research on this subject will be given special emphasis at this conference.

We, the two presidents of ISLA (Dr. Michael H. Weber and Prof. Gerhard Litscher), would be pleased to welcome you personally in Bangkok (29 November-1 December 2018; translation into Chinese will be available). An exciting event awaits you.

Funding: The scientific work on laser acupuncture at the TCM Research Center, Graz, within the cooperation with China was supported by the Austrian Federal Ministry of Science, Research and Economy and by Eurasia Pacific Uninet (EPU).

Conflicts of Interest: The author declares no conflict of interest.

\section{References}

1. Bahr, F.; Litscher, G. Laser Acupuncture and Innovative Laser Medicine; Bahr \& Fuechtenbusch: Munich, Germany, 2018.

2. Litscher, G. Laser acupuncture and heart rate variability—Scientific considerations. Medicines 2018, 5, 43. [CrossRef] [PubMed]

3. Litscher, D.; Wang, J.; Litscher, G.; Li, G.; Bosch, P.; Van den Noort, M.; Wang, L. Gender differences in laser acupuncture-Results of a crossover study with green and yellow laser at the ear point Shenmen. Medicines 2018, 5, 24. [CrossRef] [PubMed]

(C) 2018 by the author. Licensee MDPI, Basel, Switzerland. This article is an open access article distributed under the terms and conditions of the Creative Commons Attribution (CC BY) license (http:/ / creativecommons.org/licenses/by/4.0/). 
Article

\title{
Acupuncture and Lifestyle Myopia in Primary School Children-Results from a Transcontinental Pilot Study Performed in Comparison to Moxibustion
}

\author{
Xiaojuan Shang ${ }^{1}$, Luquan Chen ${ }^{1, *}$, Gerhard Litscher ${ }^{1,2,3,4, *}$, Yanxia Sun ${ }^{3}$, Chuxiong Pan ${ }^{3}$, \\ Cun-Zhi Liu ${ }^{4}$, Daniela Litscher ${ }^{2}$ and Lu Wang ${ }^{1,2,3}$ \\ 1 Department of Traditional Chinese Medicine, Beijing Tongren Hospital, Capital Medical University, \\ Beijing 100730, China; joy_shang@hotmail.com (X.S.); lu.wang@medunigraz.at (L.W.) \\ 2 TCM Research Center Graz, Research Unit of Biomedical Engineering in Anesthesia and Intensive Care \\ Medicine, and Research Unit for Complementary and Integrative Laser Medicine, Medical University of \\ Graz, 8036 Graz, Austria; daniela.litscher@medunigraz.at \\ 3 Department of Anesthesiology, Beijing Tongren Hospital, Capital Medical University, Beijing 100730, China; \\ sun00017@gmail.com (Y.S.); pandedao@126.com (C.P.) \\ 4 Department of Acupuncture and Moxibustion, Dongfang Hospital Affiliated to Beijing University of \\ Chinese Medicine, Beijing 100078, China; lcz623780@126.com \\ * Correspondence: chenluquan@hotmail.com (L.C.); gerhard.litscher@medunigraz.at (G.L.); \\ Tel.: +86-105-826-8094 (L.C.); +43-316-385-83907 (G.L.)
}

Received: 9 August 2018; Accepted: 30 August 2018; Published: 31 August 2018

\begin{abstract}
Background: Lifestyle risks for myopia are well known and the disease has become a major global public health issue worldwide. There is a relation between reading, writing, and computer work and the development of myopia. Methods: Within this prospective pilot study in 44 patients aged between 6 and 12 years with myopia we compared possible treatment effects of acupuncture or moxibustion. The diopters of the right and left eye were evaluated before and after the two treatment methods. Results: Myopia was improved in 14 eyes of 13 patients $(15.9 \%)$ within both complementary methods. Using acupuncture an improvement was observed in seven eyes from six patients out of 22 patients and a similar result (improvement in seven eyes from seven patients out of 22 patients) was noticed in the moxibustion group. The extent of improvement was better in the acupuncture group ( $\mathrm{p}=0.008 \mathrm{~s}$, comparison before and after treatment); however, group analysis between acupuncture and moxibustion revealed no significant difference. Conclusions: Possible therapeutic aspects with the help of evidence-based complementary methods like acupuncture or moxibustion have not yet been investigated adequately in myopic patients. Our study showed that both acupuncture and moxibustion can improve myopia of young patients. Acupuncture seems to be more effective than moxibustion in treating myopia, however group analysis did not prove this trend. Therefore, further Big data studies are necessary to confirm or refute the preliminary results.
\end{abstract}

Keywords: acupuncture; moxibustion; evidence-based complementary medicine; myopia; primary school children; lifestyle; computer; eye diseases

\section{Introduction}

Myopia has become a major global public health issue worldwide. Lifestyle risk factors are well known and summarized in recent publications [1-3]. It has been shown that there is a relation between reading and writing from a short distance and the development of myopia. Computer work is also responsible for this relationship [4-7].

The constantly increasing number of eye diseases, as a result of too intensive personal computer work, increases the need for adequate treatment methods. In this context evidence-based 
complementary methods like acupuncture and/or moxibustion could be potential starting points for early intervention of myopia, which is defined as more than equal to -0.50 diopter (D) [3].

The purpose of this study was to investigate complementary medical methods (acupuncture and moxibustion) in school children with mild or moderate myopia because conventional medical therapies do not show sufficient improvements [1-3]. Acupuncture and moxibustion are among the most important methods used clinically in myopia in school age in China. Since this is an invasive method (needle acupuncture) on the one hand and a non-invasive procedure (moxibustion) on the other hand, it is obvious to compare both methods in one study. The aim is also to find out whether the methods differ significantly in terms of a possible improvement of myopia or not.

Within this transcontinental (Asia-Europe) prospective study in 44 children with low $(<-3.0 \mathrm{D})$ and medium (between $-3.0 \mathrm{D}$ and $-6.0 \mathrm{D}$ ) myopia [3] we compared possible treatment effects of acupuncture or moxibustion for the first time. The measurements were performed at the Tongren Eye Hospital affiliated to Capital Medical University in Beijing, China and the analysis was performed at the Traditional Chinese Medicine (TCM) Research Center at the Medical University of Graz, Austria.

\section{Materials and Methods}

\subsection{Patients}

A total of 44 patients aged between 6 and 12 years, with a mean age \pm SD of $9.3 \pm 1.4$ years (27 female, 17 male) were treated either with acupuncture (group A) or with moxibustion (group B). The children suffer from mild-to-moderate myopia ( $-0.5 \mathrm{D}$ to $-4.25 \mathrm{D})$, and their lens-corrected vision was $100 \%$. The average stature of the 44 subjects was $137.7 \pm 9.4 \mathrm{~cm}(115-157 \mathrm{~cm})$, and the average body weight was $33.2 \pm 7.9 \mathrm{~kg}(21-53 \mathrm{~kg})$. No person was under the influence of drugs. The treatments (needle acupuncture or moxibustion) were approved by the local ethics committee of the Tongren Hospital for treatment and research (EPU 5/2017) and performed in accordance with the recommendations of the Helsinki Declaration of the World Medical Association. Informed consent has been obtained from at least one of their parents.

Acupuncture treatment was used in group A, moxibustion in group B. Each group consisted of 22 patients. Age, sex, and basic demographic data are shown in Table 1.

Table 1. Demographic data of the 44 patients.

\begin{tabular}{ccc}
\hline \multirow{2}{*}{ Parameter } & Group A & Group B \\
\cline { 2 - 3 } & Acupuncture $(\boldsymbol{N}=\mathbf{2 2})$ & Moxibustion $(\boldsymbol{N}=\mathbf{2 2})$ \\
\hline Age (years) & $9.4 \pm 0.9$ & $9.3 \pm 1.7$ \\
Sex (female, male) & $14 \mathrm{f}, 8 \mathrm{~m}$ & $13 \mathrm{f}, 9 \mathrm{~m}$ \\
Height $(\mathrm{cm})$ & $140.2 \pm 6.8$ & $137.2 \pm 11.4$ \\
Weight $(\mathrm{kg})$ & $34.6 \pm 8.0$ & $31.8 \pm 7.8$ \\
Treatment sessions & $6.9 \pm 1.7$ & $9.1 \pm 1.2$ \\
\hline
\end{tabular}

Randomization to one of the groups A or B has been done by an independent employee (medical doctor) from the Tongren Hospital using an envelope (group A, group B). The duration of one treatment (acupuncture or moxibustion) was $20 \mathrm{~min}$. Altogether completion of 10 sessions was planned ( 2 sessions per week) however not all participants could finish the examinations (compare treatment sessions in Table 1).

The following exclusion criteria were applied: (i) Less than -0.5 diopters; (ii) other eye diseases/disorders affecting visual acuity; (iii) secondary eye diseases (e.g., following diabetes); (iv) cardiologic, neurologic, nephrologic, hepatologic, hematologic, or psychiatric disorders; (v) chronic diseases requiring medication that must not be interrupted. 


\subsection{Treatment Methods}

\subsubsection{Acupuncture}

All 22 patients in group A received needle acupuncture at traditional point locations (see Figures 1 and 2).
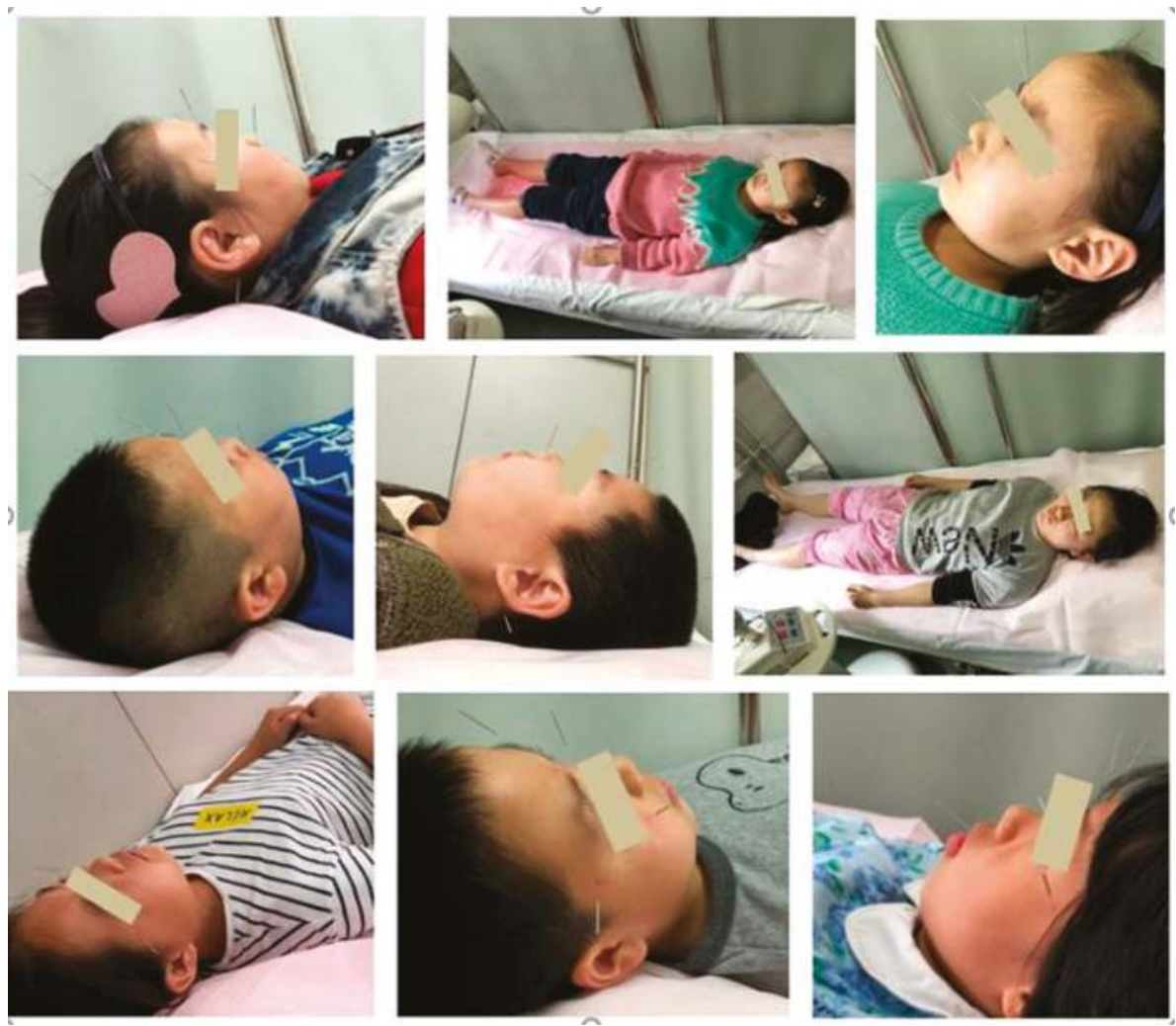

Figure 1. Acupuncture treatment in 22 young patients with myopia (group A).

After the patients lay down on a bed in a relaxed manner, the skin at the acupoint locations was disinfected with cotton which contains 75\% alcohol. Disposable acupuncture needles $(0.25 \mathrm{~mm} \times 25 \mathrm{~mm})$ were used. The needling method used is called mild reinforcing and attenuating, and was performed by inserting the needle at the appropriate depth. The angle of insertion was straight for the points on hands, body, and ankles, and oblique for the points on head, face, and neck. The depth of perpendicular needling was $25 \mathrm{~mm}$, which of oblique is $15 \mathrm{~mm}$. The needles were not stimulated and stayed in the body. After $20 \mathrm{~min}$ the needles were removed with dry cotton. An expert panel of acupuncturists from the Tongren Hospital in Beijing, China have reviewed and participated in the selection of the points. Acupuncture was always performed by the same highly experienced acupuncturist. 


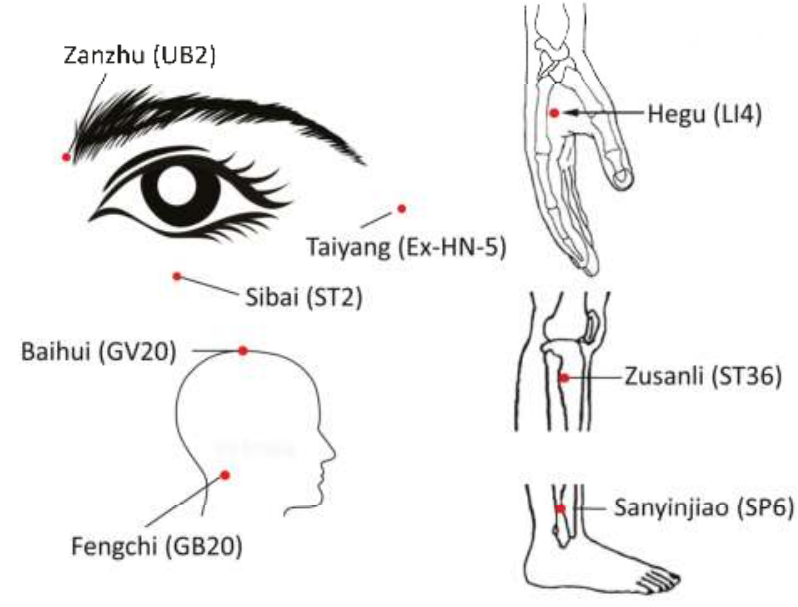

Figure 2. Acupuncture points for group A (acupuncture treatment). UB2 = Urinary Bladder 2; ST2 = Stomach 2; Ex-HN-5 = Extra Point Head $/$ Neck 5; GV20 = Governing Vessel 20; GB20 = Gallbladder 20; LI4 = Large Intestine 4; ST36 = Stomach 36; SP6 = Spleen 6.

\subsubsection{Moxibustion}

For moxibustion treatment the patients sat down and closed their eyes. Then moxibustion on the forehead was performed for two minutes moving the stick in a horizontal direction (see Figure 3). Moxibustion was also performed around the eyes for duration of three minutes (moving the moxa in a horizontal direction for one minute, clockwise for one minute, vertical direction for one minute). Then sparrow-pecking Moxa on acupuncture points near the eyes (Ex-HN5, ST2 and UB2) was done for two minutes. This method is characterized by the ignited moxa stick being moved up and down over the point like a bird pecking or moving left and right, or circularly simultaneously. Acupressure was made on the same points simultaneously. In addition, moxibustion around the ears was made for two minutes moving the stick in vertical directions. Sparrow-pecking moxa on LI4 and simultaneous acupressure at the same point for one minute completed the Zhao's thunder-fire moxa (manufacturer: Chongqing Zhao's Thunder-fire Moxa Institute of Traditional Medicine, Chongqing, China) procedure. The points for moxibustion are shown in Figure 4.

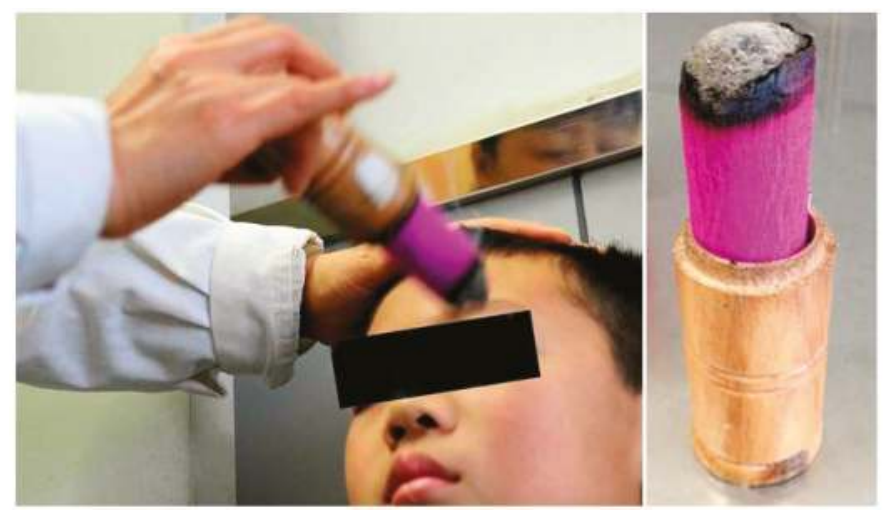

Figure 3. A part of the moxibustion treatment in 22 young patients with myopia (group B). 


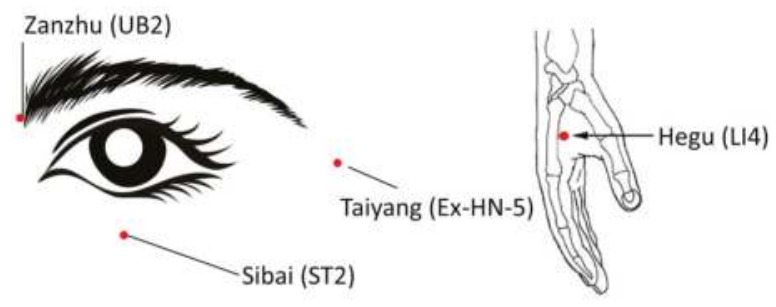

Figure 4. Points for group B (moxibustion treatment). UB2 = Urinary Bladder 2; Ex-HN-5 = Extra Point Head $/$ Neck 5; ST2 = Stomach 2; LI4 = Large Intestine 4.

\subsection{Evaluation Parameters}

Axial lengths were observed before and after treatment with acupuncture or moxibustion. The diopters of the right (OD) and left (OS) eye were evaluated before and after the two treatment methods by a blinded assessor (medical doctor from Tongren Hospital). Compound tropicamide eye drops ( $0.5 \%$ tropicamide, $0.5 \%$ phenylephrine hydrochloride) were used before and after the last treatment session.

\subsection{Statistical Analysis}

The statistical analysis was carried out with the computer program SigmaPlot 14.0 (Systat Software, Chicago, IL, USA). Kruskal-Wallis One Way Analysis of Variance (ANOVA) on Ranks for group analysis and box plot analysis was used. In addition, paired t-tests before and after the treatments were carried out. The level of significance was set at $p<0.05$. The original data can be found at the Department of Traditional Chinese Medicine \& Acupuncture, Tongren Hospital affiliated to Capital Medical University, 100730 Beijing, China and at the TCM Research Center Graz, Medical University of Graz, 8036 Graz, Austria.

\section{Results}

All 44 patients finished at least five treatment session (mean sessions: $8.0 \pm 1.8$ (range: 5-10 treatments)). Due to time reasons, treatment in the children in Beijing was only possible during holiday time. Group analysis of the demographic data showed no statistical difference in age, sex, height, and weight. Acupuncture and moxibustion were accepted well and there were no side effects monitored by the medical doctors of the Tongren Hospital in any of the children. Table 2 demonstrates the mean $\pm \mathrm{SD}$ of OD and OS from all patients and each from both groups (A and B) respectively.

Table 2. Diopters of the right (OD) and left (OS) eye before and after the two treatment methods ( $\mathrm{N}=$ number of eyes).

\begin{tabular}{cccc}
\hline \multirow{2}{*}{ N: Number of Eyes } & \multirow{2}{*}{ Both Complementary Treatment Methods } & Group A & Group B \\
\cline { 3 - 4 } & & Acupuncture & Moxibustion \\
\hline OD + OS before & $-1.68 \pm 1.03(N=88)$ & $-1.57 \pm 0.84(N=44)$ & $-1.79 \pm 1.18(N=44)$ \\
OD + OS after & $-1.67 \pm 1.08^{\#}(N=88)$ & $-1.52 \pm 0.87^{* *}(N=44)$ & $-1.81 \pm 1.25(N=44)$ \\
OD before & $-1.66 \pm 1.03(N=44)$ & $-1.53 \pm 0.86(N=22)$ & $-1.80 \pm 1.20(N=22)$ \\
OD after & $-1.72 \pm 1.08(N=4)$ & $-1.50 \pm 0.88(N=22)$ & $-1.80 \pm 1.20(N=22)$ \\
OS before & $-1.69 \pm 1.03(N=44)$ & $-1.60 \pm 0.83(N=22)$ & $-1.81 \pm 1.20(N=22)$ \\
OS after & $-1.61 \pm 1.08^{*}(N=44)$ & $-1.53 \pm 0.87^{+}(N=22)$ & $-1.71 \pm 1.31(N=22)$ \\
\hline & ${ }^{\#} p=0.011 ;^{*} p=0.002 ;{ }^{* *} p=0.00 ;^{+} p=0.030$.
\end{tabular}

Altogether myopia was improved (diopters) in 14 eyes of 13 patients $(15.9 \%)$ with both complementary methods. Using acupuncture, an improvement was observed in seven eyes from six patients out of 22 patients and a similar result (improvement in seven eyes from seven patients out of 
22 patients) was noticed in the moxibustion group (group B). However the extent of the improvement was significantly different between the acupuncture (group A: $p=0.008$ ) and the moxibustion (group B: No significance).

The results are graphically presented in Figure 5 . The basic values before the treatment of both acupuncture and moxibustion are similar (see median values). Only needle acupuncture treatment changes the diopters in the sense of an improvement of myopic children significantly.

\section{Acupuncture - Moxibustion}

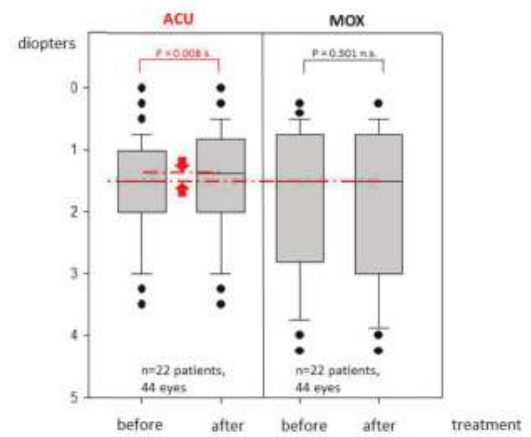

Figure 5. Box-plot of change in diopter values of all 44 subjects before and after treatment. The line in the box indicates the position of the median; the ends of the boxes define the 25th and 75th percentiles. The error bars show the 10th and 90th percentiles, and the dots represent "outliers". Note the significance ( $p=0.008 \mathrm{~s}$.) of the decrease in diopters after acupuncture treatment (left part).

In addition, a group analysis has been performed. The differences in the median values among the two treatment groups (acupuncture and moxibustion) was not great enough to exclude the possibility that the difference is due to random sampling variability; there was not a statistically significant difference ( $p=0.973$ n.s.) between the acupuncture and moxibustion group.

\section{Discussion}

A current literature analysis in the two databases PubMed and Cochrane Library regarding this important topic yielded the following results: up to now (1 June 2018) there are 28,106 published articles in PubMed under the search term "acupuncture" (11,464 at Cochrane Library). The term "myopia" provided 21,252 results in PubMed, and in Cochrane Library 1435 articles. The search term "personal computer" yielded 24,940 results in PubMed, and Cochrane Library 1905 published articles. The search with combined keywords yielded fewer results. The combined search terms "personal computer myopia", "personal computer acupuncture", and "acupuncture myopia personal computer" led to no results in Cochrane Library (in PubMed at least double-digit results, excluding "acupuncture myopia personal computer"). The only combined keyword which yielded more results in both databases was "acupuncture myopia". PubMed listed 46 articles, and in Cochrane Library 22 articles were found.

The result of the database analysis shows that until now there is very little research related to therapeutic aspects of eye diseases and screen handling. Therefore, new research like the present study is absolutely necessary. As already mentioned in the introduction, acupuncture or moxibustion could be possible starting points. The database analysis also clearly shows that acupuncture has already been used in myopia, but currently plays a very minor role in relation to PC-work induced disorders.

A study from Beijing which has been published in 2015 in PLoS One [2], deals with myopia in high school students. The title of the article is "Prevalence and associated factors of myopia in high-school 
students in Beijing". The authors came to the worrying result that students aged between 16 and 18 years have an $80 \%$ prevalence of myopia. They even speak of a $10 \%$ prevalence of severe myopia. When this generation which has grown up with PCs gets older, it will cause enormous costs for the health care system. Experts warn that myopia will win importance as a cause of visual impairment and blindness [2].

"Acupuncture for teenagers with mild to moderate myopia: study protocol for a randomized controlled trial" is the title of another important work. Especially the safety of acupuncture application in this field and its effectiveness should be investigated for a period of six months. Here is a brief excerpt from the study protocol: This randomized, parallel, blinded clinical trial will be conducted controlled. A total of 100 young people aged between seven and twelve years with mild to moderate myopia are recruited. The patients are randomized into two groups (control group and acupuncture group). Each group consists of 50 young people. In the acupuncture group, the five acupoints Zanzhu bilaterally, Tongziliao, Sibai, Muchuang and Hegu are stimulated daily for nine consecutive days. Then there is a one-day treatment break. Six of these treatment cycles are carried out continuously over a total of 60 days. After six months, a follow-up examination takes place. The primary endpoint is the determination of the diopter [8]. This is in context with our present study and also some acupoint are the same. The study could provide very interesting results. Another work that should be mentioned in the context of this discussion was written by Ming Yeung. According to this work, $3-4 \%$ of children are affected by tired eyes. Attention is drawn to a treatment with acupuncture. This method of treatment is according to the authors well tolerated by children and shows promising results [9].

In the following some important experiences from our own research should be mentioned briefly.

Myopia in children and adolescents up to the age of 21 is also well treatable with complementary medical methods. In adults, however, only little success has been recorded [10].

Our study has been performed as a transcontinental research pilot study. This means that two main research teams were involved; one team from Asia (Beijing, China) and one from Europe (Graz, Austria). Although it was a pilot study, the preliminary results are promising. The examinations showed that a total of 14 eyes of 13 patients out of 44 patients showed a significant improvement in myopia. The improvements were better with acupuncture than with moxibustion (comparison before and after treatment). The invasiveness of acupuncture seems to play a role over the non-invasiveness of moxibustion or acupressure.

However, the investigation has also limitations. Firstly, the sample size was very small and in the future sample size will be calculated according to rigorous methodology and considered in the improvement rate of this pilot study. Secondly, the average number of treatment sessions was lower in the moxibustion group than in the acupuncture group. Thirdly, because of ethical principles and actual clinical conditions in China, neither a control group of individuals who did not receive treatment nor a placebo group who received sham acupuncture was included. Fourthly, without a follow-up evaluation it would be difficult to determine if the treatment produces only temporary improvement or more clinically relevant long-term sustainable effects. Nevertheless, the scientific methodological guidelines were followed strictly through the trial, and the outcomes still showed meaningful and effective treatment corresponding to other previous publications.

\section{Conclusions}

In summary it can be stated that the enormously important topic screen handling, eye diseases, and possible therapeutic aspects with the help of acupuncture or moxibustion has not yet been investigated adequately from a scientific perspective, although some work (mainly from China) already exists. The problem, however, is not only interesting for Asia, also in the Western world ametropia [11] caused by screen handling will increase, as the scientific search and research of this work illustrates.

Our transcontinental pilot study showed that both acupuncture and moxibustion can improve mild and/or moderate myopia of young patients (6-12 years). Acupuncture seems to be more 
effective than moxibustion in treating myopia however at the moment we do not have conclusive explanations concerning the underling mechanisms of needle and thermal stimulation on myopia from a neurophysiological perspective.

Author Contributions: X.S., L.C., G.L., Y.S., C.P., C.-Z.L., D.L. and L.W. created the study design, X.S. and L.C. performed the measurements, G.L., D.L. and L.W. performed the data analyzes, G.L. designed the manuscript, and all authors (X.S., L.C., G.L., Y.S., C.P., C.-Z.L., D.L. and L.W.) participated in the discussion section and read the final manuscript.

Funding: In Austria the work was supported by Eurasia Pacific Uninet (EPU project May 2017; "Acupuncture and Modern Eye Diseases-A Transcontinental Pilot Study") financed from funds of the Austrian Federal Ministry of Education, Science and Research and from the same Ministry (project title "Sino-Austrian TCM Research on Lifestyle-Related Diseases: Innovative Acupuncture Research" (2016-2019); leader of both projects $\mathrm{G}$. Litscher).

Acknowledgments: Lu Wang and Gerhard Litscher are also visiting professors at the Capital Medical University, Beijing, China and G. Litscher is also guest professor at the Beijing University of Chinese Medicine in Beijing, China.

Conflicts of Interest: The authors declare no conflict of interest.

\section{References}

1. Wu, L.J.; Wang, Y.X.; You, Q.S.; Duan, J.L.; Luo, Y.X.; Liu, L.J.; Li, X.; Gao, Q.; Zhu, H.P.; He, Y.; et al. Risk factors of myopic shift among primary school children in Beijing, China: A prospective study. Int. J. Med. Sci. 2015, 12, 633-638. [CrossRef] [PubMed]

2. Wu, L.J.; You, Q.S.; Duan, J.L.; Luo, Y.X.; Liu, L.J.; Li, X.; Gao, Q.; Zhu, H.P.; He, Y.; Xu, L.; et al. Prevalence and associated factors of myopia in high-school students in Beijing. PLoS ONE 2015, 10. [CrossRef] [PubMed]

3. Zorena, K.; Gladysiak, A.; Slezak, D. Early intervention and nonpharmacological therapy of myopia in young adults. J. Ophthalmol. 2018, 2018. [CrossRef] [PubMed]

4. Holden, B.A.; Fricke, T.R.; Wilson, D.A.; Jong, M.; Naidoo, K.S.; Sankaridury, P.; Wong, T.Y.; Naduvilath, T.J.; Resnikoff, S. Global prevalence of myopia and high myopia and temporal trends from 2000 through 2050. J. Ophthalmol. 2016, 123, 1036-1042. [CrossRef] [PubMed]

5. Czepita, M.; Czepita, D.; Lubiński, W. The influence of environmental factors on the prevalence of myopia in Poland. J. Ophthalmol. 2017, 2017. [CrossRef] [PubMed]

6. Eye Problems through Screen Work. Available online: http://vorarlberg.orf.at/news/stories/2726280/ (accessed on 13 August 2015).

7. Le, Q.; Zhou, X.; Ge, L.; Wu, L.; Hong, J.; Xu, J. Impact of dry eye syndrome on vision-related quality of life in a non-clinic-based general population. BMC Ophthalmol. 2012, 12. [CrossRef] [PubMed]

8. Wang, Y.; Gao, Y.X.; Sun, Q.; Bu, Q.; Shi, J.; Zhang, Y.N.; Xu, Q.; Ji, Y.; Tong, M.; Jiang, G.L. Acupuncture for adolescents with mild-to-moderate myopia: Study protocol for a randomized controlled trial. Trials 2014, 15. [CrossRef] [PubMed]

9. Acupuncture Breakthrough for Treating Eye Condition. Available online: http:/ /www.chinadaily.com.cn/ hkedition/2010-06/15/content_9977403.htm (accessed on 15 June 2010).

10. Brucker, K. Augen-Akupunktur: Sehstörungen Natürlich Heilen; Georg Thieme Verlag: Stuttgart, Germany, 2001.

11. Disease and Injury Country Estimates. Available online: http://www.who.int/healthinfo/global_burden_ disease/estimates_country/en/ (accessed on 12 February 2012).

(C) 2018 by the authors. Licensee MDPI, Basel, Switzerland. This article is an open access article distributed under the terms and conditions of the Creative Commons Attribution (CC BY) license (http:/ / creativecommons.org/licenses/by/4.0/). 
Article

\title{
Individual Differences in Responsiveness to Acupuncture: An Exploratory Survey of Practitioner Opinion
}

\author{
David F. Mayor ${ }^{1, *}$, Lara S. McClure ${ }^{2}$ and J. Helgi Clayton McClure ${ }^{2}$ \\ 1 Department of Allied Health Professions and Midwifery, School of Health and Social Work, \\ University of Hertfordshire, Hatfield AL10 9AB, UK \\ 2 Northern College of Acupuncture, York YO1 6LJ, UK; LaraMcClure@chinese-medicine.co.uk (L.S.M.); \\ helgi.claytonmcclure@oxon.org (J.H.C.M.) \\ * Correspondence: davidmayor@welwynacupuncture.co.uk; Tel.: +44-1707-320-782
}

Received: 3 July 2018; Accepted: 31 July 2018; Published: 6 August 2018

\begin{abstract}
Background: Previous research has considered the impact of personal and situational factors on treatment responses. This article documents the first phase of a four-stage project on patient characteristics that may influence responsiveness to acupuncture treatment, reporting results from an exploratory practitioner survey. Methods: Acupuncture practitioners from various medical professions were recruited through professional organisations to complete an online survey about their demographics and attitudes as well as 60 questions on specific factors that might influence treatment. They gave categorical ("Yes", "No", and "Don't know") and free-text responses. Quantitative and qualitative (thematic) analyses were then conducted. Results: There were more affirmative than negative or uncertain responses overall. Certain characteristics, including ability to relax, exercise and diet, were most often considered relevant. Younger and male practitioners were more likely to respond negatively. Limited support was found for groupings between characteristics. Qualitative data provide explanatory depth. Response fatigue was evident over the course of the survey. Conclusions: Targeting and reminders may benefit uptake when conducting survey research. Practitioner characteristics influence their appreciation of patient characteristics. Factors consistently viewed as important included ability to relax, exercise and diet. Acupuncture practitioners may benefit from additional training in certain areas. Surveys may produce more informative results if reduced in length and complexity.
\end{abstract}

Keywords: acupuncture; responsiveness; practitioner survey; patient characteristics; thematic analysis; Shannon entropy

\section{Introduction}

Outcomes from acupuncture treatment have been considered to depend on many interacting factors, including-among others-the condition treated, treatment parameters (acupuncture points and procedures used), setting, practitioner experience, characteristics and attitude, the patient-practitioner relationship, advice given, co-interventions, conditioning (e.g., from treatment repetition) and expectation [1-11].

What about the patient in the acupuncture scenario? The respected German-born British pioneering medical acupuncture practitioner Felix Mann (1931-2014) introduced the term "strong reactor" to describe a subset of patients who respond particularly strongly to acupuncture [12], with very rapid alleviation of their symptoms, although he was not able to define such patients otherwise than by observing that they seemed more likely to be artistic or inclined toward religious belief than less strong reactors. Similar to Mann, some British proponents of medical acupuncture 
such as Anthony Campbell and Peter Baldry have noted that strong reactors are also often "good responders" to acupuncture [1,13], with Campbell following a suggestion by Johnson et al. [14] concerning transcutaneous electrical nerve stimulation (TENS) that strong reactors could be people whose central nervous system, including the limbic system, is particularly sensitive to sensory stimulation [13]. Among the present authors, in D.F.M.'s experience over 36 years of clinical practice and in line with Campbell's findings [15], some patients have certainly seemed to respond well to acupuncture and benefit a great deal from receiving treatment, whereas others have appeared to respond less well, or even poorly, and benefit less from treatment-almost regardless of what that treatment is.

A central aim of this paper is to explore what practitioners consider as possible individual characteristics, attitudes and experiences that may contribute to someone being a "good" or "poor" responder. We make no claims about what actually are the factors that influence responsiveness, but contribute to a framework for assessing the impact of patient characteristics on treatment outcomes. This may ultimately assist in developing models of patient response tendencies, such as that of the "good responder" [1,13]. Further aims are to present some preliminary findings concerning such general questions as: "Are some patients more receptive to acupuncture in general, with a better, faster or more enduring response to treatment than others?", "Can acupuncture responders be consistently categorised as 'good', 'average' or 'poor', or does this vary?", or "Is placebo responsiveness considered materially to contribute to acupuncture responsiveness?"

Investigating such characteristics and questions is potentially important for any therapeutic intervention, and certainly not acupuncture alone, but they are rarely addressed in the literature except in a very limited way. In recent years, for example, genetic polymorphism (genotyping) has been investigated for its effects on treatment outcome in several fields-particularly in hepatology [16,17] — with a view to developing more personalised approaches to treatment or improving outcome prediction. Genomic correlates of the placebo response (the "placebome") have also been proposed [18,19], and such an approach has been used, if sparsely, in the field of acupuncture. Thus, response to acupuncture for smoking cessation was found in one Korean study to vary with genetic polymorphisms [20], and using serotonin transporter polymorphism techniques has been proposed as a method of guiding individualised treatment of irritable bowel syndrome in Chinese medicine [21]. More generally, genetic polymorphism has been shown to regulate the default mode network (DMN) in the brain, and so to regulate response to acupuncture stimulation [22]. In a very different approach, poor response to acupuncture used as an adjuvant treatment for In Vitro Fertilisation was found to be more likely in those with high peak levels of follicular stimulating hormone, longer histories of infertility and worse sperm morphology [23], but a quick PubMed search revealed no other studies that looked explicitly at the effects of such factors on treatment outcome.

Furthermore, genetic testing is highly technical and costly, and offers little insight to the clinician in daily practice. Similarly, although there are many studies on the endocrinology [24] and neurochemistry of acupuncture [25,26], again few are relevant in everyday practice. Therefore, a simpler, more accessible questionnaire-based research protocol was developed in an attempt to assess whether there might be any simple answers to the question "who responds well to acupuncture?" without recourse to complex and costly biomarkers (a similar approach, using psychometric data to evaluate the effects of patient personality on their response to placebo acupuncture, was explored by Kaptchuk and colleagues [27]). Such a protocol might seem not just simple but naïve and simplistic to those used to large-scale scientific research, but its feasibility and limited funding requirements recommended it for the current exploratory work. Development was by D.F.M. in association with a small focus group comprising six other experienced acupuncturists and researchers (one of whom previously published a paper about the effects of attachment style on response to acupuncture [28]), one neurofeedback practitioner and a retired medical doctor/government advisor.

To contextualise this paper, the protocol, still in development, is in four phases: 
A A survey of UK acupuncture practitioners to find why members of the profession think some patients respond better to acupuncture than others.

B Use of self-report personality scales with around 100 participants who have taken part in acupuncture-related studies conducted at the University of Hertfordshire since 2011, to assess whether there are any meaningful associations between these traits and their electroencephalography (EEG), heart rate variability (HRV) and outcomes data already collected.

C A (blinded) retrospective survey of acupuncture teaching clinic patients who have responded either well or poorly to acupuncture, using a variety of short, established self-report personality questionnaires to determine whether any of the traits assessed have a bearing on outcome.

D A prospective study of patients using a smaller selection of self-report questionnaires (based on Phases A-C above), together with outcome measures such as the Measure Yourself Medical Outcome Profile (MYMOP) and perhaps a multiple measure of mood change similar to those developed and piloted by D.F.M. and other collaborators [29,30].

Phase A of the project is presented here. The survey process is described in Sections 2.1 and 2.2; a quantitative analysis of the categorical "Yes" / "No" / Don't know" survey responses is undertaken in Section 3.2.3, with a nested qualitative analysis of the free-text responses in Section 3.3; the main conclusions are given in Section 5 . The survey questions and the actual data gathered are provided in the Supplementary Materials (http:/ / www.mdpi.com/2305-6320/5/3/85/s1).

Data for Phase B have now been collected and are currently in process of analysis. Phases $C$ and $\mathrm{D}$ are still in the planning stage. In preparation, some small pilot studies have been undertaken to test the use of selected self-report questionnaires for the retrospective self-assessment of acupuncture's effectiveness and prospective assessment of mood changes in response to electroacupuncture in a teaching situation $[30,31]$, with a further pilot study still in process.

\section{Materials and Methods}

Ethics approval was obtained from the University of Hertfordshire for Phases A and B of this project (Protocol HSK/SF/UH/02930, 3 August 2017).

Initially, the acupuncture literature as well as general literature on factors having an impact on health and wellbeing was reviewed to locate possible individual characteristics and experiences that might possibly affect treatment responsiveness and for which validated self-report questionnaires exist. Based on this review, the pilot studies mentioned above and prior experience of running acupuncture surveys [32,33], a survey was developed in consultation with the focus group, members of which were recruited informally from among those with an interest in the survey subject matter. The survey was then trialled by the group prior to launch. Several revisions were made at each stage of this process until the survey was finally considered ready for use.

\subsection{The Survey}

The final online version of the survey, hosted by Jisc (Bristol Online Surveys), was launched on 16 October 2017 and closed after 19 weeks on 28 February 2018. Before respondents could take the survey, they were informed about its purpose, origins and how long it was likely to take them to complete, and then asked for their consent to continue [34]. The 13-page survey included three initial questions about the respondents themselves, four about their acupuncture training, professional affiliation and practice, and one (Q9) asking whether-before becoming aware of the survey-they had ever considered that patient characteristics (such as temperament or personality traits) might affect treatment response.

Then followed the main part of the survey, consisting of 60 questions on particular patient characteristics, attitudes or experience that could contribute to how well (or poorly) they respond to acupuncture, derived from the literature on what can affect health (Q10.1 to Q12.18). Respondents were asked which of the listed suggestions they currently considered might have an important effect 
on treatment response ("What you THINK NOW"). They were also asked whether, in their own clinical practice, they thought at the time of giving a treatment or shortly afterwards that any of the listed suggestions had an impact on an individual patient's response to acupuncture ("What you THOUGHT THEN"). Answers could be "Yes", "No" or "Don't know" ("Yes", "No" and blank for the "THEN" responses). NOW and THEN questions were separately included deliberately to encompass responses based on both current knowledge (or opinion) and historical experience, which could relate to a single, specific past experience or on the practitioner's career experience as a whole. Explanations were provided for terms used in 10 of the questions which might be unfamiliar to those taking the survey. The survey also included 69 free-text boxes where respondents could choose to qualify their categorical answers with further comments.

In addition, respondents were asked further questions about their views on consistency of response to acupuncture treatment $(\mathrm{Q} 13)$, short-term and long-term response to acupuncture treatment (Q14), three questions on their own response to acupuncture (Q15), two about their patients' response to acupuncture (Q16-17), and a final two about conditions they consider as responding particularly well or badly to acupuncture (Q18-19).

The survey questions and responses are summarised in the Supplementary Materials.

\subsection{Recruitment}

Information about the survey was sent to all the major (and some less established) UK professional acupuncture associations (Table 1), and also to selected training institutions whose graduates tended to become members of these associations. A template was provided for them to inform their members/graduates about the survey using various methods-newsletters (printed and/or electronic), emails, member forums and social media. No incentives were offered for completing the survey. Survey uptake was monitored by D.F.M.; reminders were sent to the associations, and by them to their members, some five weeks before the survey closed. Clearly, the reminder appears to have been effective (Figure 1); it also seems possible that members of the smaller associations (apart from the Chinese Medical Institute and Register (CMIR)) were more likely to take the survey; although the correlation between membership numbers and percentages of these that took the survey was not significant $\left(r_{s}=-0.464, p=0.294\right)$, the trendline of a scatterplot for the two remaining sets of six numbers-without the CMIR data-shows a tantalisingly clear power distribution, so that overall numbers were low (median percentage of membership 1.43\%, interquartile range $0.43-1.94 \%$ ).

Table 1. Acupuncture Associations and training institutions informed about the survey, showing percentage of association members who completed the survey.

\begin{tabular}{|c|c|c|c|}
\hline Association/Institution & Membership $M$ & Respondents $R$ & $R / M(\%)$ \\
\hline Acupuncture Society (AS) & 1000 & 20 & $2.0 \%$ \\
\hline British Academy of Western Medical Acupuncture (BAWMA) & 150 & 12 & $8.00 \%$ \\
\hline British Acupuncture Council (BAcC) & 3000 & 56 & $1.87 \%$ \\
\hline British Medical Acupuncture Society (BMAS) & 2300 & 10 & $0.43 \%$ \\
\hline College of Integrated Chinese Medicine (CICM) & & unknown & $\mathrm{n} / \mathrm{a}$ \\
\hline Northern College of Acupuncture (NCA) & & unknown & $\mathrm{n} / \mathrm{a}$ \\
\hline
\end{tabular}

Notes: Some membership numbers are taken from Mayor and Bovey 2016 [33], so percentage figures are indicative; 13 respondents stated they were members of "Other" associations, and 12 were concurrently members of two associations. 


\section{Survey uptake}

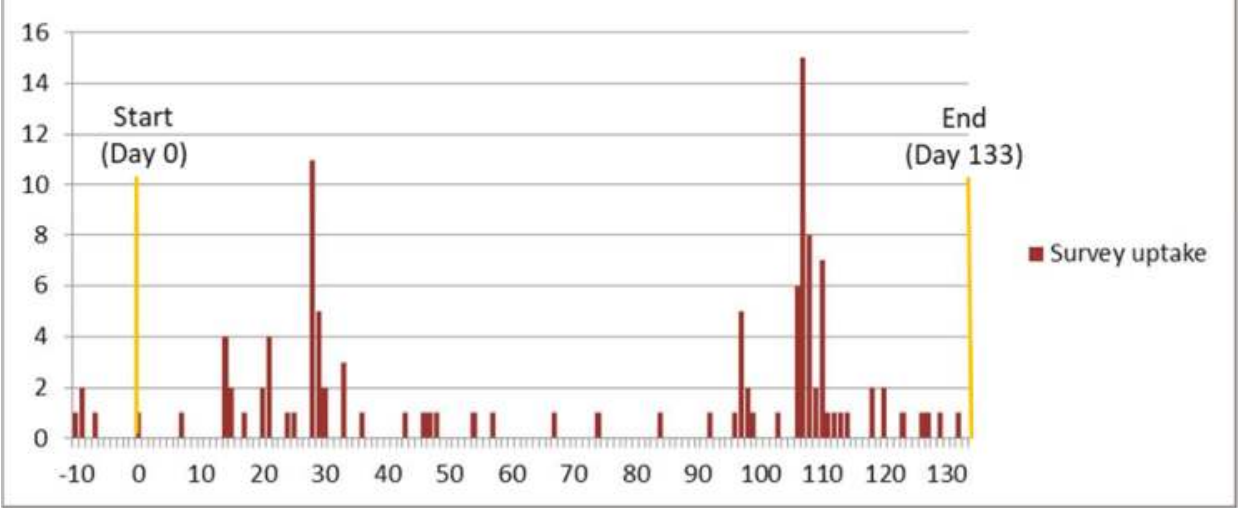

Figure 1. Survey uptake over time, showing the effects of the reminder sent five weeks before closure.

\subsection{Analysis}

For the most part, data were not normally distributed when tested using the Shapiro-Wilk test and for skewness and kurtosis. Analysis was therefore conducted using non-parametric methods in SPSS (v23) and Excel (2010). Randolph's free-marginal multi-rater kappa was calculated using the online calculator (at http://justusrandolph.net/kappa/), and Shannon entropy using the simple Excel-based method described in a previous study [30].

\section{Results}

\subsection{The Respondents}

In total, 114 people completed the survey, including four members of the focus group before the official survey start date (the results for these four are not included in the Supplementary Materials). One of these was not an acupuncture practitioner, one other respondent was also not an acupuncturist (although trained), and one completed the survey prior to training.

There were 79 female and 35 male respondents, the median age for both genders being 52 (interquartile ranges, IQR, being $42-57$ and 48-64, respectively).

Most respondents (83) considered themselves primarily as acupuncturists or practitioners of traditional Chinese medicine (TCM), as against only seven as medical doctors, six as physiotherapists or nurses (including midwives) and two as chiropractors. There were more male than female medical doctors and chiropractors among the respondents, although not significantly.

Median ages for the acupuncturists/TCM practitioners, chiropractors and other professionals who completed the survey were very similar (52, IQR 46-58). However, those for medical doctors were much greater (63, IQR 59.5-69.5), and those for physiotherapists much less (35.5, IQR 30.5-48).

There was a strong correlation between respondents' age and how long they had used acupuncture in clinical practice (Spearman's rank correlation coefficient $r$ tho or $r_{s}=0.535, p<0.0001$ ); this was more marked for men $\left(r_{s}=0.712\right)$ than for women $\left(r_{s}=0.438\right)$.

Respondents had used acupuncture for a median of ten years (IQR 5-19), with medical doctors using it for longest (20 years, IQR 13.5-35) and "other" practitioners for the shortest time (3 years, IQR 1.5-10).

Different styles of acupuncture treatment were used, which could be categorised as more "traditional" (e.g., TCM, Five-Element, Japanese or "Tung's style"), used by 88 respondents, and 
more "modern" or "Western" (e.g., Western medical, Trigger point or "Formula"), used by 23. Those using more Western styles tended to be older (median age 56, IQR 47-63) than the traditionalists (median age 52, IQR 42.25-57), although not significantly. There was also a higher proportion of males among those using Western styles $(72.7 \%)$ than those using more traditional methods $(65.2 \%)$, but again this difference was not significant.

Of those who classed themselves as good responders to acupuncture (Q15), 34 were older than the median age for the sample, and 26 younger, whereas this was reversed for those who considered themselves only as average responders ( 20 being younger and 15 older than the median age). Those who considered themselves good responders were also more likely than those who thought of themselves as average responders to assess their own patients as good responders (Q16): 65.6\% of the former described $80 \%$ or $100 \%$ of their patients as good responders, as against only $43.2 \%$ of the latter (with good responder practitioners correspondingly less likely to describe their patients as poor responders (Q17)). However, none of these differences were significant.

\subsection{The Questions}

\subsubsection{Questions Requiring "Yes" or "No" Responses-An Overview}

In total, 124 questions required a "Yes" or "No" response. The 60 questions on particular patient characteristics, attitudes or experience could be answered as "What you THINK NOW" and "What you THOUGHT THEN", with "Yes", "No" or "Don't know" responses, and a further four more general questions could be answered simply with "Yes" or "No". A full list of responses for these questions is given in Appendix A.

The 60 specific questions were generally answered in the affirmative, both when considered by respondent and by question (Table 2$)$. This is consistent with the fact that 96 respondents $(84.2 \%)$ stated that they had previously considered that patient characteristics (such as their temperament or personality traits) might affect their response to treatment (Q9), and that 70 respondents $(61.4 \%)$ stated their believe that that some patients respond consistently well or poorly to acupuncture, almost regardless of other factors such as the condition treated or their state of health at the time (Q13).

Table 2. Medians and IQRs of "Yes", "No" and "Don't know" (DK) answers to the 60 main survey questions, as percentages of total possible counts ( 60 by respondent, 114 by question).

\begin{tabular}{ccccc}
\hline “Now" or "Then" & How counted & "Yes" responses & "No" responses & "DK" responses \\
\hline \multirow{2}{*}{ NOW } & By respondent & $53.3(35.4-66.7)$ & $25.0(8.3-38.3)$ & $15.0(6.7-29.6)$ \\
& By question & $53.1(40.6-62.3)$ & $25.4(19.5-31.8)$ & $16.2(12.8-26.5)$ \\
\hline \multirow{2}{*}{ THEN } & By respondent & $42.5(18.8-63.3)$ & $21.7(5.0-44.2)$ & $13.3(1.7-47.9)$ \\
& By question & $43.9(35.3-49.8)$ & $25.4(20.8-33.1)$ & $28.9(23.7-34.2)$ \\
\hline
\end{tabular}

Note: "DK" responses THEN calculated as 60-("Yes" + "No" counts).

There were strong correlations between "Yes" (NOW) and "Yes" (THEN) responses $\left(r_{s}=0.655\right.$, $p<0.0001)$, between "No" (NOW) and "No" (THEN) responses $\left(r_{s}=0.609, p<0.0001\right)$, and between "Yes" and "No" (NOW) responses $\left(r_{s}=-0.685, p<0.0001\right)$. There was also a slightly weaker correlation between "Don't know" (NOW) and "Don't know" (THEN) responses $\left(r_{s}=0.487, p<0.0001\right)$, but none between "Yes" and "No" (THEN) responses $\left(r_{S}=0.001, p=0.989\right)$.

\subsubsection{On Specific Questions Requiring "Yes" or "No" Responses}

Of the 60 questions in the main part of the survey, those in the upper and lower deciles for numbers of "Yes" and "No" scores are shown in Table 3 (with numbers of responses in each case). 
Table 3. "Yes", "No" and "Don't know" (DK) responses in the upper and lower deciles for the 60 main survey questions (numbers of responses in brackets). Items shown in bold red type appear in the same deciles both NOW and THEN; those underlined appear in Most "Yes" responses and Least "No" responses (NOW or THEN), or vice versa.

\begin{tabular}{|c|c|c|c|c|}
\hline & \multicolumn{2}{|c|}{ NOW } & \multicolumn{2}{|c|}{ THEN } \\
\hline & Most responses & Fewest responses & Most responses & Fewest responses \\
\hline Yes & $\begin{array}{c}\text { Willing to follow advice } \\
(101) \\
\text { Able to relax }(93) \\
\text { Self-motivated }(90) \\
\text { Exercise }(89) \\
\text { Diet }(85) \\
\text { General health }(85) \\
\text { Openness (85) }\end{array}$ & $\begin{array}{c}\text { Gender issues (17) } \\
\text { Ethnicity (21) } \\
\text { Alexithymia (21) } \\
\text { Education (28) } \\
\text { Relnship status (30) } \\
\text { (and } 4 \text { others, }{ }^{\text {a tied }} \text { 31) }\end{array}$ & $\begin{array}{c}\text { Willing to follow advice } \\
(84) \\
\text { Exercise (74) } \\
\text { Able to relax (73) } \\
\text { General health (73) } \\
\frac{\text { Self-motivated }}{\text { Diet (71) }}\end{array}$ & $\begin{array}{c}\text { Ethnicity (13) } \\
\text { Alexithymia (15) } \\
\text { Gender issues (16) } \\
\text { Character when young } \\
\text { (22) } \\
\text { Birth/prenatal (23) } \\
\text { Child poverty (26) }\end{array}$ \\
\hline No & $\begin{array}{c}\text { Gender (75) } \\
\text { Ethnicity (74) } \\
\frac{\text { Education }(69)}{\text { Relnship status }(60)} \\
\frac{\text { Age (59) }}{\text { Sceptical (57) }}\end{array}$ & $\begin{array}{c}\text { Willing to follow advice } \\
\text { (9) } \\
\text { Central sensitisn (13) } \\
\text { Able to relax (14) } \\
\text { Alexithymia (15) } \\
\text { Psychotic (15) } \\
\text { Self-motivated (15) }\end{array}$ & $\begin{array}{c}\text { Ethnicity (73) } \\
\text { Gender (68) } \\
\text { Education (56) } \\
\text { Relnship status (53) } \\
\text { Gender issues (50) } \\
\text { Age (47) }\end{array}$ & $\begin{array}{c}\text { Willing to follow advice } \\
(7) \\
\text { Commitment (14) } \\
\text { General health (14) } \\
\text { Openness (16) } \\
\text { Self-motivated (16) } \\
\text { Exercise (17) }\end{array}$ \\
\hline DK & $\begin{array}{c}\text { Alexithymia (78) } \\
\text { Gender issues (52) } \\
\text { Central sensitsn (51) } \\
\text { TCM pattern (47) } \\
\text { Child poverty (45) } \\
\text { Character when young } \\
(44)\end{array}$ & $\begin{array}{c}\text { Willing to follow advice } \\
\text { (5) } \\
\frac{\text { Able to relax (6) }}{\text { Age (6) }} \\
\text { Negativity (7) } \\
\text { Gender (7) } \\
\text { Self-motivated (8) }\end{array}$ & & \\
\hline
\end{tabular}

a gender, character when young, childhood poverty and extraverted/introverted. Two of these also appear under "Fewest responses (THEN)".

A graphical representation of salient findings for "Yes" and "No" responses is given in Figure 2.

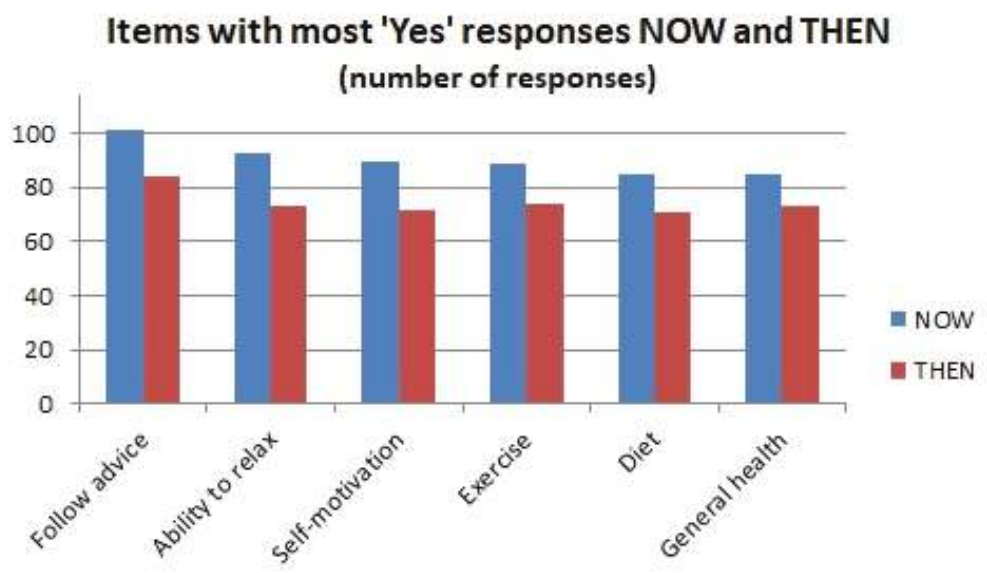

Figure 2. Cont. 


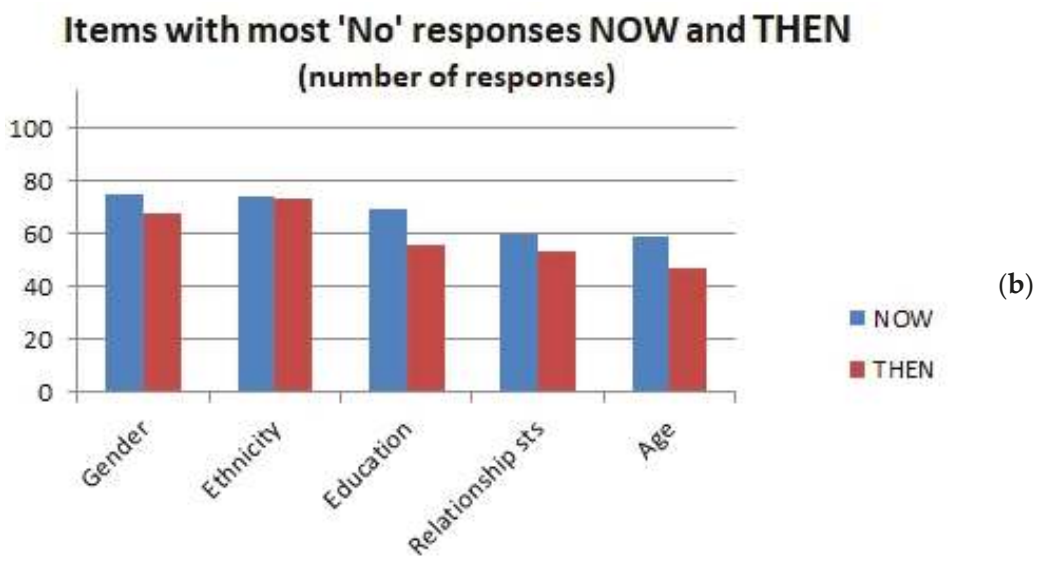

Figure 2. Salient findings for the "Yes" and "No" responses in Table 3. (a): Items with most "Yes" responses; (b): Items with most "No" responses.

As for the "Yes" and "No" responses in general, there is thus considerable agreement between the patient characteristics perceived to affect treatment outcome in past clinical practice and at the time of responding.

Attributes most consistently considered to affect response are willingness to follow advice, self-motivation, general health status, ability to relax, exercise and diet. Those most consistently considered not to affect response are patient age, gender, ethnicity, education and relationship status ("Relnship status" in Table 3).

Respondents were least likely to hazard a guess for the somewhat abstract characteristics of alexithymia and central sensitisation ("Central sensitisn" in Table 3), as well as gender issues, child poverty, character when young and TCM pattern.

\subsubsection{Respondent Characteristics and Yes/No Responses}

Age and Years in Practice

Other than a small negative correlation between respondent age and the number of "No" (THEN) answers given $\left(r_{s}=-0.215, p=0.022\right)$, there were no particular correlations between numbers of "Yes" or "No" responses and either respondents' ages or years in practice. However, if the sample was divided into those younger and older than the median age (52), a Mann-Whitney test showed significant differences of "No" and "Don't know" (THEN) responses between older and younger respondents ("No": $U=903.0, p=0.004$; “Don't know": $U=928.5, p=0.006$ ). Younger respondents (THEN) were more likely to answer "No", and older to answer "Don't know" (the same was true for the NOW responses considered together, but these differences were nonsignificant).

These patterns in age differences were significant for responses to ten of the 60 questions (three NOW and seven THEN), with a Kruskal-Wallis test indicating $p$ values $<0.01$ for three of them: Birth and prenatal experience (NOW) $\left(p=0.008, \chi^{2}=9.57\right)$, Housing situation (THEN) $\left(p=0.002, \chi^{2}=12.19\right)$ and Work situation (NOW) $\left(p=0.005, \chi^{2}=10.54\right)$.

There were also eight significant differences among responses to specific questions with years in practice ( $p$ values $<0.05$ ), those in practice for longer being more likely to consider central sensitisation (both NOW and THEN) a relevant factor, for example, but also less likely to consider optimism (both NOW and THEN) as having an impact on treatment outcome. 
Gender

Table 4 illustrates differences in response frequencies by respondent gender.

Table 4. Median numbers of "Yes", "No" and "Don't know" responses for female and male respondents.

\begin{tabular}{ccccccc}
\hline & \multicolumn{3}{c}{ NOW } & \multicolumn{3}{c}{ THEN } \\
\hline Gender & Yes & No & DK & Yes & No & DK \\
\hline Female & $33(22-42)$ & $15(4-21)$ & $10(4-17)$ & $31^{*}(15-40)$ & $16(3-27)$ & $6^{*}(1-21)$ \\
Male & $27(20-36)$ & $15(6-30)$ & $8(3-21)$ & $20 *(0-34)$ & $8(0-27)$ & $19 *(2-59)$ \\
\hline
\end{tabular}

Note: “DK" responses THEN calculated as $60-\left(" Y e s "+{ }^{\prime \prime} \mathrm{No}^{\prime \prime}\right.$ counts); significant differences indicated with $\left({ }^{*}\right)$.

A Mann-Whitney test indicated that significantly more women than men gave "Yes" (THEN) responses (two-tailed significance, $U=941.5, p=0.007$ ), but this difference was not significant for the "Yes" (NOW) responses $(p=0.071)$. Conversely, men provided significantly more "Don't know" (THEN) responses (i.e., did not answer these questions) than women $(U=1000.0, p=0.018)$.

One particular question exemplifies this difference between female and male respondents, as shown in Figure 3: most women considered NOW that childhood health could impact treatment response, whereas men generally did not (Pearson's $\chi^{2}=7.30, p=0.026$ ).

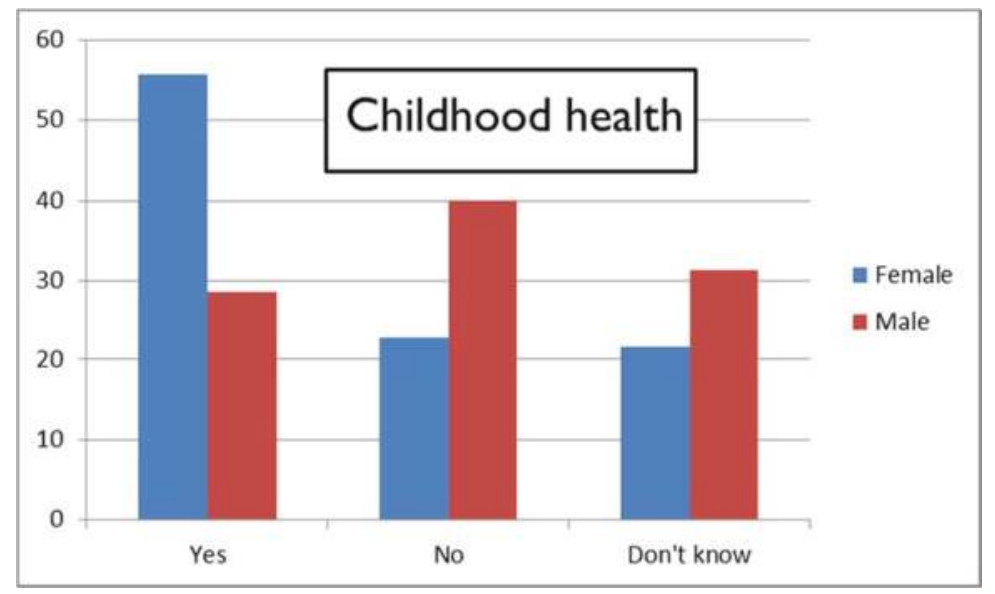

Figure 3. Percentages of female and male respondents giving "Yes", "No", and "Don't know" responses regarding the item on childhood health (NOW responses).

A very similar result was found for family health in the patient's childhood (Pearson's $\chi^{2}=7.26$, $p=0.027$ ). In all there were 11 questions (three NOW, seven THEN) for which female and male responses differed significantly. As in Table 4 for the 60 questions considered together, more males than females replied "Don't know" to these individual questions.

\section{Main Profession}

The medical doctors (who were mostly male) gave fewer "Yes" responses than the remainder of the respondents, although a Kruskal-Wallis test showed these difference not to be significant. When ratios of numbers of "Yes" to "No" scores are considered, acupuncturists appear least likely to consider that individual patient characteristics may affect outcome. In contrast, physiotherapists and nurses (including midwives) showed the highest ratio of numbers of "Yes" to "No" scores (both NOW and THEN) (Table 5). 
Table 5. Yes-to-No count ratios NOW and THEN, by profession, showing medians and IQRs.

\begin{tabular}{ccc}
\hline Profession & Yes-To-No Count Ratios NOW & Yes-To-No Count Ratios THEN \\
\hline Acupuncturists & $1.7(0.9-5.1)$ & $1.4(0.6-4.9)$ \\
Medical doctors & $2.3(2-2.7)$ & $2.4(1.3-2.5)$ \\
Physiotherapists & $6.2(1.8-17.6)$ & $2.9(1.7-4.1)$ \\
Nurses (and midwives) & $4.8(1.3-12.5)$ & $3.5(2.5-5.1)$ \\
Others & $2.4(1.5-2.9)$ & $2.1(1.0-3.1)$ \\
\hline
\end{tabular}

Note: Cases with no "No" responses are omitted, and as this only left one chiropractor, this category was removed from analysis.

Taking only those professions showing the most extreme NOW ratios from the table above (acupuncturists and physiotherapists), responses for the individual questions were examined. Mostly Yes-to-No count ratios were of a similar order and in the same direction for both professions; they were only significantly different and definitively in the opposite direction for one question: religious beliefs or practices $\left(p=0.005, \chi^{2}=10.41\right)$. All the physiotherapists considered this might be a factor in treatment response, whereas only $33.8 \%$ of the acupuncturists did.

\section{Professional Association Membership}

BAcC and ATCM members, although all acupuncturists, responded in different ways to this survey. The median ages of those belonging to the two associations were comparable, but, whereas there were equal numbers of female and male ATCM respondents, there were many more female than male BAcC respondents (47 versus 9). The former recorded the most "No" (THEN) responses of any association members (median per member 18.5, IQR 4-28), and the latter the least (median 4.5, IQR 0.8-9.3), a significant difference ( $p$ values of between 0.014 and 0.043 using the Mann-Whitney test, depending on analysis of multiple-affiliated respondents). Correspondingly, median Yes-to-No count ratios THEN were highest for ATCM members (although ratios NOW were highest for AACP members). Otherwise, association membership did not appear to have a significant effect on the total number of "Yes", "No" or "Don't know" responses (NOW or THEN). Lowest Yes-to-No count ratios (whether NOW or THEN) were for those stating they belonged to another association than those listed.

Analysing only the THEN responses for ATCM and BAcC members using the same procedure as for acupuncturists and physiotherapists in the previous section, again Yes-to-No count ratios were mostly of a similar order and in the same direction for both groups.

Style of Practice

There were no significant differences in numbers of "Yes" or "No" responses (either NOW or THEN) with style of practice-more "traditional" or more "Western"- although the former tended to respond more definitively (whether with "Yes" or "No") and the latter more with "Don't know" (both NOW and THEN).

\section{Prior Opinion That Patient Characteristics Might Affect Treatment Response}

In total, 113 respondents answered the question on whether in the past they had considered that patient characteristics might affect treatment response, 97 of them in the affirmative.

Those who held the prior opinion that patient characteristics might affect their response to treatment were more likely to respond "Yes" to both NOW $(U=366.0, p=0.001)$ and THEN $(U=480.0, p=0.015)$ questions than those who did not, and were correspondingly less likely to give "No" responses.

\subsubsection{Associations between the 60 Main Questions in the Survey}

There is no unique or perfectly precise way of classifying the 60 questions on individual characteristics that might affect treatment outcome, and the list itself is not exhaustive. An initial 
attempt was made to group them under 14 different headings, such as early life, social/financial, behavioural attitudes, and so forth. A confirmatory cluster analysis was then undertaken on the basis of these groupings, but did not yield useful results. Therefore, an alternative approach was used, assessing associations among "Yes", "No" and "Don't know" responses for the different questions using $\chi^{2}$ tests.

These showed strong associations (low $p$ values) between "Yes", "No" and "Don't know" responses for some measures within the anticipated groupings. However, not all of these supported the groupings initially proposed, so that these were adjusted in an attempt to maximise significance of the associations, resulting in the final groupings shown in Appendix A. Even so, some groupings have more explanatory value than others.

The limited convergence of the $\chi^{2}$ (or phi or Cramer's V) measures of association and the results of the hierarchical cluster analysis for NOW (only 19 of 100 tested associations appearing at the first stage of the agglomeration process) led to the decision not to investigate such a relationship for the THEN questions.

Some of the $\chi^{2}$ groupings appeared as consecutive questions in the original survey, so this may have swayed respondents to answer similarly. To test this, associations between eight consecutive but unrelated questions were also explored (see Appendix A). The results of this test indicate that just because questions follow each other consecutively, they are not necessarily answered in the same manner.

As for internal consistency, Cronbach's alpha was 0.930 for the NOW responses, and 0.981 for the THEN responses. Removal of individual items did not greatly affect these values—for NOW, alpha ranged from 0.928 to 0.931 , and, for THEN, from 0.981 to 0.982 .

\subsubsection{Agreement between Respondents, Variability and Variance of Responses}

Three methods were used to assess the consistency of responses across respondents. Firstly, Randolph's free-marginal multi-rater kappa $[35,36]$ was calculated for both NOW and THEN questions and used to derive a measure of "overall agreement" between participants on each question. The questions for which kappa exceeded 0.4 (considered at least a moderate level of agreement [37]) are tabulated in Appendix A. Secondly, Shannon Entropy (SE) values were calculated for each question, both NOW and THEN. SE is a measure of the inherent "informativity" (uncertainty or randomness of information) in a given string of data, where higher values indicate more uncertainty or informativity [38]; we have used this approach in previous pilot studies [30,31]. Randolph's kappa and $\mathrm{SE}$ are corollaries, since they respectively measure agreement and variability in a data sample. This was reflected by extremely strong negative correlations between kappa (or overall agreement) and SE across all questions in both NOW and THEN responses $\left(r_{s} \leq-0.998, p<0.0001\right)$. This pattern is shown graphically in Appendix A. A third measure, a non-parametric version of coefficient of variance $(\mathrm{CV})$, defined as inter-quartile range divided by the median and multiplied by 100 , produced significant correlations in the variance of both "Yes" and "No" responses between NOW and THEN $\left(r_{s}=0.870\right.$ and $0.632, p<0.0001$ and $\left.p=0.006\right)$, but was omitted from further analysis due to its lack of convergence with kappa or SE (correlations ns).

When individual questions were considered, there was considerable overlap with the previous analysis of "Yes", "No" and "Don't know" response frequencies outlined in Table 3 (Section 3.2.2). Only two questions with lowest inter-rater agreement (or greatest SE) appear in that table, both under "DK" responses. Thus, our analysis of respondent agreement (or variability) tallies with our previous analysis of consistency of response by question. 
3.2.6. Patterns in Survey Completion Assessed from Numbers of "Yes", "No" and "Don't know" Answers

There are clear trends in the numbers of "Yes" and "No" responses to the 60 main questions over the course of the survey, with considerable agreement between the NOW and THEN responses, but rather less pronounced trends in the numbers of "Don't know" responses (Figure 4).



Figure 4. Changes in numbers of "Yes", "No" and "Don't know" responses to the 60 main questions over the course of the survey completing them.

When variability values were computed for four consecutive quarters of the main questions (1-15, 16-30, etc.), a similar pattern was observed, with $95.3 \%$ and $80.0 \%$ overall increases in the kappa values for NOW and THEN questions between the first and last quarter, but generally smaller corresponding changes in SE and non-parametric CV (npCV). 


\subsection{Thematic Analysis of Free-Text Responses}

Respondents providing qualitative responses are self-selecting participants; by first ticking a box to indicate understanding of a question's underlying premise ("Yes", "No", "Don't know"), and then deciding at each free-text prompt whether to provide further information, respondents declare buy-in at two levels. Simple counts of the number of responses made to each question (Figure 5) show where this second level of buy-in is strongest.

The maximum number of free-text responses to any survey item was 106, and the minimum 1 (median 10, IQR 7-13). The maximum number of free-text responses for any respondent was 65, and the minimum 0 (median 5, IQR 4-10), as shown in Figure 5. In what follows, respondents are identified by number (from 1 to 114), and the questions to which they respond by their alphanumeric code (from 9.a to 20); thus, "11.4.c/63" refers to Respondent 63's answer to question 11.4.c.

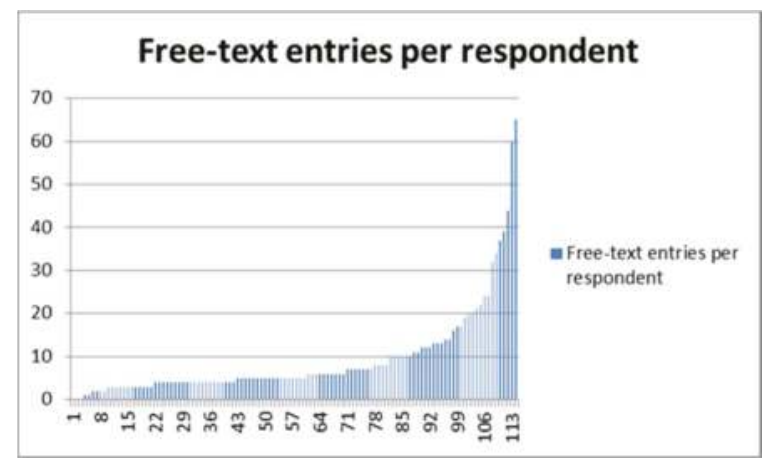

Figure 5. Free-text entries across all parts of the survey, shown in ascending order by respondent.

Questions that elicited the most free-text responses were the general questions (9, 15, 18 and 19), with fewest in the areas of resilience (3 responses), self-regulation (3), suggestibility (3) and extraversion-introversion (1).

It is perhaps unsurprising that Question 9, the first and most fundamental question-"Before you knew about this survey, did you ever consider that patient characteristics (such as their temperament or personality traits) might affect their response to treatment?"- - elicited the largest number of responses (94/114), indicating a perceived need for qualification of the key issue at the outset. Some respondents pick out a single characteristic to highlight here-for example, "calm" patients (9.a/68) are deemed more responsive, "anxious or hostile" (9.a/66) or "depressed and negative" patients (9.a/71) less so. Variation in response intensity is allowed, with some patients identified as "super responders" (9.a/100).

This questionnaire deliberately uses the distinction between the general and the particular, asking respondents to both consider their general opinion at the time of responding, and give deliberately separate consideration to their opinion of a specific patient interaction in the past. A response of "Don't know" is only possible in the "NOW" answers, demanding concrete judgment of the evoked historical event.

Some characteristics are in themselves symptoms or medical conditions and could be the reason for treatment being sought-e.g., anxiety, depression. One respondent highlights this with a repeat response-"depends if this is a symptom/being treated" (verbatim at 11.4.c/63, 11.5.c/63, 11.19.c/63).

Respondents' comments about patient response are predicated on their own understanding of what "response" means in this context. Notions of "response" are unpacked in the introductory matter for the survey, with a range of meanings suggested encompassing improvement in symptoms and changes in wellbeing and quality of life. However, no formal definition of a "good" or "poor" response or responder was provided. 
Texts were extracted from the optional free-text fields to a spreadsheet for thematic analysis. Whilst these texts are researcher-instigated data, they have been generated independently by respondents without the researcher present and so remain subjective, "re-presentations of reality rather than simply true or false" [39] (p. 275). These occupy a middle ground within the continuum of qualitative data between the "gold standard" interview and "naturally occurring" texts such as transcribed conversations and fieldnotes [40] (pp. 669-670). We allow that unique statements have as much potential importance as frequently-found words [41].

A relatively informal approach to analysis was appropriate, as "the qualitative text analysis is not at the core of the research but instead is in a subsidiary or complementary role" [40] (p. 670). Immersion in the data led to emergence of themes, illustrated below by means of in vivo quotes. Mason's tripartite levels of analysis were used to arrange the themes at literal, interpretive, and reflexive levels [42] (p. 180) to gain understanding of what acupuncturists think about their patients' identity as "responders" to acupuncture. These themes apply axially across the different question areas [43].

\subsubsection{Literal Analysis}

Literal analysis assigns literal meaning to statements. Many emergent literal themes (indicated here in italics) in the present data directly stem from specific topic areas established in the survey.

Questions about the impact of gender and age on response elicit high levels of response (23 responses to each, the second-highest count amongst all the free-text responses). There is broad consensus that women are better responders than men, and younger patients better than older (for multiple examples, see the data repository at http:/ / www.mdpi.com/2305-6320/5/3/85/s1). Respondent 99 is a lone voice opining that neither gender nor age affects response (10.1.c/99 and 10.2.c/99).

By contrast, there is no consensus on the effect of ethnicity on response, and only 11 responses are made, perhaps indicating that responder fatigue is already in play by this point in the survey [44].

Of the 15 free-text responses offered in relation to work, seven mention stress.

Childhood aspects are important for a small set of respondents, but as the factors listed multiply, answers become less specific, with certain respondents opting for generic "Ibid"-type responses (see, for example, 10.6.c/45 and 10.6.c/70, and Respondent 5's generic approach to all answers). Others rephrase ideas already expressed in connection with the age question, perhaps indicating some theoretical saturation and respondent fatigue as well as consistency of views. Some respondents may not have been able to make subtle distinctions between overlapping categories such as self-motivation and optimism, self-efficacy and resilience-in some cases declaredly so, despite the provision of glossary information in the survey itself.

An important outcome of the present survey is an update to the acupuncture profession's perceived scope of expertise as represented by the list of conditions that these practitioners find respond well to acupuncture. There is strong consensus around certain conditions, including musculoskeletal problems, anxiety, depression, irritable bowel syndrome (IBS), headaches and chronic pain conditions (see data repository for full details). There is clear overlap between this list and the "effectiveness gaps" identified in UK GP care over a decade ago [45], and also with those conditions identified as having the strongest published evidence for the effectiveness of acupuncture [46].

\subsubsection{Interpretive Analysis}

Interpretive analysis assigns contextualised meaning to statements. Emergent themes are again indicated here in italics.

Paired polarised positions of belief and scepticism are given as baseline patient characteristics for some respondents, with general consensus that belief improves response, although the premise is also contested-"Belief is irrelevant" (9.a/11), "non believers can get the same benefit as well!" (9.a/21). Belief finds 69 direct mentions in the data and can also be discerned in "softened" forms such as expectation of positive outcome (9.a/5) and willingness to engage (9.a/34). Scepticism (24 mentions) is depicted as an undesirable starting-point characteristic which acupuncture treatment 
can shift-"attitude changes with improvement in their condition" (9.a/114). A reinforcing cycle of improved outcomes with increased buy-in to the system responsible is perceived, and acupuncture's capacity to potentiate positive change and enhance self-efficacy is acknowledged as it is in current literature [47]. Respondent 43 (amongst others) is repeatedly concerned with acupuncture's impact on individuals' ability to cope, emphasising that this is a more important factor than changes to symptoms, in particular pain levels (see, for e.g., 10.12.c/43 and 10.13.c/43).

Placebo finds frequent mention both as a pejorative and as a self-evident absolute- "Positivity helps the placebo response" (9.a/40). Individual respondents' understanding of and political attitude towards the term influences response. Debate on the elusive nature of a plausible inert placebo for use in clinical trials of acupuncture is not new [48]. Superficial needling or the application of non-penetrative devices to acupuncture points is recognised to stimulate these points in a manner equitable to a lower dose of the same treatment $[49,50]$ and subsequent research in this area has led to the development of pragmatic trial models which assess the effectiveness of acupuncture treatment against active comparators in ecologically valid settings [51,52]. Awareness of this context is discernible in many responses here.

Appearing in relation to hypochondria (now more formally known as "illness anxiety disorder"), and elsewhere, the notion of sick role is important to several respondents, with reference to patients who "may not want to get well" (11.20.c/37), "have an identity with being ill" (11.20.c/109) or even "a victim complex" (9.a/77). Notions of belief are again in play-"some people are clearly stuck in the 'sick role' mindset and therefore physically get better but don't believe they are" (9.a/30).

The experience of appropriately-placed experts is being deliberately sought by this survey, so evocation of the theoretical knowledge base particular to the profession is perhaps inevitable: "more metal types can be more resistant" (9.a/29). Specialisms appear too, with Respondent 74 focusing on pregnancy and Respondent 43 on chronic pain. Information being elicited is to some degree held as self-evident-"anyone qualified would know this as part of their studies if not common sense" (9.a/27), "pretty obvious" (10.8.c/45).

Individual patient diagnosis emerges as a priority with regard to response/non-response, with consensus found across many areas and specifically with regard to depression (see, for example, 11.18.c/4 and 11.18.c/18) that the innate and unique characteristics of each individual patient are the deciding factor with regard to response level. There are repeated pleas for the diagnostic specificity of the medicine (such as Respondent 63's answers above) and acknowledgement of the non-specific treatment effects known to accompany it $[47,53,54]$.

\subsubsection{Reflexive Analysis}

Reflexive analysis assigns reflexive meaning to statements. In this context, this analysis considers the data in relation to the acupuncture profession as a whole. Emergent themes are again indicated here in italics.

Belief reappears in the form of witness-type statements when respondents are asked about themselves as responders, with 18 counts of "I believe" as well as mentions of "faith". Pseudo-religious language may stem from the acupuncture profession's self-identification as distinct, special and "other". This question also prompts ego-driven statements: "since I started practising I've become quite adept at predicting who will respond well based on the initial consultation" (9.a/82).

Consideration of Belief and scepticism may have roots in the dichotomy-driven nature of Traditional Chinese Medicine theory. Thirty-two responses detail specific TCM/5-element diagnostic patterns, again indicating recourse to the theoretical knowledge base of the profession. Evocation of the particulars of a medicine system about which respondents are passionate indicates a desire to establish professional credibility and expertise. This is in places wielded with discernible defensiveness against the survey instrument, the questions, and the non-responsive sick role patient, who is "never satisfied" (11.20.c/30) and "not quite engaged into getting well" (9.a/39). Focus on scepticism may indicate a defensiveness on behalf of a medicine seen as contested-"there is always an element of you having to prove 
yourself continually" (9.a/49): "Some patients seem to be self sabotaging and come convinced that acupuncture does not work" (9.a/54). Judgmental language permeates the discourse of certain individuals (e.g., Respondent 43).

The response trajectory of specific individual respondent personalities can be traced through the data set. Respondent 45, a 69 year old male, gives 65 free-text answers, the maximum number of free-text responses by any respondent (minimum $=1$, median $=5$ ). Respondent 45 establishes a distinctive "voice" early on, taking issue with the fundamental premise of the endeavour- "characteristics such as temperament or personality traits seem a little fuzzy to me" (9.a/45), and succumbing to petulant exasperation later on-"I repeat: a patient with a healthy, balanced qi will respond better to acupuncture treatment and vice versa" (10.8.c/45). Respondent 45's desire to return to a repeated universal answer reiterates his perception of the universality of the medicine he practises. When asked about factors like housing and work, he consistently holds that these things have relevance only insofar as they "affect the state of the person's qi" (verbatim at 10.14.c/45 and 10.15.c/45).

45 personifies the survey instrument, adopting a tone of debate with the researcher, who is assigned an assumed medicopolitical stance- " "all actions (external, internal, emotional, etc.) that affect the state of our qi, blood, jing, shen, etc. will have an effect on how we function, both in the language of CM or that of biomedical science, which you seem to favour" (11.1.c/45).

\section{Discussion}

This study resulted in several unexpected and useful findings. The first of these (Figure 1) is that it may clearly be useful, when survey uptake is flagging, to remind potential respondents of its existence. Another finding on recruitment (Table 1) is that members of the smaller professional associations were more likely to take the survey, suggesting that personal contact with association staff may be an important factor in increasing uptake. Even so, only 114 people completed the survey out of more than 12,000 potential respondents, an uptake of less than one percent. However, in this age of internet marketing, low response rates are not uncommon. As another organiser of acupuncture surveys has stated, "The number of acupuncture practitioners who respond to electronic surveys tends to be disappointing, but reasons are unclear why this is so" [55]. Personal contact may always be useful, but equally may bias responses.

Considerably more women than men took the survey (Section 3.1), as in our previous survey on electroacupuncture usage, where this was particularly true for UK respondents [33]. Again, as in the earlier survey, male respondents outnumbered females among medical doctors and chiropractors (osteopaths in the earlier survey), although numbers were too small for this to reach significance. Medical doctors tended to be older, and physiotherapists younger, than the majority of survey respondents. It is possible that those doctors that did respond had an interest in the subject matter of the survey because of early contact or training with the doyens of medical acupuncture who first proposed the notions of "strong reactor" and "good responder". Acupuncturists often enter the profession as a second career, but for physiotherapists acupuncture is usually an add-on to their first main career, so it makes sense that physiotherapists would be the youngest group.

A high proportion (84.2\%) of respondents stated that in the past (before they knew about this survey) they had considered that patient characteristics might affect their response to treatment (Section 3.2.1). Correspondingly, the vast majority of individual THEN and NOW questions were given "Yes" answers. This suggests that responses to the main body of the survey were generally made in a manner congruent with existing practitioner attitudes, rather than being arbitrary. The qualitative evidence indicating clear conceptual understanding of relevant patient characteristics supports this, also suggesting that the respondents answered with reference to theoretical frameworks central to their practice (Section 3.3). The fact that respondents generally did not make suggestions for additional attributes that ought to be included suggests that the "long-list" of 60 questions was quite comprehensive in terms of the factors readily encountered in a treatment context. 
The overall positive correlation between "NOW" and "THEN" responses may be driven by various factors, including a simple tendency to tick the same box twice while completing the survey (response perseveration). Although it is of course possible that previous clinical experience heavily shapes later attitudes (i.e., a true similarity between what they thought THEN and NOW), it is difficult to conclude this from the current data alone, since the clinical context(s) on the basis of which practitioners made their THEN judgments were not controlled. More recently qualified practitioners (50 of 114 within the last 10 years) may have made these judgments in a very different manner from those who have had both greater subsequent experience and longer to forget!

The specific questions that elicited most and fewest responses (Section 3.2.2) merit particular attention. Those characteristics/behaviours which were most often considered to impact on treatment outcome (Table 3) included what acupuncture author Bob Flaws once called "the three frees" - relaxation, diet and exercise—but also self-motivation, willingness to follow advice given, general state of health and openness to new experiences. In the HRV literature on acupuncture, parasympathetic activation or an improvement in sympathovagal balance is often found to result from acupuncture treatment [56-58], so a pre-existing ability to relax could facilitate this. The remaining items are all quite straightforward and easy to interpret in the context of acupuncture, where for instance patients less open to new experiences are presumably less likely to procure treatment in the first place.

The items judged least often to impact outcome included age and gender. Statements are often found in the paediatric acupuncture literature $[59,60]$ to the effect that children tend to respond particularly well, but at the other end of the age spectrum there appears to be little information available on whether elderly patients respond better or worse than those in their middle years, despite the existence of many studies on the use of acupuncture for conditions of old age. This is in sharp contrast with the qualitative findings, where many of the free-text comments regarding patient age and gender emphasised their general significance for treatment response-with younger and female patients perceived as likely to respond better to acupuncture. It is important to qualify this apparently contradictory result by noting that, although both were relatively popular items for free-text commentary, only 23 qualitative responses were given regarding patient age and gender across 114 respondents.

There was considerable agreement that relationship status per se does not have much effect on responsiveness to acupuncture, although arguments could be made that a lack of close satisfactory relationship(s) is likely to affect general health as well as the practitioner-patient relationship [28]. Other general characteristics such as level of education and ethnicity were also thought to have little effect on treatment outcome. It is certainly of interest that $50 \%$ of respondents were of the opinion that scepticism does not affect outcome-implying a lack of consensus from a quantitative perspective. The qualitative data help to clarify this by showing distinct schools of thought about the impact of belief in the treatment technique, with some mentioning a positive impact, while most respondents acknowledged that patients show different levels of scepticism-whether it is influential on treatment outcomes.

Items about which respondents were least certain included alexithymia and central sensitisation (which may be unfamiliar or difficult to grasp), gender issues (which have only become salient zeitgeist issues fairly recently), and TCM or Five-element pattern. It was unexpected that this last item should appear here, as both models differentiate diagnostic categories by their expected response to treatment: dampness and phlegm are considered relatively difficult to treat in TCM, for instance [61]. Theoretical constructs such as the three major blocks to treatment, namely "possession", "husband/wife imbalance" and "aggressive energy" [62], further imply that choice of theoretical framework may have an impact on how patient characteristics are expected to influence treatment response.

All in all, only around 20 items appear in Table 3; there was no clear convergence of opinion among respondents about the remaining two-thirds of the questions. The groupings for which the lowest proportions of items were included in the table are shown in Table A20 in Appendix A. Those groupings which produced least consensus (from which fewest items are therefore included in Table 3) were 
4 (Trauma), 6 (Beliefs/attitudes), 5 (Social/financial) and particularly 12 (Psychological attitudes 1), whereas those producing the clearest consensus were 1 (Demographic 1), 2 (Demographic 2), 7 (Lifestyle) and 15 (Behavioural attitudes).

It may well be the case that groupings where respondents did not show clear consensus include items which really do have little impact on treatment outcome, and those where they concurred, items which do have an impact. However, it is also possible that acupuncture practitioners in general may not be trained to have sufficient awareness of the impacts on health and recovery of such things as social and financial situations [63] and psychological attitude [64,65]. This gap in knowledge may be pertinent for those who design acupuncture training courses (especially those for continuing professional education).

There was some variation in response patterns between groups of practitioners (Section 3.2.3). For example, younger respondents (i.e., those earlier in their acupuncture careers) were more likely than their elders to discount particular patient characteristics as having a possible impact on treatment outcome, whereas older respondents (those likely to have had more experience of actual practice) were less decided (Age and Years in Practice). This may in part be due to changes in acupuncture education over the years, with younger/more recently trained practitioners placing more emphasis on core protocols and theory; older practitioners, on the other hand, may have had less information-rich instruction and so more of a desire to explore for themselves. However, such an interpretation is conjectural, and would need to be confirmed with further investigation. Furthermore, male respondents appeared slightly less inclined than female respondents to consider particular patient characteristics as having a possible impact on treatment outcome. This gender difference was significant for several specific questions (Gender). Medical doctors (who were mostly male) gave fewer "Yes" responses than the remainder of the respondents, physiotherapists and nurses more; physiotherapists were unanimous in their view that religious beliefs or practices might be a factor in treatment response, as against only a third of the acupuncturists (Main Profession); however, this could be a chance finding, the result of small sample size and asking a large number of questions, and should certainly not be taken to imply that physiotherapists have a fundamentally more positive view on the influence of religious beliefs.

The differences in survey responses between BACC and ATCM members are intriguing (Professional Association Membership). In addition to the observed difference in gender profile in the two groups of respondents, it is worth noting that ATCM members are mostly TCM doctors trained in China. As already discussed, (Western) medical doctors tended to give fewer affirmative responses than non-doctors, but there is perhaps a greater tendency to conformity among Chinese than Western practitioners, which may have influenced their responses [66]. Style of practice (Style of Practice) and prior opinion that patient characteristics might affect treatment response (Prior Opinion That Patient Characteristics Might Affect Treatment Response) did not appear to affect survey responses in any striking or unexpected ways.

Different methods of grouping the questions were attempted (Section 3.2.4), from prima facie to cluster analysis to $\chi^{2}$ tests. A compromise set of 17 groupings, using three methods, was arrived at, and performed well (using $\chi^{2}$ tests) against a set of unrelated but consecutive questions in the survey, indicating that the groupings were not simply the result of perseveration of responses over strings of questions (Appendix A). When numbers of "Yes", "No" and "Don't know" responses for the groupings were calculated, as a generalisation, respondents appear to have considered Lifestyle, Stress/relaxation and Behavioural attitudes as having more of an impact on treatment outcomes than Early life, Attitudes to religion or nature, basic Demographics and some of the more complex (less behavioural) issues such as attachment or central sensitisation, which clearly did not strike a chord with many respondents.

This again perhaps suggests a lack of awareness of some less behavioural psychological perspectives on health among acupuncture practitioners. 
Three measures of consistency of response were explored (Section 3.2.5), namely Randolph's free-marginal multi-rater kappa, Shannon entropy (SE) and a novel non-parametric equivalent of the coefficient of variation (npCV). As expected from their complementary mathematical basis, kappa and SE values showed strong negative correlations.

Surprisingly, given its origin in information theory, SE has rarely been used in the analysis of questionnaire responses, with only two relevant citations found in PubMed [67,68], although the long-term dynamics of questionnaire mood responses have been studied using a similar measure, approximate entropy [69]. To our knowledge, this is the first time that an explicit association between SE and kappa has been reported, although given that the former is a measure of response variability and the latter of agreement, the negative correlation between them would be expected. Indeed, SE-based measures of consensus and dissention for Likert scale data have been suggested before [70,71], although they do not appear to have been used except by their originators. For both datasets (NOW and THEN), a kappa value of 0.4 corresponds to SE of 1.02; thus, an intermediate or better value of kappa, using Fleiss's definitions, corresponds to a SE of 1.02 or less. Conversely, an SE of 1 corresponds to a kappa value of $0.41-0.42$. This suggests a useful rule of thumb for interrogating questionnaire $S E$ data, and further avenues for exploring relationships between other measures of inter-rater agreement and measures of entropy.

In contrast to the very strong inverse association between kappa and $\mathrm{SE}$, correlations between $\mathrm{npCV}$ and kappa or SE were not significant. Thus, $\mathrm{npCV}$ measures a different construct from the other two methods. Further research will be needed to determine if it is useful in the context of analysing questionnaire or survey responses.

Survey fatigue is suggested by the trending of "Yes" and "No" responses over the course of the survey (Section 3.2.6), although numbers of "Don't know" responses did not increase markedly, as can sometimes occur when respondents experience fatigue [72]. Increases in kappa, as well as decreases in $\mathrm{SE}$ and (for the most part) npCV, also suggest that participants were fatigued by the end of the survey, perhaps tending to fall into a pattern of repeating responses without giving each question due attention.

This was indeed a long survey for people to take, and it is not known how many of those targeted started but did not complete it, or did not even contemplate taking the survey because the topic did not interest them. Many of the questions may have seemed irrelevant, strange or even bewildering to some acupuncture practitioners unfamiliar with the vast literature on other therapeutic approaches or the sociology of health. It may indeed be "a waste of time" (as one respondent put it) to try to determine whether individual characteristics or attributes can affect response to acupuncture in general, but results from our other pilot studies are encouraging, and the results of this survey, together with those from Phase B of this project, will be useful in designing Phase $\mathrm{C}$ before, we hope, moving on to a prospective study to investigate the question of whether good and poor responders to acupuncture can be predicted in advance from their psychometric or other data.

Looking at the qualitative arm alone, the existence of "good responders" appears confirmed by this survey of opinion-with some areas of consensus as to the nature of that "good response" and an understanding that it can vary in intensity.

The acupuncturists who responded to this survey appear to have clear concepts of the characteristics that contribute to their patients' response to acupuncture treatment-although probably for a variety of reasons-and found a range of ways to link these characteristics to the core theoretical base of their medicine. Individual variation is a priority. Acupuncture treatment is characterised by these respondents as a collaborative endeavour which builds self-efficacy in a cycle of reinforcement and has an important preventative aspect. The agendas of both individuals and the whole of the profession they represent can be discerned in these texts [40] (p. 686).

\section{Conclusions}

The main conclusions from this study are: 
1 If appropriate, reminders sent out a few weeks before a survey is closed could well increase uptake. Authors of acupuncture surveys should not expect enthusiastic uptake unless their survey is of particular relevance to their pool of potential respondents. In addition, members of smaller professional organisations may be more likely to respond than those of larger acupuncture associations.

2 Practitioner age and gender influence how they view the importance of patient characteristics, as do the practitioner's main profession and potentially their own ethnicity.

3 Attributes most consistently reported to affect treatment outcome were diet, exercise and the ability to relax (Bob Flaws' "Three frees"), together with general health, self-motivation and a willingness to follow advice.

4 However, a lack of awareness of more complex or difficult psychological and social issues may have skewed the current findings, obscuring the potential importance of some less obvious attributes.

5 Attempts to group characteristics according to item response patterns met with limited success, perhaps relating to the aforementioned skewing.

6 Survey fatigue was observed in terms of numbers of "Yes" and "No" responses, as well as changes in response variability, over the course of completing the survey.

7 Qualitative data may support different and subtler conclusions regarding acupuncturists' appreciation of factors influencing their practice. A key example here is the varying views on belief and scepticism, which "fall through the net" of the quantitative arm of the study.

\section{Limitations}

This is a relatively small survey with a relatively large number of questions. It is also not known to what extent responses represent those of the population of UK acupuncture practitioners as a whole, or, of course, whether the results of the survey are transferrable to other populations (e.g., chiropractors, or acupuncture practitioners in other countries). Furthermore, respondents were asked about some individual characteristics and attributes about which they may have had little prior knowledge. Results should therefore be interpreted with caution. In addition, qualitative responses were optional and in many cases not given - whereas the picture provided by the quantitative data appears more comprehensive.

A serious problem with the survey-as with any survey-is that the outcomes reflect the respondents' own characteristics, attributes, and bias. The results should therefore be considered as representing trends in practitioner opinion-a first step towards further confirmatory research, and not necessarily as truly representative of patient characteristics and attributes that may underlie their responsiveness to acupuncture. Nonetheless, we hope that the results of this survey will help practitioners gain insight into their patients' responses in the clinical setting.

It is also important to note that this paper does not establish true impacts on responsiveness to acupuncture, but it does not intend to; in fact, it is preliminary to other studies which will actually investigate the effects of a subset of the characteristics currently explored.

Supplementary Materials: The original data from the survey are available online, anonymised, as "Individual responsiveness to acupuncture-original data.xlsx" at http:/ / www.mdpi.com/2305-6320/5/3/85/s1.

Author Contributions: D.F.M. drafted the survey wording, organised recruitment for the survey, carried out much of the quantitative analysis and prepared the first draft of this paper. L.S.M. conducted the qualitative analysis of free-text responses. J.H.C.M. carried out additional analysis, and edited and rewrote the article.

Funding: This research received no external funding.

Acknowledgments: The very helpful staff at the acupuncture associations and training institutions involved in recruiting their members for this project and for good-humouredly sending out reminders to them when asked, and of course all the respondents themselves for taking the time to answer quite a lengthy online survey; The eFocus Group who assisted with survey design, wording and piloting (Ashley Bennett, Mark Bovey, Karen 
Charlesworth, Amy Din, Diana Ernaelsteen, Roz Gibbs, Bea Masters and Tony Steffert); Amanda Apponyi, for sharing her recollections of Felix Mann; Justus Randolph, for assistance in calculating his free-marginal multi-rater kappa, and for an enlightening discussion on the relationship between this measure and Shannon entropy (Personal communication, 11 June 2018); Neil Spencer for his view of this relationship (Personal communication, 22 June 2018); Nicola Robinson for her comment about acupuncture surveys; and the anonymous reviewers (and Mark Bovey) who judiciously helped to reshape this article; and of course our families for continuing to support us in our never-ending research projects are gratefully acknowledged.

Conflicts of Interest: The authors declare no conflict of interest.

\section{Appendix A}

Groupings of the 60 main questions in the survey.

Seventeen groupings were selected based on strong $\chi^{2}$ associations (low $p$ values) among "Yes", "No" and "Don't know" responses for the measures within them. However, despite adjustments to maximise $p$ values, some questions remain uneasy bedfellows, such as the items in the "Trauma" grouping (Table A4), whereas others could be included in several different groupings (see, for example, the Note to Table A14, "Psychological characteristics"). The corresponding agglomeration stage for each NOW association was assessed from a dendrogram of a nine-stage confirmatory cluster analysis (using the hierarchical method, Ward's method and squared Euclidean distances), and is indicated in each of Tables A1-A17 by an asterisk and the stage number for each association.

Table A1. Demographic 1.

\begin{tabular}{cccc}
\hline NOW & Gender & Ethnicity & Education \\
\hline Gender & & $<0.0001^{* 1}$ & $<0.0001^{* 2}$ \\
Ethnicity & & $<0.0001^{* 2}$ \\
Education & & & \\
\hline THEN & Gender & Ethnicity & Education \\
\hline Gender & & $<0.0001$ & $<0.0001$ \\
Ethnicity & & $<0.0001$ \\
Education & & \\
\hline$* 1:$ Agglomeration stage $1 ;{ }^{* 2}:$ Agglomeration stage 2.
\end{tabular}

Table A2. Demographic 2.

\begin{tabular}{ccc}
\hline NOW & Age & General Health \\
\hline $\begin{array}{c}\text { Age } \\
\text { General health }\end{array}$ & & $0.001 * 3$ \\
\hline THEN & Age & General Health \\
\hline $\begin{array}{c}\text { Age } \\
\text { General health }\end{array}$ & $<0.0001$ \\
\hline \multicolumn{2}{c}{${ }^{* 3}$ : Agglomeration stage 3. }
\end{tabular}

Table A3. Early life.

\begin{tabular}{|c|c|c|c|c|c|}
\hline NOW & Birth/Prenatal & Characteristics & Health & Family Health & Poverty \\
\hline Birth/prenatal & & $<0.0001^{* 3}$ & $<0.0001 * 2$ & $<0.0001 * 2$ & $<0.0001 * 1$ \\
\hline Characteristics & & & $<0.0001 * 3$ & $<0.0001 * 3$ & $<0.0001 * 3$ \\
\hline Health & & & & $<0.0001 * 1$ & $<0.0001 * 2$ \\
\hline Family health & & & & & $<0.0001 * 2$ \\
\hline Poverty & & & & & \\
\hline THEN & Birth/Prenatal & Characteristics & Health & Family Health & Poverty \\
\hline Birth/prenatal & & $<0.0001$ & $<0.0001$ & $<0.0001$ & $<0.0001$ \\
\hline Characteristics & & & $<0.0001$ & $<0.0001$ & $<0.0001$ \\
\hline Health & & & & $<0.0001$ & $<0.0001$ \\
\hline Family health & & & & & $<0.0001$ \\
\hline Poverty & & & & & \\
\hline
\end{tabular}


Table A4. Trauma.

\begin{tabular}{cccc}
\hline NOW & Early Trauma & Later Trauma & Past Invasive Med \\
\hline $\begin{array}{c}\text { Early trauma } \\
\text { Later trauma } \\
\text { Past invasive med }\end{array}$ & & $<0.0001 * 1$ & $0.023 * 4$ \\
THEN & Early Trauma & Later Trauma & Past Invasive Med \\
\hline Early trauma & & $<0.0001$ & $<0.0001$ \\
Later trauma & & & $<0.0001$ \\
Past invasive med & & & \\
\hline & $* 1$ : Agglomeration stage $1 ; * 4:$ Agglomeration stage 4. &
\end{tabular}

Table A5. Social/financial.

\begin{tabular}{cccccc}
\hline NOW & Relationship & Soc Support & Housing & Work & Finances \\
\hline Relationship & & $<0.0001^{* 4}$ & $<0.0001^{* 4}$ & $<0.0001^{* 4}$ & $<0.0001^{* 4}$ \\
Soc support & & & $<0.0001^{* 2}$ & $<0.0001^{* 2}$ & $<0.0001^{* 2}$ \\
Housing & & & $<0.0001^{* 2}$ & $<0.0001^{* 2}$ \\
Work & & & & $<0.0001^{* 1}$ \\
Finances & & & & & \\
\hline THEN & Relationship & Soc Support & Housing & Work & Finances \\
\hline Relationship & & $<0.0001$ & $<0.0001$ & $<0.0001$ & $<0.0001$ \\
Soc support & & & $<0.0001$ & $<0.0001$ & $<0.0001$ \\
Housing & & & $<0.0001$ & $<0.0001$ \\
Work & & & & $<0.0001$ \\
Finances & & & & \\
\hline & $* 1$ : Agglomeration stage $1 ; * 2$ : Agglomeration stage $2 ; * 4$ : Agglomeration stage 4. &
\end{tabular}

Table A6. Beliefs/attitudes.

\begin{tabular}{ccc}
\hline NOW & Religion & Nature/Technology \\
\hline $\begin{array}{c}\text { Religion } \\
\text { Nature/technology }\end{array}$ & & $<0.0001^{* 2}$ \\
\hline THEN & Religion & Nature/Technology \\
\hline $\begin{array}{c}\text { Religion } \\
\text { Nature } / \text { technology }\end{array}$ & & $<0.0001$ \\
\hline & $* 2$ : Agglomeration stage 2. &
\end{tabular}

Table A7. Lifestyle.

\begin{tabular}{ccc}
\hline NOW & Nutrition & Exercise \\
\hline Nutrition & & $<0.0001^{* 1}$ \\
Exercise & & \\
\hline THEN & Nutrition & Exercise \\
\hline Nutrition & & $<0.0001$ \\
Exercise & & \\
\hline & & \\
& &
\end{tabular}


Table A8. Hypothalamic-pituitary-adrenal axis 1: Stress and relaxation.

\begin{tabular}{cccc}
\hline NOW & SensStress & Anxiety & RelaxAbil \\
\hline SensStress & & $<0.0001 * 1$ & $0.002 * 4$ \\
Anxiety & & & $<0.0001 * 4$ \\
RelaxAbil & & Anxiety & RelaxAbil \\
\hline THEN & SensStress & $<0.0001$ & $<0.0001$ \\
\hline SensStress & & & $<0.0001$ \\
Anxiety & & \\
RelaxAbil & & & \\
\hline
\end{tabular}

${ }^{* 1}$ : Agglomeration stage $1 ;{ }^{* 4}$ : Agglomeration stage 4 .

Table A9. Hypothalamic-pituitary-adrenal axis 2: "Central sensitisation" and biochemistry.

\begin{tabular}{ccc}
\hline NOW & CentrSens & Neuroch \\
\hline $\begin{array}{c}\text { CentrSens } \\
\text { Neuroch }\end{array}$ & $<0.0001^{* 1}$ \\
\hline THEN & CentrSens & Neuroch \\
\hline CentrSens & & $<0.0001$ \\
Neuroch & & \\
\hline & &
\end{tabular}

Table A10. Somatisation (MUS), catastrophising, hypochondria and psychosis.

\begin{tabular}{ccccc}
\hline NOW & MUS & Catastr & Hypoch & Psychosis $^{\text {a }}$ \\
\hline MUS & & $<0.0001^{* 4}$ & $0.001^{* 4}$ & $0.002^{* 4}$ \\
Catastr & & & $<0.0001^{* 1}$ & $<0.0001^{* 2}$ \\
Hypoch & & & $<0.0001^{* 2}$ \\
Psychosis & & & & \\
\hline THEN & MUS & Catastr & Hypoch & Psychosis \\
\hline MUS & & $<0.0001$ & $<0.0001$ & $<0.0001$ \\
Catastr & & & $<0.0001$ & $<0.0001$ \\
Hypoch & & & & $<0.0001$ \\
Psychosis & & & & \\
\hline
\end{tabular}

${ }^{a}$ This may not appear the most likely grouping to include Psychosis, but, although it fits naturally in "Psychological characteristics" (\#14 below), $p$ is high at 0.010 for its association with Extravert/introvert ( $p$ is low, $<0.0001$, for the associations of Extravert/introvert with Depressive and Emotionally unstable). ${ }^{* 1}$ : Agglomeration stage 1; *2: Agglomeration stage 2; *4: Agglomeration stage 4 .

Table A11. Attachment, addiction and identity.

\begin{tabular}{ccccc}
\hline NOW & Attachment & Addiction & Doctor Shopping & Gender Issues \\
\hline Attachment & & $0.007^{* 3}$ & $<0.0001^{* 3}$ & $<0.0001^{* 5}$ \\
Addiction & & & $0.007^{* 1}$ & $0.001^{* 5}$ \\
Doctor shopping & & & $0.007 * 5$ \\
Gender issues & & & & \\
\hline THEN & Attachment & Addiction & Doctor shopping & Gender issues \\
\hline Attachment & & $<0.0001$ & $<0.0001$ & $<0.0001$ \\
Addiction & & & $<0.0001$ & $<0.0001$ \\
Doctor shopping & & & $<0.0001$ \\
Gender issues & & & & \\
\hline
\end{tabular}

${ }^{* 1}$ : Agglomeration stage $1 ;{ }^{* 3}$ : Agglomeration stage $3 ; *{ }^{* 5}$ : Agglomeration stage 5. 
Table A12. Psychological attitudes 1.

\begin{tabular}{|c|c|c|c|c|c|c|c|c|}
\hline NOW & LifeSatis & Incontrol & S/Esteem & S/Efficacy & Resilience & Optim & Valency & S/Regul \\
\hline LifeSatis & & $<0.0001 * 1$ & $<0.0001 * 1$ & $<0.0001 * 5$ & $<0.0001 * 2$ & $<0.0001 * 4$ & $<0.0001 * 4$ & $<0.0001 * 5$ \\
\hline InControl & & & $<0.0001 * 1$ & $<0.0001 * 5$ & $<0.0001 * 2$ & $<0.0001 * 4$ & $<0.0001 * 4$ & $<0.0001 * 5$ \\
\hline $\mathrm{S} /$ Esteem & & & & $<0.0001 * 5$ & $<0.0001 * 2$ & $<0.0001 * 4$ & $<0.0001 * 4$ & $<0.0001 * 5$ \\
\hline S/Efficacy & & & & & $<0.0001 * 5$ & $<0.0001 * 5$ & $<0.0001 * 5$ & $<0.0001 * 1$ \\
\hline Resilience & & & & & & $<0.0001 * 4$ & $<0.0001 * 4$ & $<0.0001 * 5$ \\
\hline Optim & & & & & & & $<0.0001 * 1$ & $<0.0001 * 5$ \\
\hline Valency & & & & & & & & $<0.0001 * 5$ \\
\hline \multicolumn{9}{|l|}{ S/Regul } \\
\hline THEN & LifeSatis & InControl & S/ESteem & S/Efficacy & Resilience & Optim & Valency & S/Regul \\
\hline LifeSatis & & $<0.0001$ & $<0.0001$ & $<0.0001$ & $<0.0001$ & $<0.0001$ & $<0.0001$ & $<0.0001$ \\
\hline InControl & & & $<0.0001$ & $<0.0001$ & $<0.0001$ & $<0.0001$ & $<0.0001$ & $<0.0001$ \\
\hline S/ESteem & & & & $<0.0001$ & $<0.0001$ & $<0.0001$ & $<0.0001$ & $<0.0001$ \\
\hline S/Efficacy & & & & & $<0.0001$ & $<0.0001$ & $<0.0001$ & $<0.0001$ \\
\hline Resilience & & & & & & $<0.0001$ & $<0.0001$ & $<0.0001$ \\
\hline Optim & & & & & & & $<0.0001$ & $<0.0001$ \\
\hline Valency & & & & & & & & $<0.0001$ \\
\hline S/Regul & & & & & & & & \\
\hline
\end{tabular}

Table A13. Psychological attitudes 2, including placebo responsiveness.

\begin{tabular}{ccccccc}
\hline NOW & Defensive & Open & Suggestible & Sceptical & Trusting & Placebo \\
\hline Defensive & & $<0.0001^{* 5}$ & $<0.0001^{* 1}$ & $<0.0001^{* 6}$ & $<0.0001^{* 4}$ & $0.001^{* 2}$ \\
Open & & $<0.0001^{* 5}$ & $0.005^{* 5}$ & $<0.0001^{* 3}$ & $0.003^{* 5}$ \\
Suggestible & & & $<0.0001^{* 6}$ & $<0.0001^{* 4}$ & $<0.0001^{* 4}$ \\
Sceptical & & & & $<0.001 * 4$ & $<0.001^{* 5}$ \\
Trusting & & & & & $0.001^{* 4}$ \\
Placebo & & & & & & \\
\hline THEN & Defensive & Open & Suggestible & Sceptical & Trusting & Placebo \\
\hline Defensive & & $<0.0001$ & $<0.0001$ & $<0.0001$ & $<0.0001$ & $<0.0001$ \\
Open & & & $<0.0001$ & $<0.0001$ & $<0.0001$ & $<0.0001$ \\
Suggestible & & & $<0.0001$ & $<0.0001$ & $<0.0001$ \\
Sceptical & & & & $<0.0001$ & $<0.0001$ \\
Trusting & & & & & $<0.0001$ \\
Placebo & & & & & & \\
\hline
\end{tabular}

${ }^{* 1}$ : Agglomeration stage $1 ;{ }^{* 2}$ : Agglomeration stage $2 ;{ }^{* 3}$ : Agglomeration stage $3 ;{ }^{* 4}$ : Agglomeration stage 4;

${ }^{* 5}$ : Agglomeration stage $5 ;{ }^{* 6}$ : Agglomeration stage 6 .

Table A14. Psychological characteristics.

\begin{tabular}{cccc}
\hline NOW & Depressive & Unstable & Extrav/Introv \\
\hline $\begin{array}{c}\text { Depressive } \\
\text { Unstable }\end{array}$ & & $<0.0001^{* 2}$ & $<0.0001^{* 5}$ \\
Extrav $/$ Introv $^{\text {a }}$ & & & $<0.0001^{* 5}$ \\
\hline THEN & Depressive & Unstable & Extrav/Introv \\
\hline Depressive & & $<0.0001$ & $<0.0001$ \\
Unstable & & & $<0.0001$ \\
Extrav $/$ Introv $^{\text {a }}$ & & & \\
\hline
\end{tabular}

a. Extravert/Introvert also demonstrated $p$-values $<0.0001$ for groupings \#11 and \#13, for example.

${ }^{*}$ : Agglomeration stage $2 ; * 5$ : Agglomeration stage 5 . 
Table A15. Behavioural attitudes.

\begin{tabular}{cccc}
\hline NOW & Self-Motivated & Follows Advice & Commitment \\
\hline Self-motivated & & $<0.0001 * 1$ & $<0.001 * 3$ \\
Follows advice & & & $<0.0001 * 3$ \\
Commitment & & & \\
\hline THEN & Self-Motivated & Follows Advice & Commitment \\
\hline Self-motivated & & $<0.0001$ & $<0.0001$ \\
Follows advice & & $<0.0001$ \\
Commitment & & & \\
\hline & $* 1:$ Agglomeration stage $1 ; * 3$ : Agglomeration stage 3. &
\end{tabular}

Table A16. Self-awareness.

\begin{tabular}{cccc}
\hline NOW & Bodily Aware & Emotionally Aware & Alexithymic \\
\hline Bodily aware & & $<0.0001 * 1$ & $<0.0001 * 5$ \\
Emotionally aware & & $<0.0001 * 5$ \\
Alexithymic & & & \\
\hline THEN & Bodily Aware & Emotionally Aware & Alexithymic \\
\hline Bodily aware & & $<0.0001$ & $<0.0001$ \\
Emotionally aware & & $<0.0001$ \\
Alexithymic & & & \\
\hline & $* 1$ : Agglomeration stage $1 ; * 5$ : Agglomeration stage 5. &
\end{tabular}

Table A17. TCM.

\begin{tabular}{ccc}
\hline NOW & $Q i$ Strong/Weak & TCM/5E Diagnosis \\
\hline Qi strong/weak & & $<0.0001$ \\
TCM/5E diagnosis & & \\
\hline
\end{tabular}

Some of the $\chi^{2}$ groupings appeared as consecutive questions in the original survey, so this may have swayed respondents to answer similarly. To test this, associations between eight consecutive but unrelated questions were also explored (Table A18).

Table A18. Associations between consecutive survey questions from different groupings. Shown in bold are the $\chi^{2}$ associations from Table A17.

\begin{tabular}{|c|c|c|c|c|c|c|c|c|}
\hline NOW & Religion & Nature/Tech & Health & Neurochem & $\begin{array}{c}\text { Central } \\
\text { Sens }\end{array}$ & Nutrition & Exercise & $\begin{array}{l}\text { Ability } \\
\text { to Relax }\end{array}$ \\
\hline Religion & & $<0.0001$ & $<0.0001$ & 0.005 & 0.006 & n.s. & n.s. & n.s. \\
\hline Nature/Tech & & & $<0.001$ & 0.006 & $<0.001$ & 0.034 & n.s. & 0.010 \\
\hline Health & & & & $<0.001$ & 0.042 & $<0.0001$ & $<0.0001$ & n.s. \\
\hline Neurochem & & & & & $<0.0001$ & n.s. & n.s. & n.s. \\
\hline Central Sens & & & & & & n.s. & n.s. & 0.039 \\
\hline Nutrition & & & & & & & $<0.0001$ & 0.001 \\
\hline Exercise & & & & & & & & 0.014 \\
\hline Ability to Relax & & & & & & & & \\
\hline
\end{tabular}

n.s.: not significant.

Thus, the $\chi^{2}$ associations between closely consecutive items does not necessarily imply that they are answered in the same manner.

Table A19 shows values of kappa, median SE and npCV for the 17 groupings. Table A20 shows the numbers of items from each grouping included and not included in Table 3. 
Table A19. Values of kappa, median SE and npCV for the 17 groupings.

\begin{tabular}{ccccccccc}
\hline Grouping & \multicolumn{4}{c}{ NOW } & \multicolumn{4}{c}{ THEN } \\
\hline & Kappa & $\begin{array}{c}\text { Median } \\
\text { SE }\end{array}$ & $\begin{array}{c}\text { npCV } \\
\text { Yes }\end{array}$ & $\begin{array}{c}\text { npCV } \\
\text { No }\end{array}$ & Kappa & $\begin{array}{c}\text { Median } \\
\text { SE }\end{array}$ & $\begin{array}{c}\text { npCV } \\
\text { Yes }\end{array}$ & $\begin{array}{c}\text { npCV } \\
\text { No }\end{array}$ \\
\hline 1 & 0.22 & 1.29 & 18.97 & 4.05 & 0.14 & 1.36 & 32.14 & 12.50 \\
2 & 0.29 & 1.13 & 27.41 & 51.28 & 0.14 & 1.37 & 21.31 & 54.10 \\
3 & 0.01 & 1.57 & 45.45 & 7.89 & 0.02 & 1.54 & 69.23 & 29.27 \\
4 & 0.13 & 1.40 & 3.03 & 23.08 & 0.04 & 1.52 & 4.72 & 23.08 \\
5 & 0.09 & 1.43 & 40.38 & 24.00 & 0.02 & 1.55 & 41.45 & 15.91 \\
6 & 0.03 & 1.54 & 6.38 & 2.38 & 0.00 & 1.58 & 11.11 & 13.16 \\
7 & 0.43 & 1.00 & 1.71 & 8.57 & 0.21 & 1.30 & 1.37 & 5.56 \\
8 & 0.33 & 1.22 & 14.38 & 32.14 & 0.14 & 1.41 & 13.11 & 16.00 \\
9 & 0.11 & 1.40 & 9.91 & 10.34 & 0.01 & 1.55 & 8.43 & 9.09 \\
10 & 0.15 & 1.37 & 14.18 & 21.79 & 0.04 & 1.51 & 10.85 & 38.64 \\
11 & 0.06 & 1.46 & 42.38 & 41.94 & 0.03 & 1.52 & 59.15 & 47.83 \\
12 & 0.14 & 1.38 & 14.45 & 14.29 & 0.03 & 1.54 & 12.87 & 19.40 \\
13 & 0.17 & 1.43 & 28.75 & 32.35 & 0.07 & 1.51 & 4.85 & 25.00 \\
14 & 0.15 & 1.31 & 30.28 & 31.03 & 0.06 & 1.47 & 28.33 & 26.79 \\
15 & 0.52 & 0.91 & 8.79 & 36.67 & 0.26 & 1.29 & 9.59 & 32.14 \\
16 & 0.22 & 1.30 & 35.71 & 25.86 & 0.09 & 1.50 & 37.27 & 14.00 \\
17 & 0.07 & 1.48 & 30.69 & 4.92 & 0.02 & 1.54 & 25.00 & 16.13 \\
\hline
\end{tabular}

Table A20. Numbers of items from each grouping included and not included in Table 3.

\begin{tabular}{cccc}
\hline Grouping & Included & Not Included & \% Included \\
\hline 1 & 3 & 0 & 100 \\
2 & 2 & 0 & 100 \\
3 & 3 & 2 & 60 \\
4 & 0 & 3 & 0 \\
5 & 1 & 4 & 20 \\
6 & 0 & 2 & 0 \\
7 & 2 & 0 & 100 \\
8 & 1 & 2 & 33 \\
9 & 1 & 1 & 50 \\
10 & 1 & 3 & 25 \\
11 & 1 & 3 & 25 \\
12 & 1 & 7 & 12.5 \\
13 & 2 & 4 & 33 \\
14 & 1 & 2 & 33 \\
15 & 3 & 0 & 100 \\
16 & 1 & 2 & 33 \\
17 & 1 & 1 & 50 \\
\hline
\end{tabular}

Table A21 shows the individual questions in the upper and lower deciles for SE and kappa scores. Note that all questions for which kappa $\geq 0.4$ are included in this table, and that kappa for none of the THEN questions reached 0.4 .

Comparing Table A21 and Table 3, there is considerable agreement between questions for which there was greatest inter-rater agreement (or lowest SE) and those for which most responses were "Yes" (either NOW or THEN), as well as for Ethnicity, for which most responses were "No", and also for Commitment, for which the fewest responses were "No". Only two questions with lowest inter-rater agreement (or greatest SE) appeared in Table 3, both under "DK" responses.

Values of Randolph's free-marginal multi-rater kappa can range from -1.0 (complete disagreement, below chance) to 1.0 (complete agreement, above chance), with 0.0 indicating agreement equal to chance. Values of kappa less than 0.40 are considered poor, values from 0.40 to 0.75 intermediate to good, and values above 0.75 excellent [37]. "Overall agreement", a slightly more sensitive measure derived from kappa, can range from around 33\% (equivalent to kappa $=0$ ) to $100 \%$ (for kappa $=1$ ). 
Table A21. Survey questions in the upper and lower deciles for SE and kappa scores. As in Table 3, items shown in bold red type appear in the same deciles both NOW and THEN.

\begin{tabular}{|c|c|c|c|c|c|}
\hline \multicolumn{4}{|c|}{ Shannon Entropy (SE) } & \multicolumn{2}{|c|}{ Free-Marginal Kappa } \\
\hline & NOW & THEN & & NOW & THEN \\
\hline \multirow{6}{*}{ SE Q3 } & Birth/prenatal & Religious beliefs & & Birth/prenatal & Family health young \\
\hline & Char when young a & Attitude to nature/t & & Character when young a & Religious beliefs \\
\hline & Child poverty $^{a}$ & Self-efficacy & $\kappa$ & Child poverty ${ }^{\mathrm{a}}$ & Attitude to nature/t \\
\hline & Housing & Attachment style & Q1 & Housing & Self-efficacy \\
\hline & Attachment style & Self-regulation & & Attachment style & Self-regulation \\
\hline & Extravert/introvert & TCM diagnosis & & TCM diagnosis & TCM diagnosis \\
\hline \multirow{6}{*}{ SE Q1 } & General health ${ }^{\mathrm{b}, \mathrm{d}}$ & Ethnicity $^{c}$ & & Diet $^{\mathrm{b}, \mathrm{d}}$ & Ethnicity $^{c}$ \\
\hline & Diet $^{b, d}$ & General health ${ }^{b}$ & & Exercise ${ }^{b, d}$ & General health ${ }^{\mathrm{b}}$ \\
\hline & Exercise ${ }^{b, d}$ & Exercise $^{\mathrm{b}}$ & $\kappa$ & Ability to relax ${ }^{b, d}$ & Exercise $^{\mathrm{b}}$ \\
\hline & Ability to relax ${ }^{b, d}$ & Ability to relax ${ }^{b}$ & Q3 & Self-motivated ${ }^{b, d}$ & Self-motivated ${ }^{\mathrm{b}}$ \\
\hline & Self-motived ${ }^{\mathrm{b}, \mathrm{d}}$ & Self-motivated ${ }^{\mathrm{b}}$ & & Openness b,d & Will follow advice ${ }^{b}$ \\
\hline & Will follow advice ${ }^{b, d}$ & Will follow advice ${ }^{\mathrm{b}}$ & & Will follow advice ${ }^{\mathrm{b}, \mathrm{d}}$ & Commitment $^{c}$ \\
\hline
\end{tabular}

Values of SE can range from 0 (no variability or informativity), through 1 (which would result from repeated tosses using an unbiased coin [73]) to > 2.6 for some questionnaires (Body Awareness Questionnaire, data in course of analysis).

For the 60 main survey questions here, SE varies between 0.62 and 1.57, kappa between 0 and 0.7 .

When SE was plotted against kappa and overall agreement for each of the 60 question responses, very strong correlations were found between them (Figure A1).

These correlations are seemingly quite dramatic, but may in fact be trivial. They will be explored in a future paper.
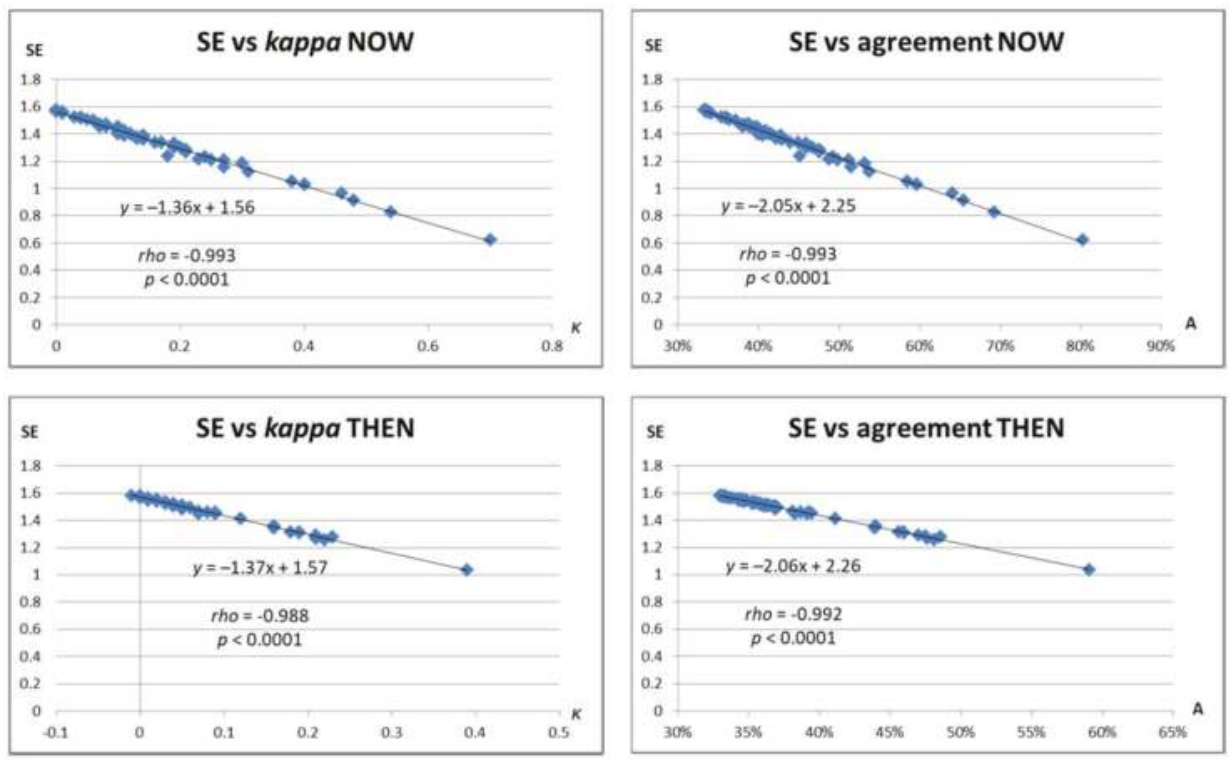

Figure A1. Scatter plots of Shannon entropy (SE) vs. free-marginal kappa and overall agreement for the 60 main survey questions. 


\section{References}

1. Baldry, P. Superficial versus deep dry needling. Acupunct. Med. 2002, 20, 78-81. [CrossRef] [PubMed]

2. Grant, S.; Colaiaco, B.; Motala, A.; Shanman, R.M.; Sorbero, M.E.; Hempel, S. Needle Acupuncture for Posttraumatic Stress Disorder (PTSD): A Systematic Review; RAND Corporation: Santa Monica, CA, USA, 2017.

3. Paterson, C.; Britten, N. The patient's experience of holistic care: Insights from acupuncture research. Chronic Illn. 2008, 4, 264-277. [CrossRef] [PubMed]

4. McPhail, P.; Sandhu, H.; Dale, J.; Stewart-Brown, S. Acupuncture in hospice settings: A qualitative exploration of patients' experiences. Eur. J. Cancer Care 2018, 27. [CrossRef] [PubMed]

5. White, P.; Bishop, F.L.; Prescott, P.; Scott, C.; Little, P.; Lewith, G. Practice, practitioner, or placebo? A multifactorial, mixed-methods randomized controlled trial of acupuncture. Pain 2012, 153, 455-462. [CrossRef] [PubMed]

6. Powell, J.; Wojnarowska, F. Acupuncture for vulvodynia. J. R. Soc. Med. 1999, 92, 579-581. [CrossRef] [PubMed]

7. Ko, S.J.; Park, J.W.; Leem, J.; Kaptchuk, T.J.; Napadow, V.; Kuo, B.; Gerber, J.; Dimisko, L.; Yeo, I.; Lee, J.; et al. Influence of the patient-practitioner interaction context on acupuncture outcomes in functional dyspepsia: Study protocol for a multicenter randomized controlled trial. BMC Complement. Altern. Med. 2017, 17. [CrossRef] [PubMed]

8. MacPherson, H.; Elliot, B.; Hopton, A.; Lansdown, H.; Birch, S.; Hewitt, C. Lifestyle advice and self-care integral to acupuncture treatment for patients with chronic neck pain: Secondary analysis of outcomes within a randomized controlled trial. J. Altern. Complement. Med. 2017, 23, 180-187. [CrossRef] [PubMed]

9. Karst, M.; Schneidewind, D.; Scheinichen, D.; Juettner, B.; Bernateck, M.; Molsberger, A.; Parlesak, A.; Passie, T.; Hoy, L.; Fink, M. Acupuncture induces a pro-inflammatory immune response intensified by a conditioning-expectation effect. Forsch. Komplementmed. 2010, 17, 21-27. [CrossRef] [PubMed]

10. Kong, J.; Wang, Z.; Leiser, J.; Minicucci, D.; Edwards, R.; Kirsch, I.; Wasan, A.D.; Lang, C.; Gerber, J.; Yu, S.; et al. Enhancing treatment of osteoarthritis knee pain by boosting expectancy: A functional neuroimaging study. Neuroimage Clin. 2018, 18, 325-334. [CrossRef] [PubMed]

11. Mayor, D.F.; McClure, L.S.; McClure, J.H.C. Nonspecific feelings expected and experienced during or immediately after electroacupuncture: A pilot study in a teaching situation. Medicines 2017, 8. [CrossRef] [PubMed]

12. Mann, F. Reinventing Acupuncture: A New Concept of Ancient Medicine, 2nd ed.; Butterworth-Heinemann: Oxford, UK, 2000; ISBN 9780702038280.

13. Campbell, A. The limbic system and emotion in relation to acupuncture. Acupunct. Med. 1999, 17, $124-130$. [CrossRef]

14. Johnson, M.I.; Ashton, C.H.; Thompson, J.W. The consistency of pulse frequencies and pulse patterns of transcutaneous nerve stimulation (TENS) used by chronic pain patients. Pain 1991, 44, 231-234. [CrossRef]

15. Campbell, A. Acupuncture: Where to place the needles and for how long. Acupunct. Med. 1999, 17, $113-117$. [CrossRef]

16. Alborzi, A.; Hashempour, T.; Moayedi, J.; Musavi, Z.; Pouladfar, G.; Merat, S. Role of serum level and genetic variation of IL-28B in interferon responsiveness and advanced liver disease in chronic hepatitis $\mathrm{C}$ patients. Med. Microbiol. Immunol. 2017, 206, 165-174. [CrossRef] [PubMed]

17. Yan, Z.; Wang, Y. Viral and host factors associated with outcomes of hepatitis C virus infection (Review). Mol. Med. Rep. 2017, 15, 2909-2924. [CrossRef] [PubMed]

18. Hall, K.T.; Loscalzo, J.; Kaptchuk, T.J. Genetics and the placebo effect: The placebome. Trends Mol. Med. 2015, 21, 285-294. [CrossRef] [PubMed]

19. Wang, R.S.; Hall, K.T.; Giulianini, F.; Passow, D.; Kaptchuk, T.J.; Loscalzo, J. Network analysis of the genomic basis of the placebo effect. JCI Insight 2017, 2. [CrossRef] [PubMed]

20. Park, H.J.; Kim, S.T.; Yoon, D.H.; Jin, S.H.; Lee, S.J.; Lee, H.J.; Lim, S. The association between the DRD2 TaqI A polymorphism and smoking cessation in response to acupuncture in Koreans. J. Altern. Complement. Med. 2005, 11, 401-405. [CrossRef] [PubMed]

21. Wu, X.L.; Sun, J.H.; Liu, L.Y.; Fu, H.Y.; Jiao, D.Y.; Shu, Y.Y.; Chen, D.; Liu, C.Y.; Zhan, D.W.; Zhang, W. A feasibility analysis on individualized acupuncture treatment of irritable bowel syndrome under help of genetic polymorphism technique. Zhen Ci Yan Jiu 2014, 39, 252-255. [PubMed] 
22. Yang, X.; Gong, J.; Jin, L.; Liu, L.; Sun, J.; Qin, W. Effect of catechol-O-methyltransferase Val158Met polymorphism on resting-state brain default mode network after acupuncture stimulation. Brain Imaging Behav. 2017, 12, 798-805. [CrossRef] [PubMed]

23. Magarelli, P.; Cridennda, D. Acupuncture \& IVF poor responders: A cure? Fertil. Steril. 2004, 81. [CrossRef]

24. Jo, J.; Lee, Y.J.; Lee, H. Acupuncture for polycystic ovarian syndrome: A systematic review and meta-analysis. Medicine 2017, 96. [CrossRef] [PubMed]

25. Han, J.S. The Neurochemical Basis of Pain Relief by Acupuncture. A Collection of Papers 1973-1987; Beijing Medical University: Beijing, China, 1987.

26. Han, J.S. The Neurochemical Basis of Pain Relief by Acupuncture; Hubei Science and Technology Press: Xianning, China, 1998; Volume 2, ISBN 9787535221995.

27. Kelley, J.M.; Lembo, A.J.; Ablon, J.S.; Villanueva, J.J.; Conboy, L.A.; Levy, R.; Marci, C.D.; Kerr, C.E.; Kirsch, I.; Jacobson, E.E.; et al. Patient and practitioner influences on the placebo effect in irritable bowel syndrome. Psychosom. Med. 2009, 71, 789-797. [CrossRef] [PubMed]

28. Sochos, A.; Bennett, A. Psychological distress, physical symptoms, and the role of attachment Style in acupuncture. Altern. Ther. Health Med. 2016, 22, 8-16. [PubMed]

29. Mayor, D.; Steffert, T. Measuring mood-Relative sensitivity of numerical rating and Likert scales in the context of teaching electroacupuncture. Initial findings and the influence of response style on results. In Proceedings of the 18th ARRC International Acupuncture Research Symposium, London, UK, 19 March 2016. [CrossRef]

30. Mayor, D.; Steffert, T. Personality and treatment response to electroacupuncture. A new measure of mood change and further analysis of questionnaire response styles. In Proceedings of the 20th ARRC International Acupuncture Research Symposium, London, UK, 17 March 2018. [CrossRef]

31. Steffert, T.; Mayor, D. Mood changes in response to electroacupuncturetreatment in a classroom situation. Personality type, emotional intelligence and prior acupuncture experience, with an exploration of Shannon entropy, response style and graphology variables. In Proceedings of the 19th ARRC International Acupuncture Research Symposium, London, UK, 25 March 2017. [CrossRef]

32. Mayor, D.F. The teaching of electroacupuncture in North America: An informal survey. Clin. Acupunt. Orient. Med. 2001, 2, 116-128. [CrossRef]

33. Mayor, D.; Bovey, M. An international survey on the current use of electroacupuncture. Acupunct. Med. 2017, 35, 30-37. [CrossRef] [PubMed]

34. Eysenbach, G. Improving the quality of Web surveys: The Checklist for Reporting Results of Internet E-Surveys (CHERRIES). J. Med. Internet Res. 2004, 6. [CrossRef] [PubMed]

35. Randolph, J.J. Free-Marginal Multi-Rater kappa: An Alternative to Fleiss' Fixed-Marginal Multi-Rater Kappa. Ph.D. Thesis, University of Joensuu, Joensuu, Finland, 2005.

36. Randolph, J.J. Online Kappa Calculator. Available online: http://justus.randolph.name/kappa (accessed on 10 May 2018).

37. Fleiss, J.L.; Levin, B.; Paik, M.C. Statistical Methods for Rates and Proportions, 3rd ed.; John Wiley \& Sons: Hoboken, NJ, USA, 2004; ISBN 9780471526292.

38. Shannon, C.E.; Weaver, W. The Mathematical Theory of Communication; University of Illinois Press: Chicago, IL, USA, 1949; ISBN 9780252725487.

39. Silverman, D. Interpreting Qualitative Data, 5th ed.; Sage: London, UK, 2015; ISBN 9781446295434.

40. Peräkylä, A.; Ruusuvuori, J. Analyzing talk and text. In The Sage Handbook of Qualitative Research, 5th ed.; Denzin, N.K., Lincoln, Y.S., Eds.; Sage: London, UK, 2017; pp. 669-690. ISBN 9781483349800.

41. Croke, S. The Need for Novel Methodologies and Introduction to Theatricality; Research Council for Complementary Medicine (CAMSTRAND): Manchester, UK, Unpublished Conference Paper, 2018.

42. Mason, J. Qualitative Researching, 3rd ed.; Sage: London, UK, 2018; ISBN 9781473912182.

43. Saldaña, J. The Coding Manual for Qualitative Researchers, 3rd ed.; Sage: London, UK, 2015; ISBN 9781473902497.

44. O'Reilly-Shah, V.N. Factors influencing healthcare provider respondent fatigue answering a globally-administered in-app survey. Peer] 2017, 5. [CrossRef] [PubMed]

45. Fisher, P.; Van Haselen, R.; Hardy, K.; Berkovitz, S.; McCarney, R. Effectiveness gaps: A new concept for evaluating health service and research needs applied to complementary and alternative medicine. J. Altern. Complement. Med. 2004, 10, 627-632. [CrossRef] [PubMed] 
46. McDonald, J.; Janz, S. The Acupuncture Evidence Project: A Comparative Literature Review, rev ed.; Brisbane: Australian Acupuncture and Chinese Medicine Association: Brisbane, Australia, 2017. Available online: https://www.acupuncture.org.au/wp-content/uploads/2017/11/28-NOV-TheAcupuncture-Evidence-Project_Mcdonald-and-Janz_-REISSUED_28_Nov.pdf (accessed on 2 July 2018).

47. Wenham, A.; Atkin, K.; Woodman, J.; Ballard, K.; MacPherson, H. Self-efficacy and embodiment associated with Alexander Technique lessons or with acupuncture sessions: A longitudinal qualitative sub-study within the ATLAS trial. Complement. Ther. Clin. Pract. 2018, 31, 308-314. [CrossRef] [PubMed]

48. Campbell, A. Hunting the Snark: The quest for the perfect acupuncture placebo. Acupunct. Med. 1991, 9, 83-84. [CrossRef]

49. Birch, S. A review and analysis of placebo treatments, placebo effects, and placebo controls in trials of medical procedures when sham is not inert. J. Altern. Complement. Med. 2006, 12, 303-310. [CrossRef] [PubMed]

50. Itoh, K.; Kitakoji, H. Acupuncture for chronic pain in Japan: A review. Evid. Based Complement. Alternat. Med. 2007, 4, 431-438. [CrossRef] [PubMed]

51. MacPherson, H.; Tilbrook, H.; Bland, J.M.; Bloor, K.; Brabyn, S.; Cox, H.; Kang'ombe, A.R.; Man, M.-S.; Stuardi, T.; Torgerson, D.; et al. Acupuncture for irritable bowel syndrome: Primary care based pragmatic randomised controlled trial. BMC Gastroenterol. 2012, 12. [CrossRef] [PubMed]

52. MacPherson, H.; Richmond, S.; Bland, M.; Brealey, S.; Gabe, R.; Hopton, A.; Keding, A.; Lansdown, H.; Perren, S.; Sculpher, M.; et al. Acupuncture and counselling for depression in primary care: A randomised controlled trial. PLoS Med. 2013, 10. [CrossRef] [PubMed]

53. Paterson, C.; Britten, N. Acupuncture as a complex intervention: A holistic model. J. Altern. Complement. Med. 2004, 10, 791-801. [CrossRef] [PubMed]

54. Linde, K.; Niemann, K.; Schneider, A.; Meissner, K. How large are the nonspecific effects of acupuncture? A meta-analysis of randomised controlled trials. BMC Med. 2010, 8, 1-14. [CrossRef] [PubMed]

55. Robinson, N.; London South Bank University. Personal communication, 2018.

56. Longhurst, J. Acupuncture's cardiovascular actions: A mechanistic perspective. Med. Acupunct. 2013, 25, 101-113. [CrossRef]

57. Villas-Boas, J.D.; Dias, D.P.; Trigo, P.I.; Almeida, N.A.; de Almeida, F.Q.; de Medeiros, M.A. Acupuncture affects autonomic and endocrine but not behavioural responses induced by startle in horses. Evid. Based Complement. Alternat. Med. 2015, 2015. [CrossRef] [PubMed]

58. Uchida, C.; Waki, H.; Minakawa, Y.; Tamai, H.; Hisajima, T.; Imai, K. Evaluation of autonomic nervous system function using heart rate variability analysis during transient heart rate reduction caused by acupuncture. Med. Acupunct. 2018, 30, 89-95. [CrossRef] [PubMed]

59. Scott, J.; Barlow, T. Acupuncture in the Treatment of Children, 3rd ed.; Eastland Press: Seattle, WA, USA, 1999; ISBN 9780939616305.

60. Loo, M. Pediatric Acupuncture; Churchill Livingstone: Edinburgh, UK, 2002; ISBN 9780443070327.

61. Maciocia, G. The Foundations of Chinese Medicine. A comprehensive Test for Acupuncturists and Herbalists; Churchill Livingstone: Edinburgh, UK, 1989; ISBN 9780443039805.

62. Franglen, N. The Handbook of Five Element Practice, rev ed.; Singing Dragon: London, UK, 2014; ISBN 9781848191884.

63. Marmot, M. Status Syndrome: How Your Place on the Social Gradient Directly Affects Your Health; Bloomsbury: London, UK, 2015; ISBN 9781408872680.

64. Náfrádi, L.; Nakamoto, K.; Schulz, P.J. Is patient empowerment the key to promote adherence? A systematic review of the relationship between self-efficacy, health locus of control and medication adherence. PLOS ONE 2017, 12. [CrossRef] [PubMed]

65. Pashang, S.; Khanlou, N.; Clarke, J. Today's Youth and Mental Health: Hope, Power, and Resilience; Springer: Cham, Switzerland, 2018; ISBN 9783319648361.

66. Meade, R.D.; Barnard, W.A. Conformity and Anticonformity among Americans and Chinese. J. Soc. Psychol. 2010, 89, 15-24. [CrossRef]

67. Glynn, L.M.; Howland, M.A.; Sandman, C.A.; Davis, E.P.; Phelan, M.; Baram, T.Z.; Stern, H.S. Prenatal maternal mood patterns predict child temperament and adolescent mental health. J. Affect. Disord. 2018, 228, 83-90. [CrossRef] [PubMed] 
68. Handayani, P.W.; Hidayanto, A.N.; Pinem, A.A.; Sandhyaduhita, P.I.; Budi, I. Hospital nformation system user acceptance factors: User group perspectives. Inform. Health Soc. Care 2018, 43, 84-107. [CrossRef] [PubMed]

69. Pincus, S.M.; Schmidt, P.J.; Palladino-Negro, P.; Rubinow, D.R. Differentiation of women with premenstrual dysphoric disorder, recurrent brief depression, and healthy controls by daily mood rating dynamics. J. Psychiatr. Res. 2008, 42, 337-347. [CrossRef] [PubMed]

70. Tastle, W.J.; Wierman, M.J. An information theoretic measure for the evaluation of ordinal scale data. Behav. Res. Methods 2006, 38, 487-494. [CrossRef] [PubMed]

71. Tastle, W.J.; Wierman, M.J. Consensus and dissention: A measure of ordinal dispersion. Int. J. Approx. Reason. 2007, 45, 531-545. [CrossRef]

72. Lavrakas, P.J. Encyclopedia of Survey Research Methods; Sage: Thousand Oaks, CA, USA, 2008; ISBN 9781412918084.

73. Lesne, A. Shannon entropy: A rigorous notion at the crossroads between probability, information theory, dynamical systems and statistical physics. Math. Struct. Comput. Sci. 2014, 24. [CrossRef]

(C) 2018 by the authors. Licensee MDPI, Basel, Switzerland. This article is an open access article distributed under the terms and conditions of the Creative Commons Attribution (CC BY) license (http:/ / creativecommons.org/licenses/by/4.0/). 
Article

\title{
The Effect of Acupuncture on Visual Function in Patients with Congenital and Acquired Nystagmus
}

\author{
Tilo Blechschmidt, Maike Krumsiek and Margarita G. Todorova * \\ Department of Ophthalmology, University of Basel, Mittlere Strasse 91, CH-4031 Basel, Switzerland; \\ tilo.blechschmidt@usb.ch (T.B.); maike.krumsiek@usb.ch (M.K.) \\ * Correspondence: margarita.todorova@usb.ch; Tel.: +41-612-658-787 \\ Academic Editors: Gerhard Litscher and William Chi-shing Cho \\ Received: 9 April 2017; Accepted: 18 May 2017; Published: 23 May 2017
}

\begin{abstract}
Background: The aim of this study is to examine the short-term effect of visual function following acupuncture treatment in patients with congenital idiopathic nystagmus and acquired nystagmus (CIN and AN). Methods: An observational pilot study on six patients with confirmed diagnosis of nystagmus (three CIN and three AN patients (2o, $4 \sigma^{7}$; mean age 42.67; SD $\left.\pm 20.57 \mathrm{y}\right)$ ), was performed. Acupuncture treatment was done following a standardized protocol applying needle-acupuncture on the body and the ears. The treatment was scheduled with 10 sessions of 30 min duration over five weeks. To assess the effect of the treatment, we performed before, between, and after acupuncture objective measurement of the BCVA (EDTRS charts), contrast vision (CSV-1000, Vector Vision), nystagmography (Compact Integrated Pupillograph), complemented by evaluation questionnaires. A placebo non-acupuncture control group (Nr: 11, 22 eyes; 8ㅇ, 30'; mean age: 33.34 y (SD \pm 7.33 y)) was taken for comparison. Results: The results showed that, following acupuncture treatment, $\mathrm{CIN}$ and $\mathrm{AN}$ patients showed improvement (SD \pm mean) in their binocular BCVA (baseline: $0.45 \pm 0.36$; between: $0.53 \pm 0.34$ and post-treatment: $0.51 \pm 0.28$ ), and in their monocular contrast sensitivity (baseline: $11.29 \pm 12.35$; between: $11.43 \pm 11.45$ and post-treatment: $14.0 \pm 12.22$ ). The post-/baseline-difference showed a significant improvement in contrast vision and in BCVA for CIN and AN patients, but not for controls ( $p=0.029$ and $p=0.007$, respectively). The effect of the eye showed also, within CIN and AN, significant values for the examined parameters in the post-/baseline difference ( $p=0.004$ and $p \leq 0.001)$. Evaluated only binocularly, the respective between-/baseline and post-/baseline difference in the CIN and AN group showed significant values $(p<0.045)$. Two AN patients reported reduction of oscillations. Among general subjective symptoms, our patients reported reduction of tiredness and headache attacks, improvement of vision, and shorter sleep onset time. Conclusion: The applied acupuncture protocol showed improvement in the visual function of nystagmus patients and thus, in their quality of life. Further studies are mandatory to differentiate which group of nystagmus patients would benefit more from acupuncture.
\end{abstract}

Keywords: acupuncture; nystagmus; contrast vison; visual function; nystagmography

\section{Introduction}

Nystagmus refers to a heterogeneous group of diseases, characterized by an involuntary rhythmic oscillation of the eyes. The resulting excessive movement of images on the fovea leads to a reduction of central vision. The onset time and the waveform characteristics of the nystagmus, categorize it into: congenital idiopathic nystagmus (CIN), which usually appears at birth or in early infancy; and acquired nystagmus (AN), presenting later in life. Contrary to the variety of distinctive waveforms described in recordings of the eye movements of CIN patients, the nystagmus waveforms are simpler in patients with AN. CIN can be idiopathic or associated with visual sensory abnormalities, as for instance, with congenital cataracts, retinal or optic nerve dystrophy/ hypoplasia, or it can be part of neurological 
disease or syndrome [1,2]. In order to exclude any underlying ocular or systemic pathology, in children with nystagmus, further electrophysiological laboratory tests-together with neurological work-up and neuro-radiological imaging-may be necessary. Neurological disease should be ruled out when the nystagmus is asymmetric in direction, unilateral by nature, or when its characteristics have changed over time.

Generally, treatment options for nystagmus include a refractive error correction and pharmacological and surgical interventions. Spectacles and contact lenses for correction of the underlying refractive error are the first choice to reduce optical aberrations and enlarge the retinal image and visual field, thus improving the quality of the retinal image [3-5]. Pharmacological agents used for nystagmus mitigation—such as GABA and glycine agonists—have proven to be effective in patients with CIN [6]. However, in cases of obviously abnormal head posture, eye muscle surgery remains an important option in order to shift the null-zone of the nystagmus into primary gaze, and thus to alleviate the neck/ocular torticollis [7-9].

Acupuncture treatment is still considered a non-mainstream therapeutic approach. Yet, its positive effect has been shown in a variety of degenerative and psychosomatic diseases, following cerebral and peripheral ischemia, and it was also effectively used to improve blood flow. For instance, in a mice model of Parkinson's disease, the application of electro-acupuncture has proven to be effective in slowing the degeneration of dopaminergic neurons in the ventral midbrain [10]. Acupuncture has been also applied in various diseases involving psychosomatic status: such as anxiety, depression, and sleep disturbances [11]. There are also previous reports on the application of acupuncture in patients with nystagmus: vibratory and electrical stimulation of the face and neck were found to improve foveal fixation and thus, visual acuity in patients with CIN [12]. Blekher et al. reported a reduction of frequency and a decrease of slow phase velocities, as well as an improvement of foveolar fixation, following acupuncture in patients with CIN [13].

Particularly significant is the fact that patients with nystagmus often present unstable cerebral and vertebral blood flow [14]. As traditional acupuncture stimulation has shown its positive effect on systemic blood flow $[15,16]$, it seems to be a promising supporting treatment in patients with nystagmus, as well.

The quality of life of patients with nystagmus is greatly dependent on the fluctuations of their nystagmus speed and velocity, and thus on the central fixation. Any attempt to stabilize their fixation, therefore, seems to be of benefit for them.

With this background in mind, we aimed at examining the effect of needle acupuncture on the body and the ears of nystagmus patients, following standardized acupuncture protocol. In addition, we evaluated which specific nystagmus patients the acupuncture drew greater benefit from the treatment.

\section{Materials and Methods}

This was an observational pilot study, in which all subjects received acupuncture, in order to determine a preliminary short-term efficacy or proof of principle of a standardized acupuncture protocol. The patients were recruited through the Department of Ophthalmology at the University of Basel (T.M.G.; B.T.).

The acupuncture protocol was developed for a group of nystagmus diseases, based on the extensive clinical experience of an ophthalmologist and a licensed, qualified, and well-trained acupuncturist (B.T.). A placebo non-acupuncture control group (Nr: 11, 22 eyes; 8ㅇ, 30 ; mean age: 33.34 y (SD \pm 7.33 y)) was taken for comparison, as the treatment is still controversial.

All procedures took place in the acupuncture unit at the Department of Ophthalmology at the University of Basel between July 2014 and May 2015. The study and data accumulation were in conformity with institutional requirements, and in accordance with the statements and principles of the declaration of Helsinki, as well as all governmental regulations. 


\subsection{Subjects}

Patients suffering from congenital idiopathic nystagmus and acquired nystagmus (CIN and AN), followed at the Department of Ophthalmology (University of Basel, Basel, Switzerland), were enrolled in the study.

According to the clinical, diagnostic, and orthoptic findings, the patients were divided into the following groups:

- Patients with clinical characteristics of congenital idiopathic nystagmus (CIN), $N=3$ (6 eyes),

- Patients with phenotypic characteristics of acquired nystagmus (AN), $N=3$ (6 eyes).

Inclusion criteria for all patients were: congenital idiopathic nystagmus and acquired nystagmus; Caucasian origin.

Exclusion criteria were: above inclusion criteria not fulfilled; presence of ocular and/or systemic pathology other than nystagmus; currently using antidepressants, alcohol, or drugs; unwillingness to participate in the study, hyper-reactivity to acupuncture treatment.

Alarming signs and symptoms excluding any participation in the study and indicating instead further neurological, neurosensory, and imaging work-up were: history of onset after the age of four months, dissociated (asymmetric) form of nystagmus, preserved optokinetic nystagmus, presence of afferent pupillary defect, papilledema, and neurological symptoms like vertigo and nausea.

All nystagmus patients fulfilling our inclusion criteria underwent detailed ophthalmic examination including: refraction, best-corrected visual acuity at $2.5 \mathrm{~m}$ distance (BCVA), contrast vision at $2.5 \mathrm{~m}$ distance, nystagmography (Compact Integrated Pupillograph), intraocular pressure (Goldmann applanation tonometer), slit-lamp examination, biomicroscopy, and fundoscopy.

For each patient, BCVA was measured at distance with a standard decimal visual acuity Snellen charts. Contrast vision was evaluated at distance using a CSV-1000 colour vision test (CSV-1000, Vector Vision). The nystagmography was performed using compact integrated pupillograph (CIP, AMTech) and performed by the same experienced orthoptist (K.M.). Since the visual function in nystagmus patients could change from day to day or even during the day-and is thus linked to the nystagmus frequency, amplitude, and foveation periods during nystagmus—all examinations were performed in the morning. Also, in order to have reproducible measurements completed, the nystagmus was measured monocularly, in primary gaze, keeping fixation for distance. In this way, any additional effect of convergence on nystagmus characteristics could be excluded, as well. The patient was asked to keep both eyes during the examination open. Nystagmus latency was defined as delay between the onset of target movement and the initiation of target movement and nystagmus velocity was defined as the time taken to complete the saccade, once it was initiated.

Subjectively, the effect of acupuncture was evaluated using evaluation questionnaires in regard to changes in visual acuity, contrast sensitivity, as well as the presence of oscillopsias and their change following acupuncture.

For a fair comparison, our non-acupuncture control group also underwent measurements of: refraction, BCVA at $2.5 \mathrm{~m}$ distance, contrast vision at $2.5 \mathrm{~m}$ distance, intraocular pressure (Goldmann applanation tonometer), slit-lamp examination, biomicroscopy, and fundoscopy.

The acupuncture method followed a modified standardized protocol [17]: The acupuncture protocol consists of 10 sessions of 30 min duration, administered twice a week over a period of five weeks.

The scheduling of each patient and the complete orthoptic examinations were performed by the same experienced orthoptist (K.M.). Before the initial treatment appointment, the acupuncturist gave the patient a brief introduction outlining the duration and the course of treatment, as well as the possible complications. Each scheduled treatment session was initiated only after a short conversation with the patient and his answers to questions concerning his condition after the previous treatment and his present general condition. 


\subsection{Needle Acupuncture of the Body and the Ears}

Sterile and disposable single-use needles of different sizes were used, namely Seirin B type needle No.3 (0.20) × $15 \mathrm{~mm}$, No.5 (0.25) × $40 \mathrm{~mm}$, No.8 (0.30) $\times 30 \mathrm{~mm}$, Seirin Pyonex Press Needles P type $0.22 \times 1,6$ (Seirin Corporation, Shizuoka, Japan); Dong Bang needle DB106 (0.20) $\times 15$, DB105G $(0.20) \times 25$, Dong Bang Press Needles $0.20 \times 2 \times 1.0$ (Dong Bang Acupuncture, Inc., Chungnam, Korea). The established protocol indicates the specific pre-selected points for all participants, needling depths, and manipulation techniques. The needles were applied by the same certified and experienced acupuncturist (BT). The standard points for all subjects were located around the eyes, on the head, ears, back, abdomen, arms, hands, lower legs, and toes and include: GV-20 (Bai Hui), ExHN-3 (Yin Tang), CV-6 (Qi Hai), UB-18 (Gan Shu), UB-20 (Pi Shu), UB-23 (Shen Shu), GB-20 (Feng Chi), LI-4 (He Gu), HT-7 (Shen Men), SI-3 (Hou Xi), LV-3 (Tai Chong), GB-34 (Yang Ling Quan), GB-37 (Guang Ming), SP-6 (San Yin Jiao), ST-36 (Zu San Li); local points: UB-1 (Jing Ming), ST-1 (Cheng Qi), ExHN-7 (Qiu Hou); ear points: Eye Point (24a), Liver Zone (97), Zero Point, Brainstem, and Point de Jerome (29b). Additionally, semi-permanent-needles were localized at following ear points: Liver Zone (29), Zero Point, and Brainstem. The needles were applied according to a standardized protocol (Figure 1, Table 1). Individual choice of acupuncture points was not allowed in contrary to the common Chinese Medicine (CM). Likewise, due to standardization, the number of applied needles exceeded the common practices of CM. The needle application sites were determined with respect to the CM standards. The aim was to produce an irradiating needle sensation ('de qi'), if possible. The needles at LI-4 (He Gu), CV-6 (Qi Hai), LV-3 (Tai Chong), and all ear needles were manually stimulated once in each session after $15 \mathrm{~min}$ (+/ -5 min). Additional CM therapeutic techniques-like electro-stimulation, heat lamps, music during treatment, etc.-were not applied.

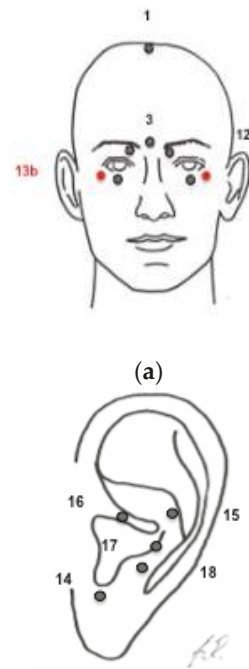

(b)

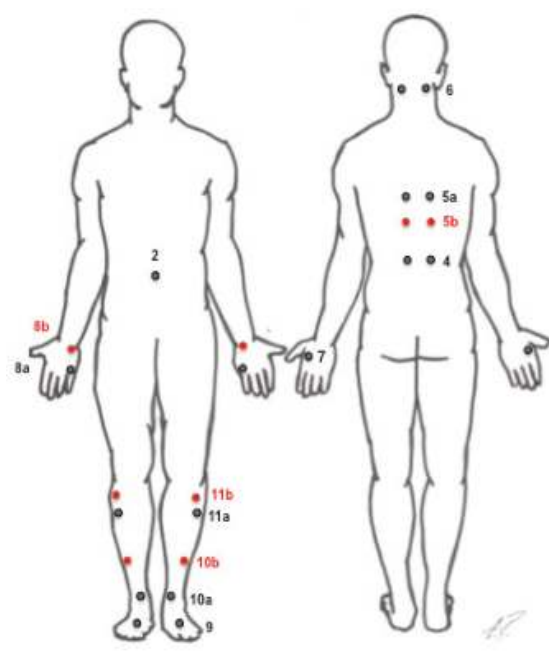

(c)

Figure 1. Needle acupuncture of the body and the ears was performed following standardized protocol (Table 1). The approximate location of the needles on the face and the ears are presented on (a,b); and on the body - on (c). The needles at LI-4 (He Gu), CV-6 (Qi Hai), LV-3 (Tai Chong), and all ear needles were manually stimulated once in each session after $15 \mathrm{~min}(+/-5 \mathrm{~min})$. Treatment 1 (labelled in black) alternated with treatment 2 (labelled in red, see also in Table 1). 
Table 1. All acupuncture points, the alternation in treatment (labeled in red, see also in Figure 1) and the stimulation duration. Standardized needles acupuncture protocol was applied as shown in Figure 1.

\begin{tabular}{|c|c|c|c|}
\hline \multicolumn{3}{|c|}{ Acupuncture Study Protocol } & \multirow{3}{*}{ Laterality } \\
\hline Treatment Modality & Treatment 1 (a) & Treatment 2 (b) & \\
\hline Needle Nr: & $\begin{array}{l}\text { Alternating with } \\
\text { Treatment } 2\end{array}$ & $\begin{array}{l}\text { Alternating with } \\
\text { Treatment } 1\end{array}$ & \\
\hline 1 & \multicolumn{2}{|c|}{ GV20 (Bai Hui) } & Median \\
\hline 2 & \multicolumn{2}{|c|}{ CV6 (Qi Hai) } & Median \\
\hline 3 & \multicolumn{2}{|c|}{ Ex-HN 3 (Yin Tang) } & Median \\
\hline 4 & \multicolumn{2}{|c|}{ UB23 (Shen Shu) } & BL \\
\hline $5(\mathrm{a} / \mathrm{b})$ & UB18 (Gan Shu) & UB20 (Pi Shu) & $\mathrm{BL}$ \\
\hline 6 & \multicolumn{2}{|c|}{ GB20 (Feng Chi) } & $\mathrm{BL}$ \\
\hline 7 & \multicolumn{2}{|c|}{ LI4 (He Gu) } & $\mathrm{BL}$ \\
\hline $8(\mathrm{a} / \mathrm{b})$ & SI3 (Hou Xi) & HT7 (Shen Men) & BL \\
\hline 9 & \multicolumn{2}{|c|}{ LV3 (Tai Chong) } & $\mathrm{BL}$ \\
\hline $10(\mathrm{a} / \mathrm{b})$ & SP6 (San Yin Jiao) & GB 37 (Guang Ming) & BL \\
\hline $11(\mathrm{a} / \mathrm{b})$ & GB 34 (Yang Ling Quan) & ST36 (Zu San Li) & BL \\
\hline 12 & \multicolumn{2}{|c|}{ UB1 (Jing Ming) } & $\mathrm{BL}$ \\
\hline $13(\mathrm{a} / \mathrm{b})$ & ST1 (Cheng Qi) & EX-HN7 (Qiu Hou) & $\mathrm{BL}$ \\
\hline \multicolumn{4}{|c|}{$\begin{array}{l}\text { Additional Ear Acupuncture Points } \\
\text { (Alternately, Starting with the Right Ear) }\end{array}$} \\
\hline 14 & Eye Po & (24a) & UL \\
\hline 15 & Liver 7 & $(97)$ & UL \\
\hline 16 & Zero & & UL \\
\hline 17 & Brai & & UL \\
\hline 18 & Point de J & he $(29 b)$ & $\mathrm{UL}$ \\
\hline \multicolumn{4}{|c|}{$\begin{array}{l}\text { + One Semi-Permanent Needle (Press Tack Needle) } \\
\text { (Alternately, Starting with the Left Ear, Points in the Order Specified Bellow): }\end{array}$} \\
\hline 15 & Liver $Z$ & $(97)$ & UL \\
\hline 16 & Zero & & UL \\
\hline 17 & Brai & & $\mathrm{UL}$ \\
\hline \multicolumn{4}{|c|}{ Needle Stimulation (after $15 \mathrm{~min}$ ) at the Following Points: } \\
\hline 1 & GV20 & Hui) & s. above \\
\hline 2 & CV6 & Hai) & s. above \\
\hline 7 & LI4 ( & $\mathrm{su})$ & s. above \\
\hline 9 & LV3 (Ta & long) & s. above \\
\hline $14-18$ & Ear & & s. above \\
\hline \multicolumn{4}{|c|}{ Duration of Needle Stimulation: } \\
\hline \multicolumn{4}{|c|}{$30 \mathrm{~min}$} \\
\hline
\end{tabular}

\subsection{Statistical Analysis}

A statistical package IBM SPSS Statistics 22 was applied. To evaluate the effect of acupuncture on visual functions, a univariate ANOVA test was performed. In our statistical model, the group was taken as a fixed factor. Each pair of the tested objective methods (best-corrected visual acuity (BCVA, Snellen charts)), contrast vision (CSV-1000, Vector Vision), amplitude, and frequency of nystagmus (Nystagmography, Compact Integrated Pupillograph CIP, AMTech), was treated as a dependent variable.

The acupuncture effect on patients was analyzed at baseline (1: baseline), after five acupuncture sessions (2: between treatment), and at the end of the acupuncture protocol (3: post-treatment). Our results are presented as the mean difference for each of the tested parameters, with the respective standard deviation.

In addition, for each nystagmus patients and for each control subject, the difference between-/pre-treatment was calculated by extracting the between treatment value from the pre-treatment one (2-1). Correspondingly, the post-/baseline-treatment difference was calculated 
extracting the post-treatment value from the baseline-treatment one (3-1). The effect of acupuncture was assessed comparing the between-/baseline-treatment difference against the post-/baseline-treatment difference within nystagmus patients. P-values of less than 0.05 are considered statistically significant.

\section{Results}

An observational pilot study on six patients with clinical picture and confirmed diagnosis of nystagmus (three CIN and three AN patients (2, 40 ; mean age 42.67; SD $\pm 20.57 \mathrm{y}$ )), was performed. A placebo non-acupuncture control group (Nr: 11, 22 eyes; 8ㅇ, 30 ; mean age: 33.34 y (SD \pm 7.33 y)) was taken, for comparison. The clinical characteristics of the patients are given in Table 2.

Table 2. Clinical characteristics of patients included in the study.

\begin{tabular}{|c|c|c|c|c|c|}
\hline \multicolumn{2}{|c|}{ Patient } & \multirow{2}{*}{$\begin{array}{l}\text { Nystagmus Characteristics, } \\
\text { Ophthalmic/Systemic Diagnosis }\end{array}$} & \multicolumn{3}{|c|}{$\begin{array}{c}\text { Subjective Findings: Before versus after } \\
\text { Acupuncture Treatment }\end{array}$} \\
\hline Nr: & $\begin{array}{l}\text { Age (y), } \\
\text { Gender }\end{array}$ & & BCVA & $\begin{array}{l}\text { Contrast } \\
\text { Vision }\end{array}$ & Oscillations \\
\hline Case 1 & $51, \mathrm{~m}$ & $\begin{array}{l}\text { Consecutive exotropia and } \\
\text { decompensated latent nystagmus after } \\
\text { Botox injection (2014) and strabismus } \\
\text { surgery, left eye (2015) for congenital } \\
\text { esotropia, latent nystagmus, and } \\
\text { dissociated vertical deviation. }\end{array}$ & $\begin{array}{l}\text { Monocular and } \\
\text { binocular } \\
\text { improvement }\end{array}$ & Stable & Reduction \\
\hline Case 2 & $23, \mathrm{~m}$ & $\begin{array}{l}\text { Congenital idiopathic nystagmus. } \\
\text { Hyperopia. } \\
\text { Macular hypoplasia. }\end{array}$ & $\begin{array}{l}\text { Binocular } \\
\text { improvement }\end{array}$ & $\begin{array}{c}\mathrm{RE}>\mathrm{LE} \\
\text { improvement }\end{array}$ & No \\
\hline Case 3 & $20, \mathrm{~m}$ & $\begin{array}{l}\text { Horizontal pendular nystagmus, latent } \\
\text { compound. Accommodative convergence } \\
\text { excess esotropia and amblyopia, left eye. } \\
\text { Optic disc hypoplasia. } \\
\text { Status after surgery for neuroepithelial } \\
\text { cyst, right lateral ventricle. Occipital } \\
\text { para-ventricular: atrophy and gliosis }\end{array}$ & Worsening & Improvement & No \\
\hline Case 4 & $70, \mathrm{f}$ & $\begin{array}{l}\text { Acquired torsional down-beat nystagmus } \\
\text { after brain stem ischemia. }\end{array}$ & Stable & Stable & Reduction \\
\hline Case 5 & $39, \mathrm{~m}$ & $\begin{array}{l}\text { Congenital idiopathic nystagmus. } \\
\text { Oculocutaneous Albinism. }\end{array}$ & $\begin{array}{l}\text { Slight } \\
\text { improvement }\end{array}$ & Stable & No \\
\hline Case 6 & $26, \mathrm{f}$ & $\begin{array}{l}\text { Pendular nystagmus. } \\
\text { Multiple sclerosis. }\end{array}$ & $\begin{array}{l}\text { Slight } \\
\text { improvement }\end{array}$ & $\begin{array}{l}\text { Slight } \\
\text { improvement }\end{array}$ & Reduction \\
\hline
\end{tabular}

A subjective improvement of visual function, following the acupuncture treatment, was stated by all nystagmus patients. Evaluated in subgroups, two AN patients and one CIN patient reported reduction of oscillations (Table 2). Among the subjective general symptoms, our patients reported on reduction of tiredness and headache attacks, improvement in vision, and shorter sleep onset time.

Objectively, CIN and AN patients showed improvement (SD \pm mean) in their binocular BCVA (baseline: $0.45 ; \pm 0.36$; between: $0.53 ; \pm 0.34$ and post-treatment: $0.51 ; \pm 0.28$ ), in monocular contrast sensitivity (baseline: $11.29 \pm 12.35$; between: $11.43 \pm 11.45$ and post- treatment: $14.0 \pm 12.22$; Figure 2a). Evaluating the between-/baseline-treatment difference against the post-/baseline-treatment difference, we found within CIN and AN patients a statistically significant increase in visual acuity $(p=0.002)$ and a statistically significant trend in improvement in contrast vision $(p=0.099$; Figure $2 b)$.

Compared to controls, CIN and AN patients showed a significant improvement in their contrast sensitivity and in their BCVA for the post-/baseline-treatment difference $(p=0.029$ and $p=0.007$, respectively). The effect of the eye also showed significant values between both groups for the examined parameters in the post-/baseline-treatment difference $(p=0.004$ and $p \leq 0.001)$. These data pointed towards a different relation, when both the eye and the group effects were taken into account. Thus, we proceeded with evaluation of the examined parameters between groups in relation to the examined eye. Within CIN and AN patients, now we could document improvement in their binocular BCVA and contrast sensitivity for both, the between-/baseline-treatment difference, as well as for the 
post-/baseline-treatment difference with respective values, as follows: $0.044,0.029 ; 0.061 ; 0.006$. Here, the corresponding monocular values did not reach statistically significant values $(p>0.005)$.

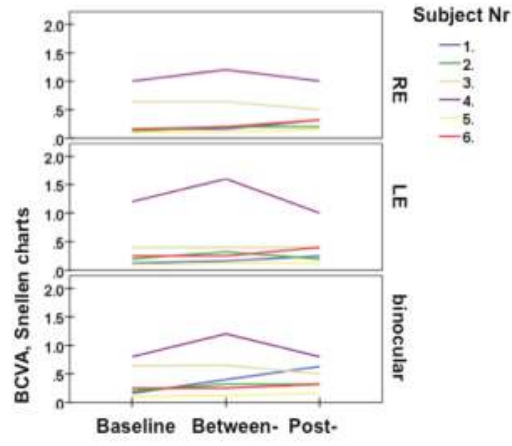

(a)

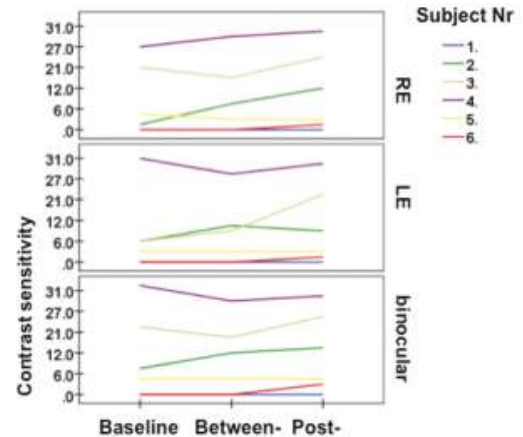

(b)

Figure 2. Line diagrams representing the individual patient's examination data (presented separately for the RE: right eye; for the LE: left eye and for both eyes: binocular); (a) BCVA, Snellen charts; (b) Contrast sensitivity. The acupuncture effect was analyzed at the beginning (1: baseline-), after five acupuncture sessions (2: between) and at the end of the acupuncture treatment (3: post-).

All six CIN and AN patients demonstrated reduction of the mean amplitude and frequency of the nystagmus, following acupuncture (Table 3). No change of the direction of the nystagmus was recorded in any patient.

Table 3. Summarized nystagmography results of all patients before- and after acupuncture treatment. In order to reduce the influence of the head position and the effect of convergence, each patient was asked to keep both eyes during the examination open while the measurement was performed monocularly, in primary gaze, keeping fixation for distance.

\begin{tabular}{|c|c|c|c|c|c|}
\hline $\begin{array}{l}\text { Patient } \\
\text { Nr/Age/Gender }\end{array}$ & Eye & $\begin{array}{c}\text { Saccades } \\
\text { within } 4 \text { Sec. } \\
\text { (before-/after } \\
\text { Acupuncture) }\end{array}$ & $\begin{array}{l}\text { Amplitude, } \\
\text { (before-/after } \\
\text { Acupuncture) }\end{array}$ & $\begin{array}{l}\text { Velocity, Sec. } \\
\text { (before-/after } \\
\text { Acupuncture) }\end{array}$ & $\begin{array}{c}\text { Subjective Evaluation after } \\
\text { a "Washout" Time } \\
\text { Following Acupuncture }\end{array}$ \\
\hline $1 / 51 / \mathrm{m}$ & $\begin{array}{l}\text { RE } \\
\text { LE }\end{array}$ & $\begin{array}{c}16 / 11 \\
9 / 10\end{array}$ & $\begin{array}{c}9 / 8 \\
4 / 4.5\end{array}$ & $\begin{array}{l}4 / 4 \\
4 / 4\end{array}$ & Stable since acupuncture \\
\hline $2 / 23 / \mathrm{m}$ & $\begin{array}{l}\text { RE } \\
\text { LE }\end{array}$ & $\begin{array}{l}36 / 18 \\
24 / 25\end{array}$ & $\begin{array}{c}6.5 / 3.5 \\
6 / 7\end{array}$ & $\begin{array}{l}4 / 4 \\
4 / 4\end{array}$ & $\begin{array}{l}\text { No control examination has } \\
\text { been done }\end{array}$ \\
\hline $3 / 20 / \mathrm{m}$ & $\begin{array}{l}\text { RE } \\
\text { LE }\end{array}$ & $\begin{array}{c}20 / 7 \\
17 / 27\end{array}$ & $\begin{array}{c}9 / 7 \\
18 / 11\end{array}$ & $\begin{array}{l}4 / 4 \\
4 / 4\end{array}$ & $\begin{array}{l}\text { Still stable three months } \\
\text { after acupuncture }\end{array}$ \\
\hline $4 / 70 / f$ & $\begin{array}{l}\mathrm{RE} \\
\mathrm{LE}\end{array}$ & \multicolumn{3}{|c|}{$\begin{array}{l}\text { Not possible objectively to be analyzed, however } \\
\text { reduced oscillations following acupuncture }\end{array}$} & Stable since acupuncture \\
\hline $5 / 39 / \mathrm{m}$ & $\begin{array}{l}\text { RE } \\
\text { LE }\end{array}$ & $\begin{array}{l}\text { Not possible to } \\
\text { analyze/11 } \\
\text { Not possible to } \\
\text { analyze/15 }\end{array}$ & $\begin{array}{l}\text { Not possible to } \\
\text { analyze/6.5 } \\
\text { Not possible to } \\
\text { analyze/17 }\end{array}$ & $\begin{array}{l}4 / 4 \\
4 / 4\end{array}$ & $\begin{array}{l}\text { No control examination has } \\
\text { been done }\end{array}$ \\
\hline $6 / 26 / f$ & $\begin{array}{l}\text { RE } \\
\text { LE }\end{array}$ & $\begin{array}{l}17 / 17 \\
17 / 17\end{array}$ & $\begin{array}{l}4.5 / 4 \\
5.5 / 5\end{array}$ & $\begin{array}{l}4 / 4 \\
4 / 4\end{array}$ & Stable since acupuncture \\
\hline
\end{tabular}

As an example, in the case with CIN, hyperopia and macula hypoplasia (patient 2, Table 2) the waveform characteristics changed from horizontal conjugate nystagmus with pendular velocity to jerk disconjugate nystagmus, with descending velocity slow phase more pronounced on the right eye (Figure 3a). Here, even if no oscillations were reported, the reduction of the nystagmus amplitude 
and frequency explained the subjective and objective improvement of monocular and binocular visual acuity of the patient, as well as in the contrast vision. As it is shown in Figure 3a, the frequency and the amplitude of nystagmus (No. saccades/amplitude/velocity) improved much following acupuncture treatment: from $19 / 6.5^{\circ} / 3.5 \mathrm{~s}$, right and $15 / 9^{\circ} / 3.5 \mathrm{~s}$, left to $6 / 6^{\circ} / 3.5 \mathrm{~s}$, right and $2 / 7^{\circ} / 3.5 \mathrm{~s}$, left. On the contrary, in the case with pendular nystagmus and multiple sclerosis (patient 6 , Figure 3b), no improvement in the velocity of nystagmus was measured, but in the amplitude, on the left. Here, by 15 objectively stable saccades at baseline and at post-treatment, a slight reduction in the amplitudes from $4.5^{\circ}$ to $4^{\circ}$ on the right eye and from $5.5^{\circ}$ to $5^{\circ}$ on the left eye was recorded (Figure $3 \mathrm{~b}$ ). In addition, the patient reported subjectively on reduction of the oscillations, as well as on improvement in her binocular and monocular vision and contrast sensitivity (Table 2).

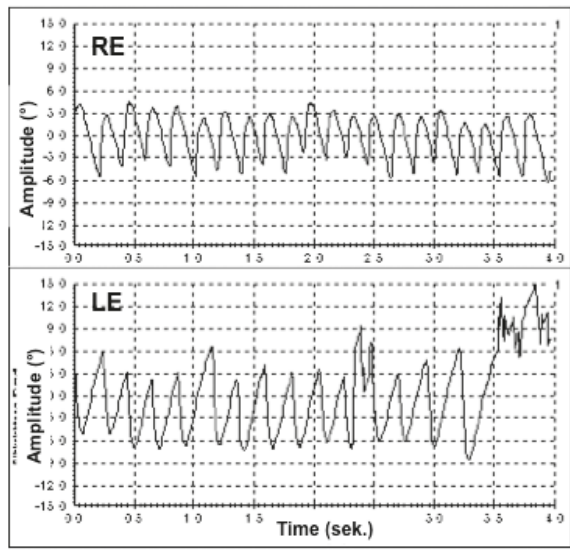

Baseline

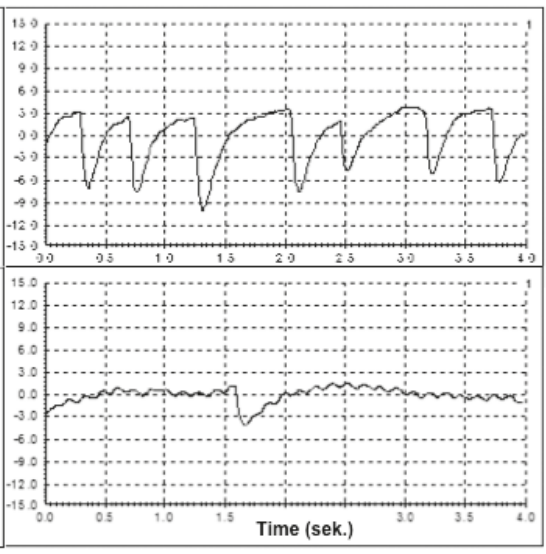

Post-acupuncture

(a)
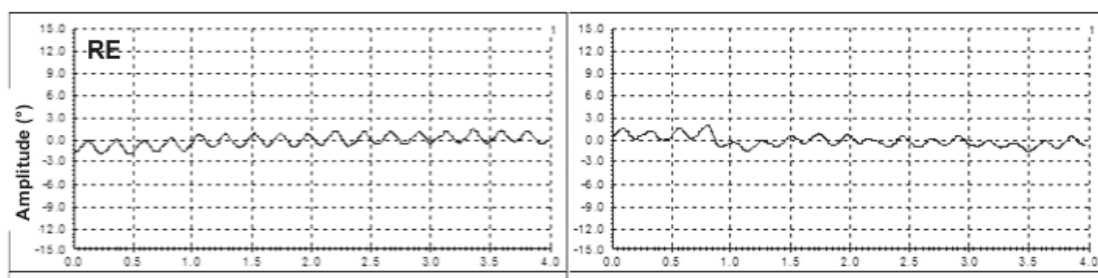

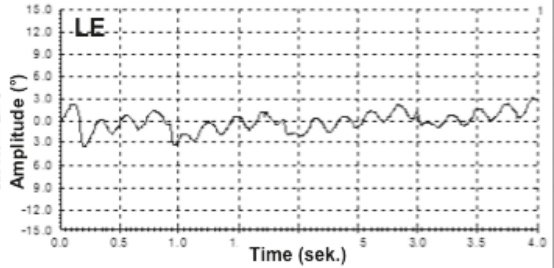

Baseline

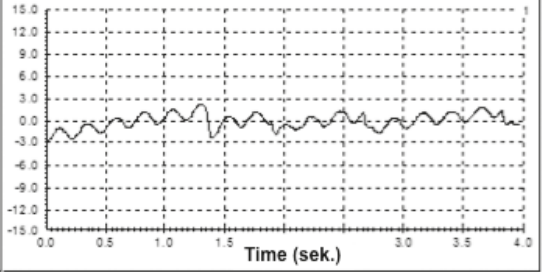

Post-acupuncture

(b)

Figure 3. Nystagmography pictures in two patients (a); (b) baseline and following acupuncture treatment, as described bellow. 
Figure 3a shows an example of nystagmography pictures of a 23-year-old male patient with congenital idiopathic nystagmus, hyperopia, and macula hypoplasia. The patient reported no oscillations. The nystagmography showed, however, a significant reduction of the nystagmus amplitude and the velocity of nystagmus (No. saccades/amplitude/velocity) improved significantly following acupuncture treatment: from $19 / 6.5^{\circ} / 3.5 \mathrm{~s}$, right and $15 / 9^{\circ} / 3.5 \mathrm{~s}$, left to $6 / 6^{\circ} / 3.5 \mathrm{~s}$, right and $2 / 7^{\circ} / 3.5 \mathrm{~s}$, left. The findings confirm his subjective and objective improvement of monocular and binocular visual acuity, and contrast sensitivity.

Figure $3 \mathrm{~b}$ shows an example of nystagmography pictures of a 26-year-old female patient with idiopathic pendular nystagmus as part of multiple sclerosis. Even if no improvement in the velocity of nystagmus (15 saccades at baseline and at post-treatment) was measured, an amplitude reduction from $4.5^{\circ}$ to 4 on the right eye and from $5.5^{\circ}$ to $5^{\circ}$ on the left eye could be found. This finding explains the subjectively reported oscillations' reduction, as well as vision- and contrast sensitivity improvement (Table 2).

Neither ocular, nor systemic adverse effects, were reported by any nystagmus patient. All patients included in the study indicated a willingness to repeat the acupuncture treatment.

\section{Discussion}

Results of our pilot study on patients suffering from nystagmus, confirmed subjective and objective improvement in their visual function, following standardized acupuncture protocol. Our data also demonstrated a dose-response relation: post-acupuncture, the effect of on visual acuity and contrast vision is more pronounced than the effect between-acupuncture, always using the baseline data for comparison.

This is not an unexpected finding, since previous reports on nystagmus patients treated with acupuncture also measured improvement of their foveal visual acuity and contrast sensitivity $[12,13]$. However, the studies reported until now have been performed on patients with CIN [12,13]. Here, the study of Blekher et al., examined the effects of acupuncture of the neck and face, reporting a reduction of frequency and a decrease of slow phase velocities, as well as an improvement of foveolar fixation, following acupuncture in patients with CIN. The improvement of these foveation periods has been thought to enhance visual acuity. Thus, the pathophysiologic mechanism of the improvement of the underlying CIN was supposed to be produced through the afferent stimulation of the reticular formation and vestibular nucleus via acupuncture of the neck and the face [12].

A novel finding in the present study was the fact that AN patients seemed to benefit from the acupuncture more. A possible explanation for this finding might be the labile nature of the CIN: the nystagmus may be exacerbated with visual effort or when fixating an imaginary target, and on the contrary may reduce with inattention or fatigue. It is noteworthy that the placement of the eyes in convergence gaze angle frequently dampens the nystagmus, which in fact is used as a treatment modality applying prism correction or divergence surgery. The latter explains why the binocular effect on visual function over time was more pronounced in our study and stays in agreement with previous studies. Nevertheless, to exclude the influence of the gaze direction and near fixation on nystagmography, and following the manufacturer's protocol (CSV-1000, Vector Vision; CIP, AMTech), we examined all six patients with the gaze directed for distance, keeping both eyes opened, while performing nystagmography monocularly.

We also found that even if the direction of the nystagmus showed no difference in either of nystagmus subgroups, patients with AN showed reduction in the nystagmus amplitude and frequency, and thus in oscillations, following acupuncture treatment. As a consequence, their central vision and contrast sensitivity seems to have improved more. On the contrary, patients with CIN showed almost stable amplitude and frequency of their nystagmus pattern.

Since patients with nystagmus often present unstable blood flow [14,16], the effect of acupuncture on systemic and ocular blood flow seems to explain in part the present finding. In agreement, studies on electro-acupuncture in rabbits with vertebrobasilar insufficiency showed improvement in their 
vestibulo-ocular reflex, through improvement of the basilar artery hemodynamic, inner ear blood flow, and blood viscosity [15]. Moreover, the traditional acupuncture stimulation has shown its positive effect on systemic blood flow, an effect, which supposedly is in part mediated by the central nervous system [16].

Even though in different ways, both nystagmus subgroups benefited from the acupuncture treatment. Acupuncture induced more foveation in CIN while mainly mitigating ocular-blood flow disturbances in AN patients. In this regard, our conclusions remain to be elucidated and elaborated upon in further studies.

\section{Conclusions}

Briefly, the applied acupuncture protocol showed improvement of the visual function and systemic condition of our nystagmus patients and was well tolerated. However, the long-term effect of this complementary therapy needs to be evaluated in further studies.

Acknowledgments: We are grateful to Rossiana Bojinova for editing the manuscript, to Hansjörg Rudin for drawing the pictures to Figure 1, and to Andy Schötzau for his support in statistical analysis.

Author Contributions: All authors have full access to all data from the study and are responsible for the data integrity and the analysis accuracy. T.B. and M.G.T. conceived and designed the experiments; T.B. and M.K. performed the experiments; M.G.T. and M.K. analyzed the data; T.B. contributed materials; M.G.T and T.B. wrote the paper.

Conflicts of Interest: The authors declare no conflict of interest.

\section{References}

1. Gelbart, S.S.; Hoyt, C.S. Congenital nystagmus: A clinical perspective in infancy. Graefes Arch. Clin. Exp. Ophthalmol. 1988, 226, 178-180. [CrossRef] [PubMed]

2. Weiss, A.H.; Biersdorf, W.R. Visual sensory disorders in congenital nystagmus. Ophthalmology 1989, 96, 517-523. [CrossRef]

3. Abadi, R.V. Visual performance with contact lenses and congenital idiopathic nystagmus. Br. J. Physiol. Opt. 1979, 33, 32-37. [PubMed]

4. $\quad$ Biousse, V.; Tusa, R.J.; Russell, B.; Azran, M.S.; Das, V.; Schubert, M.S.; Ward, M.; Newman, N.J. The use of contact lenses to treat visually symptomatic congenital nystagmus. J. Neurol. Neurosurg. Psychiatry 2004, 75 , 314-316. [CrossRef] [PubMed]

5. Beuschel, R.; Todorova, M.G. Okulokutaner Albinismus. Focus 2016, 7/8, 52-54.

6. McLean, R.; Proudlock, F.; Thomas, S.; Degg, C.; Gottlob, I. Congenital nystagmus: Randomized, controlled, double-masked trial of memantine/gabapentin. Ann. Neurol. 2007, 61, 130-138. [CrossRef] [PubMed]

7. Abadi, R.V.; Whittle, J. Surgery and compensatory head postures in congenital nystagmus. A longitudinal study. Arch. Ophthalmol. 1992, 110, 632-635. [CrossRef] [PubMed]

8. Bagheri, A.; Farahi, A.; Yazdani, S. The effect of bilateral horizontal rectus recession on visual acuity, ocular deviation or head posture in patients with nystagmus. J. AAPOS 2005, 9, 433-437. [CrossRef] [PubMed]

9. Dell'Osso, L.F.; Tomsak, R.L.; Thurtell, M.J. Two hypothetical nystagmus procedures: Augmented tenotomy and reattachment and augmented tendon suture (Sans tenotomy). J. Pediatr. Ophthalmol. Strabismus 2009, 46, 337-344. [CrossRef] [PubMed]

10. Liang, X.B.; Liu, X.Y.; Li, F.Q.; Luo, Y.; Lu, J.; Zhang, W.M.; Wang, X.M.; Han, J.S. Long-term high-frequency electro-acupuncture stimulation prevents neuronal degeneration and up-regulates BDNF mRNA in the substantia nigra and ventral tegmental area following medial forebrain bundle axotomy. Brain Res. Mol. Brain Res. 2002, 108, 51-59. [CrossRef]

11. Chung, K.F.; Yeung, W.F.; Yu, Y.M.; Yung, K.P.; Zhang, S.P.; Zhang, Z.J.; Wong, M.T.; Lee, W.K.; Chan, L.W. Acupuncture for residual insomnia associated with major depressive disorder: A placeboand sham-controlled, subject- and assessor-blind, randomized trial. J. Clin. Psychiatry 2015, 76, e752-e760. [CrossRef] [PubMed]

12. Sheth, N.V.; Dell'Osso, L.F.; Leigh, R.J.; Van Doren, C.L.; Peckham, H.P. The effects of afferent stimulation on congenital nystagmus foveation periods. Vis. Res. 1995, 35, 2371-2382. [CrossRef] 
13. Blekher, T.; Yamada, T.; Yee, R.D.; Abel, L.A. Effects of acupuncture on foveation characteristics in congenital nystagmus. Br. J. Ophthalmol. 1998, 82, 115-120. [CrossRef] [PubMed]

14. Yamamoto, K.; Kubo, T.; Matsunaga, T. Effects of asymmetric vertebral blood flow upon the vestibulo-ocular reflex of the rabbit. Eur. Arch. Otorhinolaryngol. 1985, 241, 195-202. [CrossRef]

15. Zheng, Z.; Song, K.Y.; Hu, X.M.; Yu, F.; Deng, X.Z.; Zhang, Q.; Wen, G.W.; Cao, X.M. Experimental study of electroacupuncture improving the obstruction of vestibular microcirculation in vertebrobasilar insufficiency and the effect on vestibulo-ocular reflex. Zhongguo Ying Yong Sheng Li Xue Za Zhi 2006, 22, 99-104. [PubMed]

16. Takamoto, K.; Hori, E.; Urakawa, S.; Sakai, S.; Ishikawa, A.; Kohno, S.; Ono, T.; Nishijo, H. Cerebral hemodynamic responses induced by specific acupuncture sensations during needling at trigger points: A near-infrared spectroscopic study. Brain Topogr. 2010, 23, 279-291. [CrossRef] [PubMed]

17. Blechschmidt, T.; Krumsiek, M.; Todorova, M.G. Improvement in Visual Function in Patients with Inherited Diseases of the Retina Following Acupuncture Treatment. Klin. Monatsbl. Augenheilkd. 2016, 233, 416-423. [CrossRef] [PubMed]

(C) 2017 by the authors. Licensee MDPI, Basel, Switzerland. This article is an open access article distributed under the terms and conditions of the Creative Commons Attribution (CC BY) license (http:/ / creativecommons.org/licenses/by/4.0/). 
Article

\title{
Nonspecific Feelings Expected and Experienced during or Immediately after Electroacupuncture: A Pilot Study in a Teaching Situation
}

\author{
David F. Mayor ${ }^{1, *}$, Lara S. McClure ${ }^{2}$ and J. Helgi Clayton McClure ${ }^{2}$ \\ 1 Department of Allied Health Professions and Midwifery, School of Health and Social Work, \\ University of Hertfordshire, Hatfield AL10 9AB, UK \\ 2 Northern College of Acupuncture, York YO1 6LJ, UK; LaraMcClure@chinese-medicine.co.uk (L.S.M.); \\ helgi.claytonmcclure@oxon.org (J.H.C.M.) \\ * Correspondence: davidmayor@welwynacupuncture.co.uk; Tel.: +44-1707-320-782
}

Academic Editors: Gerhard Litscher and William Chi-shing Cho

Received: 29 January 2017; Accepted: 28 March 2017; Published: 8 April 2017

\begin{abstract}
Background: Some feelings elicited by acupuncture-type interventions are "nonspecific", interpretable as resulting from the placebo effect, our own self-healing capacities-or, indeed, the flow of $q i$. Expectation is thought to contribute to these nonspecific effects. Here we describe the use of two innovative 20-item questionnaires (EXPre 20 and EXPost $\left.{ }_{20}\right)$ in a teaching situation. Methods: Respondents were acupuncture students or practitioners on electroacupuncture (EA) training courses $(N=68)$. EXPre 20 and EXPost 20 questionnaires were completed before and after receiving individualised treatment administered by colleagues. Respondents were also asked about their prior experience of EA or transcutaneous electroacupuncture stimulation (TEAS). Results: Respondents expected significantly more items to change than not to change, but significantly fewer were experienced as changing. Increases in given questionnaire items were both expected and experienced significantly more often than decreases. "Tingling", "Relaxation", and "Relief" or "Warmth" were most often expected to increase or were experienced as such, and "Pain" and "Tension" to decrease or experienced as decreasing. Expectations of change or no change were confirmed more often than not, particularly for "Tingling" and "Tension". This was not the result of the personal respondent style. Cluster analysis suggested the existence of two primary feeling clusters, "Relaxation" and "Alertness". Conclusions: Feelings experienced during or immediately after acupuncture-type interventions may depend both on prior experience and expectation.
\end{abstract}

Keywords: electroacupuncture; nonspecific feelings; expectation; placebo; qi; cluster analysis

\section{Introduction}

Writings about acupuncture often mention its "nonspecific" effects, although even those familiar with the literature on these effects vary in their interpretation of the term [1]. The placebo effect is sometimes considered as evidence for an activation of what some consider as our "nonspecific" self-healing capacities [2-4]. There are also accounts of how, in response to placebo (more accurately, sham) acupuncture, bodily sensations of warmth, tingling, pulsing, flow (spreading, radiating), and electricity have been elicited-warmth and tingling being particularly associated with treatment efficacy $[5,6]$. Such sensations are also reported in other complementary and alternative medicine (CAM) modalities such as "biofield energy healing" [7], and have been interpreted by many CAM practitioners as resulting from the flow of $q i$, the immanent life force of the body and the world (part agency, part image or form, part metaphor), of key importance in acupuncture and Chinese culture as a whole, as well as being central to Western traditions of vitalism, where it has many other names $[8,9]$. 
The expectation of a positive outcome is thought to be a major contributor to nonspecific effects of treatment [10], partly because it alters how bodily sensations are identified [11]. However, no independently developed pre-existing questionnaires were found that could be used to assess expectation or experience of the nonspecific feelings that may arise in response to acupuncture-type interventions, although scales have been developed to evaluate the common specific sensations elicited by acupuncture [12-21]. Our objectives in this study were therefore to use two previously developed 20-item questionnaires, EXPre 20 and EXPost 20 , to investigate differences in response patterns between respondent subgroups and identify any patterns of change (both expected and experienced) for particular nonspecific feelings. For further explanation on these "EXP 20 " questionnaires and their precursors, EXPre 32 and EPost 32 , see Section 2, Materials and Methods, below, and for the questionnaires themselves, see Appendixs A and B).

\section{Research questions and hypotheses}

1. Firstly, the study aims to address the question of fulfillment of expectation. Our central hypothesis is that there will be strong, generally positive correlations between the expected and experienced feelings-in other words, that expectation in this context is generally fulfilled [10,11]. (This should not be conflated with the association between expectation of treatment effectiveness and its outcome, or benefit [22-24]).

2. We aim to establish whether there are trends across responses to different questionnaire items. For instance, there might be significant overall differences between the numbers of "Yes" and "No" responses, or between the numbers of "increase" and "decrease" responses, given to the various nonspecific feelings assessed by the questionnaires. For example, feelings of "Relaxation" have been reported in response to acupuncture treatment [25], and feelings of "Aliveness" might be associated on theoretical grounds with an improvement in the flow of $q i[8]$. Would both these be found to increase in this context?

3. We also aim to address the question of prior experience effects. Those with prior experience of electroacupuncture (EA) or transcutaneous electrical nerve stimulation (TENS) might report generally different expectations or experiences of feelings elicited by EA/TEAS (transcutaneous electroacupuncture stimulation) than are reported by those without. Related to this, students might report different expectations or experiences than those reported by practitioners. Our use of Continuing Professional Development (CPD) practitioner versus Student respondent groups, as well as recording the presence versus absence of prior experience of EA/TENS, will allow us to explore the effects of the treatment experience in two different ways (general and specific).

Of course, differences by respondent group or by prior experience might be detected between questionnaire items also.

4. A final key aim of the present study is to identify any significant associations among the different feelings assessed by the questionnaires. A cluster analysis will enable us to better understand these associations, through an exploration of the relationships between them. For example, using the language of Chinese medicine, some feelings could be considered more "yang" (masculine, positive, expansive) and others more "yin" (feminine, negative, withdrawing) [26]. Are these ideational associations reflected in the clusters found?

\section{Materials and Methods}

\subsection{Recruitment, Questionnaires, and Treatments}

Respondents were recruited during pre-arranged electroacupuncture (EA) teaching sessions in the UK, three of these being university-affiliated undergraduate acupuncture training courses and two independently organised CPD courses for acupuncture practitioners (in Nottingham and Brighton). The basic structure of the sessions was similar on all courses, although one of the undergraduate courses (CICM) was only a half-day rather than a full-day session. The same lecturer-an acupuncturist with over 30 years of experience-presented and supervised all the courses.

Respondents were asked to complete two 20-item questionnaires: an initial expectation questionnaire $\left(\mathrm{EXPre}_{20}\right)$ at the beginning of the teaching session, and a follow-up experience questionnaire (EXPost 20 ) after receiving a short treatment from a fellow attendee (a flow chart of this sequence is shown in Figure 1). 


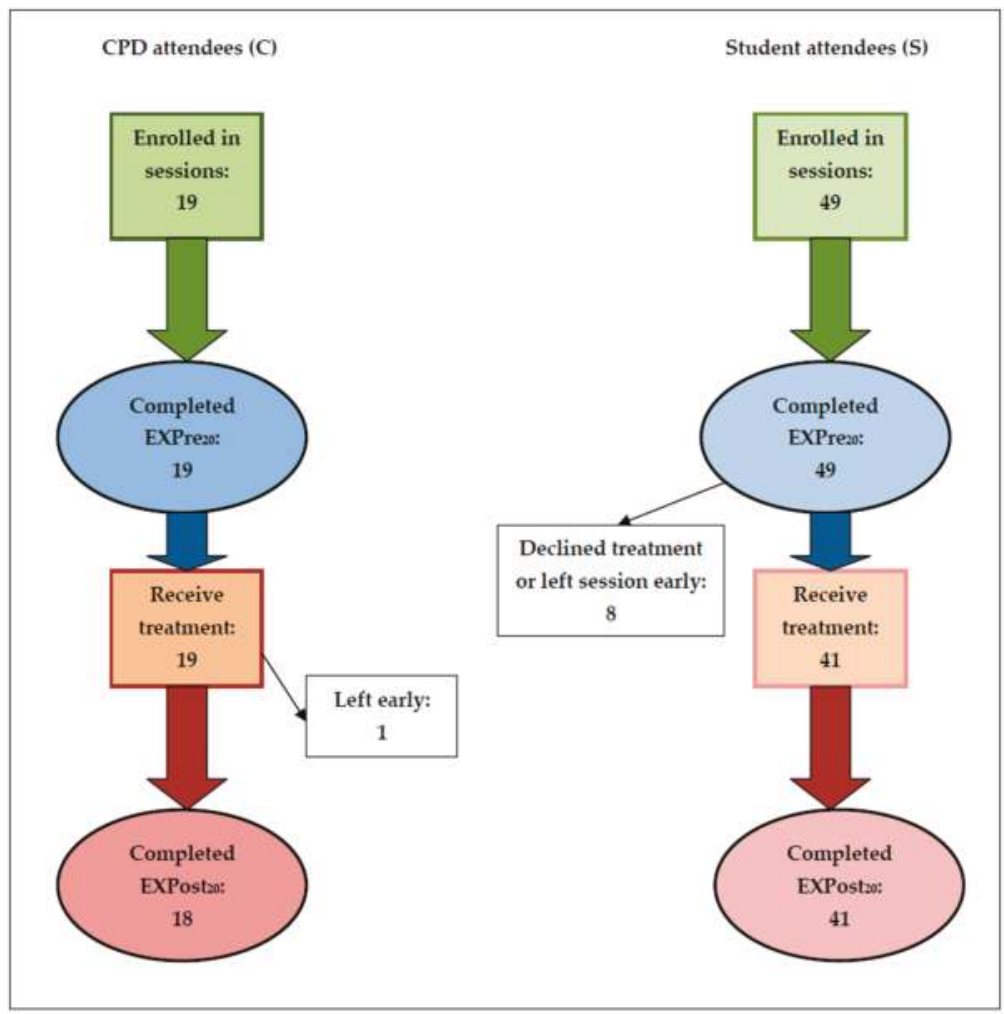

Figure 1. Study flow chart for CPD (C) and Student (S) attendees. Key: $\mathrm{EXPre}_{20}=$ initial expectation questionnaire; EXPost $_{20}=$ follow-up experience questionnaire.

\section{Pilot Studies: development of the $\mathrm{EXP}_{20}$ questionnaires from earlier 32-item versions}

In earlier research, two longer 32-item questionnaires had been piloted in three cohorts of acupuncture and other complementary health practitioners and students familiar with acupuncture, who received EA or TEAS (transcutaneous electroacupuncture stimulation as against the usual "nerve stimulation", TENS) in experimental studies or a classroom situation $(N=204)$. They were designed to assess expectation (EXPre $\left.{ }_{32}\right)$ and experience $\left(\mathrm{EXPos}_{32}\right)$ of the relatively nonspecific feelings (bodily, emotional, or mental) that may arise in response to acupuncture-type interventions, in particular the established methods of EA and TEAS [27]. Findings on their content validity and reliability, together with a cluster analysis, have been presented elsewhere [28]. The salient results were that significant numbers of feelings experienced by respondents were those they expected, and that significant numbers of feelings not experienced were those not expected. It should be noted that many of the participants in this earlier study had no prior experience of EA/TEAS, although nearly all were familiar with acupuncture.

Following this, 20 experienced acupuncture practitioners and researchers rated items in the original 32-item questionnaires as either "essential", "useful but not essential", or "not necessary". These ratings, together with the analysis of actual questionnaire usage, were used to reduce the original questionnaires from 32 to 20 items [29]. More information on the development of the $\mathrm{EXP}_{20}$ questionnaires can be found in the publications cited [28-30].

Treatment was supervised but participants were free in this teaching situation to use their own choice of acupuncture points and stimulation parameters (frequency, amplitude, mode, pulse, and overall stimulation duration). They were also encouraged to use several different EA/TEAS 
stimulators, of which 11 were provided for their use. Treatments were carried out in small groups of 3-4 participants. Information on the treatments received is provided in the Supplementary Material Table S1.

\subsection{Ethics Approval}

Ethics approval was granted under an application for a related study by the Health and Human Sciences Ethics Committee of the University of Hertfordshire, UK (Protocol HEPEC/07/11/93), approved 5 July 2011, 24 Aug 2012 . Permission was also received from course organisers and respondents.

\subsection{Questionnaire Administration}

The present paper describes and analyses the use of the shorter 20-item questionnaires in a teaching situation $(N=68)$.

The questionnaires (Appendix B) were printed with items in randomised order, so it was unlikely that they would appear in the same order in both EXPre 20 and EXPost 20 for a particular respondent. These two were also distributed and collected separately, so that they could not be seen at the same time, reducing the likelihood of respondents basing their replies to EXPost 20 on their earlier replies to EXPre 20 .

In EXPre 20 , respondents were asked "Relative to how you feel NOW, during or immediately following EA/TEAS do you expect to experience any change AT ALL in the feeling of ... " (a particular feeling). Possible responses were "Yes", "No", or "don't know/can't say" ("DK", i.e., no particular expectation). If they answered "Yes", they were then asked if they expected the feeling to increase or decrease. Similarly, in EXPost 20 , respondents were asked "Relative to how you felt when you completed the earlier questionnaire, during or immediately following EA/TEAS did you experience a change in the feeling of ...".

Questionnaires were collated using pre-printed ID codes double-checked against respondents' signatures/initials and writing styles.

\subsection{Statistical Analysis}

Anonymised scores for each questionnaire item were analysed using Excel and SPSS v20. Binomial and $\chi^{2}$ (chi-square) tests were used to assess significance of differences; to assess the degree of association, Cramer's V and Pearson's r were used (both with a range of 0 to 1 ). Three methods of hierarchical cluster analysis appropriate for binary data were used: Jaccard's index (or "similarity ratio"), Sokal and Sneath's index 5 (range 0 to 1) [31,32], and Ward's method. For the first two methods, distances were calculated using average linkage (both between and within groups), nearest neighbour (single linkage), and furthest neighbour (complete linkage). Squared Euclidean distances were used for Ward's method. Appropriate numbers of clusters were estimated visually from the dendrograms for each method, particularly where there was apparent agreement among them for the largest reasonable (readily interpretable) number of clusters [32].

\section{Results}

\subsection{Respondents}

The present study sample consisted of acupuncture practitioners undertaking continuous professional development courses (hereafter CPD or practitioners) and students of acupuncture (Students). The two groups were composed of respondents from five training centres (CPD: Brighton, Nottingham; Students: the College of Integrated Chinese Medicine, Reading (CICM), London South bank University (LSBU), and the Northern College of Acupuncture, York (NCA)).

Student respondents were obliged to attend EA sessions as part of their acupuncture training, whereas practitioner respondents signed up for EA courses voluntarily (all respondents were informed 
that they did not need to complete the questionnaires if they did not wish to). Training centre, age, gender (where known), prior experience of EA and/or TENS, and numbers completing the two questionnaires are shown in Table 1. All attendees completed the initial questionnaire. A few attendees declined treatment because of known contraindications (e.g., pregnancy or a heart condition), an aversion to "non-traditional" EA/TEAS, or to electricity itself. Some students left the sessions early,

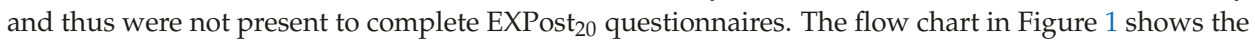
numbers at the start of the EA sessions and those at the end.

Table 1. Respondent cohorts, showing age (mean, SD), gender, whether practitioner/CPD (C) or student (S), prior experience of electroacupuncture (EA) and/or transcutaneous electrical nerve stimulation (TENS), and numbers completing each of the two questionnaires, EXPre 20 and EXPost 20 , as well as both EXP questionnaires.

\begin{tabular}{|c|c|c|c|c|c|c|c|c|}
\hline Training Centre & Total $N$ & Age & Gender & $\mathrm{C} / \mathrm{S}$ & Prior & No Prior & EXPre $_{20}$ & EXPost $_{20}$ \\
\hline LSBU (19.10.13) & 14 & $37.8,8.3$ & $11 \mathrm{~F}, 2 \mathrm{M}$ & $S$ & 8 & 6 & 14 & 11 \\
\hline $\begin{array}{c}\text { Nottingham } \\
(23.11 .13)\end{array}$ & 8 & $52.1,5.7$ & $\mathrm{n} / \mathrm{a}^{\mathrm{a}}$ & C & 6 & 2 & 8 & 7 \\
\hline Brighton (06.04.14) & 11 & $45.9,7.9$ & $9 \mathrm{~F}, 2 \mathrm{M}$ & C & $6^{\mathrm{b}}$ & $4^{\mathrm{b}}$ & 11 & 11 \\
\hline CICM (07.04.14) & 24 & $39.7,9.5$ & $19 \mathrm{~F}, 5 \mathrm{M}$ & S & 10 & 14 & 24 & 19 \\
\hline NCA (12.04.14) & 11 & $39.8,9.8$ & $9 \mathrm{~F}, 2 \mathrm{M}$ & S & 6 & 5 & 11 & 11 \\
\hline$C P D N$ & 19 & $48.3,7.6$ & $9-17 F, 2-10 \mathrm{M}^{\mathrm{a}}$ & C & 12 & 6 & 19 & 18 \\
\hline Student N & 49 & $39.1,9.1$ & $39 F, 9 M$ & $S$ & 24 & 25 & 49 & 41 \\
\hline Total $N$ & 68 & $41.7,9.6$ & $48-56 \mathrm{~F}, 11-19 \mathrm{M}$ & $\mathrm{n} / \mathrm{a}$ & 36 & 31 & 68 & 59 \\
\hline
\end{tabular}

${ }^{a}$ Information not available; ${ }^{\mathrm{b}}$ One respondent did not answer this question.

As would be expected, students were consistently younger than practitioners $(p<0.001$ for the difference in their ages, using an independent-samples $t$-test, with $t(64)=3.8$ ). As for the gender of the attendees, even if all missing cases were men, there is still a significant preponderance of women ( $p=0.001$ using the Binomial test with a test proportion of 0.5$)$. Again, for CAM practitioners, this would be expected [33].

Details of the treatments received are summarised in Supplementary Materials Table S1.

\subsection{Research Question 1: Fulfilment of Expectation}

\subsubsection{Overall Patterns of Expectation}

Although individuals' responses varied considerably, overall there were clear patterns of the relationships between the counts of expected and experienced " $\mathrm{Y}$ ", " $\mathrm{N}$ ", and "DK" change scores, shown in Figure 2 as " $\mathrm{N} \rightarrow \mathrm{DK}$ ", etc.
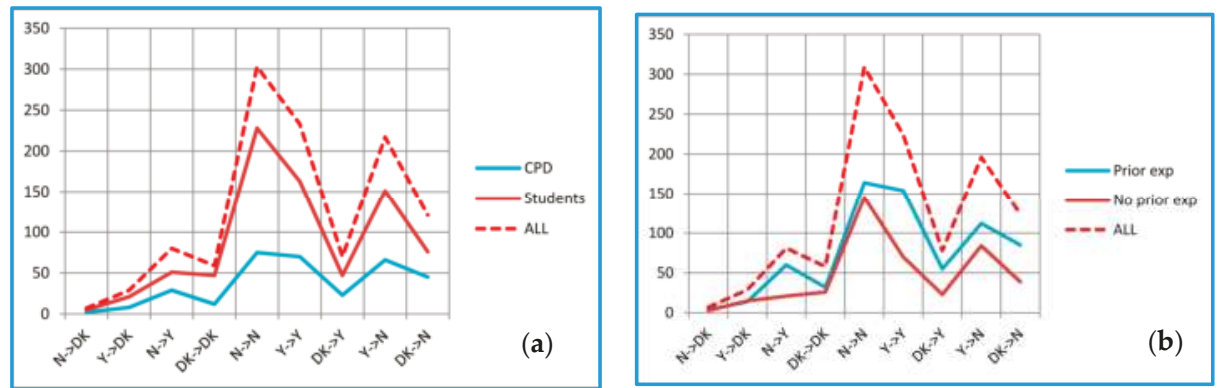

Figure 2. Relationships between counts of expected and experienced "Yes" (Y), "No" (N), and "Don't know" (DK) change scores: (a) CPD and student subgroups; (b) Subgroups of those with prior or no prior experience of EA/TENS. 
Thus the expectations of change, whether negative or positive, were confirmed $(N \rightarrow N$ and $Y \rightarrow Y$ ) more often than other combinations, the next most common combination being expected changes that were not confirmed in practice. DK $\rightarrow \mathrm{N}$ also outnumbered $\mathrm{DK} \rightarrow \mathrm{Y}$. (Similar patterns were found for the earlier versions of the questionnaires, EXPre 32 and EXPost 32 [28]). Furthermore, in each cohort except for the Brighton CPD group, significantly more respondents showed confirmatory scores than would be expected by chance $(p \leq 0.001$, using the Binomial test with a test proportion of 0.25 , i.e., based on $\mathrm{N} \rightarrow \mathrm{N}$ and $\mathrm{Y} \rightarrow \mathrm{Y}$, but ignoring the $\mathrm{DK} \rightarrow \mathrm{DK}$ responses).

When all items were considered together, there were positive linear correlations between items expected to change and experienced as changing $(r=0.869)$, and also between those not expected to change and not experienced as changing $(\mathrm{r}=0.722)$. There were negative correlations between items not expected to change and those experienced as changing $(r=0.727)$ and vice versa $(r=0.832)$.

Only in one cohort (Brighton, $N=11$ ) were expectations less often confirmed than not (for $Y \rightarrow N$, but $\operatorname{not} \mathrm{N} \rightarrow \mathrm{Y}$ ).

Comparing the results for $\mathrm{CPD}$ and students, only for $\mathrm{DK} \rightarrow \mathrm{N}$ was the difference between these two subgroups significant $(p=0.018)$.

Those with prior experience of EA/TENS showed rather more $\mathrm{N} \rightarrow \mathrm{Y}$ and $\mathrm{Y} \rightarrow \mathrm{Y}$ scores than those without prior experience $(p<0.001)$. Differences between these two subgroups were also significant for $\mathrm{DK} \rightarrow \mathrm{Y}(p=0.002)$ and $\mathrm{DK} \rightarrow \mathrm{N}(p=0.001)$.

For increases (i) and decreases (d), there were no significant differences between when expectations of change were confirmed $(\mathrm{i} \rightarrow \mathrm{i}$ or $\mathrm{d} \rightarrow \mathrm{d}$ ) or not $(\mathrm{i} \rightarrow \mathrm{d}$ or $\mathrm{d} \rightarrow \mathrm{i})(p>0.05)$. However, counts of each of these four combinations were higher for those with prior experience of EA/TENS than for those without prior experience, as indicated in Supplementary Materials Figure S1 (see also p 9 below).

When all the items were considered together, there were positive linear correlations between items expected to increase and experienced as increasing $(r=0.750)$, and also between those expected to decrease and experienced as decreasing $(r=0.916)$. These correlations were driven by increases in Relaxation, Tingling and Warmth, and by decreases in Being stressed, Pain and Tension. If these were removed from the analysis, the apparent linearity was no longer evident $(r=0.446$ and $\mathrm{r}=0.173$, respectively).

There was no indication that respondents who tended to answer one way to the EXPre 20 questionnaire (as "increasers", "i", or "decreasers", " $\mathrm{d}$ " [29]) were likely to answer the same way to the EXPost 20 questionnaire $(p>0.05)$.

\subsubsection{Patterns of Expectation for Individual Questionnaire Items}

Counts of the various change responses for individual items were made. The highest counts for the various EXPre 20 /EXPOst ${ }_{20}$ combinations are shown in Supplementary Materials Table S3. For $\mathrm{DK} \rightarrow \mathrm{DK}$ and $\mathrm{DK} \rightarrow \mathrm{N}$, two items were tied in first position, and for $\mathrm{Y} \rightarrow \mathrm{DK}$, three items.

Items above the third quartile for $Y \rightarrow Y$ were Tingling (count 40), Relaxation (20), Pain and Tension (16), and Warmth (15), all of which were included in $\operatorname{EXP}_{32}$ (although not among the $Y \rightarrow Y$ items above the third quartile there). The third quartile $\mathrm{N} \rightarrow \mathrm{N}$ items in $\mathrm{EXP}_{20}$ were Cheerfulness (26), Clarity and Heaviness (23), Sleepiness (22), and Being spaced out (21). Again, although included in $\mathrm{EXP}_{32}$, they did not occur in the third quartile $\mathrm{EXP}_{32} \mathrm{~N} \rightarrow \mathrm{N}$ items. The case for DK $\rightarrow \mathrm{DK}$ is similar.

Expected/experienced increases and decreases are shown in Supplementary Materials Table S4.

The results for Tingling and Tension are in line with those in the previous table. Those for Relaxation (inc $\rightarrow \mathrm{dec}$ ) and Pain (dec $\rightarrow$ inc) are somewhat surprising (but involve only small numbers).

\subsection{Research Question 2: Individual Questionnaire Items-Expectations of Change, Increase and Decrease}

\subsubsection{Changes/No Changes and Increases/Decreases Most and Least Expected}

Questionnaire item counts were ranked and the results were tabulated. Those above the third quartile (75th percentile, in the "top five") are shown in Table 2. 
Table 2. Changes/no changes and increases/decreases most and least expected. Items listed are for the whole sample. Subgroups in which the listed items did not occur are shown in the "not sub" columns.

\begin{tabular}{|c|c|c|c|c|c|c|c|}
\hline $\begin{array}{l}\text { Change Most } \\
\text { Expected }\end{array}$ & $\begin{array}{l}\text { Not } \\
\text { Sub }\end{array}$ & $\begin{array}{l}\text { No Change } \\
\text { Least Expected }\end{array}$ & $\begin{array}{l}\text { Not } \\
\text { Sub }\end{array}$ & $\begin{array}{l}\text { Change Least } \\
\text { Expected }\end{array}$ & $\begin{array}{l}\text { Not } \\
\text { Sub }\end{array}$ & $\begin{array}{c}\text { No Change Most } \\
\text { Expected }\end{array}$ & $\begin{array}{l}\text { Not } \\
\text { Sub }\end{array}$ \\
\hline Tingling * & - & Tingling & - & Cheerfulness & - & Cheerfulness & - \\
\hline Relaxation * & $\mathrm{n}$ & Warmth & $\mathrm{s}$ & Being spaced out & - & Being spaced out & - \\
\hline Tension * & c & $\begin{array}{l}\text { Inner bodily } \\
\text { flow }\end{array}$ & c & Sensory acuity & - & Heaviness & c \\
\hline Pain & - & Relief & $\mathrm{n}$ & Sleepiness & $\mathrm{s}, \mathrm{n}$ & Sleepiness & $\mathrm{n}$ \\
\hline Relief & $\mathrm{c}, \mathrm{n}$ & Relaxation & - & Clarity & $\mathrm{c}, \mathrm{n}$ & Clarity & - \\
\hline $\begin{array}{l}\text { Increase Most } \\
\text { Expected }\end{array}$ & $\begin{array}{l}\text { Not } \\
\text { Sub }\end{array}$ & $\begin{array}{l}\text { Decrease Least } \\
\text { Expected }\end{array}$ & $\begin{array}{l}\text { Not } \\
\text { Sub }\end{array}$ & $\begin{array}{l}\text { Increase Least } \\
\text { Expected }\end{array}$ & $\begin{array}{l}\text { Not } \\
\text { Sub }\end{array}$ & $\begin{array}{l}\text { Decrease Most } \\
\text { Expected }\end{array}$ & $\begin{array}{l}\text { Not } \\
\text { Sub }\end{array}$ \\
\hline Tingling & - & Cheerfulness & - & Being stressed & - & Pain & - \\
\hline Relaxation & - & Aliveness & - & Pain & - & Tension & - \\
\hline Warmth & c & Wellbeing & - & Cheerfulness & - & Being stressed & - \\
\hline Relief & $\mathrm{c}, \mathrm{n}$ & Warmth & - & Tension & $\mathrm{n}$ & Heaviness & - \\
\hline Wellbeing & $\mathrm{s}, \mathrm{n}$ & $\left(5\right.$ tied items $\left.{ }^{\dagger}\right)$ & - & Heaviness & $c, p$ & Sleepiness & c \\
\hline
\end{tabular}

Key: $\mathrm{c}=\mathrm{CPD} ; \mathrm{s}=$ students; $\mathrm{p}=$ prior experience of EA/TENS; $\mathrm{n}=$ no prior experience of EA/TENS. Items in bold are those for which the most agreement occurred for "change" as well as for either "increase" or "decrease".

* Agreement with results for EXPre 32 [27]; ${ }^{\dagger}$ Clarity, Inner bodily flow, Mental energy, Mental focus, Sensory acuity.

\subsubsection{Correlations between Items Expected to Change/Not Change, or Increase/Decrease}

There is evidently some correspondence between items most expected to change and those least expected not to change (three items in common) and vice versa (four items in common). Taking all items into account, there was a strong negative linear correlation between those expected to change and those not expected to change $(r=-0.893)$.

There is less correspondence between those items most expected to increase and those least expected to decrease (two items in common), and more between those items most expected to decrease and those least expected to increase (four items in common). Compared with expectations of change, there was a relatively small negative correlation between items expected to increase and those expected to decrease $(\mathrm{r}=-0.510)$.

\subsection{Research Question 2: Individual Questionnaire Items-Experiences of Change, Increase and Decrease}

\subsubsection{Changes/No Changes and Increases/Decreases Most and Least Experienced}

Questionnaire item counts were ranked and the results were tabulated. Those above the third quartile (75th percentile, in the "top five") are shown in Table 3. In addition, respondents were asked explicitly to asterisk changes they "noticed most" (see Appendix B-2). Only 16 did so (12 students, 4 practitioners), with 42 items asterisked between them (1-8 items per respondent, mode 2). The numbers of asterisked items are included (in parentheses) in Table 3. Other items asterisked but not above the third quartiles (not included in Table 3) were Aliveness (1), Being spaced out (2), Calmness (3), Heaviness (2), Inner bodily flow (1), Mental energy (1), and Sleepiness (4). Wellbeing was the only item not asterisked.

Here there is a similar degree of agreement between greater experience of change and lesser experience of no change (four items in common), and between greater experience of no change and lesser experience of change (four items in common). Taking all item counts into consideration, there was a negative linear correlation between those experienced as changing and not changing $(r=-0.944)$. This was stronger than the correlation for the expected items.

Apart from Calmness and Sleepiness (asterisked three and four times), and Relief (asterisked twice), there is agreement between those items for which changes were most often experienced and those experienced with most intensity ("noticed most", and asterisked three times or more). 
Table 3. Changes/no changes and increases/decreases most and least experienced. Items listed are for the whole sample. Subgroups in which the listed items did not occur are shown in the "not sub" columns.

\begin{tabular}{|c|c|c|c|c|c|c|c|}
\hline $\begin{array}{l}\text { Change Most } \\
\text { Experienced }\end{array}$ & $\begin{array}{l}\text { Not } \\
\text { Sub }\end{array}$ & $\begin{array}{l}\text { No change Least } \\
\text { Experienced }\end{array}$ & $\begin{array}{l}\text { Not } \\
\text { Sub }\end{array}$ & $\begin{array}{l}\text { Change Least } \\
\text { Experienced }\end{array}$ & $\begin{array}{l}\text { Not } \\
\text { Sub }\end{array}$ & $\begin{array}{l}\text { No change Most } \\
\text { Experienced }\end{array}$ & $\begin{array}{l}\text { Not } \\
\text { Sub }\end{array}$ \\
\hline Tingling (3) & - & Tingling (3) & - & Mental focus (2) & $\mathrm{n}$ & $\begin{array}{c}\text { Intestinal } \\
\text { rumblings * }(2)\end{array}$ & - \\
\hline Relaxation * (6) & - & Pain (4) & $\mathrm{p}$ & $\begin{array}{l}\text { Intestinal rumblings } \\
\text { (2) }\end{array}$ & - & Sensory acuity (0) & - \\
\hline Warmth (4) & - & Relief (2) & - & Sensory acuity (0) & - & Being stressed (0) & $\mathrm{s}, \mathrm{n}$ \\
\hline Pain (4) & $\mathrm{s}, \mathrm{p}$ & Relaxation (6) & - & Cheerfulness (1) & - & Clarity (1) & - \\
\hline Tension * (3) & c & Warmth (4) & $\mathrm{n}$ & Clarity (1) & - & Mental focus (2) & $\mathrm{c}, \mathrm{n}$ \\
\hline $\begin{array}{l}\text { Increase Most } \\
\text { Experienced }\end{array}$ & $\begin{array}{l}\text { Not } \\
\text { Sub }\end{array}$ & $\begin{array}{l}\text { Decrease Least } \\
\text { Experienced }\end{array}$ & $\begin{array}{l}\text { Not } \\
\text { sub }\end{array}$ & $\begin{array}{l}\text { Increase Least } \\
\text { Experienced }\end{array}$ & $\begin{array}{l}\text { Not } \\
\text { Sub }\end{array}$ & $\begin{array}{l}\text { Decrease Most } \\
\text { Experienced }\end{array}$ & $\begin{array}{l}\text { Not } \\
\text { Sub }\end{array}$ \\
\hline Tingling & - & Sensory acuity & - & Mental focus & - & Tension & - \\
\hline Relaxation & - & Inner bodily flow & - & Being stressed & - & Pain & - \\
\hline Warmth & - & Warmth & - & Tension & $\mathrm{n}$ & Being stressed & - \\
\hline $\begin{array}{l}\text { Being spaced out } \\
\text { Calmness }\end{array}$ & $c, n$ & Mental focus & $\mathrm{n}$ & Sensory acuity & $p$ & Aliveness & - \\
\hline Calmness & $\mathrm{c}, \mathrm{n}$ & $\left(6\right.$ tied items ${ }^{\dagger}$ & - & Intestinal rumblin & $\mathrm{n}$ & Heaviness & $\mathrm{n}$ \\
\hline
\end{tabular}

Key: $\mathrm{c}=\mathrm{CPD} ; \mathrm{s}=$ students; $\mathrm{p}=$ prior experience of EA/TENS; $\mathrm{n}=$ no prior experience of EA/TENS. Numbers in square brackets indicate the numbers of an item asterisked as "most noticed" by respondents. Items in bold are those for which the most agreement occurred for "change" as well as for either "increase" or "decrease". * Agreement with results for EXPre 32 [27]; ${ }^{\dagger}$ Being spaced out, Calmness, Cheerfulness, Clarity, Intestinal rumblings, Tingling.

\subsubsection{Correlations between Items Most/Least Experienced as Increasing/Decreasing}

There is some correspondence between those items most experienced as increasing and those least experienced as decreasing (three items in common), but less between those items most experienced as decreasing and those least experienced as increasing (two items in common). There was a very weak negative correlation between items experienced as increasing and those experienced as decreasing $(\mathrm{r}=-0.358)$.

\subsubsection{Ratios of "Yes" /"No" and "Increase" /"Decrease" Score Counts}

Significance of the ratios of "Yes" /"No" and "increase"/"decrease" score counts are shown in Supplementary Materials Table S2, together with the sign of the difference between the counts.

Only for "Cheerfulness" was there a significant Expected/Not expected change ratio in both the EXPre $_{20}$ and EXPost 20 . In contrast, 12 items $(60 \%)$ showed a significant increased/decreased ratio in both EXPre 20 and EXPost 20 . For all these 12 items, increases outnumbered decreases (whether expected or experienced).

\subsection{Research Question —Differences in Response Patterns between Respondent Subgroups}

\subsubsection{Drop-outs, i.e., Those Not Completing the EXPost20 Questionnaire}

Nine respondents did not complete the EXPost 20 questionnaire. Eight of these (more than expected) had no prior experience of EA/TENS, and were also students ( $p=0.039$ each, using the ratio test).

\subsubsection{Those with and without Prior Experience of EA or TENS}

Overall, similar numbers had (36) and had not (31) had prior experience of EA/TENS, with proportionally more in the practitioner/CPD cohorts having prior experience (however, this was a nonsignificant difference). 


\subsubsection{Prior Experience and Expectation}

For no single EXPre $_{20}$ item was the Binomial test for those expecting a change significant. "Tingling" was the only item significant $(p=0.025)$ for those not expecting a change (none of those without prior experience expected no change in this item). Those who did expect a change in "Tingling" were divided almost equally between those with prior experience (28) and those without (27). For all EXPre $_{20}$ items taken together, however, the expectation of change and the expectation of increase approached significance for the 0.54 test proportion (and would have been significant had group sizes been equal).

Significantly more of those with prior experience were uncertain whether an increase or decrease was expected ( $p=0.023 ; p=0.001$ for test proportion 0.50 ).

\subsubsection{Practitioner and Student Expectation}

No significant differences in expectation of change/no change were found between students and practitioners. Practitioners expected fewer decreases than students $(p=0.024)$, and were less likely to report uncertainty in their expectation of increase or decrease $(p=0.003)$. No differences were significant for any individual item.

\subsubsection{Practitioner and Student Questionnaire Responses}

Across all questionnaire items in EXPre 20 , practitioners recorded 142 "yes" responses (106 increases, 26 decreases), 111 "no" responses, and 78 no-expectation responses. Students recorded 419 "yes" responses (294 increases, 104 decreases), 314 "no" responses, and 187 no-expectation responses.

Across all questionnaire items in EXPost 20 , practitioners recorded 126 "yes" responses (72 increases, 17 decreases), 189 "no" responses, and 22 no-expectation responses. Students recorded 264 "yes" responses (202 increases, 50 decreases), 458 "no" responses, and 74 no-expectation responses.

Unspecified "yes" responses in both cases were those where neither increase nor decrease was indicated.

Across all responses in EXPre 20 there was no significant difference in the distribution between practitioners and students $(p>0.05)$. Similarly, there was no significant difference with respect to the direction of change ("increase" or "decrease"). Across all responses in EXPost 20 , again the distributions were not significantly different when missing data responses were excluded $(p>0.05)$. In subsequent analyses (other than in Section 3.5 below), "don't know" (DK) and missing data responses were disregarded.

\subsubsection{Ratios of "Yes" and "No" Counts in Questionnaire Responses}

Ratios of "Yes" /"No" and "increase" /"decrease" counts are shown in Tables 4 and 5, respectively.

Table 4. Ratios of "Yes" and "No" counts for $\mathrm{EXP}_{20}$.

\begin{tabular}{ccccc}
\hline EXP $_{\mathbf{2 0}}$ & $\mathbf{Y} / \mathbf{N}$ (Pre) & $\mathbf{Y} / \mathbf{N}$ (Post) & $\mathbf{Y}$ (Post/Pre) & $\mathbf{N}$ (Post/Pre) \\
\hline CPD & $1.28^{* *}($ n.s.) & $0.67^{* *}$ & $0.89($ n.s.) & $1.70^{* *}$ \\
Student & $1.33^{* *}$ & $0.58^{* *}$ & $0.63^{* *}$ & $1.46^{* *}$ \\
Total & $1.32^{* *}$ & $0.60^{* *}$ & $0.70^{* *}$ & $1.52^{* *}$ \\
\hline \multicolumn{5}{c}{$p<0.001$ (Binomial test, test ratio 0.50). }
\end{tabular}

Table 5. Ratios of "increase" and "decrease" counts for $\mathrm{EXP}_{20}$.

\begin{tabular}{ccccc}
\hline Subgroup & Inc/Dec (Pre) & Inc/Dec (Post) & Inc (Post/Pre) & Dec (Post/Pre) \\
\hline CPD & $4.07^{* *}$ & $4.24^{* *}$ & $0.68^{*}$ & $0.65($ n.s.) \\
Student & $2.83^{* *}$ & $4.04^{* *}$ & $0.69^{* *}$ & $0.48^{* *}$ \\
Total & $3.08^{* *}$ & $4.09^{* *}$ & $0.69^{* *}$ & $0.52^{* *}$ \\
\hline \multicolumn{5}{c}{$p=0.0011^{* *} p<0.001$}
\end{tabular}


All the EXPre 20 count ratios, except for the practitioner EXPre 20 "Yes/No" ratio and the practitioner EXPost 20 /EXPre 20 "Yes" ratio, are significantly different from $1(p<0.001)$.

Obvious patterns are also that "Yes" responses outnumber "No's" in EXPre 20 , but "No" responses outnumber "Yes" responses in EXPost 20 , and that "No" responses in EXPost 20 outnumber those in EXPre $_{20}$, but that "Yes" responses in EXPre 20 outnumber those in EXPost 20 . (Similar results were found for EXPre 32 and EXPost 32 [28]).

Again, all count ratios are significantly different from $1(p<0.001)$ except for the practitioner EXPost $_{20} /$ EXPre $_{20}$ "increase" ratio $(p=0.001)$ and the practitioner "decrease" ratio (n.s.).

However, whereas the ratios of the change counts (Table 4) are quite dissimilar (median 1.76, interquartile range [IQR] 0.67-4.05), the "increase" /"decrease" ratios (Table 5) are quite similar for both EXPre 20 and EXPost 20 , as are the EXPost 20 /EXPre 20 ratios for both "increase" and "decrease" (median 1.09, IQR 0.66\%-1.36\%).

\subsection{Research Question 4-Associations between Different Items and Exploratory Cluster Analysis}

\subsubsection{Associations between Pairs of Items}

Cramer's V was used as a simple method of assessing how closely the different items were associated, based on the categorical scores ("Y" or "N") allocated by the respondents. Low values of $\mathrm{V}(<0.3)$ were ignored $(\mathrm{V} \geq 0.3$ is considered by Cohen to indicate a medium level of association, and $V \geq 0.5$ a high level [34]). Figure 3 shows how frequently each item appeared in item pairs with a medium or high level of Cramer's V.

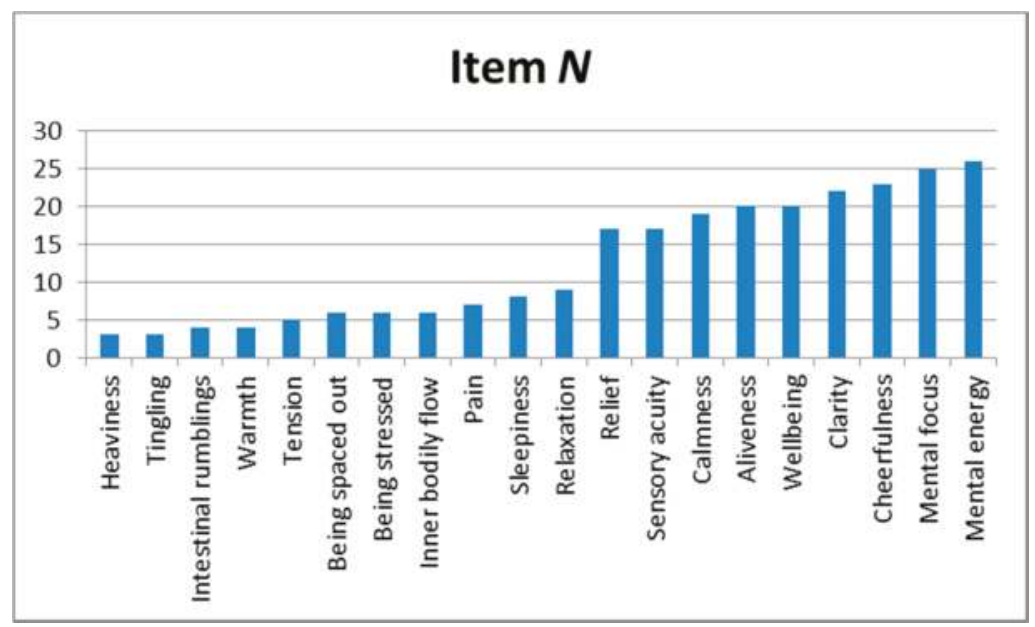

Figure 3. Number of times each item appeared in item pairs with a medium or high level of Cramer's V.

Using Cramer's V, there was a higher percentage (with a higher average V) of items showing significant EXPre 20 -EXPre 20 associations than of items with significant EXPre 20 -EXPost 20 or EXPost $_{20}$-EXPost 20 associations.

There are two subgroups of items here: a lower one (mean occurrence rate 5.5, range 3-9) and an upper one (mean occurrence rate 21.0, range 17-26). Of the EXPre 20 -EXPre 20 pairs, 24 of 35 (68.6\%) consisted of items only in the upper subgroup, of the EXPost ${ }_{20}$-EXPost 20 pairs, 28 of 46 (60.9\%), and of the EXPre 20 -EXPost 20 pairs, 31 of $46(67.4 \%)$. 


\subsubsection{Cluster Analysis}

Numbers of estimated clusters using Jaccard's index, Sokal and Sneath's index 5, and Ward's method are shown in Supplementary Materials Table S5. Items in the clusters obtained using the different methods were compared, and those for which there was the most agreement were selected.

A comparison between Cramer's V and Ward's proximities showed no obvious relationship between the two measures overall. However, in both EXPre 20 and EXPost 20 two clusters stood out from all the others, having the highest mean $\mathrm{V}$ and lowest mean proximity. These could be considered as clusters for "Relaxation" and "Alertness". The values of mean Ward proximities (W) and Cramer's V for the two clusters suggest that "Alertness" was the more robust of the two (Supplementary Materials Table S6). Other possible clusters were "Relief" and "Bodily sensation", but there was less agreement between EXPre $_{20}$ and EXPost 20 on the items included.

If the data was split by subgroup (CPD vs. student respondents, or with vs. without prior experience of EA/TENS), no combinations of items appeared in corresponding clusters for all four subgroups. In the EXPre 20 responses, the Calmness/Relaxation dyad did not appear in any cluster for those with no prior experience of EA/TENS, and in the EXPost 20 responses only in the student subgroup. In the EXPre 20 responses, the triad of Aliveness, Cheerfulness, and Mental focus appeared together in a cluster for all subgroups except for that of students, and that of Cheerfulness, Mental energy, and Mental focus in a cluster for all but the subgroup with prior experience of EA/TENS. In the EXPost $_{20}$ responses, the dyad of Aliveness and Mental energy and the tetrad of Cheerfulness, Clarity, Mental focus, and Sensory acuity appeared together (albeit in separate clusters) for all subgroups except for those with no prior experience of EA/TENS. Subgroup analysis was not carried out for the EXPre $_{20}$ and EXPost 20 items taken together.

\section{Discussion}

\subsection{Respondents}

The pattern evident in those respondents who only filled out the EXPre 20 and not the EXPost 20 questionnaire suggests that those who did not complete the second questionnaire (predominantly students) had not really become more interested in EA/TEAS after the course than they were before attending. This could reflect a failure of teaching skill on the part of the instructor, or a lack of openness to something outside the normal ("traditional") curriculum among students, for whom this was an obligatory session (whereas the CPD respondents signed up for their sessions because of an interest in what was being taught). In addition, some of the students will have left the session early to ensure they were able to catch their usual transport home.

Practitioners tended to have somewhat more prior experience of the EA and TENS modalities than students. Given that the students were all enrolled in "traditional" acupuncture training courses, this was to be expected, even if the difference between the practitioners and students did not reach significance in this respect.

Somewhat surprisingly, six of the 36 respondents who had prior experience of EA/TENS expected no change in "Tingling", whereas none of the 31 without such prior experience expected no change in "Tingling". Electricity is commonly associated with a "Tingling" feeling [8].

Those with no prior experience of EA/TENS showed less uncertainty in their expectations of increases or decreases in feelings than those who did have prior experience. Real life clinical experience may soften the certainty of preconceptions.

\subsection{Questionnaire Items-Overall Patterns}

Overall, students and practitioners scored the questionnaires in a similar way. In particular, whereas more respondents expected feelings to change than did not expect them to, fewer respondents actually experienced changes in feelings (cf [28]). Thus there were fewer EXPost 20 than EXPre 20 "Yes" responses, but more "No" responses. 
In contrast, more "increases" than "decreases" were both expected and experienced (with a slightly higher ratio of "increases" to "decreases" in EXPost 20 than EXPre 20 ). As there were fewer "Yes" counts following treatment than before, the EXPost $20 /$ EXPre $_{20}$ ratios for both "increases" and "decreases" were all $<1$.

\subsection{Individual Questionnaire Items-Expectations of Change, Increase and Decrease}

Some responses might be self-evident to anyone familiar with any complementary therapy: following a treatment, a change (increase) in relaxation or relief would be expected or hoped for, and also a change (decrease) in pain or tension.

Inner bodily flow (which might be expected on the basis of prior experience of or teachings on energy-based medicine [8], and could be interpreted by some respondents in terms of electrical current flow) was considered less likely to change or increase by those with prior experience. Heaviness and Sleepiness were both among those items considered least likely to change AND those items likely to decrease. Calmness and Heaviness were considered likely to change by CPD respondents, but less so by the students.

\subsection{Individual Questionnaire Items-Experiences of Change, Increase and Decrease}

The changes most commonly experienced (Pain, Relaxation, Tension, Tingling, Warmth) were similar to those expected (Pain, Relaxation, Relief, Tension, Tingling), with Relaxation, Tingling, and Warmth among the items most often increasing, and Pain and Tension among those most often decreasing. There was overall agreement between those items for which changes were most often experienced and those experienced with most intensity ("noticed most").

Sleepiness was among the items most experienced as not changing for the (CPD/no prior experience) respondents, Heaviness for the (student/no prior experience) respondents, and Calmness and Mental focus for all those with no prior experience. Conversely, Relief was among the items most experienced as changing for the CPD and no prior experience respondents. The no prior experience subgroup therefore appears to have had a different experience of what did and did not change than the others.

Of the 12 items showing significantly more increases than decreases in both $\mathrm{EXPre}_{20}$ and EXPost $_{20}$, all could be considered as "positive" in the sense of increasing with overall wellbeing rather than decreasing.

\subsection{Fulfilment of Expectation}

A key finding is that-as for the $\mathrm{EXP}_{32}$ questionnaires-expectations of change, whether negative or positive, were confirmed rather than not. Only in one cohort $(N=11)$ was this not the case.

Positive expectations of change were more marked among those with prior experience of EA/TENS than those without.

In contrast, expectations of increase or decrease were not fulfilled (rather than confirmed) by experience. However, there were significantly more counts of all four combinations of EXPre 20 and EXPost $_{20}$ " $\mathrm{i}$ " and " $\mathrm{d}$ " scores from respondents with prior experience of EA/TENS than from those without. Further study would be required to confirm these findings, as missing data rates were high (31 of 561 , or $5.5 \%$, for EXPre 20 , and 49 of 390 , or $12.6 \%$, for EXPost E $_{20}$ ).

That 10 out of the $59(17 \%)$ respondents who completed both the EXPre 20 and EXPost 20 questionnaires reported a change in Being stressed, whereas they had expected not to, is concordant with the experienced decreases shown in Table 3 above (where "Being stressed" was included among the items above the third quartile). Eleven (19\%) who were uncertain if they would experience a change in the feeling of Being stressed experienced no change, and $18(31 \%)$ who expected a change in the feeling of tension experienced no change.

Nine of those who were uncertain if they would experience a change in warmth in fact did (it being one of the items most experienced as increasing, as shown in Table 3), whereas 11 (19\%) 
who were uncertain if they would experience a change in Intestinal rumblings also did not (this, like Sensory acuity and Mental focus, being an item that was least experienced as either increasing or decreasing, as shown in Table 3).

Taking Table 2, Table 3 and Tables S2-S4 together, the salient items are Relaxation, Tingling and Warmth, and Pain and Tension. Future research into the feelings elicited by EA and TEAS should at least take these into account (Cheerfulness also appears frequently in the Tables, but mostly because little change in this feeling was expected or experienced).

Associations were more evident between $\mathrm{EXPre}_{20}-\mathrm{EXPre}_{20}$ item pairs than between EXPre $_{20}$-EXPost 20 or EXPost 20 -EXPost 20 pairs. Counts of items occurring in pairs with medium or high levels of Cramer's V showed that they fell into two groups, one of relatively low counts (range 3-9), and one with higher counts (range 17-26). Cluster analysis suggested the existence of two clusters for both EXPre 20 and EXPost 20 items, one which could be considered as indicating "Relaxation", and the other "Alertness". The latter appeared more robust; the two clusters considered together are redolent of the traditional acupuncture concepts of yin and yang [26].

Although there was no obvious relationship between Cramer's V and Ward's proximities, all but one of the items in the "Alertness" cluster were all in the higher count range for Cramer's V. In contrast, of the two items consistently occurring in the "Relaxation" cluster, the "Relaxation" item itself was in the lower count range (albeit at the top end of that range).

Further research using the $\mathrm{EXP}_{20}$ questionnaires should be conducted to replicate our findings and explore their application in different contexts, in particular in more rigorously designed clinical studies, and in relation to mainstream or CAM treatments other than EA. They could also be applied outside academic institutions, and even in everyday life situations. Such research should take into account the various issues flagged under "Limitations", described below.

\section{Conclusions}

Our main findings were that expectations of change, whether negative or positive, were confirmed rather than not, and that the changes most commonly experienced (Pain, Relaxation, Tension, Tingling, Warmth) were indeed similar to those expected (Pain, Relaxation, Relief, Tension, Tingling), with Relaxation, Tingling, and Warmth among the items most often increasing, and Pain and Tension among those most often decreasing. Cluster analysis suggested the existence of two primary clusters for both EXPre 20 and EXPost 20 items, one which could be considered as indicating "Relaxation" (consisting of the items Calmness and Relaxation), the other "Alertness" (Aliveness, Cheerfulness, [Clarity], Mental energy, Mental focus, and Sensory acuity).

It is hoped that the $\mathrm{EXP}_{20}$ questionnaires will be used by other researchers to replicate these findings, and also be developed further. It would be interesting, for example, to see whether results differ for men and women, and also whether different feelings are elicited by different types of acupuncture (in particular, sham acupuncture where significant debate exists surrounding the assumed inertia of the intervention $[21,35,36])$. They could perhaps also be used with outcome measures to explore whether "good responders" tend to experience complementary therapy treatments in a way that is different from those who respond less well.

\subsection{Limitations}

Attendees were not asked to provide information about their gender. Where available, this data was gathered retrospectively for each cohort, so that it is not possible to relate individuals' responses and their gender. Given the preponderance of women in the study (at least $68 \%$ and possibly as high as $81 \%$ ), it is highly likely that our results are valid for women alone, but further research will be required to confirm that findings are valid for men as well as for women.

CPD attendees were not asked how many years they had been in practice. Differences between them could have impacted both the treatments they gave and their expectations and experiences of treatment effects. It would require a larger study to explore this factor. 
CPD respondents attended these EA teaching sessions voluntarily, whereas the students did not. This may have had an impact on how seriously they took the task of completing the questionnaires. Nonetheless, this does not appear to have led to major differences between the $\mathrm{C}$ and $\mathrm{S}$ respondents (other than for Research question 1).

Because this study was conducted in teaching situations where attendees from different acupuncture training backgrounds were encouraged to explore the techniques of EA and TEAS for themselves, the treatments given were very heterogeneous. Beyond suggesting that it was good practice to obtain a deqi response before applying electrical stimulation through the needles, no attempt was made to control the needling technique or to change the methods of needling with which the attendees were already comfortable.

Furthermore, this is a small pilot study on participants familiar with acupuncture and the subjective sensations it may elicit. It is not known how far the results can be extrapolated to the wider population who are likely to be less familiar with such sensations, nor how they would be reflected in a purely clinical context.

A potential weakness in the test procedure concerns the contamination of responses to the later $\left(\right.$ ExPost $\left._{20}\right)$ questionnaire. Small group discussion on the EA/TEAS techniques used was encouraged during the treatment exchange sessions before this questionnaire was administered, so that even though individuals completed it independently, their responses may have been somewhat influenced by others' comments. However, it is important to note that this effect is likely to be minimal since time was limited, the treatment/discussion groups were indeed small ( $N=3$ or 4$)$, and the focus of the discussion was on the technicalities of EA/TEAS rather than on participants' subjective experience. Furthermore, although the "grain size" of the resulting ExPost 20 data may have been fairly coarse, it is highly unlikely that there was contamination between the small groups. In our view, despite the strong contrary opinion of our most rigorous anonymous reviewer, the results still support our conclusions regarding fulfillment of expectation, since: (A) the initial (ExPre 20 ) questionnaire was completed with no potential for contamination; (B) ExPost 20 was presented with a separately randomised question order, without recourse to ExPre 20 responses; (C) although there may conceivably have been contamination of responses within some of the small groups, it is highly unlikely that this was so consistent as to explain our findings; and (D) results were similar across the different cohorts. In other words, the experiences reported by the respondents were consistently in accord with and very likely influenced by their expectations (and not just their earlier reporting of expectations), and any within-group distortion was minimal.

Of course it must be kept in mind that the data analysed in the present study represent inherently subjective reports of feelings and experiences. There are therefore likely to be many factors contributing to the responses both to ExPre 20 and ExPost 20 , the fine-grain investigation of which was not within the scope of this present study.

Finally, whereas most respondents were able to score most items for expected or experienced changes, there were more lacunae in the data for increases/decreases. Because of this missing data, the results for expected/experienced increases and decreases are less certain, and should be confirmed in further studies with more respondents.

Supplementary Materials: The following are available online at www.mdpi.com/2305-6320/4/2/19/s1, Table S1: Respondent cohorts, Table S2: Differences between score counts (change/no change, increase/decrease) for the EXPre 20 and EXPost 20 items, Table S3: Questionnaire items with the highest counts for the various "expected" /"experienced" combinations, Table S4: Questionnaire items with the highest counts for the various "increase" and "decrease" combinations, Table S5: Numbers of estimated clusters of EXPre 20 , EXPost 20 and EXPre $_{20}$ and EXPost 20 items; Figure S1: Relationships between counts of expected and experienced increase (i) and decrease $(\mathrm{d})$ scores.

Acknowledgments: To those who supported the development of these questionnaires, in particular Tony Steffert and Tim Watson; to Louise Percival, market research consultant, for her input on the questionnaire design; to Neil Spencer for the clarity of his teaching on statistics; to Ian Appleyard, Angie Hicks, Linda Johnson, and Deborah Woolf for providing descriptive data on the course participants at extremely short notice; to Medicines' 
anonymous reviewers for their very helpful critiques, and to all our participants. No funding was received for this project.

Author Contributions: D.F.M. proposed the pilot study as part of an ongoing research project, completed the Ethics application, collected and analysed the data, and wrote the first draft of this paper. L.S.M. and H.C.M. critiqued and rewrote this draft.

Conflicts of Interest: The authors declare no conflict of interest.

Appendix A. The original 32-item questionnaires, EXPre 32 and EXPost ${ }_{32}$

\section{A-1. EXPre $_{32}$}

What do you expect from the electroacupuncture/TENS treatment you will receive today?

In one of the practical sessions today you will receive a session of electroacupuncture and/or TENS at one or two pairs of acupuncture points, such as LI-4 (Hegu) and ST-36 (Zusanli).

Do you expect to experience changes in any of the feelings listed below?

Instructions (please read carefully)

This questionnaire contains 32 statements about feelings.

For each feeling, ring the word/s that best represents your expectation of change in the feeling in your own case (this change may be an increase or a decrease):

Make sure that you ring the word/s in the correct column.

Please be as honest and accurate as you can throughout. Respond to each statement as if it were the only one. That is, don't worry about being 'consistent' in your responses. There are no 'correct' or 'incorrect' answers. Answer according to your own expectation, rather than how you think 'most acupuncturists' would answer.

I expect to experience a change in the feeling of ...

\begin{tabular}{||l|c|c|c||}
\hline Feeling & $\begin{array}{c}\text { Yes, I expect to } \\
\text { experience a change in } \\
\text { this feeling }\end{array}$ & $\begin{array}{c}\text { No, I do not expect to } \\
\text { experience } \\
\text { a change in this feeling }\end{array}$ & $\begin{array}{c}\text { I don't know if I } \\
\text { expect to experience } \\
\text { achange in this feeling }\end{array}$ \\
\hline 1. Aliveness & Yes & No & Don't know \\
\hline 2. Being at ease & Yes & No & Don't know \\
\hline $\begin{array}{l}\text { 3. Being blue or down } \\
\text { in the dumps }\end{array}$ & Yes & No & Don't know \\
\hline 4. Being in control & Yes & No & Don't know \\
\hline 5. Being spaced- out & Yes & No & Don't know \\
\hline 6. Calmness & Yes & No & Don't know \\
\hline 7. Cheerfulness & Yes & No & Don't know \\
\hline 8. Clarity & Yes & No & Don't know \\
\hline $\begin{array}{l}\text { 9. Connectedness with } \\
\text { others }\end{array}$ & Yes & No & Don't know \\
\hline 10. Contentment & Yes & No & Don't know \\
\hline 11. Excitement & Yes & No & Don't know \\
\hline 12. Heaviness & Yes & No & Don't know \\
\hline 13. Hunger & Yes & No & Don't know \\
\hline $\begin{array}{l}\text { 14. Inner bodily } \\
\text { awareness }\end{array}$ & Yes & & \\
\hline \hline
\end{tabular}




\begin{tabular}{||l|l|l|l||}
\hline \hline \multicolumn{3}{||}{} & \multicolumn{3}{|c||}{} \\
\hline $\begin{array}{l}\text { 15. Inner bodily flow } \\
\text { rumblings }\end{array}$ & Yes & No & Don't know \\
\hline 17. Mental energy & Yes & No & Don't know \\
\hline 18. Mental focus & Yes & No & Don't know \\
\hline 19. Nervousness & Yes & No & Don't know \\
\hline 20. Pain & Yes & No & Don't know \\
\hline 21. Peacefulness & Yes & No & Don't know \\
\hline 22. Physical vitality & Yes & No & Don't know \\
\hline 23. Receptivity & Yes & No & Don't know \\
\hline 24. Relaxation & Yes & No & Don't know \\
\hline 25. Restlessness & Yes & No & Don't know \\
\hline 26. Sensory acuteness & Yes & No & Don't know \\
\hline 27. Sleepiness & Yes & No & Don't know \\
\hline 28. Suppleness & Yes & No & Don't know \\
\hline 29. Tension & Yes & No & Don't know \\
\hline 30. Tingling & Yes & No & Don't know \\
\hline 31. Warmth or coolness & Yes & No & Don't know \\
\hline 32. Worry & Yes & No & Don't know \\
\hline \hline
\end{tabular}

If you have any comments you would like to make on this questionnaire, you can include them here:

\section{A-2. EXPost $_{32}$}

\begin{tabular}{|c|c|c|c|}
\hline \multicolumn{4}{|c|}{$\begin{array}{l}\text { What did you experience from the standardised electroacupuncture/TENS treatment you will receive } \\
\text { today? }\end{array}$} \\
\hline \multicolumn{4}{|c|}{ Did you experience changes in any of the feelings listed below? } \\
\hline \multicolumn{4}{|c|}{ Instructions (please read carefully) } \\
\hline \multicolumn{4}{|c|}{ This questionnaire contains 32 statements about feelings. } \\
\hline \multicolumn{4}{|c|}{$\begin{array}{l}\text { For each feeling, ring the word/s that best represents the change in feeling you experienced in your own } \\
\text { case (this change may have been an increase or a decrease): }\end{array}$} \\
\hline \multicolumn{4}{|c|}{ Make sure that you ring the word/s in the correct column. } \\
\hline \multicolumn{4}{|c|}{$\begin{array}{l}\text { Please be as honest and accurate as you can throughout. Respond to each statement as if it were the only } \\
\text { one. That is, don't worry about being 'consistent' in your responses. There are no 'correct' or 'incorrect' } \\
\text { answers. Answer according to what you experienced, rather than how you think 'most acupuncturists' } \\
\text { would answer. }\end{array}$} \\
\hline \multicolumn{4}{|c|}{ I experienced a change in the feeling of ... } \\
\hline Feeling & $\begin{array}{l}\text { Yes, I experienced a } \\
\text { change in this feeling }\end{array}$ & $\begin{array}{l}\text { No, I did not } \\
\text { experience a change in } \\
\text { this feeling }\end{array}$ & $\begin{array}{l}\text { I don't know if I } \\
\text { experienced a change } \\
\text { in this feeling }\end{array}$ \\
\hline 1. Aliveness & Yes & No & Don't know \\
\hline 2. Being at ease & Yes & No & Don't know \\
\hline $\begin{array}{l}\text { 3. Being blue or down } \\
\text { in the dumps }\end{array}$ & Yes & No & Don't know \\
\hline 4. Being in control & Yes & No & Don't know \\
\hline
\end{tabular}




\begin{tabular}{|c|c|c|c|}
\hline 5. Being spaced- out & Yes & $\mathrm{No}$ & Don't know \\
\hline 6. Calmness & Yes & No & Don't know \\
\hline 7. Cheerfulness & Yes & No & Don't know \\
\hline 8. Clarity & Yes & No & Don't know \\
\hline $\begin{array}{l}\text { 9. Connectedness with } \\
\text { others }\end{array}$ & Yes & No & Don't know \\
\hline 10. Contentment & Yes & No & Don't know \\
\hline 11. Excitement & Yes & No & Don't know \\
\hline 12. Heaviness & Yes & No & Don't know \\
\hline 13. Hunger & Yes & No & Don't know \\
\hline $\begin{array}{l}\text { 14. Inner bodily } \\
\text { awareness }\end{array}$ & Yes & No & Don't know \\
\hline 15. Inner bodily flow & Yes & No & Don't know \\
\hline $\begin{array}{l}\text { 16. Intestinal } \\
\text { rumblings }\end{array}$ & Yes & No & Don't know \\
\hline 17. Mental energy & Yes & No & Don't know \\
\hline 18. Mental focus & Yes & No & Don't know \\
\hline 19. Nervousness & Yes & No & Don't know \\
\hline 20. Pain & Yes & No & Don't know \\
\hline 21. Peacefulness & Yes & No & Don't know \\
\hline 22. Physical vitality & Yes & No & Don't know \\
\hline 23. Receptivity & Yes & No & Don't know \\
\hline 24. Relaxation & Yes & No & Don't know \\
\hline 25. Restlessness & Yes & No & Don't know \\
\hline 26. Sensory acuteness & Yes & No & Don't know \\
\hline 27. Sleepiness & Yes & No & Don't know \\
\hline 28. Suppleness & Yes & No & Don't know \\
\hline 29. Tension & Yes & No & Don't know \\
\hline 30. Tingling & Yes & No & Don't know \\
\hline $\begin{array}{l}\text { 31. Warmth or } \\
\text { coolness }\end{array}$ & Yes & No & Don't know \\
\hline 32. Worry & Yes & No & Don't know \\
\hline
\end{tabular}

Please asterisk $\left({ }^{*}\right)$ those changes you noticed most.

If you have any comments you would like to make on this questionnaire, you can include them here:

Appendix B. The revised 20-item questionnaires, EXPre 20 and EXPost 20.

\section{B-1. EXPre $_{20}$}

\section{Instructions}

\begin{tabular}{|l|l|l|}
\hline & \multicolumn{1}{c}{ Yes } & No \\
\hline First, please tell us if you have received EA or TEAS before & & \\
\hline
\end{tabular}

There are twenty FEELINGS listed on the following page which we would like you to consider carefully.

We would like to know if you expect any of these feelings to increase or decrease for you personally in response to the standardised EA or TEAS treatment that you will receive today.

This will be at points such as LI-4 (Hegu) and ST-36 (Zusanli). 


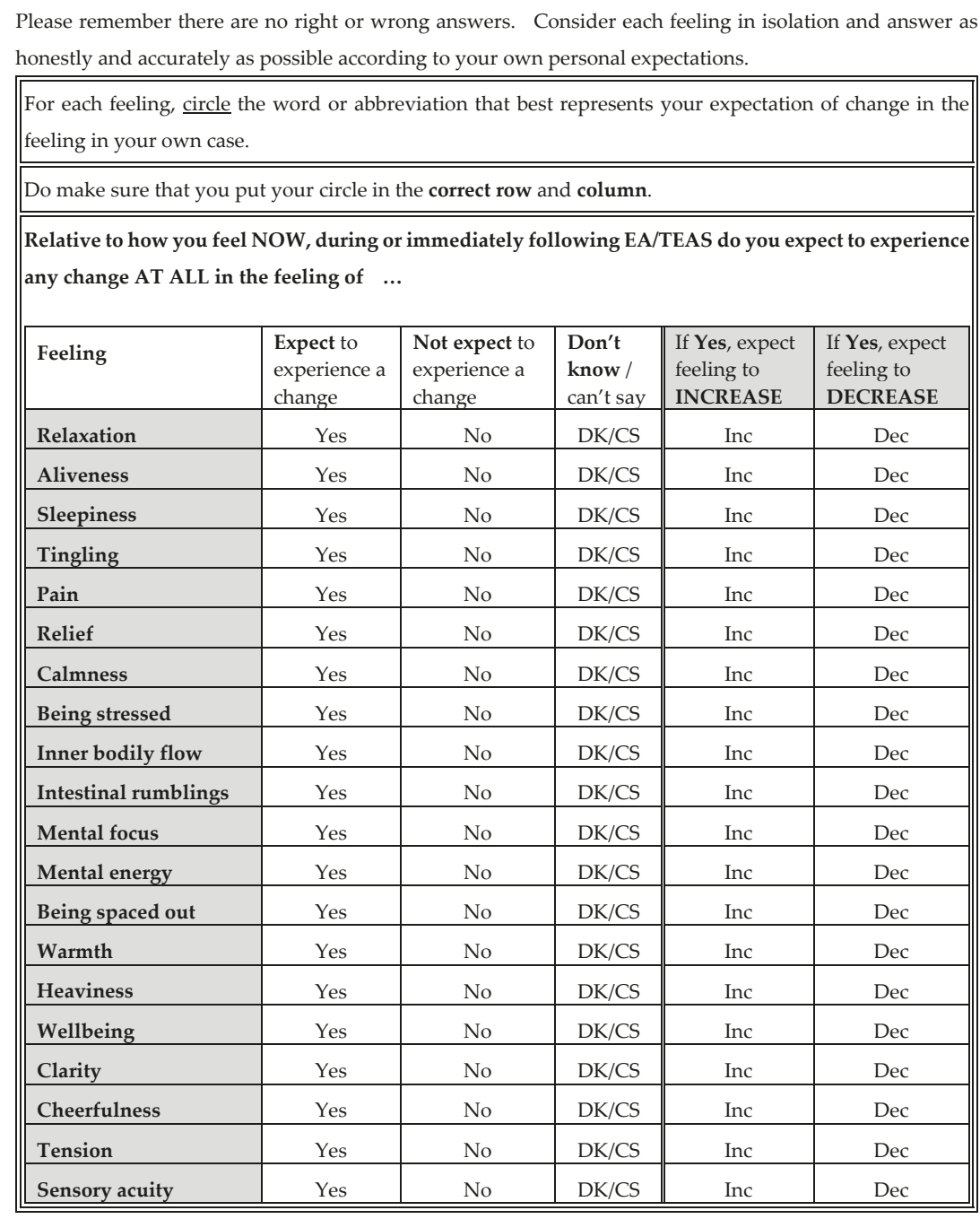

Do you have anything else you would like to add?

\section{B-2. EXPost $_{20}$}

\section{Instructions}

There are twenty FEELINGS listed on the following page which we would like you to consider carefully. 
We would like to know if you experienced any changes in these feelings in response to the standardised EA or TEAS treatment that you received today.

Please remember there are no right or wrong answers. Consider each feeling in isolation and answer as honestly and accurately as possible according to your own personal experience.

For each feeling, circle the word or abbreviation that best represents what you experienced in your own case.

Do make sure that you put your circle in the correct row and column.

\section{Please also asterisk $\left({ }^{*}\right)$ those 'Yes' changes you noticed most!}

Relative to how you felt when you completed the earlier questionnaire, during or immediately following EA/TEAS did you experience a change in the feeling of ...

\begin{tabular}{||l|c|l|l||c|c||}
\hline Feeling & $\begin{array}{l}\text { Experienced } \\
\text { a change }\end{array}$ & $\begin{array}{l}\text { Not } \\
\text { experienced a } \\
\text { change }\end{array}$ & $\begin{array}{l}\text { Don't } \\
\text { know } \\
\text { can't } \\
\text { say }\end{array}$ & $\begin{array}{l}\text { If Yes, } \\
\text { experienced } \\
\text { INCREASE } \\
\text { in feeling }\end{array}$ & $\begin{array}{l}\text { If Yes, } \\
\text { experienced } \\
\text { DECREASE } \\
\text { in feeling }\end{array}$ \\
\hline Pain & Yes & No & DK/CS & Inc & Dec \\
\hline Inner bodily flow & Yes & No & DK/CS & Inc & Dec \\
\hline Calmness & Yes & No & DK/CS & Inc & Dec \\
\hline Clarity & Yes & No & DK/CS & Inc & Dec \\
\hline Mental energy & Yes & No & DK/CS & Inc & Dec \\
\hline Tension & Yes & No & DK/CS & Inc & Dec \\
\hline Being spaced out & Yes & No & DK/CS & Inc & Dec \\
\hline Being stressed & Yes & No & DK/CS & Inc & Dec \\
\hline Warmth & Yes & No & DK/CS & Inc & Dec \\
\hline Wellbeing & Yes & No & DK/CS & Inc & Dec \\
\hline Heaviness & Yes & No & DK/CS & Inc & Dec \\
\hline Mental focus & Yes & No & DK/CS & Inc & Dec \\
\hline Sensory acuity & Yes & No & DK/CS & Inc & Dec \\
\hline Aliveness & Yes & No & DK/CS & Inc & Dec \\
\hline Relaxation & Yes & No & DK/CS & Inc & Dec \\
\hline Tingling & Yes & No & DK/CS & Inc & Dec \\
\hline Sleepiness & Yes & No & DK/CS & Inc & Dec \\
\hline Cheerfulness & No & DK/CS & Inc & Dec \\
\hline Intestinal rumblings & No & DK/CS & Inc & Dec \\
\hline Relief & & & Dec \\
\hline \hline
\end{tabular}




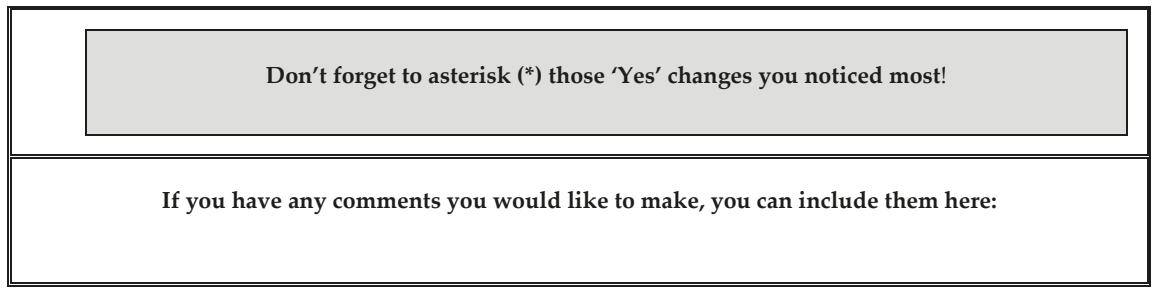

\section{References}

1. Mayor, D.F. What do we mean by the 'nonspecific' effects of acupuncture treatment? A survey of experienced acupuncture practitioners and researchers. Eur. J. Orient. Med. 2014, 7, 38-43.

2. Peters, D. (Ed.) Understanding the Placebo Effect in Complementary Medicine: Theory, Practice and Research; Churchill Livingstone: London, UK, 2001.

3. Caspi, O.; Bootzin, R.R. Evaluating how placebos produce change. Logical and causal traps and understanding cognitive explanatory mechanisms. Eval. Health. Prof. 2002, 25, 436-464. [CrossRef] [PubMed]

4. Walach, H.; Jonas, W.B. Placebo research: The evidence base for harnessing self-healing capacities. J. Altern. Complement. Med. 2004, 10 (Suppl. 1), S103-S112. [CrossRef] [PubMed]

5. Salih, N.; Bäumler, P.I.; Simang, M.; Irnich, D. Deqi sensations without cutaneous sensory input: Results of an RCT. BMC Complement. Altern. Med. 2010, 10, 81. [CrossRef] [PubMed]

6. Kerr, C.E.; Shaw, J.R.; Conboy, L.A.; Kelley, J.M.; Jacobson, E.; Kaptchuk, T.J. Placebo acupuncture as a form of ritual touch healing: A neurophenomenological model. Conscious. Cogn. 2011, 20, 784-791. [CrossRef] [PubMed]

7. Warber, S.L.; Cornelio, D.; Straughn, J.; Kile, G. Biofield energy healing from the inside. J. Altern. Complement. Med. 2004, 10, 1107-1113. [CrossRef] [PubMed]

8. Mayor, D. Elemental souls and vernacular qi: Some attributes of what moves us. In Energy Medicine East and West: A Natural History of qi; Mayor, D., Micozzi, M.S., Eds.; Churchill Livingstone: Edinburgh, UK, 2011; pp. 24-47.

9. Lundeberg, T. To be or not to be: The needling sensation (de qi) in acupuncture. Acupunct. Med. 2013, 31, 129-131. [CrossRef] [PubMed]

10. Pacheco-López, G.; Engler, H.; Niemi, M.B.; Schedlowski, M. Expectations and associations that heal: Immunomodulatory placebo effects and its neurobiology. Brain Behav. Immun. 2006, 20, 430-446. [CrossRef] [PubMed]

11. Geers, A.L.; Wellman, J.A.; Fowler, S.L.; Rasinski, H.M.; Helfer, S.G. Placebo expectations and the detection of somatic information. J. Behav. Med. 2011, 34, 208-217. [CrossRef] [PubMed]

12. Vincent, C.A.; Richardson, P.H.; Black, J.J.; Pither, C.E. The significance of needle placement site in acupuncture. J. Psychosom. Res. 1989, 33, 489-496. [CrossRef]

13. Park, H.; Park, J.; Lee, H.; Lee, H. Does deqi (needle sensation) exist? Am. J. Chin. Med. 2002, 30, 45-50. [CrossRef] [PubMed]

14. Park, J.; Park, H.; Lee, H.; Lim, S.; Ahn, K.; Lee, H. Deqi sensation between the acupuncture-experienced and the naïve: A Korean study II. Am. J. Chin. Med. 2005, 33, 329-337. [CrossRef] [PubMed]

15. Kong, J.; Fufa, D.T.; Gerber, A.J.; Rosman, I.S.; Vangel, M.G.; Gracely, R.H.; Gollub, R.L. Psychophysical outcomes from a randomized pilot study of manual, electro, and sham acupuncture treatment on experimentally induced thermal pain. J. Pain 2005, 6, 55-64. [CrossRef] [PubMed]

16. Kong, J.; Gollub, R.; Huang, T.; Polich, G.; Napadow, V.; Hui, K.; Vangel, M.; Rosen, B.; Kaptchuk, T.J. Acupuncture de $q i$, from qualitative history to quantitative measurement. J. Altern. Complement. Med. 2007, 13, 1059-1070. [CrossRef] [PubMed]

17. Kim, Y.; Park, J.; Lee, H.; Bang, H.; Park, H.J. Content validity of an acupuncture sensation questionnaire. J. Altern. Complement. Med. 2008, 14, 957-963. [CrossRef] [PubMed] 
18. White, P.; Bishop, F.; Hardy, H.; Abdollahian, S.; White, A.; Park, J.; Kaptchuk, T.J.; Lewith, G.T. Southampton needle sensation questionnaire: Development and validation of a measure to gauge acupuncture needle sensation. J. Altern. Complement. Med. 2008, 14, 373-379. [CrossRef] [PubMed]

19. Pach, D.; Hohmann, C.; Lüdtke, R.; Zimmermann-Viehoff, F.; Witt, C.M.; Thiele, C. German translation of the Southampton Needle Sensation Questionnaire: use in an experimental acupuncture study. Forsch. Komplementmed. 2011, 18, 321-326. [CrossRef] [PubMed]

20. Yu, D.T.; Jones, A.Y.; Pang, M.Y. Development and validation of the Chinese version of the Massachusetts General Hospital Acupuncture Sensation Scale: An exploratory and methodological study. Acupunct. Med. 2012, 30, 214-221. [CrossRef] [PubMed]

21. Bauml, J.; Xie, S.X.; Farrar, J.T.; Bowman, M.A.; Li, S.Q.; Bruner, D.; DeMichele, A.; Mao, J.J. Expectancy in real and sham electroacupuncture: Does believing make it so? J. Natl. Cancer Inst. Monogr. 2014, 2014, 302-307. [CrossRef] [PubMed]

22. Judge, A.; Cooper, C.; Arden, N.K.; Williams, S.; Hobbs, N.; Dixon, D.; Günther, K.P.; Dreinhoefer, K.; Dieppe, P.A. Pre-operative expectation predicts 12-month post-operative outcome among patients undergoing primary total hip replacement in European orthopaedic centres. Osteoarthr. Cartil. 2011, 19, 659-667. [CrossRef] [PubMed]

23. Kongsted, A.; Vach, W.; Axø, M.; Bech, R.N.; Hestbaek, L. Expectation of recovery from low back pain: A longitudinal cohort study investigating patient characteristics related to expectations and the association between expectations and 3-month outcome. Spine 2014, 39, 81-90. [CrossRef] [PubMed]

24. Vîslă, A.; Constantino, M.J.; Newkirk, K.; Ogrodniczuk, J.S.; Söchting, I. The relation between outcome expectation, therapeutic alliance, and outcome among depressed patients in group cognitive-behavioral therapy. Psychother. Res 2016, 1-11. [CrossRef]

25. Roccia, L.; Rogora, G.A. [Acupuncture and relaxation]. Minerva Med. 1976, 67, 1918-1920. [PubMed]

26. Wang, R.R. Yinyang (Yin-Yang). Internet Encyclopedia of Philosophy: A Peer-Reviewed Academic Resource. Available online: http:/ / www.iep.utm.edu/yinyang/ (accessed on 26 February 2017).

27. Mayor, D.F. (Ed.) Electroacupuncture: A Practical Manual and Resource; Churchill Livingstone: Edinburgh, UK, 2007.

28. Mayor, D.; Steffert, T. Expectation and Experience of 'Nonspecific' Feelings Elicited by Acupuncture: Developing and Piloting a Set of Questionnaires. In Proceedings of the British Medical Acupuncture Society (BMAS) and Portuguese Medical Acupuncture Society (PMAS) Autumn Meeting, Porto, Portugal, 27-29 September 2013; Available online: http://www.qeeg.co.uk/electroacupuncture/eaq1.htm or http:/ /f1000research.com/posters/1094397 (accessed on 17 October 2015).

29. Steffert, T.; Mayor, D. Mood changes in response to electroacupuncture treatment in a classroom situation. Personality type, emotional intelligence and prior acupuncture experience, with an exploration of Shannon entropy, response style and graphology variables. In Proceedings of the 19th International Acupuncture Research Symposium, London, UK, 25 March 2017.

30. Mayor, D.F. Expectation and experience of 'nonspecific' (whole person) feelings elicited by acupuncture: Content validity of a set of questionnaires. Ger. J. Acupunct. Relat. Tech. 2014, 57, 14-19. [CrossRef]

31. Hierarchical Cluster Analysis Measures for Binary Data. IBM Knowledge Center, 2011. Available online: http:/ /www-01.ibm.com/support/knowledgecenter/SSLVMB_20.0.0/com.ibm.spss.statistics.help/ cmd_cluster_measure_binary.htm (accessed on 16 October 2015).

32. Spencer, N. Cluster Analysis seminar. Statistical Services and Consultancy Unit; University of Hertfordshire: Hatfield, UK, 2015.

33. Keshet, Y.; Simchai, D. The 'gender puzzle' of alternative medicine and holistic spirituality: A literature review. Soc. Sci. Med. 2014, 113, 77-86. [CrossRef] [PubMed]

34. Gravetter, F.J.; Wallnau, L.B. Study Guide: Essentials of Statistics for the Behavioral Sciences, 6th ed.; Thomson/Wadsworth: Belmont, CA, USA, 2008. 
35. Lund, I.; Lundeberg, T. Are minimal, superficial or sham acupuncture procedures acceptable as inert placebo controls? Acupunct. Med. 2006, 24, 13-15. [CrossRef] [PubMed]

36. Lundeberg, T.; Lund, I.; Sing, A.; Näslund, J. Is placebo acupuncture what it is intended to be? Evid. Based Complement. Alternat. Med. 2011, 2011, 932407. [CrossRef] [PubMed]

(c) (1)

(C) 2017 by the authors. Licensee MDPI, Basel, Switzerland. This article is an open access article distributed under the terms and conditions of the Creative Commons Attribution (CC BY) license (http:/ / creativecommons.org/licenses/by/4.0/). 
Article

\title{
A Population-Based Cohort Study on the Ability of Acupuncture to Reduce Post-Stroke Depression
}

\author{
Shuo-Ping Tseng ${ }^{1}$, Yu-Ching Hsu ${ }^{2, *}$, Ching-Ju Chiu ${ }^{3, *}$ and Shang-Te $\mathrm{Wu}^{4}$ \\ 1 Department of Chinese Medicine, Tainan Municipal Hospital, Tainan 700, Taiwan; cfc54321@gmail.com \\ 2 Department of Chinese Medicine, Tainan Hospital, Ministry of Health and Welfare, Tainan 701, Taiwan \\ 3 Institute of Gerontology, College of Medicine, National Cheng Kung University, Tainan 701, Taiwan \\ 4 Department of Internal Medicine and Neurology, Kuo General Hospital, Tainan 700, Taiwan; \\ wst31853@yahoo.com.tw \\ * Correspondence: yuchinghsupro@gmail.com (Y.-C.H.); cjchiu@mail.ncku.edu.tw (C.-J.C.); \\ Tel.: +886-6220-0055 (ext. 3086) (Y.-C.H.); +886-6235-3535 (ext. 5739) (C.-J.C.); \\ Fax: +886-6222-2236 (Y.-C.H.); +886-6302-8175 (C.-J.C.)
}

Academic Editors: Gerhard Litscher and William Chi-shing Cho

Received: 17 January 2017; Accepted: 8 March 2017; Published: 15 March 2017

\begin{abstract}
Objective: Post-stroke depression (PSD) is common and has a negative impact on recovery. Although many stroke patients in Taiwan have used acupuncture as a supplementary treatment for reducing stroke comorbidities, little research has been done on the use of acupuncture to prevent PSD. Accordingly, our goal is to investigate whether using acupuncture after a stroke can reduce the risk of PSD. Method: This population-based cohort study examined medical claims data from a random sample of 1 million insured people registered in Taiwan. Newly diagnosed stroke patients in the period 2000-2005 were recruited in our study. All patients were followed through to the end of 2007 to determine whether they had developed symptoms of depression. A Cox proportional hazard model was used to estimate the relative risk of depression in patients after being diagnosed as having had a stroke, with a focus on the differences in those with and without acupuncture treatment. Results: A total of 8487 newly-diagnosed stroke patients were included in our study; of these, 1036 patients received acupuncture more than five times following their stroke, 1053 patients received acupuncture 1-5 times following their stroke and $6398 \mathrm{did}$ not receive acupuncture. After we controlled for potential confounders (e.g., age, sex, insurance premium, residential area, type of stroke, length of hospital stay, stroke severity index, rehabilitation and major illness-related depression), we found that acupuncture after stroke significantly reduced the risk of depression, with a hazard ratio (HR) of 0.475 (95\% CI, 0.389-0.580) in frequent acupuncture users and 0.718 (95\% CI, 0.612-0.842) in infrequent acupuncture users, indicating that acupuncture may lower the risk of PSD by an estimated $52.5 \%$ in frequent users and $28.2 \%$ in infrequent users. Conclusions: After we controlled for potential confounders, it appears that using acupuncture after a stroke lowers the risk of depression. Additional strictly-designed randomized controlled trials are needed to better understand the specific mechanisms relating acupuncture to health outcomes.
\end{abstract}

Keywords: post-stroke depression; acupuncture

\section{Introduction}

Strokes are the third leading cause of death and the most common cause of complex disability in Taiwan [1]. Many medical complications of stroke are common and often lead to poor clinical outcomes, such as depression, known as post-stroke depression (PSD). PSD has a high prevalence and a negative impact on stroke patients' long-term survival and well-being [2]. Thus, it is important to reduce or prevent PSD in stroke survivors. 
Many studies have evaluated various approaches to prevent PSD, including pharmacological therapy and psychotherapy. In some clinical trials, medicines such as Escitalopram and Duloxetine have shown some effectiveness in preventing PSD; however, most remedies had small treatment effect [3]. Other studies have also revealed that rehabilitation after a stroke may have positive effects in preventing PSD [4].

Traditional Chinese medicine (TCM) is classified as one form of complementary and alternative medicine (CAM) and is popular in Asian countries; for example, $52.7 \%$ of stroke patients receive both Chinese herbal remedies and acupuncture/traumatology treatment in Taiwan [5]. Some studies have reported that acupuncture may be effective in preventing PSD; however, such studies have so far been either too small or lacking big data analysis. If a case is to be made for the usefulness of acupuncture in relation to PSD, it is imperative to provide empirical evidence showing its positive effects on stroke patients' psychological well-being.

Potential confounders related to PSD have been explored, including gender (female) [6], disabilities, comorbidities [7], stroke severity [8], pre-stroke depression [9], cognitive impairment after stroke, dysphagia [10], incontinence [10], anxiety, and social isolation at follow-up [10]. In order to evaluate the preventive effect of acupuncture after subjects have been diagnosed as having had a stroke, a more rigorous study must be performed. In response, the main purpose of this study was to investigate whether acupuncture treatment after stroke attack reduces the risk of PSD after empirically controlling for covariates during the observation period.

\section{Materials and Method}

\subsection{Source of Data}

Our study used reimbursement claims data obtained from the National Health Insurance Research Dataset (NHIRD) in Taiwan. The NHIRD covers more than $99 \%$ of the population and has contracts with $97 \%$ of the hospitals and clinics in Taiwan [11]. The National Health Research Institute maintains and updates the NHIRD. The institute has publicly released a sub-dataset composed of claims data for $1,000,000$ randomly selected insurance enrollees for research and administrative purposes. This random subgroup represents approximately $5 \%$ of the entire insured population in Taiwan. This sub-dataset, consisting of a longitudinal health insurance database for 2005 (LHID2005), was employed for this study after obtaining approval from the National Health Research Institute review committee. For data analysis, we retrieved information about patients' characteristics and medical care records by linking ambulatory care visit claims, in-patient expenditures by admissions, and the registry for beneficiaries. Secondary data were collected and administered by the Taiwan National Institute of Family Planning (now the Bureau of Health Promotion, BHP), and approved by their IRB. All data analyzed in this study were anonymized.

\subsection{Participants and End-Point}

Patients who were newly diagnosed with a stroke (ICD-9-CM codes: 430-434, 436-437) between 2000 and 2005 were included in this study. We excluded patients who had had a head injury before 2000 $(N=340)$; who had suffered from depression before their stroke $(N=1381)$; who were not insured or had died within 3 months of suffering the stroke $(N=256)$; had sought ambulatory care for depression within the first 3 months following their stroke $(N=58)$; or had not had an acupuncture interval for more than six months $(N=98)$. The study criteria, the exclusion criteria, and the follow-up procedure are presented in Figure 1.

In Taiwan, TCM doctors must finish a training course in Chinese medicine and acupuncture and pass the national examination before they are certified to practice and, thereafter, qualified for filing $\mathrm{NHI}$ claims for acupuncture reimbursement. We classified the stroke patients into two groups based upon their acupuncture use or non-use after their stroke: (1) acupuncture users: those who received six or more or 1-5 acupuncture treatments after being diagnosed with a stroke from 2000 to 2007 
(respectively $N=1036,12.21 \%$; and $N=1053,12.41 \%$ ); these were respectively called frequent and infrequent users; and (2) acupuncture non-users: those who were defined as reporting no acupuncture received after their stroke from 2000 to $2007(N=6398,75.39 \%)$.

\begin{tabular}{|c|c|c|c|}
\hline \multicolumn{3}{|c|}{ Newly reported first stroke patients in 2000-2005 } & $n=10.620$ \\
\hline \multicolumn{4}{|c|}{ Excluded } \\
\hline & Head injury & & $n=340$ \\
\hline & Previous depressi & & $n=1.381$ \\
\hline$\longrightarrow$ & \multicolumn{3}{|c|}{ Not in insurance or death within 3 months after first stroke $n=256$} \\
\hline & \multicolumn{3}{|c|}{ Depression within 3 months after first stroke $\quad n=58$} \\
\hline & \multicolumn{3}{|c|}{ Had not had an acupuncture interval for more than six months $n=98$} \\
\hline \multicolumn{4}{|c|}{ Patients who received acupuncture } \\
\hline \multicolumn{4}{|c|}{ Frequent users $\quad n=1.036$} \\
\hline \multicolumn{4}{|c|}{ Infrequent users } \\
\hline \multicolumn{4}{|c|}{ Did not receive acupuncture } \\
\hline
\end{tabular}

Figure 1. Flow chart showing details of subject recruitment from the National Health Insurance Research Dataset (NHIRD) of Taiwan for the years 2000 to 2005.

The Diagnostic and Statistical Manual (DSM) IV categorizes PSD as a "mood disorder due to a general medical condition (i.e., stroke)" with certain depressive features serving as specifiers, for example, major depressive-like episodes, manic features, or mixed features [12]. The patients were linked to the ambulatory care visit claims and inpatient expenditures by admissions claims during the years 2000-2007 to identify possible treatment for depression. The follow-up ended on the date of depression diagnosis (diagnosed according to ICD-9-CM code 296, 309, or 311, or A-code A212 or A219) in outpatient care or on the date of censoring, which was either the date of withdrawal (including death) from the NHI program or the date of the follow-up end (i.e., 31 December 2007).

\subsection{Covariates}

The covariates considered in our analysis include socio-economic factors and covariates related to stroke severity or progress. The socio-economic factors include gender, age, living area (categorized as "urban area", "satellite city", and "rural area") [13], and insurance premium (categorized as " $<15,000$ New Taiwan Dollars (NTD)", and “ $\geq 15,000$ NTD”).

The covariates related to stroke severity or progress include type of stroke (categorized as hemorrhagic, occlusion or others (e.g., transient ischemic attack)), length of hospital stay, rehabilitation after stroke in 3 months, comorbidities that are correlated to depression or disability, such as cancer (ICD-9-CM code: 140-208), arthritis or rheumatism (ICD-9-CM code: 714.0, 729.0), chronic obstructive pulmonary disease (ICD-9-CM code: 490-496), peripheral arterial disease (ICD-9-CM code: 440-449), diabetes (ICD-9-CM code: 250) chronic kidney disease (ICD-9-CM: 585) and ranking according to the stroke severity index (SSI). The SSI is an index that estimates a stroke's severity by using six items listed in the hospitalization data in the NHI database [14], namely airway suction, bacterial sensitivity test, general ward stay, intensive care unit stay, nasogastric intubation, osmotherapy, and urinary catheterization.

\subsection{Statistical Analysis}

A chi-square test was used to compare differences in age, sex, residential area, insurance premium, type of stroke, length of hospital stay, and the aforementioned comorbidities between 
groups. A Kaplan-Meier analysis was performed for censored graft survival. To assess the independent effects of acupuncture on the risk of depression, we conducted a Cox proportional hazard regression analysis with age, sex, insurance premium, urbanization level, SSI, rehabilitation after stroke in three months, and selected comorbidities adjusted simultaneously in the model. We also adjusted the urbanization level to account for the urban rural difference in accessibility to medical care in Taiwan. All statistical analyses were performed using SAS (version 9.4, SAS Institute, Inc., Cary, NC, USA), in which a $p$-value $<0.05$ was considered statistically significant.

\section{Results}

\subsection{Sample Characteristics}

Characteristics of the newly-diagnosed stroke patients based on whether they are acupuncture users or non-users are presented in Table 1. A total of 8487 newly-diagnosed stroke patients were included in our study, 1036 patients defined as higher acupuncture users, 1053 patients defined as lower acupuncture users and 6735 patients defined as acupuncture non-users after stroke diagnosis. According to Table 1, stroke patients who received frequent acupuncture treatment were, on average, younger, more likely to live in an urban area, of higher economic status, more likely to have had a hemorrhagic stroke, and had more hospitalization days compared to nonusers. Both frequent or infrequent acupuncture users also received more rehabilitation treatment than non-users. The three participating groups also had different comorbid diseases, including rheumatoid arthritis, peripheral arterial disease, diabetes or hypertension. However, other factors such as gender, comorbidities with myocardial infarction, cancer, chronic kidney disease, chronic obstructive pulmonary disease or head traumatic injury were not statistically different between frequent and infrequent users and non-users. It was found that patients not using acupuncture treatment had a higher chance of being diagnosed with PSD or withdrawal (including death) from the NHI program than those in both the frequent and infrequent acupuncture groups. Over a 7-year follow-up, 110 patients (10.62\%) from the frequent acupuncture group, 177 patients (16.81\%) from the infrequent acupuncture group and 1551 non-users (24.24\%) developed PSD.

Table 1. Demographic characteristics between frequent, infrequent acupuncture users and non-users in patients using acupuncture with newly diagnosed strokes from the 1-million enrollee random sample of the National Health Insurance Research Database (NHIRD) from 2000 to 2007 in Taiwan.

\begin{tabular}{|c|c|c|c|c|}
\hline Characteristic & $\begin{array}{c}\text { Frequent } \\
\text { Acupuncture Users a } \\
(N=1036,12.21 \%)\end{array}$ & $\begin{array}{c}\text { Infrequent } \\
\text { Acupuncture Users b } \\
(N=1053,12.41 \%)\end{array}$ & $\begin{array}{c}\text { Acupuncture } \\
\text { Non-Users }{ }^{c} \\
(N=6398,75.39 \%)\end{array}$ & $p$ Value \\
\hline Female $(\%)$ & $444(42.86)$ & $425(40.36)$ & $2622(40.98)$ & 0.378 \\
\hline Age of diagnosis (Mean \pm SD) & $61.28 \pm 13.19$ & $61.77 \pm 13.59$ & $66.21 \pm 14.35$ & $<0.001$ \\
\hline Follow-up time (year) (Mean $\pm S D$ ) & $4.67 \pm 1.78$ & $4.82 \pm 1.76$ & $4.28 \pm 1.87$ & $<0.001$ \\
\hline Living area $(\%)$ & & & & $<0.001$ \\
\hline Urban area & $307(30.10)$ & $275(26.52)$ & $1471(23.45)$ & \\
\hline Satellite city & $303(29.71)$ & $305(29.41)$ & $1668(26.59)$ & \\
\hline Rural area & $410(40.20)$ & $457(44.07)$ & 3133 (49.95) & \\
\hline Insurance income ranks (\%) $\mathrm{d}, \mathrm{e}$ & & & & $<0.001$ \\
\hline$<15,000 \mathrm{NTD}$ & $320(30.89 \%)$ & $314(29.82)$ & $2379(37.18 \%)$ & \\
\hline$\geq 15,000 \mathrm{NTD}$ & $716(69.11 \%)$ & $739(70.18)$ & $4019(62.82 \%)$ & \\
\hline Type of stroke & & & & $<0.001$ \\
\hline hemorrhagic stroke & $261(25.19)$ & $217(20.61)$ & $1288(20.13)$ & \\
\hline occlusion stroke & $617(59.56)$ & $647(61.44)$ & $3923(61.32)$ & \\
\hline unknown & $158(15.25)$ & $189(17.95)$ & $1187(18.55)$ & \\
\hline Hospitalization days & & & & $<0.001$ \\
\hline$\leq 7$ days & $458(44.21)$ & $536(50.90)$ & $3540(52.20)$ & \\
\hline $8-14$ days & $253(24.42)$ & $298(28.30)$ & $1626(25.52)$ & \\
\hline 15-21 days & $111(10.71)$ & $74(7.03)$ & $541(8.46)$ & \\
\hline $22-28$ days & $63(6.08)$ & $52(4.94)$ & $316(4.94)$ & \\
\hline$\geq 28$ days & $151(14.58)$ & $93(8.83)$ & $575(8.99)$ & \\
\hline \multicolumn{5}{|l|}{ Comorbidities ${ }^{f}$} \\
\hline Rheumatoid arthritis (\%) & $91(8.78)$ & $83(7.88)$ & $440(6.88)$ & 0.018 \\
\hline Peripheral arterial disease (\%) & $265(25.58)$ & $234(22.22)$ & $1216(19.01)$ & $<0.001$ \\
\hline
\end{tabular}


Table 1. Cont.

\begin{tabular}{|c|c|c|c|c|}
\hline Characteristic & $\begin{array}{c}\text { Frequent } \\
\text { Acupuncture Users }^{\text {a }} \\
(N=1036,12.21 \%)\end{array}$ & $\begin{array}{c}\text { Infrequent } \\
\text { Acupuncture Users } \\
(N=1053,12.41 \%)\end{array}$ & $\begin{array}{c}\text { Acupuncture } \\
\text { Non-Users }^{c} \\
(N=6398,75.39 \%)\end{array}$ & $p$ Value \\
\hline Myocardial infarction (\%) & $50(4.83)$ & $54(5.13)$ & $278(4.35)$ & 0.312 \\
\hline Cancer $(\%)$ & $152(14.67)$ & $173(16.43)$ & $919(14.36)$ & 0.400 \\
\hline Diabetes (\%) & $531(51.25)$ & $520(49.38)$ & $2989(46.72)$ & 0.003 \\
\hline Hypertension (\%) & $873(84.27)$ & $887(84.24)$ & $5160(80.65)$ & $<0.001$ \\
\hline Chronic kidney diseases (\%) & $112(10.81)$ & $110(10.45)$ & 767 (11.99) & 0.140 \\
\hline Chronic obstructive pulmonary diseases (\%) & $554(53.47)$ & $572(54.32)$ & $3592(56.14)$ & 0.070 \\
\hline Head traumatic injury $(\%)$ & $23(2.22)$ & $31(2.94)$ & $231(3.33)$ & 0.055 \\
\hline Rehabilitation $\mathrm{g}$ & $390(37.64)$ & $295(28.02)$ & $1126(17.60)$ & $<0.001$ \\
\hline $\mathrm{SSI}(\text { Mean } \pm \mathrm{SD})^{\mathrm{h}}$ & $-0.16 \pm 1.39$ & $-0.35 \pm 1.22$ & $-0.14 \pm 1.40$ & $<0.001$ \\
\hline \multicolumn{5}{|l|}{ Censor after stroke ${ }^{i}$} \\
\hline Yes & $110(10.62)$ & $177(16.81)$ & $1551(24.24)$ & $<0.001$ \\
\hline
\end{tabular}

\begin{abstract}
Abbreviation: NHIRD = National Health Insurance Research Database; SD = standard deviation; NTD = New Taiwan Dollar. ${ }^{a}$ Frequent acupuncture users: Subjects received six or more acupuncture treatments between 2000 and 2007 after stroke diagnosis; ${ }^{b}$ Infrequent acupuncture users: Subjects received 1-5 acupuncture treatments between 2000 and 2007 after stroke diagnosis; ${ }^{c}$ Acupuncture non-users: Subjects did not receive any acupuncture treatment between 2000 and 2007 after stroke diagnosis; ${ }^{d}$ The income-related insurance payment category set by the Bureau of National Health Insurance in Taiwan; ${ }^{\mathrm{e}} 1 \mathrm{US} \$=30$ NTD (New Taiwan Dollars); ${ }^{\mathrm{f}}$ Comorbidities $=$ Medical illness, including rheumatoid arthritis, peripheral arterial disease, myocardial infarction, cancer, diabetes, hypertension, chronic kidney diseases, chronic obstructive pulmonary disease, and head traumatic injury, which are related to acupuncture use and depression; $g$ Rehabilitation: had rehabilitation in the 3 months after stroke; h SSI = Stroke severity index; ${ }^{\mathrm{i}}$ Censor after stroke: Subjects sought ambulatory care for depression in outpatient care after stroke diagnosis between 2000 and 2005 or withdrew (including death) from the NHI program in 2000-2007.
\end{abstract}

\title{
3.2. Cox Proportional Hazard Regression Analysis
}

Figure 2 compares the Kaplan-Meier Survival Curves of depression between patients in the frequent and infrequent acupuncture treatment groups and the non-user group. As can be seen, patients with acupuncture treatment after stroke had a significantly lower risk of depression over the study period ( $p$ value for log-rank test $\leq 0.0001$ ).

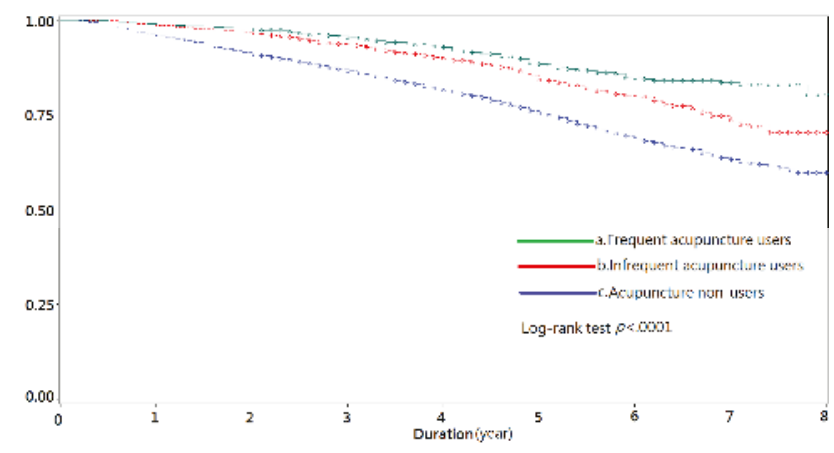

Figure 2. Kaplan-Meier Survival Curves of depression for comparing frequent acupuncture users, infrequent acupuncture users and non-users. a. Frequent acupuncture users: Subjects received six or more acupuncture treatments between 2000 and 2007 after stroke diagnosis; b. Infrequent acupuncture users: Subjects received 1-5 acupuncture treatments between 2000 and 2007 after stroke diagnosis; c. Acupuncture non-users: Subjects did not receive any acupuncture treatment between 2000 and 2007 after stroke diagnosis.

In Table 2, after controlling for potential confounders (e.g., age at diagnosis, gender, insurance premium level, living area, type of stroke, length of hospital stay, SSI, rehabilitation and major illness-related depression), acupuncture treatment after stroke appeared to significantly reduce the risk of PSD, with a hazard ratio (HR) of 0.475 (95\% CI, 0.389-0.580) and 0.718 (95\% CI, 0.612-0.842) for the frequent and infrequent acupuncture groups, respectively. In the multivariate analysis, females 
had a lower risk of depression than males (HR $=0.777 ; 95 \% \mathrm{CI}, 0.705-0.856)$. Stroke patients with longer hospital stays, who are older, or have higher SSI tended to be at significantly greater risk of PSD after their stroke than the other patients in this study (HR $=1.098 ; 95 \% \mathrm{CI}, 1.053-1.145 ; \mathrm{HR}=1.045$; $95 \%$ CI, 1.040-1.050; HR $=1.210 ; 95 \%$ CI, 1.166-1.256, respectively). Comorbidity with myocardial infarction $(\mathrm{HR}=1.298 ; 95 \% \mathrm{CI}, 1.080-1.559)$, cancer $(\mathrm{HR}=1.423 ; 95 \% \mathrm{CI}, 1.268-1.597)$, diabetes $(\mathrm{HR}=1.136 ; 95 \% \mathrm{CI}, 1.032-1.251)$, chronic kidney diseases $(\mathrm{HR}=1.519 ; 95 \% \mathrm{CI}, 1.345-1.715)$, chronic obstructive pulmonary disease $(\mathrm{HR}=1.219 ; 95 \% \mathrm{CI}, 1.097-1.355)$ or traumatic head injury $(\mathrm{HR}=1.629$; 95\% CI, 1.335-1.988) also showed higher risk than those without these comorbidities. However, stroke patients living in urban areas, with peripheral arterial disease or hypertension had a lower risk of PSD after stroke diagnosis $(\mathrm{HR}=0.836 ; 95 \% \mathrm{CI}, 0.738-0.947$; $\mathrm{HR}=0.878$; $95 \% \mathrm{CI}, 0.781-0.986$; $\mathrm{HR}=0.844$; $95 \%$ CI, 0.744-0.956, respectively). Meanwhile, economic status, rehabilitation, and presence of comorbid diseases with rheumatoid arthritis were not significantly more likely to be correlated with PSD risk. However, different risk of PSD development was found between hemorrhagic stroke and other types of stroke ( $\mathrm{HR}=0.796 ; 95 \% \mathrm{CI}, 0.676-0.936$ ). We further analyzed the effects of acupuncture treatment in developing PSD in hemorrhagic stroke and occlusion stroke (Table 3). The results suggest that occlusion-stroke patients receiving acupuncture treatment (either frequent or infrequent) would decrease the risk of developing PSD ( $\mathrm{HR}=0.499 ; 95 \% \mathrm{CI}, 0.391-0.638$; $\mathrm{HR}=0.707 ; 95 \% \mathrm{CI}, 0.578-0.865$, respectively). In addition, patients with hemorrhagic stroke that received frequent acupuncture treatments appeared to minimize the risk of PSD (HR = 0.446; 95\% CI, 0.283-0.702); however, those in the infrequent acupuncture group had no significant benefit over the non-users group ( $\mathrm{HR}=0.831$; $95 \%$ CI, 0.577-1.196).

Table 2. Multivariable adjusted hazard ratios of covariates for depression.

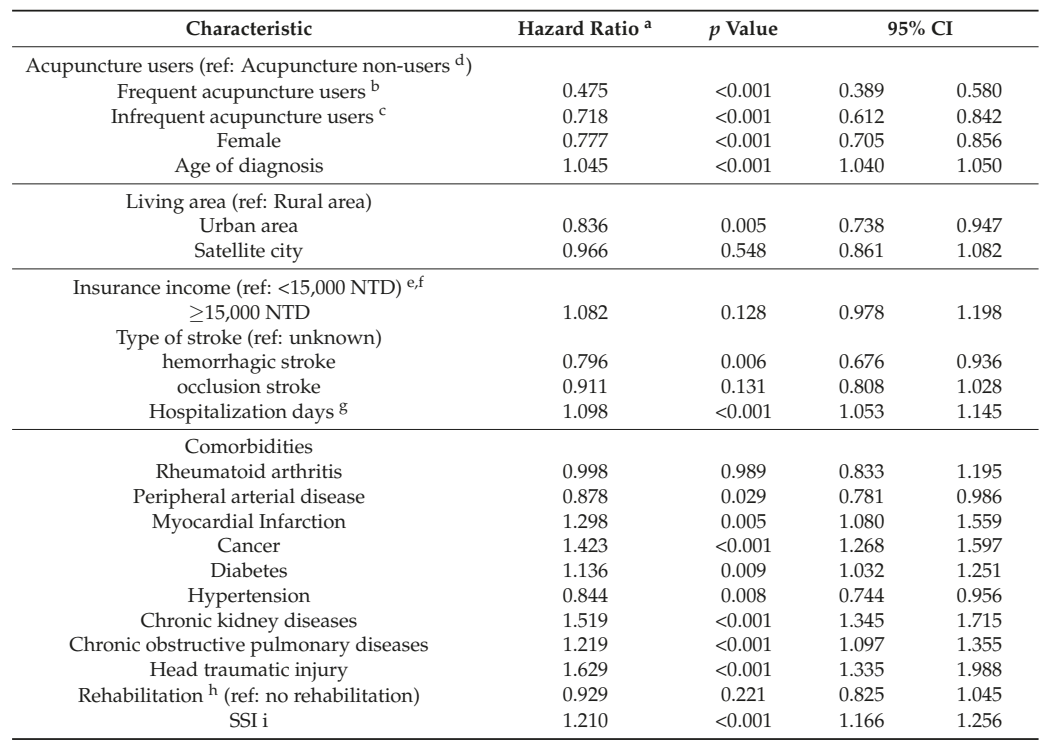

Abbreviation: SD = standard deviation; NTD = New Taiwan Dollar; $\mathrm{CI}=$ confidence interval; ref = reference . ${ }^{a}$ Hazard ratio (95\% confidence interval) was adjusted for all listed variables in the table; ${ }^{b}$ Frequent acupuncture users: Subjects received six or more acupuncture treatments between 2000 and 2007 after stroke diagnosis;

c Infrequent acupuncture users: Subjects received 1-5 acupuncture treatments between 2000 and 2007 after stroke diagnosis; d Acupuncture non-users: Subjects did not receive any acupuncture treatment between 2000 and 2007 after stroke diagnosis; ${ }^{e}$ The income-related insurance payment category set by the Bureau of National Health Insurance in Taiwan; ${ }^{\mathrm{f}} 1$ US $\$=30$ NTD(New Taiwan Dollars); $g$ Hospitalization days treated as continuous variable ( $\leq 7,8-14,15-21,22-28$ and $\geq 28$ days); ${ }^{\text {h }}$ Rehabilitation: had rehabilitation in the 3 months after stroke; ${ }^{\mathrm{i}} \mathrm{SSI}=$ Stroke severity index. 
Table 3. Multivariable adjusted hazard ratios of covariates for depression between hemorrhagic stroke and occlusion stroke.

\begin{tabular}{|c|c|c|c|c|c|c|c|c|}
\hline \multirow[b]{2}{*}{ Characteristic $^{e}$} & \multicolumn{4}{|c|}{ Hemorrhagic Stroke } & \multicolumn{4}{|c|}{ Occlusion Stroke } \\
\hline & $\begin{array}{l}\text { Hazard } \\
\text { Ratio }^{\text {a }}\end{array}$ & $p$ Value & \multicolumn{2}{|c|}{$95 \% \mathrm{CI}$} & $\begin{array}{l}\text { Hazard } \\
\text { Ratio }^{\text {a }}\end{array}$ & $p$ Value & \multicolumn{2}{|c|}{$95 \% \mathrm{CI}$} \\
\hline & & & & & & & & \\
\hline Frequen & 0.446 & $<0.001$ & 0.283 & 0.702 & 0.499 & $<0.001$ & 0.391 & 0.638 \\
\hline Infrequent acupuncture users ${ }^{c}$ & 0.831 & 0.318 & 0.577 & 1.170 & 0.707 & $<0.001$ & 0.578 & 0.865 \\
\hline \multicolumn{9}{|c|}{ 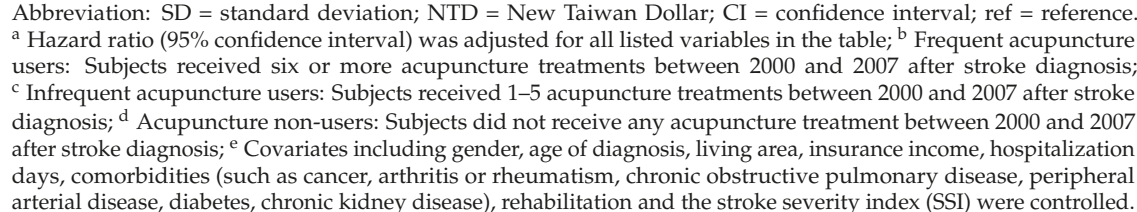 } \\
\hline
\end{tabular}

\section{Discussion}

Our results indicate that using acupuncture after stroke diagnosis lowers the risk of PSD by an estimated $52.5 \%(1-0.475)$ in frequent acupuncture users and $28.2 \%(1-0.718)$ in infrequent acupuncture users. Applying acupuncture to treat stroke complications is common in Taiwan, and to our knowledge, our study is the first to investigate the effects of acupuncture in preventing PSD in a large population-based cohort. Within a 7-year observation period, the results indicate that recently-diagnosed stroke patients using acupuncture after being diagnosed were likely to have a lower risk of PSD. The overall risk reduction is estimated to be about $30.6 \%$.

Strokes may increase vulnerability to the development of depression through a variety of neurobiological mechanisms. Three possible explanations for the association between physical illness and depression include a coincidental relationship; a negative mood reaction to the physical consequences of the stroke; and a neurotransmitter imbalance as a result of cerebral damage caused by the stroke [15]. Based on these PSD mechanisms, our hypothesis is that using acupuncture after a stroke might improve stroke complications and result in the prevention of PSD. Studies suggest that acupuncture after a stroke may improve problems with pain [16], spasticity [16], physical functions [17], quality of life [18] and cognitive functions [19]. Our findings seem to support the hypothesis that acupuncture reduces complications caused by a stroke and thus lowers the risk of PSD.

However, the short-term or long-term effects of using acupuncture to prevent PSD are unknown. To address this issue, a sensitivity analysis controlling for acupuncture over a three-month or six-month period after a stroke diagnosis was performed (table not shown). The results did not show that receiving acupuncture offered benefits in terms of depression symptoms. Nevertheless, the study did reveal that TCM-use benefited patients with higher depressive symptoms by attenuating their worsening [20]. These results suggest that the preventive effect from a continuous acupuncture treatment period may vary widely after a stroke. Further randomized control trials between short-term or long-term follow-up times are needed for verification.

In addition, our study also explored potential confounders related to PSD. Females have a lower risk of depression than males, and the overall risk reduction is estimated to be about $22.1 \%$ in our study. Although these findings are similar to those found in [4], other research has reported that female stroke patients have a higher risk of PSD. However, our findings that stroke patients with advanced age [21], greater stroke severity [8] and compounded comorbidities [7] have a higher risk of PSD are consistent with much of the related prior literature. Be that as it may, a summed measure of comorbidities may ignore potentially important relationships between diseases and PSD. For example, our study revealed that stroke patients comorbid with myocardial infarction $(\mathrm{HR}=1.301)$, cancer $(\mathrm{HR}=1.414)$, diabetes $(\mathrm{HR}=1.139)$, chronic kidney diseases $(\mathrm{HR}=1.518)$, chronic obstructive pulmonary disease $(\mathrm{HR}=1.218)$ or head traumatic injury $(\mathrm{HR}=1.658)$ are at higher risk than their counterparts without 
these comorbidities. Furthermore, stroke patients with peripheral arterial disease or hypertension have a lower risk of depression after stroke diagnosis, while comorbid rheumatoid arthritis is not significantly correlated with PSD. Meanwhile, the benefit of 3-months rehabilitation was evaluated after stroke diagnosis in a previous study [4], but those results do not correspond with ours. This might be due to the short-term and long-term ability of acupuncture or rehabilitation to prevent PSD being unknown. Accordingly, it is suggested that future research include these comorbid factors or the long-term effects of rehabilitation to further our understanding in this line of research. In addition, there was little evidence that compared the risk of PSD between occlusion-stroke and hemorrhagic stroke. Our study provided some information to fill this research gap. The results also indicated that patients, with occlusion-stroke or hemorrhagic stroke, who received frequent acupuncture treatments, may minimize the risk of PSD ( $\mathrm{HR}=0.446-0.499)$.

Our study has some strong points. One is that it is the first population-based study to investigate acupuncture's potential in preventing PSD based upon the real clinical conditions of stroke patients. A second is that acupuncture is a relatively low-cost treatment and, when performed by a TCM doctor, has none of the potential side effects associated with taking medicines. A third is that our study is an observational study based on reimbursement claims data obtained from the National Health Insurance Research Dataset (NHIRD). Compared to studies using questionnaires to detect depressive symptoms, our study reduced the potential of being confounded by the Hawthorne Effect. A fourth strong point is that stroke severity was evaluated in our study [14] to a greater degree than in other studies [4].

Nevertheless, this study still has some limitations. First, acupoints are hard to define using the NHI database; moreover, different acupuncturists use different acupoints in different patients, depending on the symptoms and severity of stroke complications. However, some clinical studies have shown that even sham-acupuncture may have treatment effects in some diseases. Thus, there may be a positive effect even without considering the location of acupoints in different individuals in our study. Second, disability is an important predictor of PSD, but the severity of disabilities is hard to define using the NHI database. However, we controlled for stroke severity and comorbidities to minimize the effects of the severity of disability. Third, potential confounders, such as brain lesion of stroke [22], cognitive impairment after stroke, dysphagia [10], incontinence [10], anxiety, and social isolation [10], are not included in the NHI database, and so may confound our research results. Accordingly, future work is needed to further this understanding. Fourth, patients in the acupuncture group may have also received other complementary treatments such as massage, herbs, and aromatherapy, among others. Thus, we may overestimate the treatment effect of acupuncture. As such, the effects of the more specific acupuncture mechanisms or interactions deserves future investigation when data is available. Moreover, we conducted the exclusion criteria for depression within the first 3 months following their stroke for the purpose of minimizing survivorship bias. Further sensitivity analysis (table not shown) was conducted and was found to be similar to the present results, suggesting the possible role of acupuncture in preventing PSD development. Fifth, because the benefits of medicines and psychotherapy or pre-acupuncture depression screening in preventing PSD were not available in our dataset or relevant to acupuncture treatment, we did not control for these variables in our study. Sixth, we cannot know the total number of dropouts and the main reasons for dropping out because our study used NHIRD, and so the reasons that patients choose not to continue acupuncture were based on individual will. Accordingly, further research examining the choice to dropout or remain is therefore warranted.

\section{Conclusions}

In conclusion, controlling for potential confounders, stroke patients who receive acupuncture may have a lower risk of PSD than those who do not. Moreover, acupuncture after a stroke may have a protective effect on depression, thus stemming further deterioration. Further strictly designed randomized controlled trials are needed to better understand the specific mechanisms of acupuncture and its impact on psychological health outcomes. 
Acknowledgments: This work was supported by the Office of Research and Development at National Cheng Kung University (P.I.: Ching-Ju Chiu, Ph.D. D100-35B19).

Author Contributions: Shuo-Ping Tseng, Yu-Ching Hsu reviewed the literature, analyzed the data, and wrote the draft of the manuscript. Ching-Ju Chiu guided the study design, had full access to all of the data in the study and takes responsibility for the integrity of the data and the accuracy of the discussion. Shang-Te Wu contributed to the discussion.

Conflicts of Interest: None of the authors of this report has any conflicts of interest.

\section{References}

1. Hsieh, F.I.; Chiou, H.Y. Stroke-Morbidity, Risk Factors, and Care in Taiwan. J. Stroke 2014, 16, 59-64. [CrossRef] [PubMed]

2. Pohjasvaara, T.V.R.; Vataja, R.; Leppävuori, A.; Kaste, M.; Erkinjuntti, T. Cognitive functions and depression as predictors of poor outcome 15 months after stroke. Cerebrovasc. Dis. 2002, 14, 228-233. [CrossRef] [PubMed]

3. Hackett, M.L.; Anderson, C.S.; House, A.; Halteh, C. Interventions for preventing depression after stroke. Cochrane Database Syst. Rev. 2008. [CrossRef]

4. Hou, W.H.; Liang, H.W.; Hsieh, C.L.; Hou, C.Y.; Wen, P.C.; Li, C.Y. Effects of stroke rehabilitation on incidence of poststroke depression: A population-based cohort study. J. Clin. Psychiatry 2013, 74, 859-866. [CrossRef] [PubMed]

5. Chang, C.C.; Lee, Y.C.; Lin, C.C.; Chang, C.H.; Chiu, C.D.; Chou, L.W.; Sun, M.F.; Yen, H.R. Characteristics of traditional Chinese medicine usage in patients with stroke in Taiwan: A nationwide population-based study. J. Ethnopharmacol. 2016, 186, 311-321. [CrossRef] [PubMed]

6. Andersen, G.; Vestergaard, K.; Ingemann-Nielsen, M.; Lauritzen, L. Risk factors for post-stroke depression. Acta Psychiatrica Scand. 1995, 92, 193-198. [CrossRef]

7. Hirata, S.; Ovbiagele, B.; Markovic, D.; Towfighi, A. Key factors associated with major depression in a national sample of stroke survivors. J. Stroke Cerebrovasc. Dis. 2016, 25, 1090-1095. [CrossRef] [PubMed]

8. De Ryck, A.; Brouns, R.; Geurden, M.; Elseviers, M.; De Deyn, P.P.; Engelborghs, S. Risk factors for poststroke depression identification of inconsistencies based on a systematic review. J. Geriatr. Psychiatry Neurol. 2014, 27, 147-158. [CrossRef] [PubMed]

9. Caeiro, L.; Ferro, J.M.; Santos, C.O.; Figueira, M.L. Depression in acute stroke. J. Psychiatry Neurosci. 2006, 31, 377-383. [PubMed]

10. Ayerbe, L.; Ayis, S.; Rudd, A.G.; Heuschmann, P.U.; Wolfe, C.D. Natural history, predictors, and associations of depression 5 years after stroke the South London Stroke Register. Stroke 2011, 42, 1907-1911. [CrossRef] [PubMed]

11. Chen, H.-F.; Lee, S.-P.; Li, C.-Y. Sex differences in the incidence of hemorrhagic and ischemic stroke among diabetics in Taiwan. J. Women's Health 2009, 18, 647-654.

12. American Psychiatric Association. Diagnostic and Statistical Manual of Mental Disorders; American Psychiatric Association: Washington, DC, USA, 2000.

13. Liu, C.-Y.; Hung, Y.T.; Chuang, Y.L.; Chen, Y.J.; Weng, W.S.; Liu, J.S.; Liang, K.Y. Incorporating development stratification of Taiwan townships into sampling design of large scale health interview survey. J. Health Manag. 2006, 4, 1-22.

14. Sung, S.F.; Hsieh, C.Y.; KaoYang, Y.H.; Lin, H.J.; Chen, C.H.; Chen, Y.W.; Hu, Y.H. Developing a stroke severity index based on administrative data was feasible using data mining techniques. J. Clin. Epidemiol. 2015, 68, 1292-1300. [CrossRef] [PubMed]

15. Post Stroke Depression. Available online: https://www.researchgate.net/publication/228850728_18_PostStroke_Depression (accessed on 13 March 2017).

16. Salom-Moreno, J.; Sánchez-Mila, Z.; Ortega-Santiago, R.; Palacios-Ceña, M.; Truyol-Domínguez, S.; Fernández-de-las-Peñas, C. Changes in Spasticity, Widespread Pressure Pain Sensitivity, and Baropodometry After the Application of Dry Needling in Patients Who Have Had a Stroke: A Randomized Controlled Trial. J. Manip. Physiol. Ther. 2014, 37, 569-579. [CrossRef] [PubMed] 
17. Man, S.-C.; Hung, B.H.; Ng, R.M.; Yu, X.-C.; Cheung, H.; Fung, M.P.; Li, L.S.; Leung, K.-P.; Leung, K.-P.; Tsang, K.W.; et al. A pilot controlled trial of a combination of dense cranial electroacupuncture stimulation and body acupuncture for post-stroke depression. BMC Complement. Altern. Med. 2014. [CrossRef] [PubMed]

18. Gosman-Hedström, G.; Claesson, L.; Klingenstierna, U.; Carlsson, J.; Olausson, B.; Frizell, M.; Fagerberg, B.; Blomstrand, C. Effects of acupuncture treatment on daily life activities and quality of life a controlled, prospective, and randomized study of acute stroke patients. Stroke 1998, 29, 2100-2108. [CrossRef] [PubMed]

19. Liu, F.; Li, Z.M.; Jiang, Y.J.; Chen, L.D. A Meta-Analysis of Acupuncture Use in the Treatment of Cognitive Impairment After Stroke. J. Altern. Complement. Med. 2014, 20, 535-544. [CrossRef]

20. Hsu, Y.-C.; Chiu, C.-J.; Wray, L.A.; Beverly, E.A.; Tseng, S.-P. Impact of traditional Chinese medicine on age trajectories of health: Evidence from the Taiwan longitudinal study on aging. J. Am. Geriatr. Soc. 2015, 63, 351-357. [CrossRef] [PubMed]

21. Salinas, J.; Beiser, A.; Himali, J.; Rosand, J.; Seshadri, S.; Dunn, E. Incidence and Predictors of Poststroke Depression: Results from the Framingham Heart Study (P5. 034). Neurology 2015, 84 (Suppl. 14), 35-41.

22. Robinson, R.G.; Jorge, R.E.; Moser, D.J.; Acion, L.; Solodkin, A.; Small, S.L.; Fonzetti, P.; Hegel, M.; Arndt, S. Escitalopram and problem-solving therapy for prevention of poststroke depression: A randomized controlled trial. Jama 2008, 299, 2391-2400. [CrossRef] [PubMed]

(C) 2017 by the authors. Licensee MDPI, Basel, Switzerland. This article is an open access article distributed under the terms and conditions of the Creative Commons Attribution (CC BY) license (http:/ / creativecommons.org/licenses/by/4.0/). 
Article

\title{
The Pilot Study of Evaluating Fluctuation in the Blood Flow Volume of the Radial Artery, a Site for Traditional Pulse Diagnosis
}

\author{
Masashi Watanabe ${ }^{1}$, Soichiro Kaneko ${ }^{1,2}$, Shin Takayama ${ }^{1,2, *}$, Yasuyuki Shiraishi ${ }^{3}$, \\ Takehiro Numata ${ }^{1,2}$, Natsumi Saito ${ }^{1}$, Takashi Seki ${ }^{4}$, Norihiro Sugita ${ }^{5}$, Satoshi Konno ${ }^{3}$, \\ Tomoyuki Yambe ${ }^{3}$, Makoto Yoshizawa ${ }^{6}$, Nobuo Yaegashi ${ }^{7}$ and Tadashi Ishii ${ }^{1}$ \\ 1 Department of Education and Support for Regional Medicine, Department of Kampo Medicine, \\ Tohoku University Hospital, 1-1 Seiryou-machi, Aoba-ku, Sendai, Miyagi 980-8574, Japan; \\ egao.2008@wine.ocn.ne.jp (M.W.); souichi0134@gmail.com (S.K.); numatatakehiro@gmail.com (T.N.); \\ natsu.beauty.summer@gmail.com (N.S.); t-ishi23@green.ocn.ne.jp (T.I.) \\ 2 Comprehensive Education Center for Community Medicine, Graduate School of Medicine, \\ Tohoku University, 2-1 Seiryou-machi, Aoba-ku, Sendai, Miyagi 980-8575, Japan \\ 3 Institute of Development, Aging and Cancer, Tohoku University, 4-1 Seiryo-machi, Aoba-ku, Sendai, \\ Miyagi 980-8575, Japan; shiraishi@idac.tohoku.ac.jp (Y.S.); konnos@idac.tohoku.ac.jp (S.K.); \\ yambe@idac.tohoku.ac.jp (T.Y.) \\ 4 Division of Cyclotron Nuclear Medicine, Cyclotron and Radioisotope Center, Tohoku University, 6-3 Aoba, \\ Aramaki, Aoba-ku, Sendai, Miyagi 980-8578, Japan; tseki.tohoku@gmail.com \\ 5 Department of Management Science and Technology, Graduate School of Engineering, Tohoku University, \\ 6-6-05 Aramaki Aza Aoba, Aoba-ku, Sendai, Miyagi 980-8579, Japan; sugita@yoshizawa.ecei.tohoku.ac.jp \\ 6 Research Division on Advanced Information Technology, Cyberscience Center, Tohoku University, \\ 6-3 Aramaki Aza Aoba, Aoba-ku, Sendai, Miyagi 980-8578, Japan; yoshizawa@yoshizawa.ecei.tohoku.ac.jp \\ 7 Department of Obstetrics and Gynecology, Graduate School of Medicine, Tohoku University, \\ 1-1 Seiryou-machi, Aoba-ku, Sendai, Miyagi 980-8574, Japan; yaegashi@med.tohoku.ac.jp \\ * Correspondence: takayama@med.tohoku.ac.jp; Tel.: +81-22-717-7185; Fax: +81-22-717-7186
}

Academic Editor: Gerhard Litscher

Received: 24 January 2016; Accepted: 14 April 2016; Published: 17 May 2016

\begin{abstract}
Background: Radial artery (RA) pulse diagnosis has been used in traditional Asian medicine. Blood pressure (BP) and pulse rate related to heart rate variability (HRV) can be monitored via the RA. The fluctuation in these parameters has been assessed using fast Fourier transform (FFT) analytical methods that calculate power spectra. Methods: We measured blood flow volume (Volume) in the RA and evaluated its fluctuations. Normal participants $(n=34)$ were enrolled. We measured the hemodynamics of the right RA for approximately $50 \mathrm{~s}$ using ultrasonography. Results: The parameters showed the center frequency (CF) of the power spectrum at low frequency (LF) and high frequency (HF). More than one spectral component indicated that there were fluctuations. The CF at LF for Volume was significantly different from that for vessel diameter (VD); however, it was significantly correlated with blood flow velocity (Velocity). On the other hand, the CF at HF for Volume was significantly different from that for Velocity; however, it was significantly correlated with VD. Conclusion: It is suggested that fluctuation in the Volume at LF of RA is influenced by the fluctuation in Velocity; on the other hand, fluctuation in the Volume at HF is influenced by the fluctuation in VD.
\end{abstract}

Keywords: pulse diagnosis; radial artery; blood flow volume; fluctuation; ultrasonography 


\section{Introduction}

Pulse diagnosis has been used in traditional medicine since ancient times (e.g., traditional Chinese medicine [1], Ayurveda [2], Unani medicine [3] and Tibetan medicine [4-7]). It is performed on the radial artery in the area around the radial styloid process, carotid artery and other arteries [8]. Traditional pulse diagnosis depends on experience, and quantification is very difficult. Therefore, it is difficult to carry out by education in Western medicine. Recently, a technique to measure a pulse wave was developed. Additionally, it is expected that various things become clear by evaluating the fluctuation included in the pulse wave [9].

Blood pressure (BP) and heart rate (HR) related to heart rate variability (HRV) can be monitored via the radial artery [10]. Fluctuations in the HR and BP have been assessed using fast Fourier transform (FFT) analytical methods that calculate power spectra [11-15]. Low frequency (LF) and high frequency (HF) components are observed in the spectrum of HRV $[14,16,17]$. The LF fluctuations in HRV are mediated by both the sympathetic and parasympathetic nervous systems, whereas the HF fluctuations are mediated solely by the parasympathetic system [14]. The blood flow volume is calculated using the vascular diameter (VD) and blood flow velocity (velocity). VD and velocity are evaluated using ultrasonic diagnostic equipment. VD is affected by the fluid content and through neurogenic control. The cell membranes of the smooth muscle cells in the vessels contain $\alpha$ - and $\beta$-adrenergic receptors that bind to neurotransmitters. Activation of $\alpha$-adrenergic receptors promotes vasoconstriction, while the activation of $\beta$-adrenergic receptors mediates the relaxation of muscle cells, resulting in vasodilation. Normally, $\alpha$-adrenergic receptors predominate in the smooth muscle of resistance vessels. Thus, vascular smooth muscle is ruled out of the sympathetic nerve-mediated tonicity. In addition, there are few reports about vasomotor fluctuation $[18,19]$. However, there are no studies yet that have measured the variability of the blood flow volume (Volume) in the radial artery. We measured the Volume in the radial artery and evaluated its fluctuations at the site of traditional pulse diagnosis using a high-resolution ultrasonography in the participants at rest.

The purpose of the pilot study was to measure the blood flow in the pulse diagnosis site and to explore its fluctuation related to the physiological parameters.

\section{Experimental Section}

\subsection{Subjects}

Thirty-three healthy volunteers ( 26 men and 7 women; mean age $34.2 \pm 7.6$ years) were enrolled in the study. All participants provided written informed consent before participation, and the study protocol was approved by the Ethics Committee of Tohoku University Graduate School of Medicine, Project identification code (2009-175) and approval date (27 July 2009) (Table 1).

Table 1. Participant's characteristics for this study.

\begin{tabular}{ccc}
\hline Characteristic & Variable \\
\hline Age $(y)$ & Male & $34.2 \pm 7.6$ \\
Sex $(n)$ & Female & 7 \\
& & $168.4 \pm 6.7$ \\
Body height $(\mathrm{cm})$ & & $67.0 \pm 13.0$ \\
Body weight $(\mathrm{kg})$ & & \\
\hline
\end{tabular}

\subsection{Study Protocol}

All investigations were performed under fasting conditions in a quiet air-conditioned room (constant temperature of $25-26^{\circ} \mathrm{C}$ ). Each participant was at rest in the supine position, and three electrocardiography electrodes (BP-608 Evolution II, Colin Healthcare Co. Ltd., Kyoto, Japan) were attached to the chest for monitoring. Radial artery hemodynamics were assessed using ultrasonography 
(Prosound $\alpha 10^{\circledR}$; Hitachi-Aloka Medical, Ltd., Tokyo, Japan). This system had a high-resolution linear array transducer (13 MHz, Prosound $\alpha 10^{\circledR}$; Hitachi-Aloka Medical, Ltd., Tokyo, Japan) and computer-assisted analysis software (e-Tracking system ${ }^{\circledR}$; Hitachi-Aloka Medical, Ltd., Tokyo, Japan) that could automatically detect a blood vessel edge and continuously measure the vessel diameter and Volume [20]. The right arm was fixed and the right radial artery was scanned longitudinally at $1-2 \mathrm{~cm}$ above the radial styloid process at a point where the vessel diameter and Doppler wave readings were stable. At a site where the clearest B-mode image of the anterior and posterior intimal interfaces between the lumen and vessel wall was obtained, the transducer was fixed in place using a special probe holder (MP-PH0001; Hitachi-Aloka Medical, Ltd., Tokyo, Japan). Compression of the artery was carefully avoided (Figure 1). When the tracking gate was placed on the intima, the radial artery diameter was monitored automatically, and a waveform representing the changes of vessel diameter during a cardiac cycle was displayed in real time using the e-Tracking system ${ }^{\circledR}$ (Figure 2). To obtain accurate measurements, a Doppler angle of $\leqslant 60$ degrees was maintained [21,22]. Volume was calculated automatically as the Doppler flow velocity (corrected for the angle) multiplied by the vessel cross-sectional area [21-23]. We measured right radial artery hemodynamics for approximately $50 \mathrm{~s}$ after $10 \mathrm{~min}$ of rest in the supine position [24,25]. The hemodynamic parameters, including the radial artery diameter and Volume, and the HR were recorded continuously. To minimize the influence of respiration on the hemodynamic data, the participants were asked to breathe every $6 \mathrm{~s}$ during the test. Measured parameters were systolic vessel diameter (Sys-VD) per beat, diastolic vessel diameter (Dia-VD) per beat, Velocity per second, volume per beat and HR per minute.

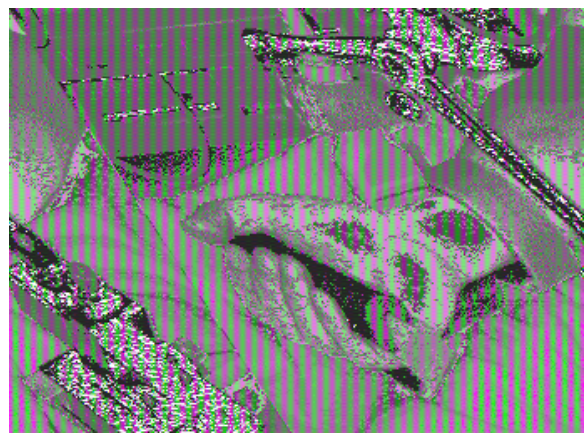

Figure 1. Ultrasonography measurement of radial artery using a special probe holder.

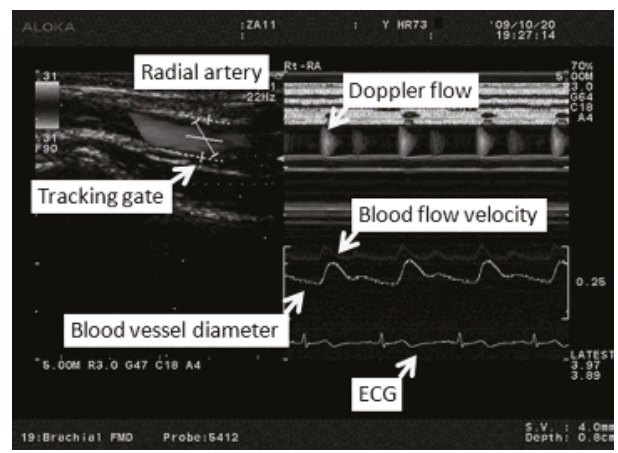

Figure 2. The image on the left shows the radial artery and the position of the tracking gate on the artery. The image on the right shows the changes in the vessel diameter, Doppler flow and flow velocity determined using an automated edge detection device and computer analysis software. 


\subsection{Analysis}

In order to produce an evenly-sampled time series prior to FFT-based spectral estimation, linear spline interpolation and resampling of measured parameter data are usually employed [26,27]. After removal of linear trends included in the data, FFT analysis was applied using MATLAB software (Version 2007b; MathWorks, Natick, MA, USA) to obtain power spectra (periodogram) for Sys-VD, Dia-VD, HR, Velocity and Volume. In a low frequency component (LF; 0.04-0.15 Hz), we compared each of the center frequencies (CF) as follows: (1) Volume with Sys-VD; (2) Volume with Dia-VD; and (3) Volume with Velocity. In a high frequency component (HF; <0.15 Hz), we compared each of the CF as follows: (1) Volume with Sys-VD; (2) Volume with Dia-VD; and (3) Volume with Velocity.

\subsection{Statistical Methods}

Statistical analyses were performed using the PASW software (Version 17.0, SPSS Japan Inc., Tokyo, Japan). Comparisons between parameters were performed using ANOVA with Dunnett's post hoc tests and Pearson's product-moment correlation coefficient. Statistical significance was assumed at $p<0.05$. Values are the mean \pm standard deviation (SD).

\section{Results}

In all participants, the CF was seen in the LF and HF (Table 2). Comparisons of the CF of the LF and HF are shown in Figure 3a,b, respectively. There were significant differences in the CF between (1) the LF in Volume and the LF in HR $(p<0.01)$ and $(2)$ the LF in Volume and the LF in Sys-VD $(p<0.05)$. There were significant correlate in the CF between (3) the LF in Volume and the LF in Velocity $(r=0.64, p<0.01)$ and (4) the LF in Sys-VD and the LF in Dia-VD $(r=0.57, p<0.01)$. On the other hand, there were significant differences in the CF between (5) the HF in Volume and the HF in Velocity $(p<0.01)$. There were significant correlate in the CF between (6) the HF in Volume and the HF in Sys-VD $(r=0.39, p<0.05)$, (7) the HF in Sys-VD and the HF in Dia-VD $(r=0.59, p<0.01)$ and (8) the $\mathrm{HF}$ in Dia-VD and the HF in HR $(r=0.61, p<0.01)$.

Table 2. Center frequencies (Hz) and low frequency (LF)/high frequency (HF) ratio in the LF component and HF component of all subjects in blood flow volume (Volume), blood flow velocity (Velocity), systolic vessel diameter (Sys-VD), diastolic vessel diameter (Dia-VD) and heart rate (HR).

\begin{tabular}{|c|c|c|c|c|c|c|c|c|c|c|}
\hline \multirow{2}{*}{$\frac{\text { Participant }}{\text { No. }}$} & \multicolumn{2}{|c|}{ Volume } & \multicolumn{2}{|c|}{ Velocity } & \multicolumn{2}{|c|}{ Sys-VD } & \multicolumn{2}{|c|}{ Dia-VD } & \multicolumn{2}{|c|}{ HR } \\
\hline & LF (Hz) & HF (Hz) & LF (Hz) & HF (Hz) & LF (Hz) & HF (Hz) & LF (Hz) & HF (Hz) & LF (Hz) & $\mathrm{HF}(\mathrm{Hz})$ \\
\hline 1 & 0.137 & 0.156 & 0.137 & 0.156 & 0.049 & 0.156 & 0.049 & 0.166 & 0.049 & 0.146 \\
\hline 2 & 0.049 & 0.166 & 0.049 & 0.166 & 0.137 & 0.176 & 0.049 & 0.156 & 0.068 & 0.166 \\
\hline 3 & 0.137 & 0.166 & 0.137 & 0.156 & 0.137 & 0.166 & 0.049 & 0.166 & 0.137 & 0.166 \\
\hline 4 & 0.049 & 0.156 & 0.098 & 0.166 & 0.059 & 0.166 & 0.068 & 0.146 & 0.059 & 0.166 \\
\hline 5 & 0.059 & 0.166 & 0.059 & 0.166 & 0.049 & 0.156 & 0.049 & 0.156 & 0.059 & 0.156 \\
\hline 6 & 0.078 & 0.156 & 0.088 & 0.186 & 0.107 & 0.156 & 0.049 & 0.156 & 0.137 & 0.146 \\
\hline 7 & 0.059 & 0.234 & 0.059 & 0.313 & 0.078 & 0.273 & 0.078 & 0.225 & 0.068 & 0.156 \\
\hline 8 & 0.078 & 0.146 & 0.088 & 0.410 & 0.137 & 0.146 & 0.137 & 0.146 & 0.137 & 0.146 \\
\hline 9 & 0.049 & 0.146 & 0.088 & 0.146 & 0.137 & 0.156 & 0.049 & 0.488 & 0.137 & 0.146 \\
\hline 10 & 0.049 & 0.303 & 0.049 & 0.293 & 0.078 & 0.264 & 0.088 & 0.332 & 0.088 & 0.273 \\
\hline 11 & 0.049 & 0.146 & 0.049 & 0.303 & 0.049 & 0.176 & 0.088 & 0.488 & 0.049 & 0.498 \\
\hline 12 & 0.049 & 0.156 & 0.059 & 0.332 & 0.049 & 0.156 & 0.049 & 0.146 & 0.127 & 0.146 \\
\hline 13 & 0.049 & 0.146 & 0.117 & 0.342 & 0.049 & 0.146 & 0.049 & 0.146 & 0.137 & 0.146 \\
\hline 14 & 0.049 & 0.176 & 0.049 & 0.215 & 0.088 & 0.488 & 0.078 & 0.498 & 0.088 & 0.195 \\
\hline 15 & 0.049 & 0.166 & 0.049 & 0.166 & 0.137 & 0.156 & 0.137 & 0.156 & 0.137 & 0.156 \\
\hline 16 & 0.059 & 0.156 & 0.059 & 0.156 & 0.137 & 0.166 & 0.117 & 0.166 & 0.059 & 0.166 \\
\hline 17 & 0.049 & 0.156 & 0.049 & 0.322 & 0.137 & 0.166 & 0.088 & 0.166 & 0.068 & 0.166 \\
\hline 18 & 0.049 & 0.146 & 0.049 & 0.371 & 0.049 & 0.215 & 0.049 & 0.166 & 0.137 & 0.146 \\
\hline 19 & 0.049 & 0.166 & 0.049 & 0.244 & 0.049 & 0.146 & 0.117 & 0.156 & 0.049 & 0.166 \\
\hline 20 & 0.049 & 0.166 & 0.107 & 0.166 & 0.049 & 0.166 & 0.049 & 0.166 & 0.137 & 0.166 \\
\hline 21 & 0.059 & 0.166 & 0.068 & 0.166 & 0.137 & 0.166 & 0.098 & 0.166 & 0.137 & 0.156 \\
\hline 22 & 0.049 & 0.166 & 0.078 & 0.361 & 0.137 & 0.156 & 0.137 & 0.156 & 0.117 & 0.166 \\
\hline 23 & 0.098 & 0.176 & 0.127 & 0.176 & 0.049 & 0.166 & 0.098 & 0.166 & 0.088 & 0.166 \\
\hline
\end{tabular}


Table 2. Cont.

\begin{tabular}{|c|c|c|c|c|c|c|c|c|c|c|}
\hline \multirow{2}{*}{$\begin{array}{c}\text { Participant } \\
\text { No. }\end{array}$} & \multicolumn{2}{|c|}{ Volume } & \multicolumn{2}{|c|}{ Velocity } & \multicolumn{2}{|c|}{ Sys-VD } & \multicolumn{2}{|c|}{ Dia-VD } & \multicolumn{2}{|c|}{ HR } \\
\hline & LF (Hz) & $\mathrm{HF}(\mathrm{Hz})$ & LF (Hz) & $\mathrm{HF}(\mathrm{Hz})$ & LF (Hz) & $\mathrm{HF}(\mathrm{Hz})$ & LF (Hz) & $\mathrm{HF}(\mathrm{Hz})$ & LF (Hz) & $\mathrm{HF}(\mathrm{Hz})$ \\
\hline 24 & 0.068 & 0.166 & 0.068 & 0.166 & 0.098 & 0.166 & 0.107 & 0.176 & 0.049 & 0.166 \\
\hline 25 & 0.137 & 0.166 & 0.137 & 0.166 & 0.049 & 0.166 & 0.049 & 0.166 & 0.137 & 0.166 \\
\hline 26 & 0.049 & 0.146 & 0.049 & 0.205 & 0.049 & 0.166 & 0.049 & 0.156 & 0.137 & 0.146 \\
\hline 27 & 0.049 & 0.195 & 0.049 & 0.146 & 0.049 & 0.146 & 0.049 & 0.244 & 0.078 & 0.156 \\
\hline 28 & 0.049 & 0.166 & 0.049 & 0.166 & 0.049 & 0.166 & 0.049 & 0.166 & 0.137 & 0.166 \\
\hline 29 & 0.127 & 0.146 & 0.049 & 0.166 & 0.137 & 0.166 & 0.137 & 0.166 & 0.137 & 0.156 \\
\hline 30 & 0.059 & 0.146 & 0.137 & 0.166 & 0.127 & 0.186 & 0.127 & 0.186 & 0.078 & 0.186 \\
\hline 31 & 0.117 & 0.146 & 0.127 & 0.146 & 0.127 & 0.146 & 0.127 & 0.146 & 0.117 & 0.146 \\
\hline 32 & 0.049 & 0.146 & 0.049 & 0.146 & 0.137 & 0.156 & 0.137 & 0.156 & 0.137 & 0.156 \\
\hline 33 & 0.049 & 0.166 & 0.068 & 0.166 & 0.049 & 0.166 & 0.049 & 0.166 & 0.137 & 0.166 \\
\hline 34 & 0.049 & 0.166 & 0.049 & 0.322 & 0.068 & 0.156 & 0.107 & 0.176 & 0.137 & 0.166 \\
\hline Mean \pm SD & $\begin{array}{c}0.066 \pm \\
0.030\end{array}$ & $\begin{array}{c}0.166 \pm \\
0.030\end{array}$ & $\begin{array}{c}0.076 \pm \\
0.033\end{array}$ & $\begin{array}{c}0.219 \pm \\
0.082\end{array}$ & $\begin{array}{c}0.089 \pm \\
0.040\end{array}$ & $\begin{array}{c}0.179 \pm \\
0.062\end{array}$ & $\begin{array}{c}0.082 \pm \\
0.035\end{array}$ & $\begin{array}{c}0.200 \pm \\
0.098\end{array}$ & $\begin{array}{c}0.104 \pm \\
0.036\end{array}$ & $\begin{array}{c}0.173 \pm \\
0.062\end{array}$ \\
\hline $\begin{array}{c}\mathrm{LF} / \mathrm{HF} \\
\text { Mean } \pm \mathrm{SD}\end{array}$ & \multicolumn{2}{|c|}{$2.1 \pm 1.6$} & \multicolumn{2}{|c|}{$0.9 \pm 0.5$} & \multicolumn{2}{|c|}{$0.8 \pm 0.5$} & \multicolumn{2}{|c|}{$0.9 \pm 0.5$} & \multicolumn{2}{|c|}{$0.8 \pm 0.4$} \\
\hline
\end{tabular}

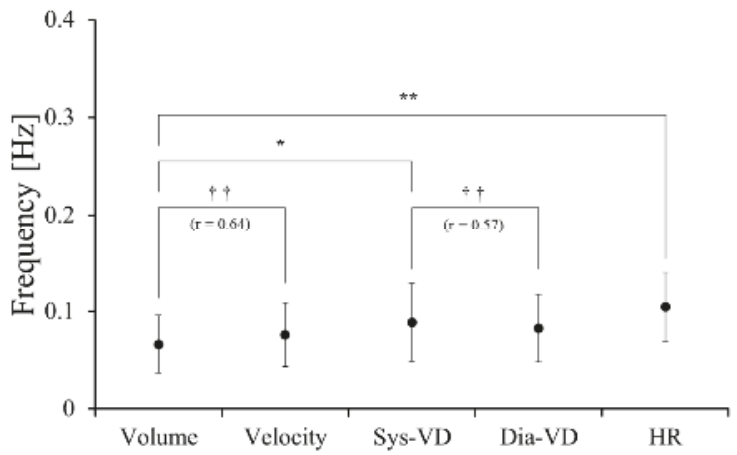

(a)

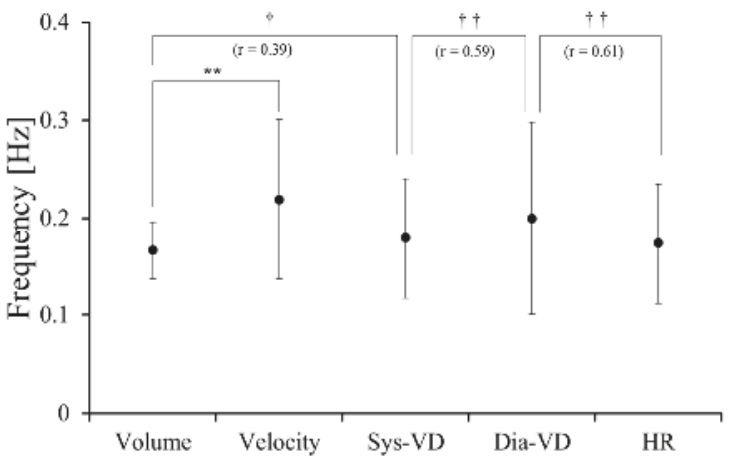

(b)

Figure 3. Comparison among the center frequency of blood flow volume (Volume), blood flow velocity (Velocity), systolic vessel diameter (Sys-VD), diastolic vessel diameter (Dia-VD) and heart rate (HR) in (a) the low-frequency component (LF) and (b) the high-frequency component (HF). Values represent the mean \pm standard deviation (SD). Comparisons between parameters were performed using ANOVA with Dunnett's post hoc tests $\left({ }^{*} p<0.05 ;{ }^{* *} p<0.01\right)$ and Pearson's product-moment correlation coefficient ( $r$ : correlation coefficient, $+p<0.05 ;+\dagger p<0.01)$. Statistical significance was assumed at $p<0.05$. 


\section{Discussion}

A peak appears in the spectrum only due to the superposition of a number of waves from a time series comprising multiple waves [28]. HRV has different LF and HF that are observed in a spectrum for individual peaks [28]. In our analysis, we observed LF and HF in Sys-VD, Dia-VD, HR, Velocity and Volume in the radial artery while subjects were at rest. More than one spectral component indicated that there were fluctuations in each of these parameters. In a previous study on fluctuations in the circulatory system, only HRV and BP were studied [10,13,16,17,28-34], but there has been no report on Volume of the peripheral artery. In this study, to our knowledge, this is the first report of the investigation of the fluctuations in Volume of the radial artery. Frequencies of 0.085 and $0.09 \mathrm{~Hz}$ have been reported as the CF in the LF, and those of 0.21 and $0.24 \mathrm{~Hz}$ have been reported as the CF in the HF $[17,31]$. The LF appears to correspond to Mayer waves, while the HF is synchronous with respiration and has been considered as a quantitative evaluation of respiratory arrhythmia [17]. The HF varies in its CF with variations in the respiratory cycle [35]. In this study, the participants were asked to breathe every $6 \mathrm{~s}$ during the test, and this could have influenced the HF. The frequency during breathe control is $0.167 \mathrm{~Hz}$, which was equivalent to that of the $\mathrm{HF}(0.166 \mathrm{~Hz})$ in our results. It will be necessary to repeat the study without breath control. According to our results, in LF, there was a significant difference in the CF between Volume and HR/vessel diameter, while there was significant correlation between Volume and Velocity. In HF, there was a significant difference in the CF between Volume and Velocity, while there was significant correlation between Volume and vessel diameter. These results show that the CF of the Volume in LF is correlated with the CF of the Velocity in LF; on the other hand, the CF of the Volume in HF is correlated with the CF of the vessel diameter in HF.

In peripheral arteries, such as radial arteries, there are influences of local vasoconstrictor and vasodilator nerves, as well as the influence of the autonomic nerves on the heart. There are differences with regard to the LF. Some studies suggest that LF is a quantitative marker of sympathetic modulations, while other studies view LF as reflecting both sympathetic and vagal activities. Consequently, an LF/HF ratio is considered by some investigators to mirror a sympathovagal balance or to reflect sympathetic modulations [30]. In this study, the value of the LF/HF ratio for the Volume was 2.10. According to the previous reports, this value shows a rest state, but there is a difference by some reports [36-39].

Investigators from the Framingham Heart Study reported that HRV offers prognostic information independent of and beyond that provided by traditional risk factors [30]. The fluctuations of the LF/HF ratio in Volume of the radial artery could be a new index for the prognosis of cardiac vascular disease. The CF of the LF in Volume of the radial artery indicates a cycle of 7-25 s. This suggests that more than $25 \mathrm{~s}$ might be required for pulse diagnosis.

At the site of a pulse diagnosis using a radial artery, the blood vessel diameter is so small that the instrument used for measurement points can slip off due to slight movements by the participants. Therefore, in this study, it was difficult to make measurements for prolonged periods. For future investigations, an easier, more stable method of measurement must be established. The limitation of this study is also a lack of measurements of continuous BP and the sampling duration. To evaluate the relation among the $\mathrm{HR}, \mathrm{BP}$ and blood flow, simultaneous measurements of these parameters are needed. We have conducted a further study that solves these problems and the evaluation introduced to investigate acupuncture effects. The duration of blood flow sampling used for analysis is a little shorter than ideal. Generally, the spectral analysis requires over $60 \mathrm{~s}$ of data. In the present study, the arms of the subjects were fixed to measure blood flow using ultrasonography; however, occasionally, the subjects moved their arms during long duration measurements. We have tried analyzing over $60 \mathrm{~s}$ of data for spectral analysis; unfortunately, error is introduced once the subjects move their arm. Therefore, we used data for a shorter period (50 s), which was free of errors. Thus, the sampling duration is one of the limitations of this study. The present study is a pilot study; therefore, we will conduct experiments using a revised protocol in the future. We also intend to increase the number of subjects and to perform these studies with considerations of gender, age and disease. 
Further investigation will be needed for healthy subjects and patients with cardiovascular disease to show the clinical difference and meanings.

\section{Conclusions}

We measured the blood flow volume in the radial artery and evaluated its fluctuations at the site of traditional pulse diagnosis using ultrasonography in the participants at rest. We observed LF and HF in vessel diameter, HR, Velocity and Volume. More than one spectral component indicated that there were fluctuations in each of these parameters. This study showed that the CF of the Volume in LF was correlated with CF of the Velocity in LF, on the other hand, the CF of the Volume in HF was correlated with CF of the vessel diameter in HF.

Acknowledgments: We thank all of the participants who took part in this study. This work was supported by Special Coordination Funds for Promoting Science and Technology from the Japanese Ministry of Education, Culture, Sports, Science and Technology.

Author Contributions: Masashi Watanabe, Soichiro Kaneko, Shin Takayama, Yasuyuki Shiraishi, Takehiro Numata, Natsumi Saito, Takashi Seki, Norihiro Sugita, Satoshi Konno, Tomoyuki Yambe, Makoto Yoshizawa, Nobuo Yaegashi and Tadashi Ishii conceived and designed the experiments; Shin Takayama performed the experiments; Masashi Watanabe, Soichiro Kaneko, Yasuyuki Shiraishi, Natsumi Saito, Satoshi Konno, Tomoyuki Yambe, and Makoto Yoshizawa analyzed the data; all authors wrote the paper.

Conflicts of Interest: The authors declare no conflict of interest.

\section{References}

1. King, E.; Cobbin, D.; Ryan, D. The reliable measurement of radial pulse: Gender differences in pulse profiles. Acupunct. Med. 2002, 20, 160-167. [CrossRef] [PubMed]

2. Lad, V. Secrets of the Pulse: The Ancient Art of Ayurvedic Pulse Diagnosis, 2nd ed.; The Ayurvedic Press: Albuquerque, NM, USA, 2006.

3. Subbarayappa, B.V. The roots of ancient medicine: An historical outline. J. Biosci. 2001, 26, 135-143. [CrossRef] [PubMed]

4. Hsu, E. A hybrid body technique: Does the pulse diagnostic cun guan chi method have Chinese-Tibetan origins? Gesnerus 2008, 65, 5-29. [PubMed]

5. Steiner, R.P. Tibetan medicine: Part II: Pulse diagnosis in Tibetan medicine: Translated from the first chapter for the fourth tantra (rGyud-bzi). Am. J. Chin. Med. 1987, 15, 165-170. [CrossRef] [PubMed]

6. Steiner, R.P. Tibetan medicine. Part III: Pulse diagnosis in Tibetan medicine. Translated from the first chapter of the Fourth Tantra (rGyud-bzi). Am. J. Chin. Med. 1988, 16, 173-178. [CrossRef] [PubMed]

7. Steiner, R.P. Tibetan medicine Part IV: Pulse diagnosis in Tibetan medicine. Am. J. Chin. Med. 1989, 17, 79-84. [CrossRef] [PubMed]

8. Zhu, W. Zhongyi Zhenduanxue (Study of the Chinese Medicine Diagnosis); Renmin Weisheng Chuban: Beijing, China, 1999.

9. Yambe, T.; Yoshizawa, M.; Taira, R.; Tanaka, A.; Iquchi, A.; Tabayashi, K.; Tobita, S.; Nitta, S. Fluctuations of Emax of the left ventricle: Effect of atrial natriuretic polypeptide. Biomed. Pharmacother. 2001, 55 (Suppl. S1), 147s-152s. [CrossRef]

10. Sato, T.; Nishinaga, M.; Kawamoto, A.; Ozawa, T.; Takatsuji, H. Accuracy of a continuous blood pressure monitor based on arterial tonometry. Hypertension 1993, 21, 866-874. [CrossRef] [PubMed]

11. Castiglioni, J.; Frattola, A.; Parati, G.; Rieenzo, M. 1/f-modelling of blood pressure and heart rate spectra: Relations to aging. In Proceedings of the 1992 14th Annual International Conference of the IEEE Engineering in Medicine and Biology Society, Paris, France, 29 October-1 November 1992; pp. 465-466.

12. Kuusela, T.A.; Kaila, T.J.; Kahonen, M. Fine structure of the low-frequency spectra of heart rate and blood pressure. BMC Physiol. 2003, 3, 11. [CrossRef] [PubMed]

13. Marsh, D.J.; Osborn, J.L.; Cowley, A.W., Jr. 1/f fluctuations in arterial pressure and regulation of renal blood flow in dogs. Am. J. Physiol. 1990, 258, F1394-F1400. [PubMed]

14. Pomeranz, B.; Macaulay, R.J.; Caudill, M.A.; Kutz, L.; Adam, D.; Gordon, D.; Kilborn, K.M.; Barger, A.C.; Shannon, D.C.; Cohen, R.J.; et al. Assessment of autonomic function in humans by heart rate spectral analysis. Am. J. Physiol. 1985, 248, H151-H153. [PubMed] 
15. Parati, G.; Saul, J.P.; di Rienzo, M.; Mancia, G. Spectral analysis of blood pressure and heart rate variability in evaluating cardiovascular regulation. A critical appraisal. Hypertension 1995, 25, 1276-1286. [CrossRef] [PubMed]

16. Akselrod, S.; Gordon, D.; Ubel, F.A.; Shannon, D.C.; Berger, A.C.; Cohen, R.J. Power spectrum analysis of heart rate fluctuation: A quantitative probe of beat-to-beat cardiovascular control. Science 1981, 213, 220-222. [CrossRef] [PubMed]

17. Pagani, M.; Lombardi, F.; Guzzetti, S.; Rimoldi, O.; Furlan, R.; Pizzinelli, P.; Sandrone, G.; Malfatto, G.; Dell'Orto, S.; Piccaluga, E.; et al. Power spectral analysis of heart rate and arterial pressure variabilities as a marker of sympatho-vagal interaction in man and conscious dog. Circ. Res. 1986, 59, 178-193. [CrossRef] [PubMed]

18. Hall, J.E. Guyton and Hall, Textbook of Medical Physiology; SAUNDERS ELSEVIE: Philaclclphia, PA, USA, 2011.

19. Griffith, T.M. Vasomotioin: The case for chaos. J. Biorheol. 2009, 23, 11-23. [CrossRef]

20. Soga, J.; Nishioka, K.; Nakamura, S.; Umemura, T.; Jitsuiki, D.; Hidaka, T.; Teragawa, H.; Takemoto, H.; Goto, C.; Yoshizumi, M.; et al. Measurement of flow-mediated vasodilation of the brachial artery: A comparison of measurements in the seated and supine positions. Circ. J. 2007, 71, 736-740. [CrossRef] [PubMed]

21. Burns, P.N.; Jaffe, C.C. Quantitative flow measurements with Doppler ultrasound: Techniques, accuracy, and limitations. Radiol. Clin. N. Am. 1986, 23, 641-657.

22. Taylor, K.J.; Holland, S. Doppler US. Part I. Basic principles, instrumentation, and pitfalls. Radiology 1990, 174, 297-307. [CrossRef] [PubMed]

23. Gill, R.W. Measurement of blood flow by ultrasound: Accuracy and sources of error. Ultrasound. Med. Biol. 1985, 11, 625-641. [CrossRef]

24. Corretti, M.C.; Anderson, T.J.; Benjamin, E.J.; Celermajer, D.; Charbonneau, F.; Creager, M.A.; Deanfield, J.; Drexler, H.; Gerhard-Herman, M.; Herrington, D.; et al. Guidelines for the ultrasound assessment of endothelial-dependent flow-mediated vasodilation of the brachial artery: A report of the International Brachial Artery Reactivity Task Force. J. Am. Coll. Cardiol. 2002, 39, 257-265. [CrossRef]

25. Deanfield, J.; Donald, A.; Ferri, C.; Giannattasio, C.; Halcox, J.; Halligan, S.; Lerman, A.; Mancia, G.; Oliver, J.J.; Pessina, A.C.; et al. Endothelial function and dysfunction. Part I: Methodological issues for assessment in the different vascular beds: A statement by the Working Group on Endothelin and Endothelial Factors of the European Society of Hypertension. J. Hypertens. 2005, 23, 7-17. [CrossRef] [PubMed]

26. Clifford, G.D.; Tarassenko, L. Quantifying errors in spectral estimates of HRV due to beat replacement and resampling. IEEE Trans. Biomed. Eng. 2005, 52, 630-638. [CrossRef] [PubMed]

27. Daskalov, I.; Christov, I. Improvement of resolution in measurement of electrocardiogram RR intervals by interpolation. Med. Eng. Phys. 1997, 19, 375-379. [CrossRef]

28. Hayano, J. Therapeutic Research; Life Science Publishing: Tokyo, Japan, 1996.

29. Berger, R.D.; Saul, J.P.; Cohen, R.J. Transfer function analysis of autonomic regulation. I. Canine atrial rate response. Am. J. Physiol. 1989, 256, H142-H152. [PubMed]

30. Malik, M. Heart rate bvariability: Standards of measurement, physiological interpretation, and clinical use. Circulation 1996, 93, 1043-1065.

31. Montano, N.; Ruscone, T.G.; Porta, A.; Lombardi, F.; Pagani, M.; Malliani, A. Power spectrum analysis of heart rate variability to assess the changes in sympathovagal balance during graded orthostatic tilt. Circulation 1994, 90, 1826-1831. [CrossRef] [PubMed]

32. Perini, R.; Veicsteinas, A. Heart rate variability and autonomic activity at rest and during exercise in various physiological conditions. Eur. J. Appl. Physiol. 2003, 90, 317-325. [CrossRef] [PubMed]

33. Persson, P.B. Spectrum analysis of cardiovascular time series. Am. J. Physiol. 1997, 273, R1201-R1210. [PubMed]

34. Kudaiberdieva, G.; Gorenek, B.; Timuralp, B. Heart rate variability as a predictor of sudden cardiac death. Anadolu Kardiyol. Derg. 2007, 7 (Suppl. S1), 68-70. [PubMed]

35. Hirsch, J.A.; Bishop, B. Respiratory sinus arrhythmia in humans: How breathing pattern modulates heart rate. Am. J. Physiol. 1981, 241, H620-H629. [PubMed]

36. De Angelis, C.; Perelli, P.; Trezza, R.; Casagrande, M.; Biselli, R.; Pannitteri, G.; Marino, B.; Farrace, S. Modified autonomic balance in offsprings of diabeties detected by spectral analysis of heart rate variability. Metab. Clin. Exp. 2001, 50, 1270-1274. [CrossRef] [PubMed] 
37. Mendonca, G.V.; Fernhall, B.; Heffernan, K.S.; Pereira, F.D. Spectral methods of heart rate variability analysis during dynamic exercise. Clin. Auton. Res. 2009, 19, 237-245. [CrossRef] [PubMed]

38. Pichon, A.; Roulaud, M.; Antoine-Jonville, S.; Bisschop, C.D.; Denjean, A. Spectral analysis of heart rate variability: Interchangeability between autoregressive analysis and fast Fourier transform. J. Electrocardiol. 2006, 39, 31-37. [CrossRef] [PubMed]

39. Takada, H.T.; Katayama, M.A. The significance of "LF-component and HF-component which resulted from frequency analysis of heart rate" and "the coefficient of the heart rate variability": Evaluation of autonomic nerve function by acceleration plethysmography. Health Eval. Promot. 2005, 32, 504-512. [CrossRef]

(C) 2016 by the authors. Licensee MDPI, Basel, Switzerland. This article is an open access article distributed under the terms and conditions of the Creative Commons Attribution (CC BY) license (http:/ / creativecommons.org/licenses/by/4.0/). 
Review

\title{
Acupuncture and Neural Mechanism in the Management of Low Back Pain-An Update
}

\author{
Tiaw-Kee Lim ${ }^{1}$, Yan Ma ${ }^{1,2}$, Frederic Berger ${ }^{3}$ and Gerhard Litscher ${ }^{1,4, *}$ \\ 1 University Postgraduate Education of Principles and Practice of Traditional Chinese Medicine, Medical \\ University of Vienna, 1090 Vienna, Austria; jalimee@gmail.com (T.-K.L.); yan.ma@meduniwien.ac.at (Y.M.) \\ 2 Institute of Pathophysiology and Allergy Research, Center for Pathophysiology, Infectiology and \\ Immunology, Medical University of Vienna, 1090 Vienna, Austria \\ 3 Gregor Mendel Institute of Molecular Plant Biology GmbH, Austrian Academy of Sciences, 1030 Vienna, \\ Austria; frederic.berger@gmi.oeaw.ac.at \\ 4 Research Unit of Biomedical Engineering in Anesthesia and Intensive Care Medicine, Research Unit for \\ Complementary and Integrative Laser Medicine, and TCM Research Center Graz, Medical University of \\ Graz, 8036 Graz, Austria \\ * Correspondence: gerhard.litscher@medunigraz.at; Tel.: +43-316-385-83907
}

Received: 6 June 2018; Accepted: 21 June 2018; Published: 25 June 2018

\begin{abstract}
Within the last 10 years, the percentage of low back pain (LBP) prevalence increased by $18 \%$. The management and high cost of LBP put a tremendous burden on the healthcare system. Many risk factors have been identified, such as lifestyle, trauma, degeneration, postural impairment, and occupational related factors; however, as high as $95 \%$ of the cases of LBP are non-specific. Currently, LBP is treated pharmacologically. Approximately 25 to $30 \%$ of the patients develop serious side effects, such as drowsiness and drug addiction. Spinal surgery often does not result in a massive improvement of pain relief. Therefore, complementary approaches are being integrated into the rehabilitation programs. These include chiropractic therapy, physiotherapy, massage, exercise, herbal medicine and acupuncture. Acupuncture for LBP is one of the most commonly used non-pharmacological pain-relieving techniques. This is due to its low adverse effects and cost-effectiveness. Currently, many randomized controlled trials and clinical research studies have produced promising results. In this article, the causes and incidence of LBP on global health care are reviewed. The importance of treatment by acupuncture is considered. The efforts to reveal the link between acupuncture points and anatomical features and the neurological mechanisms that lead to acupuncture-induced analgesic effect are reviewed.
\end{abstract}

Keywords: low back pain (LBP); acupuncture; mechanism of acupuncture; anti-nociceptive; purinergic receptors; adenosine triphosphate (ATP); adenosine

\section{Introduction}

Low back pain (LBP) is one of the most frequently encountered musculoskeletal disorders in today's society. LBP is defined as pain and discomfort, located in between the costal margin and the inferior gluteal folds, with or without referred leg pain [1-4]. LBP is categorised according to duration as acute (less than 6 weeks), sub-acute (between 6 and 12 weeks), or chronic (more than 12 weeks) [4-6].

LBP interferes with activities of daily living [7], work performance [8,9], and is a major reason for people to seek medical consultation $[10,11]$. This disorder contributes to a substantial burden on individuals, employers, the healthcare system and society in general. According to a report published by the World Health Organization (WHO) in 2013, back pain, together with neck pain, was the second highest cause amongst the 20 leading non-fatal health outcomes from the year 2000 to 2011 [12]. 
The survey, The Global Burden of Disease Study 2016 (GBD 2016), published in the Lancet in $2017[13,14]$, highlights the extent of health loss due to diseases, injuries, risk factors, prevalence and mortality rate by age, sex, and geography at specific points in time. In the GBD 2016, LBP was the number one cause for the most years lived with disability (YLDs) in the world [13].

The disability-adjusted life years (DALYs) are calculated as the combination of years of life lost (YLLs) due to premature mortality and years lived with disability (YLDs) [14,15]. Because LBP does not cause mortality, therefore YLDs are the same as disability-adjusted life years (DALYs). DALYs for LBP, together with neck pain, was on the 4th position out of the 30 leading global DALYs in the GBD 2016 [14]. This was much higher than the average DALYs related to road injuries, HIV/AIDS, diabetes, chronic obstructive pulmonary disease (COPD) and lung cancer [14]. The overall estimation of DALYs for LBP in 2016 was 57.6 million, which represents more than $40 \%$ of the total number of 140 million DALYs of all the musculoskeletal disorders combined. In Austria, the GBD 2015 for YLDs and DALYs due to LBP and neck pain are ranked at No. 1 and No. 2, respectively [16].

The estimated global prevalence of the population affected by LBP was $9.2 \%$ according to $\mathrm{WHO}$ in 2010 [12]. Hoy et al. estimated that the ranges of prevalence of LBP at a point, 1-month, 1-year and over a lifetime were $18.3 \%, 30.8 \%, 38.0 \%$ and $38.9 \%$, respectively [17]. In the GBD 2016, it was estimated that the prevalence of LBP for the year 2016 was more than 511 million of the world's population, an increase of $18.0 \%$, as compared to 2006 [7]. LBP results in high costs to society due to increased demands on the healthcare system and work absence. In the USA alone, it has been estimated that LBP costed between US $\$ 100-200$ billion yearly [1]. This amount has more than doubled from 1991 to 2016 [18].

In this scientific article, causes of LBP are surveyed and the links between anatomical features and acupuncture points are outlined. This is followed by a review of randomized controlled trials (RCTs) and of mechanisms potentially targeted by acupuncture treatments.

\section{Causes and Risk Factors of Lower Back Pain}

LBP is very common, and yet is a very complex multifactorial disorder with much possible etiology. These originate from injuries, trauma or fractures to the anatomical structure [19-21]; lumbar spine degeneration [22,23]; and disc herniation or nerve entrapment [24-26]. Other causes associated with an increased risk of LBP, include infections, autoimmune diseases, orthopedic diseases or tumours [27-33]. LBP results also from occupational ergonomic factors related to heavy physical work, repetitive actions due to occupational requirements [1,2,34-39]; as well as sports activities or sports-related injuries [40,41]; sedentary lifestyle, prolonged sitting or inactivity and lack of exercises [42-44]; post operation or surgery-induced [45,46]; secondary from other medical conditions [47-49]; lifestyle factors [50]; poor trunk control and postural impairment [51]; psychosocial and behavior-related factors from smoking, alcohol abuse, obesity, depression and stress [1,6,14,52-57]; socio-economic factors [58]; and ageing $[59,60]$. However, it is often difficult to identify the origin of LBP $[1,5,6,61-65]$ and $85-95 \%$ of the total cases of back problems [1,63-65] are not associated with a specific patho-anatomical origin, or attributed to any recognizable pathology patterns.

\subsection{Age and Gender}

The age group 40-69 is affected with the highest incidence of LBP [17], and women have higher LPB prevalence than men $[17,50,57,66-69]$.

Großschädl et al. studied the LBP prevalence of the Austrian population in 1983, 1991, 1999, and 2006/7. During this period, they found a marked increase in the rate of LBP for both sexes, especially more so in women over recent years [69]. This increasing trend of the rate of LBP is recorded worldwide and might be related to women's involvement in the workforce, while their house chores do not diminish $[69,70]$. LBP's risk factors specific to women comprise exposure to musculoskeletal loads due to pregnancy [71-73]; menstruation [74,75]; menopausal [66,76,77]; hormone [66,78]; osteoporosis [68,79]; low bone mineral density [80,81]; and conditions associated 
with ageing [59,82]. In contrast, certain studies show that men have a higher rate of LBP [1,2], especially those involved in heavy physical work and repetitive movements [1,2,6,38,39].

\subsection{Obesity and Smoking}

Schneider et al. reported that the prevalence of LBP is significantly higher for women affected by overweight, low level of social support, a sedentary lifestyle, smoking and lower income groups [67]. The association between obesity and LBP remains controversial. Few studies on the relation between obesity and LBP have been published so far. Obesity is considered as one of the elements that contributes to the increasing rate of LBP $[56,57,67-69,83,84]$. Heuch et al. estimated that the rate of LBP increases in parallel with the rate of body mass index (BMI) [83]. As stated by a guideline by WHO, an adult is viewed as overweight when the BMI is greater or equal to 25 , and one is considered obese when the BMI has reached 30 or more [85]. In addition, increased BMI also affects the incidence of neck pain and arthritis [86]. A group of studies led to speculation of connections between smoking and obesity that may result in LBP $[67,87]$. Yet, such a conclusion was challenged by another study, which did not find such link between LBP, smoking and obesity [88].

\section{Theories of Pain}

For many centuries, people have been seeking the origin of pain and ways to alleviate it. Despite a marked progress in our understanding of pain, many aspects of the mechanisms involved remain unclear. Pain is a very subjective issue, as it is interpreted differently by each patient. Some people have a very high pain threshold, which allows them to tolerate pain extremely well. For others, even a slight trigger of stimulation might cause them to suffer in agony. Because of this huge difference in perception of pain magnitude, it is difficult to understand the degree of suffering by a patient. The visual analogue scale (VAS), which was created in 1921 by Hayes and Patterson [89], is a simple tool to judge a patient's perspective of pain, to translate a subjective level of pain into an objective measurement.

Pain is classified as a nociceptive pain (caused by excitation of nociceptors by external stimuli), inflammatory pain (intervened by inflammatory mediators released by an inflamed organ), or neuropathic pain (induced by lesions of the central or peripheral nervous system) [90]. According to Merskey and Bogduk, "pain is an unpleasant sensory and emotional experience associated with actual or potential tissue damage or described in terms of such damage" [91].

The discovery of nociceptor by Charles Sherrington in 1906, has changed forever the way we consider the concept of the central nervous system (CNS) [92]. This gave rise to many modern studies about pain management, such as nerve blocking and analgesic effect by acupuncture. The Gate Control Theory of Pain, which was proposed in 1965 by Melzack and Wall, suggested that the brain has a "gate" mechanism either blocking or allowing pain messages to reach the brain [93]. Although their theory was later proven to be flawed, it did provide a useful overall concept of how pain is experienced and many researchers engaged in this field of study. One of them resulted in the invention of transcutaneous electric nerve stimulation (TENS) for the management of LBP [94].

In 1973, Pert and Synder discovered the opiate receptor, the cellular binding site for endorphins in the brain [95]. Two years later, a group of British scientists led by Hughes and Kosterlitz, found the breakthrough in the field of molecular receptor studies, the discovery of enkephalin [96]. This was followed by studies that led to our current knowledge of endorphins, the body's very own natural mechanism of painkiller [97-100].

To be able to ease the pain experienced by patients, first we need to understand the root cause of pain and the mechanism that triggered the transmission of pain. Having a better understanding of the nervous system's own mechanism of analgesia, such as that triggered by the stimulation of needles by acupuncture, pain management of LBP by acupuncture is no longer a placebo or a contextual effect, but rather, an evidence-based scientific proof of an ancient practice. These topics are addressed in more detail below. 


\section{Pain Mechanism}

The mechanism of pain is a very complex process, due to the involvement of multiple layers of the neural circuit, from the stimulation of the receptors to the chemical reaction in the CNS. The perception of pain is called nociception, and it is initiated by nociceptors present at free nerve endings [101]. The nociceptors, part of the architecture of neural circuits, are spread all over the body, from the superficial layers of skin to the deeper tissues and internal organs.

Tissue injury by noxious stimuli is detected by the nociceptors. This information is transmitted as electrical nerve impulses, or action potentials, via the nerve fibres, called the primary afferent neurons to the dorsal root ganglia (DRG). DRG are linked to dorsal root in the spinal cord through the dorsal root. The electrical signal synapses with the second afferent neuron at the dorsal horn of the grey matter. From here, the signal crosses over to the opposite side of the spinal cord, and connects to the ventral white matter and further links to the spinothalamic tract. The signal is now traveling upward from the spinal cord to the thalamus in the brain where pain is generated. In the thalamus, a third synapse occurs and the nerve impulse is transmitted via the thalamocortical tract to the cerebral cortex. This process tells us the exact location of the pain. Nociceptors enable humans to recognise pain stimuli and therefore to respond accordingly, such as pulling away our hand from a fire or sharp object [102-109].

\subsection{Nerve Fibres}

There are two types of nerve fibres, afferent and efferent. Afferent means ascending, and qualifies sensory fibres sending signals to the brain. While efferent signifies descending, and defines motor fibres, which relay messages away from the CNS. The afferent nerve fibres convey signals concerning potential damage or injury from outside and inside the body.

The afferent nerve fibres in the human's body are further divided into four major types of primary sensory neurons, which can be differentiated morphologically and functionally into A-alpha $(\mathrm{A} \alpha)$, A-beta $(\mathrm{A} \beta), \mathrm{A}$-delta $(\mathrm{A} \delta)$ and $\mathrm{C}$ fibre [110]. A $\alpha$ fibres represent motor fibres connected to voluntary muscles and include certain sensory fibres that transmit position sensation from skeletal muscles. $\mathrm{A} \beta$ fibres carry non-noxious stimuli and convey the sensations of touch, vibration and pressure from the skin [111]. There are only two types of nerve fibres involved in the transmission of painful impulses. The A $\delta$ fibre is myelinated, enables fast transmission of impulses and produces sharp and well localised pain. The second type, the unmyelinated C fibre, is slow in transmission and produces dull or burning pain, the exact location of which is diffused and poorly localised [105-107,109]. Kagitani et al. demonstrated that acupuncture stimulation enables production of various autonomic functions on both $A \delta$ and $C$ fibres [110]. While Zhao suggested that stimulation by manual acupuncture (MA) and electroacupuncture (EA) activates $A \delta$ and C fibres to produce an analgesic effect [112].

\subsection{Inflammatory Soup}

Tissue damage causes release of a variety of chemical substances into the extracellular space around the receptor terminals. These chemical substances comprise bradykinin, histamine, serotonin, prostaglandins, nerve growth factor (NGF), substance $\mathrm{P}$, adenosine triphosphate (ATP), calcitonin gene-related peptide (CGRP), protons $\left(\mathrm{H}^{+}\right)$and other purines and indolamines. Altogether, they form the "inflammatory soup" and are able to interact and activate the nociceptive fibres that cause localised pain and inflammation [102-109].

\section{Treatment of LBP by Acupuncture}

The goal of LBP treatment is to control or reduce pain, to improve structure impairment of the spine and to return to the normal life activities as soon as possible. Most current international guidelines recommend pharmacological management for pain relief of LBP, including paracetamol, non-steroidal anti-inflammatory drugs (NSAIDs), muscle relaxant, opioid analgesics, epidural steroid, 
anticonvulsants, antidepressants, and corticosteroids, among others [1,5,61,65,113-116]. However, most of these pharmacological treatments produce limited pain relief and are accompanied by serious side effects, such as drowsiness, dizziness, addiction, allergic responses, reversible reduction of liver function, and negative impacts on gastrointestinal functions [1,5,61,113,114,116,117]. At least one of these side effects is experienced in approximately 25 to $30 \%$ of patients treated with opioids [118]. The major problem with this approach is that pain may be temporarily relieved but the source of LBP is not identified and alternative treatments of LBP are required. These include multidisciplinary rehabilitations based on physiotherapy, spinal manipulation, exercise therapy, massage therapy, cognitive-behaviour therapy, yoga, tai-chi, and acupuncture $[5,61,65,113,115]$. Here, the focus is on a critical assessment of the benefits of acupuncture in LBP treatment.

\subsection{Acupuncture}

Acupuncture is part of the healing system of Traditional Chinese Medicine (TCM). It consists of insertion of thin needles into the muscle, on specific acupuncture points placed along meridians to treat a variety of conditions. Apart from the traditional manual acupuncture (MA), there are other methods to stimulate acupuncture points for therapeutic purposes, such as electroacupuncture (EA), acupressure, laser acupuncture and moxibustion.

The practice of acupuncture as pain relief is widely used in many of the countries throughout the world [119]. Despite a lack of well-designed clinical studies supporting its efficacy, and skeptical opinions from many, it is nevertheless well accepted by many patients globally. Acupuncture is legally recognised by many countries in Asia, Australia, America, Canada, and some parts of Europe and Latin America [120].

World Health Organization (WHO) estimated that one-third of the world's population has no regular access to modern medicines, especially in many parts of Africa, Asia and Latin America. Fortunately, complementary and alternative medicine (CAM) such as herbal and traditional medicine and acupuncture are available and accessible [120].

In the USA alone, the number of acupuncture users increased by 50\% between 2002 and 2012 [121]. As of December 2010, there were approximately 305,000 registered Complementary \& Alternative Medicine (CAM) providers across Europe, including 96,380 acupuncturists. Eighty-thousand were medical and 16,380 were non-medical practitioners [122]. In Austria, there were 3531 doctors qualified with the diploma of acupuncture from the Austrian Medical Association (Diplom für Akupunktur der Österreichischen Ärztekammer) in 2011 [123]. According to the Law of Health Services Austria (Bundesgesetz über die Gesundheit Österreich), acupuncture is a scientifically recognized treatment that can be provided in hospitals [124]. In contrast with increasing interest and practice of acupuncture, there is a persistent lack of infrastructure and funding dedicated to research and teaching in this field [125].

\subsection{Brief History of Acupuncture}

The root of Traditional Chinese Medicine (TCM) can be traced back over 3000 years ago in China. While acupuncture is the best known modality of TCM in the West, TCM has a long history of great use of herbal remedies. Apart from acupuncture and herbal medicine, TCM also comprises of Qigong, Taichi and Tuina. The first written medical text on acupuncture was mentioned in the Huang Di Nei Jing (The Yellow Emperor's Internal Classic). It comprised of two volumes: The first one is Su Wen (Basic Questions), which covers the diagnostic methods and theoretical foundation of TCM [126]. The second part is called Ling Shu (The Spiritual Pivot) and explains acupuncture therapy such as the description of meridians, functions of the acupuncture points, needling techniques, types of Qi and the location of 160 points [127]. Two other classic texts which mention acupuncture in depth are Nan Jing (The Classic of Difficult Issues) [128] and Zhen Jiu Jia Yi Jing (The Systematic Classic of Acupuncture and Moxibustion). The latter was written by Huangfu Mi, who added another 189 acupuncture points to reach a total of 349 [129]. The precise history of these four books is unclear 
as they were edited, annotated and reinterpreted several times. Another obstacle of learning and understanding the teaching of TCM is the difficulty in translating these ancient Chinese texts [130].

Unlike western medicine, which has a clear distinct path that can be traced back to Hippocrates [131], there is undocumented evidence to when and where the origin of acupuncture came from due to the loss of many of the valuable ancient texts. The archaeological discovery of "bian shi" (a kind of flattened and sharpened stone) from the era of the New Stone Age in China (8000-2000 $\mathrm{BC})$, was believed to represent the ancient acupuncture needle for treating illnesses by pricking certain parts of the body. During the Warring States (475-221 BC), metal needles were developed to substitute the stone needles [132].

In the 6th century, acupuncture together with the teaching of TCM spread to Korea and Japan. Later in the 10th century, acupuncture arrived in Vietnam through the commercial routes. The practice of acupuncture was brought back to France by the Jesuit missionaries in the 16th century [133]. The very first acupuncture description that appeared in the West was written by Wilhelm Ten Rhyne in 1683, a physician employed by the Dutch East India Company, who was based in Japan [134].

In the USA, acupuncture has gained sudden attention and popularity thanks to the New York Times writer James Reston's article in 1971, entitled "Now, About My Operation in Peking" [135]. He described his first-hand experience of acupuncture with an emergency appendectomy and post-operative care while on his assignment to China prior to President Nixon's visit. This has prompted many doctors visiting China to observe and study the effectiveness and benefits of acupuncture, with a specific interest in its use for surgical analgesia [136-140].

\subsection{Theory of Traditional Chinese Medicine}

Traditional Chinese Medicine (TCM), one of the most important components of Chinese culture, has a long-established history and consists of a wealth of experience and a profound source of knowledge. It has made a great contribution to the overall welfare of its people. At present, TCM is also becoming well known globally, playing a unique role in the development of public healthcare [141].

In contrast to the anatomical and scientific perspective, the theories of the mechanism of action in TCM on LBP differ significantly from those of modern pharmacology. TCM states that pain is caused by internal disharmony between Yin and Yang, imbalance between Qi and Blood, and disparity within the Five Elements [142]. Qi, the essence of life, is believed to circulate within special conduits in the body termed meridians and collaterals that connect all parts of the body, including connecting the organ systems with each other and their related sense organs. When there is insufficiency of Qi, or when the meridians are blocked, this causes an imbalance between Yin and Yang, perturbs the meridians, hinders the smooth flowing of Qi and results in stagnation of Qi and blood, leading to pain and illness [143-146].

\section{Acupuncture Principles}

Acupuncture is based on the theory of channels, simply referred to as meridians and collaterals, which are the branches of the meridians. There are 14 main meridians, and each consists of an internal pathway that runs inside the body and links to an external pathway where acupuncture points are located. Qi flows through these pathways of meridians interconnecting with each other, and is linked to specific internal organs, which are also called Zangfu organs [146]. Stimulation on the acupuncture points by acupuncture needle enables unblocking of the meridians, hence promoting a smooth flow of Qi [147].

\subsection{The Anatomical Structure of Acupuncture Points and Meridians}

Detailed lists and definition of acupuncture points are provided in several textbooks [148-151]. Deadman et al., in their book, A Manual of Acupuncture [151], mentioned that "centuries of observation of the existence of tender spots on the body during the course of disease, and the alleviation of symptoms when they were stimulated by massage or heat, led to the gradual discovery of the 
acupuncture points". This sheds a bit of light on the origin of acupuncture. The meridians and the acupuncture points can be compared with airline travel routes: They exist on a map but cannot be "seen".

Many studies have been carried out to obtain concrete evidence supporting the existence of acupuncture points and the Qi flowing meridians. Back in 1963, the North Korean scientist, Kim Bong Han, discovered the Kyungrak System (it means acupuncture meridians and collaterals in Korean), better known as the primo vascular system (PVS). PVS is a threadlike structure defining a circulatory system entirely different from the vascular, nervous, and lymphatic systems. Kim established that the PVS represents anatomical structures linked to acupuncture points and meridians. He proposed that the PVS has the ability of hematopoietic functions as well as to regenerate injured tissues and heal wounds [152]. Many scientists tried to reproduce his result but failed. That was because Kim did not mention what kind of staining blue dye was used in his studies [153]. In 2002, Shin et al. confirmed the existence of PVS [154].

Stefanov et al. proposed that the PVS is the communication system between living organisms and the environment. They believed that this system is involved in channeling the flow of energy and information relayed by biophotons (electromagnetic waves of light) and is closely related to DNA [155]. Independent experiments involved injection of radioactive tracers at acupuncture points to attempt to map out and visualize the routes of meridians [156-158]. An alternative study by Langevin and Yandow led to the hypothesis that networks of interstitial connective tissue constitute the link between acupuncture points and meridians tissue [159]. Ultrasound imaging reveals a visible connective tissue forming an intramuscular cleavage plane at acupuncture points but not at control points [159]. Another anatomical distinctive feature of acupuncture points is high densities of nerve endings [160,161].

Other studies have explored the possibility of physiological differences between acupuncture points and surrounding tissues. Several reports conclude that the skin electrical impedance along meridians is lower than in their surroundings [162-164]. However, Stux and Pomeranz were quite skeptical about these kinds of electrical properties [165] and Kramer et al. concluded that skin electrical resistance at acupuncture points can either be lower or higher compared to the surrounding area [166]. In 2010, Litscher et al. developed a miniaturized 48-channel skin impedance measurement system for needle and laser acupuncture [164]. This system was further improved and a new multi-channel skin resistance measuring system, called GEDIS (Graz ElectroDermal Impedance measurement System) was used to differentiate the electrical skin resistance measurement between an acupuncture point and a placebo point. The system performs "electrodermal mapping", and shows that the skin resistance at the acupuncture point has lower impedance values as compared to the non-acupuncture point [167].

Other studies suggested that there are more mast cells distributed at acupuncture points [168-170]. Marcelli, Peuker and Cummings, and Cheng, have made some studies of the morphological characteristics between the meridians and the anatomical structure [171-174]. Shaw and McLennan did an anatomical dissection study based on investigation of cadaveric specimens. They concluded that acupuncture points and meridians are purposefully named to reflect the observable physical form, e.g., heart meridian, lung meridian, etc. [175]. Anatomical dissections in ancient China are mentioned in chapter 12 of the Huang Di Nei Jing Ling Shu. Here, the imperial physician Qi Bo explains the fundamental structures of the human organism to the emperor Huang Di. The physician says: "After someone has died his body can be anatomically dissected and be examined (for medical investigation)" [127]. As another source of evidence to prove that acupuncture points are anatomically correct, the chapter 42 of Nanjing describes the length, diameter, weight and capacity of the internal organs [120]. In chapter 7 of Book 3 from Mi Huang-Fu's Jia Yi Jing, the measurement of bones and intestines, and the volume of the stomach and intestines were clearly explained [129]. That is why the names for the internal organs used today are the same as the name of TCM organs defined more than 2000 years ago from Huang Di Nei Jing Ling Shu [127].

Acupuncture points are thus positioned at precise anatomical structures. For example, in TCM theory, the lung (LU) meridian is paired with the large intestine (LI) meridian [146]. LU 7 Lieque 
(Broken Sequence) is also the Luo-Connecting Point of the Lung meridian. From LU 7, the meridian branches out and links to the large intestine meridian, at LI 4 Hegu (Joining Valley), also known as Yuan-Source Point [151]. From an anatomical point of view, both points are located at the branch from the main cephalic vein, which is supplied by the radial nerve [176]. This evidence supports that acupuncture points and meridians correspond to anatomically defined positions in the human body. Pushing this idea further at the molecular level, Zhang et al. studied the connection between the heart and stomach meridians to cardiovascular diseases (CVDs) and gastrointestinal disorders (GIDs) and found that both CVDs and GIDs express sets of genes which are functionally related [177].

According to Thomas Myers, the author of Anatomy Trains, the whole body is a unique linkage of myofascial and locomotor anatomy in which the muscles are connected to the fascial net. The fascia, with an appearance akin to a spider's web, is a continuous sheath of tissue, covering and interpenetrating every muscle, bone, nerve, artery, vein and lymph vessel, as well as, all internal organs, brain and spinal cord [178]. The fascial anatomy has a striking anatomical correlation to acupuncture points and meridians. Finando and Finando suggest that all fundamental characteristics of acupuncture treatment are consistent with stimulation of the fascia [179].

\subsection{Acupuncture Points, Ashi Points, Myofascial Trigger Points (mTrPs) and Referral Pain}

Interestingly, acupuncture points were rediscovered by researchers in western medicine. A study done by Kellgren in 1938 reported that intramuscular injection of sterile saline caused pain at locations away from the injection site [180]. Inspired by this study, Travell et al. realized that pressure applied to specific points (later defined as trigger points) relieved pain from shoulder and arm pain [181]. Later, Travell together with Simons, through their collaboration published their texts Myofascial Pain and Dysfunction, the Trigger Point Manual in 1983 [182,183]. Trigger points were described as locally tender points associated with focal areas of muscle shortening termed "taut bands". When palpated, trigger points can feel like small nodules within the muscle and may refer pain distally [182,183]. Dorsher, did a study based on Travell and Simons' texts, and found that $93.3 \%$ of the common myofascial trigger points (238 out of 255) correspond to the classical acupuncture points [184].

Translated into Chinese medicine terms, the above statement means that a trigger point is an area of Qi stagnation in the muscles. It also means that emotional stress may be the aetiological factor causing Qi stagnation in the muscles [144]. Ashi points, are very comparable to trigger points and were first mentioned in Bei Ji Qian Jin Yao Fang (Important Formulas Worth a Thousand Gold Pieces for Emergency) compiled by Sun Simiao in the Tang dynasty [185]. Chapter 13 of Huang Di Nei Jing Ling Shu, describes a treatment method, referring to Ashi points as "tenderness was taken as needling point" [127]. Ashi points are also used in other methods of treatment, such as Japanese shiatsu, Thai massage and Swedish deep tissue massage [186].

It is interesting to note that the route of referred pain from the heart, such as myocardial ischemia, is identical to the pathway of the heart meridian $[187,188]$. This kind of referred pain occurs due to the sharing of information between visceral and somatic afferent nerve fibres within overlapping spinal cord segments. The confusion about the origin of pain results from the density of sensory nerves higher in the skin than the heart [189].

Rong and Zhu suggested a common biological connection between the cardiac sympathetic nerve and the heart meridian (HM) [190]. Their findings provide a possible morphological and physiological explanation for the relation between referred cardiac pain and HM [190]. It is thus not surprising that traditionally, HM is being used to treat cardiac related illness, such as palpitation or cardiac arrhythmia, coronary heart disease, angina pectoris, myocardial infarction, ischaemic heart disease, cardiovascular disease and hypercholesterolemia [144,148,150,151,191-194]. 


\section{Qi and Energy Fields}

In the theory of TCM, Qi is thought to be a form of balancing energy that flows through the body. Qi keeps the body in harmony with the internal and the external environment that brings together the overall wellbeing of a person [126,129,142-144,150].

Chapter 18 of Huang Di Nei Jing Ling Shu [127], and Maciocia [192], give a detailed explanation about Qi formation. The production of Qi comes from the combination of food that we take and air that we breathe. Food is digested by the stomach and the nutrition is absorbed by the spleen and sent to the lung to form gathering Qi. The gathering Qi assists the lung in controlling Qi and breathing, and enhances the heart's function of governing blood and blood vessels. It combines with original Qi that originates from the kidney and can be compared to the dynamic motive force that activates and moves the functional activity of all the organs, to form true Qi. True Qi is the final stage in the process of refinement and transformation of Qi. True Qi is further divided into nutritive Qi and defensive Qi. The main function of nutritive Qi is to nourish the internal organs. Nutritive Qi is also related to blood, and flows in the channels and blood vessels. Nutritive Qi is activated whenever a needle is inserted in an acupuncture point. As the name implies, defensive Qi means to defend or to protect the body. Unlike nutritive Qi, it flows outside of the channels [192].

\subsection{How to Relate Qi to Molecular Knowledge of Modern Medicine?}

In modern medicine, energy is the product of metabolic degradation of food and nutrients. The process of energy formation involves a complex series of various types of chemicals, molecules and cellular reactions. The process of metabolism is a collection of chemical catabolic reactions that break down the food we eat, from protein into amino acids, fats into fatty acids, and carbohydrates into glucose by the enzymes of the digestive system. In a nutshell, the nutrients from food are converted into adenosine triphosphate (ATP), which provides the basic unit of energy required for all functions in the body. A molecule of ATP consists of adenine, ribose, and three phosphate groups. Energy together with adenosine diphosphate (ADP) and a phosphate group (symbolized as $(\mathrm{P})$ ) are released when the terminal phosphate group is split off ATP. About $40 \%$ of the energy released in metabolism is used for cellular functions. The rest is converted to heat, some of which helps with maintaining the body temperature [188]. ATP is also involved in the process of muscle contraction and relaxation [188], inflammation [102] and the analgesic effect of acupuncture [195-201], as explained below.

\subsection{Energy and Information}

Albert Szent-Györgyi, was a Hungarian biochemist who discovered vitamin C (deficiency of vitamin C from malnutrition is the main cause of scurvy [131]) and won the Nobel Prize in Physiology or Medicine in 1937. He quoted "In every culture and in every medical tradition before ours, healing was accomplished by moving energy" [202]. The word "energy", for Szent-Györgyi, meant a cloud of electrons held together by nuclei [203]. He published a trilogy [202,204,205], based on his observation in the presence of energy in the living organisms during his study on cancer research. His study of energy in biology was linked to the role of purines and ATP as extracellular signaling molecules [206]. Later, this would have a great impact on the research of acupuncture. James Oschman, author of Energy Medicine, described the involvement of energy in the healing processes. The body is capable to take in, store, release, conduct, and utilise various kinds of energy and information [207].

Energy and information are also involved in the process of intercellular communication. This is done through action potential, an electrical signal conduction transporting information from one neuron to the next [102]. For example, action potential takes place by sending electrical impulses to the brain through afferent nerve fibres, such as in the event of pain or injury. To carry the information from one neuron to the next, neurotransmitters require energy in the form of ATP [208]. An action potential is also triggered by the stimulation of acupuncture needle insertion, which in turn affects the activities in the brain neuronal network [209]. 
Robert Becker, in his book, The Body Electric [210], hypothesizes that the acupuncture meridians are electrical conductors that send injury signals to the brain, which responds with the appropriate level of direct current to stimulate healing in the injured area. He also believed that the conductivity of the skin is much higher at acupuncture points.

Björn Nordenström, a Swedish radiologist and surgeon, and the author of Biologically Closed Electric Circuits [211], believed that Qi is equivalent to or perhaps the same as the electromagnetic energy found in biologically closed electrical circuits (BCEC). Its Yin and Yang components may be compared to the positive and negative electrical charges of closed circuit ionic flow. If the acupuncture needle is inserted through the normal muscle into the injured muscle, it thus acts as a short circuit to enable the flow of ions. This facilitates healing of the injured tissue. Both Becker [210] and Nordenström [211] believed that the process of healing might work electrically.

In 1980, Cohen et al. measured the magnetic fields produced by the human body with the sensitive magnetic detector called the Superconducting Quantum Interference Device (SQUID) [212]. The body's fluctuating magnetic fields, such as those from the heart are 100 times stronger than the field generated by the brain and can be detected up to a meter away from the body, in all directions, using SQUID-based magnetometers [213]. Both the magnetic fields produced by the heart and brain, can be measured via electrocardiogram (ECG) and electroencephalogram (EEG), respectively. Russek et al. proposed that the heart plays the major role in generating as well as integrating the flow of energy in the body [214].

Probably one of the best possible ways to explain the nature of Qi in a scientific manner is to relate it to the theory of extracellular and intracellular signaling. Qi can be considered to derive from signaling processes in the body, which include phosphorylation/dephosphorylation cascades, and guanine nucleotide-binding proteins (G protein) signaling involving cyclic adenosine monophosphate (cAMP) production and degradation, or calcium release and sequestration [215]. The balance between Yin and Yang that constitutes Qi could reflect cellular activities, which balance the actions of endogenous agonists and antagonists, and the sympathetic and parasympathetic nervous systems [216].

\section{Is Acupuncture a Placebo Intervention?}

Blinded controlled studies have addressed the following question. Do contextual effect and/or placebo acupuncture needle have the same therapeutic outcome as real acupuncture? The results from many randomized controlled trials (RCTs) have both proved and disproved the benefit of acupuncture. As compared to other types of pharmacological RCTs, the study of acupuncture is very complex due to the involvement of many issues, such as inadequate sample size, randomization, sham interventions, and blinding. The tendency that potential bias might arise from both the sham interventions and blinding procedures is another great challenge in such studies. Patients' expectation may also influence the final outcomes of the trials [217]. Table 1 summarized some of the RCTs of LBP treated with acupuncture. There was no special search strategy used to select the publications for Tables 1 and 2 and therefore it is rather an overview than evidence based on a systematic search method. Most articles can be found in the database Pubmed. 


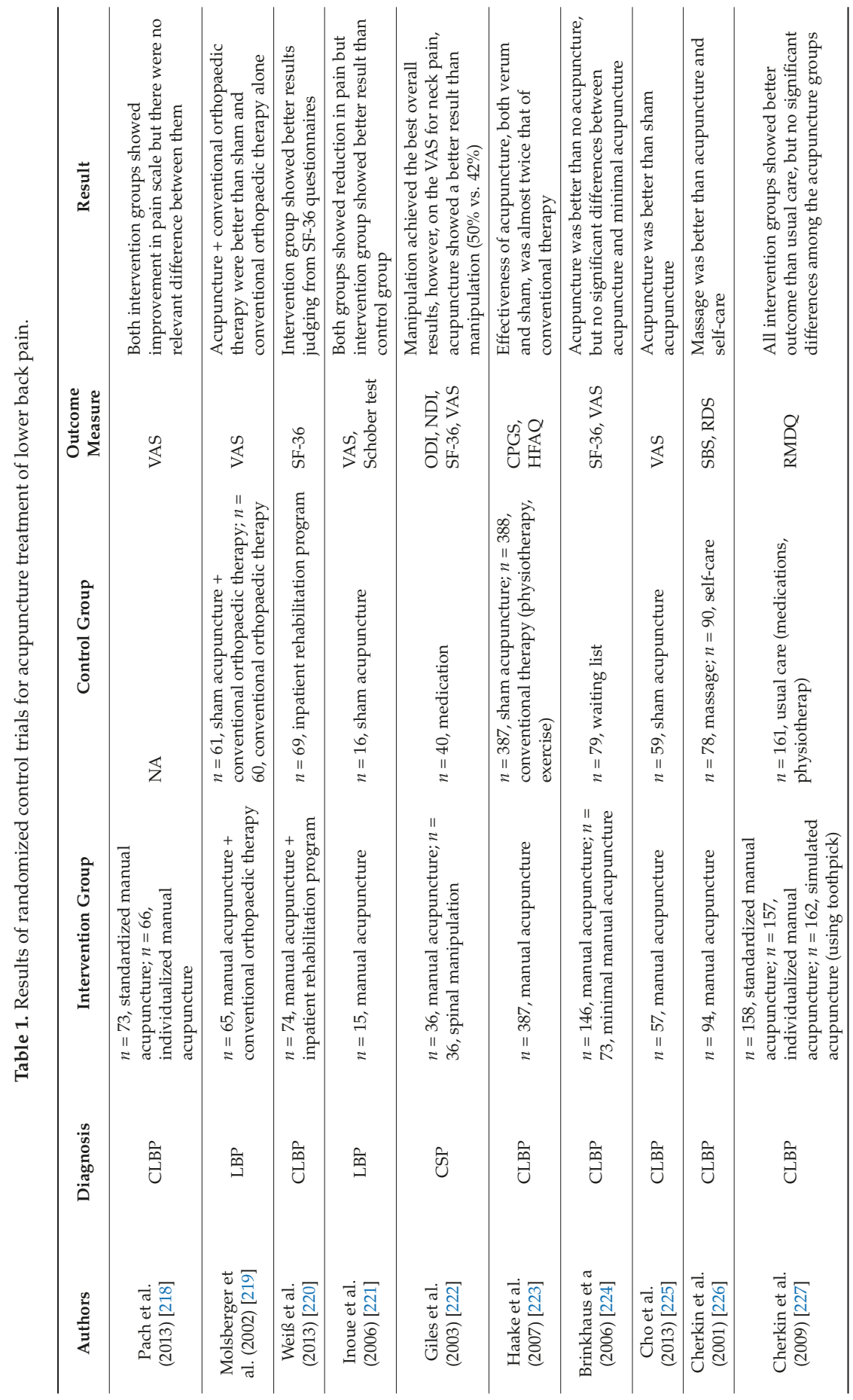




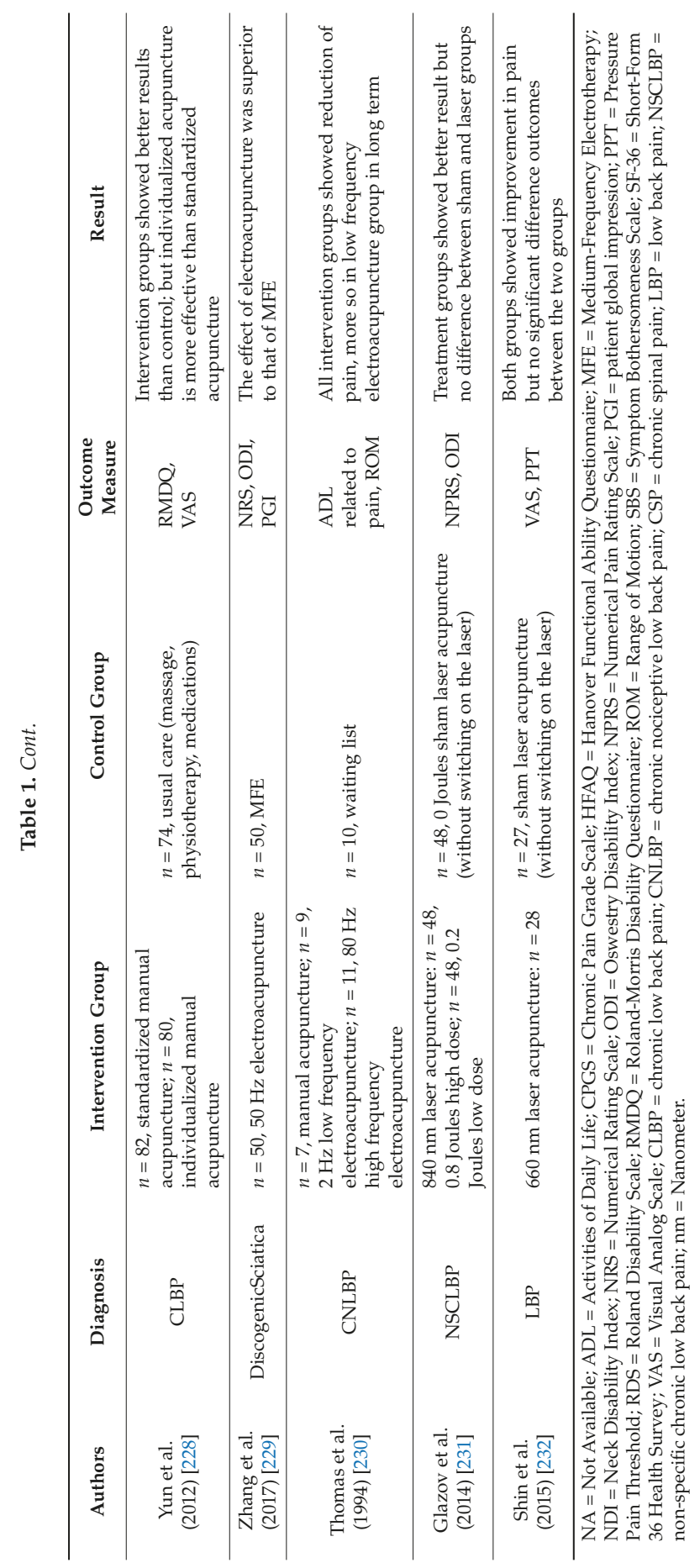




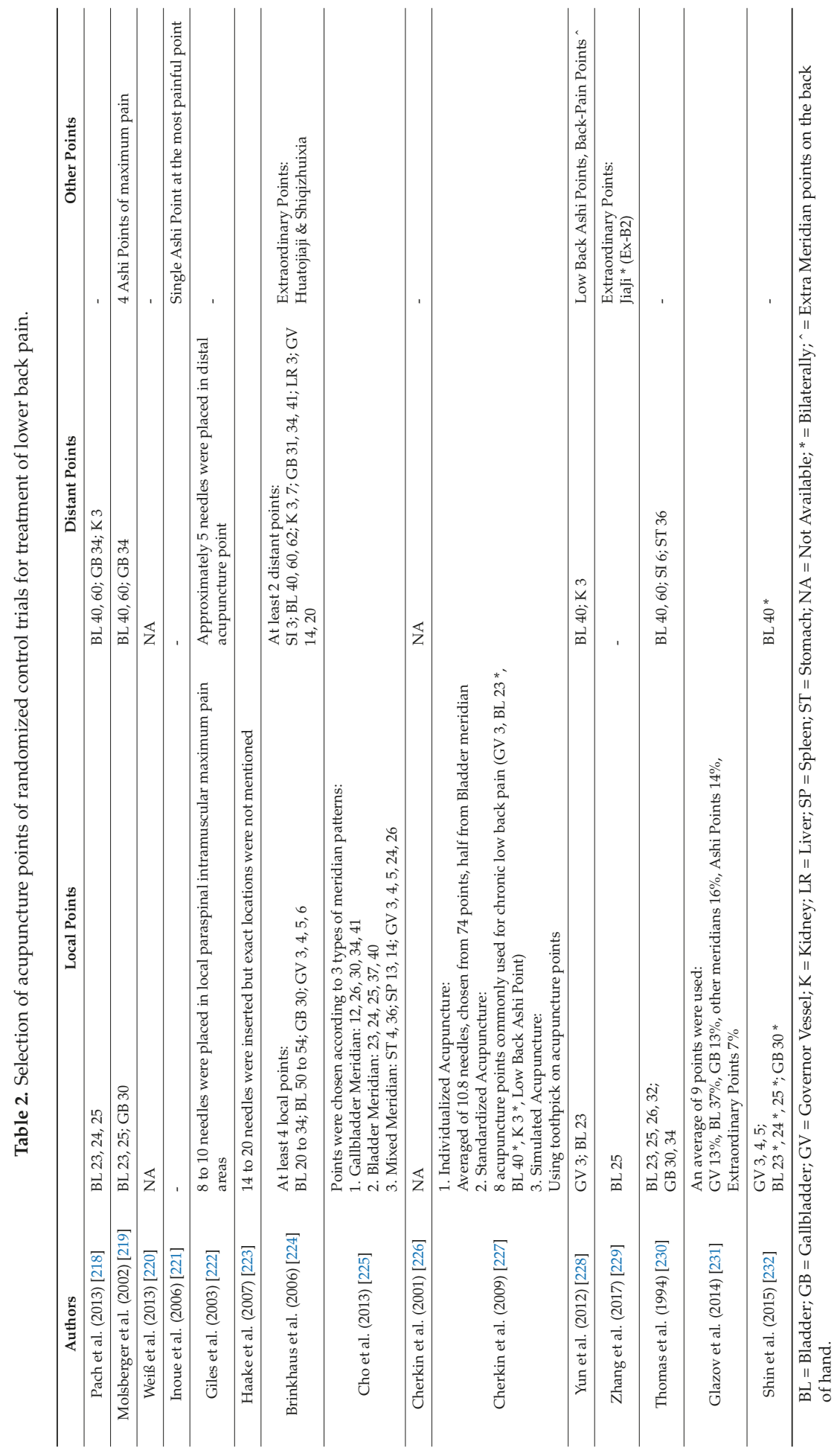




\subsection{In the Wake of Double-Blind Randomised Control Trials (RCTs)}

The double-blind placebo-controlled clinical trial is considered as the gold standard for testing or comparing the efficacy of either new or existing treatments/drugs [233]. The idea was put forward by Austin Bradford Hill back in 1937 [234]. Before the mid-20th century, the practice of informed consent was not mandatory. Patients were often not informed of their involvement in a clinical study and did not realize that they might receive a placebo instead of a real treatment [235].

The main purpose to conduct a clinical RCT is to prevent bias or manipulation of results in medical studies [217,234-236]. Such biases originate from several sources. Patients' awareness of trials might lead to exaggerated expectations and responses [217,235,237-247]. Some clinical researchers might depend heavily on the pharmaceutical industry funding and may not be effectively protected from transmitting their sponsor's bias in favour of a new drug [247,248]. Surveys showed that double-blind methodologies are still not always properly applied to clinical tests [236,249-251].

\subsection{The Placebo Effect}

The question of whether acupuncture merely produces a placebo effect has to be considered in light of numerous studies done in this field. The word "placebo", is a Latin word, usually translated as "I shall please" [237]. According to Shapiro, a placebo is defined as "any therapeutic procedure (or a component of any therapeutic procedure) which is given (1) deliberately to have an effect, or (2) unknowingly and has an effect on a symptom, syndrome, disease, or patient but which is objectively without specific activity for the condition being treated. The placebo is also used as an adequate control in research. The placebo effect is defined as the changes produced by placebos" [252].

As stated by Walter Brown, author of The Placebo Effect in Clinical Practice, the act of seeking and receiving medical care itself is a placebo effect. Some conditions are highly placebo-responsive, which could bring up to as much as 50\% relief. The placebo treatment can be used to enhance the benefits of standard treatments. The healing environment, which involves the personal attention and the two-way communication between a patient and a care provider, is a powerful antidote for illness [235]. Miller and Kaptchuk proposed this kind of placebo effect as "contextual healing", in which a specific clinical encounter contributes to therapeutic outcomes [253]. Jay Katz, author of The Silent World of Doctor and Patient, noted that "Physicians and patients may gradually learn that the placebo effect is an integral and inevitable component of the practice of medicine, that it constitutes its art and augments its science" [254]. Kerr et al. expressed "neurophenomenological" as the reason that caused the placebo effect from sham acupuncture due to the palpation and touch by the practitioner and tactile stimulation by sham acupuncture needles [255].

The mechanisms of the placebo analgesic effects include activation of endogenous opioids and dopamine release, and alteration of central processing of pain [238-240]. Expectation of benefit also plays an important role in the efficacy of placebo interventions [238-245]. Henry Beecher in his article "The Powerful Placebo", suggests that placebos can relieve pain arising from physiological causes and have an average significant effectiveness of $35.2 \pm 2.2 \%$ [256].

\subsection{Clinical Studies}

The placebo effect produced by sham acupuncture, derives from patients' expectation and bias. Yet, this does not mean that the therapeutic effect of acupuncture is only explained as a placebo intervention. In comparing placebo to no treatment, such as those shown in Table 1, placebo was significantly more effective than no-treatment groups or even standard medical care. This was demonstrated by an impressive series of three-arm studies in German Acupuncture Trials (GERAD) for relief of LBP [223]. Subsequently, the outcome of treatment of chronic LBP by acupuncture was so positive that German insurance companies agreed to cover the cost of such treatments [223,257].

Therefore, it is safe to say that a placebo intervention that produces a real effect is not supposed to be called a "placebo". There must be some physiological or psychological mechanism that explains 
such effects. Besides tactile stimulation [255], several studies proposed that afferent nerve fibres are involved in response to acupuncture treatment $[110,112]$.

\subsection{Acupuncture Points for Lower Back Pain}

In Table 2, only six out of 15 RCTs stated precisely which acupuncture points were used for the treatment of LBP. Of these, the most commonly used acupuncture points are GV 3, BL 23, BL 25 and BL 40. GV 3, BL 23 and BL 25 are all local points, while BL 40, located in the popliteal fossa, is a distal point for treating LBP. Other distal points are BL 60 and K 3, they are situated behind the lateral and medial malleolus.

The most commonly used acupuncture points in the treatment of LBP are listed in the literature [232,258]. Lee et al. did an investigation based on 53 clinical studies and came out with a summary of the most frequently used acupuncture points for the treatment of LBP [258]. It clearly shows that both the bladder and gallbladder meridians are the chosen choice for treating LBP with acupuncture, especially BL 23 (51\%), follow by BL 25 (43\%), BL 24, BL 40, BL 60 and GB 30 (32\% each), BL 26 and BL 32 (28\% each), and GB 34 (21\%). In the opinion of Maciocia, the proper selection of local and distal points is based on the location and the nature of pain, and depends on the condition, if it is either acute or chronic [144].

\subsection{Clinical Relevance}

According to Robinson [176], acupuncture points BL 23, BL 24 and BL 26 improve circulation to the local tissues and resolve myofascial dysfunction and promote tissue recovery. BL 25 is stimulated to relax the myofascia and free the nerves which are entrapped and irritated. BL 40 may improve circulation and nerve health by reducing myofascial tension caused by neurovascular compression. BL 60 and K 3 are located on each side of the ankle, and represent the distant points for LBP. They contain an extensive sympathetic nerve supply that provides homeostatic effects. GB 30 sits on top of the sciatic nerve and is a good choice to treat sciatica caused by piriformis entrapment syndromes. GB 34, located on the neck of fibular, is a choice point to treat common peroneal (fibular) nerve syndrome. GV 3, which is supplied by the spinal segmental nerve and the somatosomatic as well as somatovisceral reflex connections, has neuromodulatory properties for treating LBP, paraparesis, sciatic pain, genitourinary conditions, and lower gastrointestinal disorders.

\section{Mechanism of Acupuncture}

What is actually happening the moment an acupuncture needle penetrates the skin [259]? According to Robinson, this interesting phenomenon is due to a higher density of sensory and sympathetic nerve fibres attached to blood vessels in distal than in proximal segments. Such an anatomical arrangement accounts for the relatively stronger autonomous responses associated with distal acupuncture points, especially those at the ends of the channels [176]. Dellon et al. came to the same conclusion concerning the higher concentration of sympathetic innervation in the foot [260].

Manipulation of acupuncture needle results in deformation of connective tissues and thus alters the structure of fibroblasts $[197,261-264]$. Such micro-injury caused by the puncturing of the acupuncture needle in the skin results in release of ATP [195-201,265,266]. ATP is then further broken down into adenosine and other purines [195-201,265,266]. Both ATP and adenosine act as anti-nociception agents that block pain through purinergic receptors [195-199,265-269].

\subsection{Deqi}

The pricking sensation caused by stimulation of acupuncture needle is termed Deqi. This refers to the excitation of Qi or vital energy inside meridians. Often patients might experience a combination of various sensations, including numbness, soreness, distention, heaviness, dull pain, or sharp pain during acupuncture needle insertion [270]. Deqi, which was mentioned in the chapter 1 of Huang Di Nei Jing Ling Shu [127], literally means "the arrival of vital energy", which is widely 
viewed as an important role in the process of achieving therapeutic effectiveness of acupuncture treatment [127,165,271-274]. A functional magnetic resonance imaging (fMRI) study conducted by Napadow et al. shows an increase of blood flow to the penetrated sites that are linked to the sensation of Deqi [275]. Kong et al. found that the different intensity of acupuncture sensations is associated with the effect of analgesia [276]. Spaeth et al. concluded that real acupuncture tends to produce a stronger Deqi sensation and better clinical outcomes as compared to sham acupuncture [277]. However, White et al. indicated that the sensation of Deqi does not impact the efficacy of acupuncture treatment [278].

\subsection{Needle Grasp}

The phenomenon of needle grasp is described as a tug on the needle, like a fish biting on a fishing line, creating a tight mechanical coupling between needle and tissue. Langevin et al. proposed that needle grasp perceived by acupuncturists corresponds to the sensation of Deqi, which is felt by patients. This may play an active role in the therapeutic mechanism of acupuncture $[159,279,280]$. These authors hypothesize that the manoeuvre of the needle (by rotation or piston movement) causes needle grasp, and hence, Deqi is a result of collagen and elastic fibres winding and tightening around the needle. Such a mechanism is responsible for the increase in pull-out force induced by needle rotation $[159,279-281]$. The higher density of connective tissues at acupuncture points might explain the occurrence of needle grasp [159].

Needle grasp allows further movements of the needle to pull and deform the connective tissue surrounding the needle, delivering some of its effects through mechanical influence on the connective tissue matrix [159,279-281]. In addition, the manipulation of the acupuncture needle causes remodeling of fibroblasts in the connective tissue [261-264].

\subsection{Afferent Nerve Fibres}

Many RCT studies claimed the lack of significant difference between real and sham acupuncture (Table 1) $[224,227,231,232]$. This conclusion arose from the fact that both real and sham acupuncture in these RCTs are involved in tactile stimulation [255]. The reason behind such phenomenon is due to the stimulation of the afferent nerve fibres [110,112,282]. Such superficial pressure via sham needling intervention can have significant effects on the brain's limbic system $[245,283]$. Acupuncture fMRI studies have shown that both tactile stimulation and acupuncture manipulation activate neural activities and thus might have a potential effect on pain modulation [283-286].

The human tactile sensation is thought to be moderated primarily by large myelinated afferents $(\mathrm{A} \alpha$ and $\mathrm{A} \beta$ ), while pain and temperature sensations are brought about by small myelinated (A $\delta$ fibre) and unmyelinated (C fibre) afferents [287]. It is therefore plausible that many sham acupunctures, used as control procedures in acupuncture studies, activated this group of afferents and hence produced analgesic effects [110,112]. Zhou et al. concluded that afferent fibres of type II (A $\beta$ ) and III (A) are responsible for transmitting the acupuncture signal, which are important for acupuncture analgesia [168].

\subsection{Acupuncture Analgesic}

The study of acupuncture in pain management and its analgesic effects have been highlighted in the literature $[110,112,119,134,136-140,142-144,146,147,151,163,170,176,192,195-201,235,241,288-290]$. The gate control theory of pain, which was proposed by Melzack and Wall back in 1965 [93], and later by Melzack, suggested that the stimulation by the acupuncture needle activates the inhibitory brainstem system and therefore blocks pain signals [291]. The release of endogenous opioids [112,119,163,292] and ATP $[195-201,265,266]$ triggered by an acupuncture needle have been well documented by many studies. This suggests a link between acupuncture and signaling mediated by neurotransmitters.

Endorphins are amongst the most studied neurotransmitters in acupuncture research. They are more powerful in pain relief than exogenous morphine [293]. A recent study conducted by Grissa et al. compared the effectiveness of acupuncture versus morphine in the management of acute pain in the 
emergency department. A reduction of pain by $92 \%$ was observed in patients treated with acupuncture, while morphine-treated patients experienced only $78 \%$ reduction. In addition, acupuncture-treated patients had a much faster pain recovery time (an average of $16 \mathrm{~min}$ compared to $28 \mathrm{~min}$ in the morphine control group) [294].

\subsection{ATP as Neurotransmitter}

Adenosine triphosphate (ATP) was discovered by Karl Lohman in 1929 [295]. In that same year, Drury and Szent-Györgyi described the effects of ATP on heart excitability, lowering of blood pressure and coronary vasodilation [206]. Research by Holton and Holton in 1954 identified ATP as a neurotransmitter in the somatosensory system. They demonstrated that ATP is released from peripheral endings of primary sensory neurons [296]. The signaling function of ATP in peripheral tissues was confirmed by numerous investigations done by Geoffrey Burnstock. This led to the discovery of Purinergic Signaling that consists of neurotransmission by purinergic receptors [297].

In 2009, Burnstock proposed that stimulation of the tissue with acupuncture needle, heat or electrical current triggers the release of a large quantity of ATP from keratinocytes, fibroblasts and other cells in the skin [298]. ATP activates P2X ligand-gated ion channel 3 receptors (P2X3), which are located on sensory nerves. Resulting signals modulate the pathways that lead to the CNS responsible for conscious awareness of pain [265-268,299-302].

\subsection{Adenosine-Induced Anti-Nociception}

As mentioned before, energy in the form of ATP is one of the essential requirements for our body's function [188]. Adenosine, which is the core molecule of ATP and of nucleic acids, forms a unique link among cell energy, gene regulation, and neuronal excitability [302]. Adenosine is recognised by specific receptors, which regulate neuronal and non-neuronal cellular functions. As a neurotransmitter, adenosine regulates pain transmission in both the spinal cord and in the periphery [303]. Adenosine acts as an endogenous anti-inflammatory agent and as such plays an important role as a signaling molecule in immunity and inflammation [304]. Hence, adenosine is involved in nearly every aspect of cell function.

Recently, in a series of experiments by Goldman et al., adenosine was identified as a mediator of anti-nociceptive properties in acupuncture experiments in mice [195]. In another study conducted by the same group in human subjects, they used tissue microdialysis to demonstrate the increased release of adenosine, adenosine monophosphate (AMP), adenosine diphosphate (ADP), and ATP at stimulated acupuncture points [196]. Both studies show that the concentration of interstitial purines were increased by mechanical stimulation from the acupuncture needle. In contrast, transgenic mice lacking adenosine A1 receptors do not show any sign of pain reduction [195].

Pharmacologically, the anti-nociceptive effect of acupuncture is prolonged by 2 to $2.5 \mathrm{~h}$ when the combination of acupuncture and injection of deoxycoformycin (dCF) were introduced $[195,199]$. Hurt and Zylka suggested that a longer period of pain relief might be achieved by injecting prostatic acid phosphatase (PAP) into the acupuncture points [305]. Both dCF and PAP are agonists of ATP production in response to acupuncture treatment $[195,305]$. But the opposite is observed when an adenosine receptor antagonist, such as caffeine, is either taken orally or injected at the acupuncture points, which then interfere with the analgesic effect of acupuncture $[199,306]$. Interestingly, from their observation, Tang et al. concluded that the higher efficacy of acupuncture in China than in western countries could be due to the lower consumption of coffee in China than in Europe and America [268].

\section{Discussion}

Low back pain is one of the most common musculoskeletal disorders in modern society [1-4]. There are increasing numbers of patients seeking complementary therapies, such as acupuncture, as a mean to supplement the conventional treatments. Many studies have produced conflicting results 
relating to the efficacy of acupuncture as a method to treat LBP. This is probably due to a small sample sizes, a lack of blinding procedures and improper methodological assessment tools [5,61,65,113,115].

In most RCTs, sham acupuncture was used as a control, either using sham acupuncture needles which do not penetrate the skin, or selecting sham acupuncture points (Table 1). It was interesting to observe the outcomes from the verum and sham acupuncture groups (Table 1). Both groups produced better results than conventional therapies or non-treatment groups and it was obvious that verum acupuncture produced slightly better results than sham acupuncture. The reason behind such a phenomenon could be attributed to tactile stimulation. Both puncturing the skin by acupuncture needle, and stimulation by sham needle on the skin surface, activate the afferent sensory receptors, leading to therapeutic effects.

The high density of nerve endings under acupuncture points could be another reason that contributed to the acupuncture-induced analgesic effects, which yields better results in verum than in the sham acupuncture group. The release of purines, such as ATP and adenosine, which bind to the purinergic receptors, provide a hypothesis to explain the efficacy in acupuncture against pain $[110,112,119,134,136-140,142-144,146,147,151,163,170,176,192,195-201,235,241,288-290]$.

Why is acupuncture effective on some patients, but not on others? Many factors could give rise to such uneven responses. Patients' expectations might play a crucial role in the determination of the outcome of an acupuncture trial. So does the tendency of researchers' strong bias in favour of or against the efficacy of acupuncture, which might affect the overall outcome of a trial.

Combination of acupuncture with other regular therapies produces better results than conventional therapies alone. Therefore, a holistic approach to integrate acupuncture with other types of conventional treatments should be carried out for the benefit of the patients.

Of course our article also has potential limitations. In addition to the mentioned literature, many other high-quality RCTs on acupuncture and LBP have been conducted recently [307-309]. Although, the meta-analysis results of some of the systematic reviews indicated that acupuncture might be an effective treatment for chronic LBP in the short-term, conclusions among the reviews are inconsistent overall.

\section{Conclusions}

The WHO confirmed in 2002, the effectiveness of acupuncture treatment from controlled clinical trials for 28 diseases, symptoms, and conditions. LBP was one of the conditions that was mentioned in this report [310]. A meta-analysis of 33 RCTs of acupuncture for LBP showed better results than sham acupuncture and no treatment [311]. Meanwhile, the evidence for efficacy of the German Acupuncture Trials (GERAD) of 1162 patients with chronic low back pain compared verum acupuncture, sham acupuncture and a conventional therapy group as the control. The effectiveness of acupuncture, both verum and sham, was almost twice that of conventional therapy 6 months after the trial [223]. Acupuncture is recommended for patients with chronic LBP due to its cost-effectiveness [312] and low adverse effects [313].

The discovery of purines-mediated (both ATP and adenosine) anti-nociceptive effects of acupuncture, has led to a better understanding of molecular events underlying the mechanism of acupuncture in the peripheral nervous system. However, our knowledge of mechanisms associated with acupuncture's analgesic properties remains limited. Integration of acupuncture treatments with conventional therapies, and pharmacological agents should lead to medical strategies without addictive side effects.

Despite shown effectiveness by RCTs and the discovery of potential molecular mechanisms, acupuncture is still not well accepted by the social security services in Austria and many European countries. Such a situation results from health policy and the regulation of the healthcare bodies in different European Union (EU) members. Yet, any treatment producing better outcomes at a lower cost is a desirable step towards more sustainable health systems. 
Author Contributions: The manuscript has been written by T.-K.L. as master thesis at the Medical University of Vienna under the supervision of G.L., Head of the TCM Research Center at the Medical University of Graz, Austria. G.L. is also lecturer at the Master Program "Principles and Practice of Traditional Chinese Medicine (TCM)" (Coordinator: Y.M.) at Medical University of Vienna. The scientific work was co-supervised by F.B. from the Gregor Mendel Institute of Vienna.

Funding: This research received no external funding.

Acknowledgments: Supported by the Austrian Federal Ministry of Education, Science and Research ("Sino-Austrian TCM Research on Lifestyle-Related Diseases" (2016-2019; project leaders: Yan Ma and Gerhard Litscher)). The manuscript was read and corrected by all authors. The study was partially supported by the Austrian Ministry of Education, Science, and Research and the Eurasia Pacific Uninet as well as the German Academy of Acupuncture (President Bernd Ramme), for which a heartfelt thank you should be expressed.

Conflicts of Interest: The authors declare no conflict of interest.

\begin{tabular}{|c|c|}
\hline \multicolumn{2}{|c|}{ Abbreviations } \\
\hline $5-\mathrm{HT}$ & 5-hydroxytryptamine \\
\hline A1R & Adenosine A1 receptor \\
\hline ADL & activities of daily life \\
\hline ADP & adenosine diphosphate \\
\hline AIDS & acquired immune deficiency syndrome \\
\hline AMP & adenosine monophosphate \\
\hline ATP & adenosine triphosphate \\
\hline BCEC & Biologically Closed Electric Circuits \\
\hline BMI & body mass index \\
\hline cAMP & cyclic adenosine monophosphate \\
\hline CGRP & calcitonin gene-related peptide \\
\hline CLBP & chronic low back pain \\
\hline CNLBP & chronic nociceptive low back pain \\
\hline CNS & central nervous system \\
\hline $\mathrm{CO}_{2}$ & carbon dioxide \\
\hline COPD & chronic obstructive pulmonary disease \\
\hline CSP & chronic spinal pain \\
\hline CVDs & cardiovascular diseases \\
\hline DALYs & disability-adjusted life years \\
\hline $\mathrm{dCF}$ & deoxycoformycin \\
\hline DRG & dorsal root ganglia \\
\hline EA & electroacupuncture \\
\hline ECG & electrocardiogram \\
\hline EEG & electroencephalogram \\
\hline EU & European Union \\
\hline fMRI & functional magnetic resonance imaging \\
\hline GBD & The Global Burden of Disease Study \\
\hline GERAD & German Acupuncture Trials \\
\hline GIDs & gastrointestinal disorders \\
\hline G proteins & guanine nucleotide-binding proteins \\
\hline GV & Governing Vessel \\
\hline $\mathrm{H}^{+}$ & protons \\
\hline $\mathrm{H}_{2} \mathrm{O}$ & water \\
\hline HIV & human immunodeficiency virus \\
\hline $\mathrm{HM}$ & Heart meridian \\
\hline LBP & lower back pain \\
\hline
\end{tabular}




$\begin{array}{ll}\text { MA } & \text { manual acupuncture } \\ \text { MFE } & \text { Medium-Frequency Electrotherapy } \\ \text { mTrPs } & \text { Myofascial Trigger Points } \\ \text { MUS } & \text { medically unexplained symptoms } \\ \text { NGF } & \text { nerve growth factor } \\ \text { NRS } & \text { numerical rating scale } \\ \text { NSAIDs } & \text { non-steroidal anti-inflammatory drugs } \\ \text { NSCLBP } & \text { non-specific chronic low back pain } \\ \text { P2X3 } & \text { P2X ligand-gated ion channel 3 receptor } \\ \text { PAP } & \text { prostatic acid phosphatase } \\ \text { PGI } & \text { patient global impression } \\ \text { PN } & \text { primo node } \\ \text { PPT } & \text { pressure pain threshold } \\ \text { PV } & \text { primo vessel } \\ \text { PVS } & \text { primo vascular system } \\ \text { RCTs } & \text { randomised control trials } \\ \text { ROM } & \text { range of motion } \\ \text { SQID } & \text { Superconducting Quantum Interference Device } \\ \text { TCM } & \text { Traditional Chinese Medicine } \\ \text { TENS } & \text { transcutaneous electric nerve stimulation } \\ \text { TRP } & \text { transient receptor potential } \\ \text { TRPA1 } & \text { transient receptor potential ankyrin 1 } \\ \text { TRPV1 } & \text { transient receptor potential vanilloid 1 } \\ \text { VAS } & \text { visual analogue scale } \\ \text { WHO } & \text { World Health Organisation } \\ \text { YLDs } & \text { years lived with disability }\end{array}$

\section{References}

1. Béatrice Duthey. Background Paper 6.24 Lower Back Pain. 2013. Available online: http://www.who.int/ medicines/areas/priority_medicines/BP6_24LBP.pdf (accessed on 5 June 2018).

2. Driscoll, T.; Jacklyn, G.; Orchard, J.; Passmore, E.; Vos, T.; Freedman, G.; Lim, S.; Punnett, L. The global burden of occupationally related low back pain: Estimates from the Global Burden of Disease 2010 study. Ann. Rheum. Dis. 2014, 73, 975-981. [CrossRef] [PubMed]

3. Hoy, D.; March, L.; Brooks, P.; Blyth, F.; Woolf, A.; Bain, C.; Williams, G.; Smith, E.; Vos, T.; Barendregt, J.; et al. The global burden of low back pain: Estimates from the Global Burden of Disease 2010 study. Ann. Rheum. Dis. 2014, 73, 968-974. [CrossRef] [PubMed]

4. Van Tulder, M.; Koes, B. Low Back Pain. In Wall and Melzack's Textbook of Pain, 6th ed.; McMahon, S., Koltzenburg, M., Tracey, I., Turk, D., Eds.; Churchill Livingstone: Philadelphia, PA, USA, 2013; Chapter 49.

5. Van Tulder, M.; Becker, A.; Bekkering, T.; Breen, A.; Hutchinson, A.; Koes, B.; Laerum, E.; Malmivaara, A. Chapter 3 European guidelines for the management of acute nonspecific lower back pain in primary care. Eur. Spine J. 2006, 15 (Suppl. 2), S169-S191. [CrossRef] [PubMed]

6. Burton, A.K.; Balagué, F.; Cardon, G.; Eriksen, H.R.; Henrotin, Y.; Lahad, A.; Leclerc, A.; Müller, G.; van der Beek, A.J. Chapter 2 European guidelines for prevention in low back pain. Eur. Spine J. 2006, 15 (Suppl. 2), S136-S168. [CrossRef] [PubMed]

7. Yiengprugsawan, V.; Hoy, D.; Buchbinder, R.; Bain, C.; Seubsman, S.; Sleigh, A.C. Low back pain and limitations of daily living in Asia: Longitudinal findings in the Thai cohort study. BMC Musculoskelet. Disord. 2017, 18, 19. [CrossRef] [PubMed]

8. Norbye, A.D.; Omdal, A.V.; Nygaard, M.E.; Romild, U.; Eldøen, G.; Midgard, R. Do patients with chronic low back pain benefit from early intervention regarding absence from work? Spine 2016, 41, E1257-E1264. [CrossRef] [PubMed]

9. Kolu, P.; Tokola, K.; Kankaanpää, M.; Suni, J. Evaluation of the effects of physical activity, cardiorespiratory condition, and neuromuscular fitness on direct healthcare costs and sickness-related absence among nursing personnel with recurrent nonspecific low back pain. Spine 2017, 42, 854-862. [CrossRef] [PubMed] 
10. McPhillips-Tangum, C.A.; Cherkin, D.C.; Rhodes, L.A.; Markham, C. Reasons for repeated medical visits among patients with chronic back pain. J. Gen. Intern Med. 1998, 13, 289-295. [CrossRef] [PubMed]

11. Jöud, A.; Petersson, I.F.; Englund, M. Low back pain: Epidemiology of consultations. Arthritis Care Res. 2012, 64, 1084-1088. [CrossRef] [PubMed]

12. WHO Methods and Data Sources for Global Burden of Disease Estimates 2000-2011. Available online: http:/ / www.who.int/healthinfo/statistics/GlobalDALYmethods_2000_2011.pdf (accessed on 5 June 2018).

13. Global, regional, and national incidence, prevalence, and years lived with disability for 328 diseases and injuries for 195 countries, 1990-2016: A systematic analysis for the Global Burden of Disease Study 2016. Lancet 2017, 390, 1211-1259.

14. Global, regional, and national disability-adjusted life-years (DALYs) for 333 diseases and injuries and healthy life expectancy (HALE) for 195 countries and territories, 1990-2016: A systematic analysis for the Global Burden of Disease Study 2016. Lancet 2017, 390, 1260-1344.

15. WHO Methods and Data Sources for Global Burden of Disease Estimates 2000-2015. WHO: Geneva, Switzerland, January 2017. Available online: http://www.who.int/healthinfo/global_burden_disease/ GlobalDALYmethods_2000_2015.pdf (accessed on 5 June 2018).

16. The Institute for Health Metrics and Evaluation (IHME). Available online: http://www.healthdata.org/ austria (accessed on 5 June 2018).

17. Hoy, D.; Bain, C.; Williams, G.; March, L.; Brooks, P.; Blyth, F.; Woolf, A.; Vos, T.; Buchbinder, R. A systematic review of the global prevalence of low back pain. Arthritis Rheum. 2012, 64, 2028-2037. [CrossRef] [PubMed]

18. Frymoyer, J.W.; Cats-Baril, W.L. An overview of the incidences and costs of low back pain. Orthop. Clin. N. Am. 1991, 22, 263-271.

19. Geusens, P.; De Winter, L.; Quaden, D.; Vanhoof, J.; Vosse, D.; Van den Bergh, J.; Somers, V. The prevalence of vertebral fractures in spondyloarthritis: Relation to disease characteristics, bone mineral density, syndesmophytes and history of back pain and trauma. Arthritis Res. Ther. 2015, 17, 294. [CrossRef] [PubMed]

20. Kim, K.; Isu, T.; Chiba, Y.; Iwamoto, N.; Yamazaki, K.; Morimoto, D.; Isobe, M.; Inoue, K. Treatment of low back pain in patients with vertebral compression fractures and superior cluneal nerve entrapment neuropathies. Surg. Neurol. Int. 2015, 6 (Suppl. 24), S619-S621. [CrossRef] [PubMed]

21. Michailidou, C.; Marston, L.; De Souza, L.H.; Sutherland, I. A systematic review of the prevalence of musculoskeletal pain, back and low back pain in people with spinal cord injury. Disabil. Rehabilit. 2014, 36, 705-715. [CrossRef] [PubMed]

22. Määttä, J.H.; Wadge, S.; MacGregor, A.; Karppinen, J.; Williams, F.M. ISSLS prize winner: Vertebral endplate (Modic) change is an independent risk factor for episodes of severe and disabling low back pain. Spine 2015, 40, 1187-1193. [CrossRef] [PubMed]

23. Jensen, O.K.; Nielsen, C.V.; Sørensen, J.S.; Stengaard-Pedersen, K. Back pain was less explained than leg pain: A cross-sectional study using magnetic resonance imaging in low back pain patients with and without radiculopathy. BMC Musculoskelet. Disord. 2015, 16, 374. [CrossRef] [PubMed]

24. Daghighi, M.H.; Pouriesa, M.; Maleki, M.; Fouladi, D.F.; Pezeshki, M.Z.; Khameneh, R.M.; Bazzazi, A.M. Migration patterns of herniated disc fragments: A study on 1020 patients with extruded lumbar disc herniation. Spine J. 2014, 14, 1970-1977. [CrossRef] [PubMed]

25. Kuniya, H.; Aota, Y.; Kawai, T.; Kaneko, K.; Konno, T.; Saito, T. Prospective study of superior cluneal nerve disorder as a potential cause of low back pain and leg symptoms. J. Orthop. Surg. Res. 2014, 9, 139. [CrossRef] [PubMed]

26. Samini, F.; Gharedaghi, M.; Mahdi Khajavi, M.; Samini, M. The etiologies of low back pain in patients with lumbar disk herniation. Iran. Red Crescent Med. J. 2014, 16, E15670. [CrossRef] [PubMed]

27. Gorth, D.J.; Shapiro, I.M.; Risbud, M.V. Discovery of the drivers of inflammation induced chronic low back pain: From bacteria to diabetes. Discov. Med. 2015, 20, 177-184. [PubMed]

28. Fisher, T.J.; Osti, O.L. Do bacteria play an important role in the pathogenesis of low back pain? ANZ J. Surg. 2015, 85, 808-814. [CrossRef] [PubMed]

29. Hassoon, A.; Bydon, M.; Kerezoudis, P.; Maloney, P.R.; Rinaldo, L.; Yeh, H.C. Chronic low-back pain in adult with diabetes: NHANES 2009-2010. J. Diabetes Complicat. 2017, 31, 38-42. [CrossRef] [PubMed]

30. Piazzolla, A.; Solarino, G.; Bizzoca, D.; Montemurro, V.; Berjano, P.; Lamartina, C.; Martini, C.; Moretti, B. Spinopelvic parameter changes and low back pain improvement due to femoral neck anteversion in patients 
with severe unilateral primary hip osteoarthritis undergoing total hip replacement. Eur. Spine J. 2018, 27, 125-134. [CrossRef] [PubMed]

31. Yamada, K.; Suzuki, A.; Takahashi, S.; Yasuda, H.; Koike, T.; Nakamura, H. Severe low back pain in patients with rheumatoid arthritis is associated with Disease Activity Score but not with radiological findings on plain X-rays. Mod. Rheumatol. 2015, 25, 56-61. [CrossRef] [PubMed]

32. El Barzouhi, A.; Vleggeert-Lankamp, C.L.; van der Kallen, B.F.; Lycklama à Nijeholt, G.J.; van den Hout, W.B.; Koes, B.W.; Peul, W.C. Back pain's association with vertebral end-plate signal changes in sciatica. Spine J. 2014, 14, 225-233. [CrossRef] [PubMed]

33. Wang, C.; Yu, X.; Yan, Y.; Yang, W.; Zhang, S.; Xiang, Y.; Zhang, J.; Wang, W. Tumor necrosis factor- $\alpha$ : A key contributor to intervertebral disc degeneration. Acta Biochim. Biophys. Sin. 2017, 49, 1-13. [CrossRef] [PubMed]

34. Wang, M.; Yu, J.; Liu, N.; Liu, Z.; Wei, X.; Yan, F.; Yu, S. Low back pain among taxi drivers: A cross-sectional study. Occup. Med. 2017, 67, 290-295. [CrossRef] [PubMed]

35. Snow, C.R.; Gregory, D.E. Perceived risk of low-back injury among four occupations. Hum. Factors 2016, 58, 586-594. [CrossRef] [PubMed]

36. Esquirol, Y.; Niezborala, M.; Visentin, M.; Leguevel, A.; Gonzalez, I.; Marquié, J.C. Contribution of occupational factors to the incidence and persistence of chronic low back pain among workers: Results from the longitudinal VISAT study. Occup. Environ. Med. 2017, 74, 243-251. [CrossRef] [PubMed]

37. Rafeemanesh, E.; Omidi Kashani, F.; Parvaneh, R.; Ahmadi, F. A Survey on Low Back Pain Risk Factors in Steel Industry Workers in 2015. Asian Spine J. 2017, 11, 44-49. [CrossRef] [PubMed]

38. Sundstrup, E.; Andersen, L.L. Hard physical work intensifies the occupational consequence of physician-diagnosed back disorder: Prospective cohort study with register follow-up among 10,000 workers. Int. J. Rheumatol. 2017, 2017, 1037051. [CrossRef] [PubMed]

39. Heuch, I.; Heuch, I.; Hagen, K.; Zwart, J.A. Physical activity level at work and risk of chronic low back pain: A follow-up in the Nord-Trøndelag Health Study. PLoS ONE 2017, 12, e0175086. [CrossRef] [PubMed]

40. Trompeter, K.; Fett, D.; Platen, P. Prevalence of back pain in sports: A systematic review of the literature. Sports Med. 2017, 47, 1183-1207. [CrossRef] [PubMed]

41. Matesan, M.; Behnia, F.; Bermo, M.; Vesselle, H. SPECT/CT bone scintigraphy to evaluate low back pain in young athletes: Common and uncommon etiologies. J. Orthop. Surg. Res. 2016, 11, 76. [CrossRef] [PubMed]

42. del Pozo-Cruz, B.; Gusi, N.; Adsuar, J.C.; del Pozo-Cruz, J.; Parraca, J.A.; Hernandez-Mocholí, M. Musculoskeletal fitness and health-related quality of life characteristics among sedentary office workers affected by sub-acute, non-specific low back pain: A cross-sectional study. Physiotherapy 2013, 99, 194-200. [CrossRef] [PubMed]

43. Billy, G.G.; Lemieux, S.K.; Chow, M.X. Lumbar disc changes associated with prolonged sitting. PM R 2014, 6, 790-795. [CrossRef] [PubMed]

44. Teichtahl, A.J.; Urquhart, D.M.; Wang, Y.; Wluka, A.E.; O'Sullivan, R.; Jones, G.; Cicuttini, F.M. Physical inactivity is associated with narrower lumbar intervertebral discs, high fat content of paraspinal muscles and low back pain and disability. Arthritis Res. Ther. 2015, 17, 114. [CrossRef] [PubMed]

45. Krieg, S.M.; Meyer, B. Operative Therapiemöglichkeiten beim Postnukleotomiesyndrom. Orthopäde 2016, 45, 732-737. [CrossRef] [PubMed]

46. Manchikanti, L.; Manchikanti, K.N.; Gharibo, C.G.; Kaye, A.D. Efficacy of percutaneous adhesiolysis in the treatment of lumbar post surgery syndrome. Anesthesiol. Pain Med. 2016, 6, E26172. [CrossRef] [PubMed]

47. Kaptan, H.; Kulaksızoğlu, H.; Kasımcan, Ö.; Seçkin, B. The association between urinary incontinence and low back pain and radiculopathy in women. Open Access Maced. J. Med. Sci. 2016, 4, 665-669. [CrossRef] [PubMed]

48. Ha, I.H.; Lee, J.; Kim, M.R.; Kim, H.; Shin, J.S. The association between the history of cardiovascular diseases and chronic low back pain in South Koreans: A cross-sectional study. PLoS ONE 2014, 9, e93671. [CrossRef] [PubMed]

49. Heuch, I.; Heuch, I.; Hagen, K.; Zwart, J.A. Does high blood pressure reduce the risk of chronic low back pain? The Nord-Trøndelag Health Study. Eur. J. Pain 2014, 18, 590-598. [CrossRef] [PubMed]

50. Bohman, T.; Alfredsson, L.; Jensen, I.; Hallqvist, J.; Vingård, E.; Skillgate, E. Does a healthy lifestyle behaviour influence the prognosis of low back pain among men and women in a general population? A population-based cohort study. BMJ Open 2014, 4, e005713. [CrossRef] [PubMed] 
51. Maulik, S.; Iqbal, R.; De, A.; Chandra, A.M. Evaluation of the working posture and prevalence of musculoskeletal symptoms among medical laboratory technicians. J. Back Musculoskelet. Rehabilit. 2014, 27, 453-461. [CrossRef] [PubMed]

52. Burgel, B.J.; Elshatarat, R.A. Psychosocial work factors and low back pain in taxi drivers. Am. J. Ind. Med. 2017, 60, 734-746. [CrossRef] [PubMed]

53. Yang, H.; Haldeman, S.; Lu, M.L.; Baker, D. Low back pain prevalence and related workplace psychosocial risk factors: A study using data from the 2010 National Health Interview Survey. J. Manip. Physiol. Ther. 2016, 39, 459-472. [CrossRef] [PubMed]

54. Rahimi, A.; Vazini, H.; Alhani, F.; Anoosheh, M. Relationship between low back pain with quality of life, depression, anxiety and stress among emergency medical technicians. Trauma Mon. 2015, 20, E18686. [CrossRef] [PubMed]

55. Smuck, M.; Kao, M.C.; Brar, N.; Martinez-Ith, A.; Choi, J.; Tomkins-Lane, C.C. Does physical activity influence the relationship between low back pain and obesity? Spine J. 2014, 14, 209-216. [CrossRef] [PubMed]

56. Zhang, T.T.; Liu, Z.; Liu, Y.L.; Zhao, J.J.; Liu, D.W.; Tian, Q.B. Obesity as a risk factor for low back pain: A meta-analysis. Clin. Spine Surg. 2018, 31, 22-27. [CrossRef] [PubMed]

57. Großschädl, F.; Freidl, W.; Rásky, E.; Burkert, N.; Muckenhuber, J.; Stronegger, W.J. A 35-year trend analysis for back pain in Austria: The role of obesity. PLoS ONE 2014, 9, e107436. [CrossRef] [PubMed]

58. Farioli, A.; Mattioli, S.; Quaglieri, A.; Curti, S.; Violante, F.S.; Coggon, D. Musculoskeletal pain in Europe: Role of personal, occupational and social risk factors. Scand. J. Work Environ. Health 2014, 40, 36-46. [CrossRef] [PubMed]

59. Wong, A.Y.; Karppinen, J.; Samartzis, D. Low back pain in older adults: Risk factors, management options and future directions. Scoliosis Spinal Disord. 2017, 12, 14. [CrossRef] [PubMed]

60. Jesus-Moraleida, F.R.; Ferreira, P.H.; Ferreira, M.L.; Silva, J.P.; Maher, C.G.; Enthoven, W.T.; Bierma-Zeinstra, S.M.A.; Koes, B.W.; Luijsterburg, P.A.J.; Pereira, L.S.M. Back complaints in the elders in Brazil and the Netherlands: A cross-sectional comparison. Age Ageing 2017, 46, 476-481. [CrossRef] [PubMed]

61. Maher, C.; Underwood, M.; Buchbinder, R. Non-specific low back pain. Lancet 2017, 389, 736-747. [CrossRef]

62. Arrouas, M.; Fiala, W.; Hanna-Klinger, M.; Hartl, F.; Lampl, P.D.D.C.; Plank, V.; Schlegl, C. Update der evidenz- und konsensusbasierten österreichischen Leitlinien für das Management akuter und chronischer unspezifischer Kreuzschmerzen 2011. Ö̈̈Z 2012, 2324, 30-39. Available online: http:/ /www.aekwien.at/ aekmedia/UpdateLeitlinienKreuzschmerz_2011_0212.pdf (accessed on 5 June 2018).

63. Krismer, M.; van Tulder, M. Strategies for prevention and management of musculoskeletal conditions. Low back pain (non-specific). Best Pract. Res. Clin. Rheumatol. 2007, 21, 77-91. [CrossRef] [PubMed]

64. Hoy, D.; Brooks, P.; Blyth, F.; Buchbinder, R. The epidemiology of low back pain. Best Pract. Res. Clin. Rheumatol. 2010, 24, 769-781. [CrossRef] [PubMed]

65. Salzberg, L.D.; Manusov, E.G. Management options for patients with chronic back pain without an etiology. Health Serv. Insights 2013, 6, 33-38. [CrossRef] [PubMed]

66. Wáng, Y.X.J.; Wáng, J.Q.; Káplár, Z. Increased low back pain prevalence in females than in males after menopause age: Evidences based on synthetic literature review. Quant. Imaging Med. Surg. 2016, 6, 199-206. [CrossRef] [PubMed]

67. Schneider, S.; Randoll, D.; Buchner, M. Why do women have back pain more than men? A representative prevalence study in the federal republic of Germany. Clin. J. Pain 2006, 22, 738-747. [CrossRef] [PubMed]

68. Ochsmann, E.; Rüger, H.; Kraus, T.; Drexler, H.; Letzel, S.; Münster, E. Geschlechtsspezifische Risikofaktoren akuter Rückenschmerzen. Schmerz 2009, 23, 377-384. [CrossRef] [PubMed]

69. Großschädl, F.; Stolz, E.; Mayerl, H.; Rásky, É.; Freidl, W.; Stronegger, W. Educational inequality as a predictor of rising back pain prevalence in Austria-Sex differences. Eur. J. Public Health 2016, 26, 248-253. [CrossRef] [PubMed]

70. Kaulagekar, A. Age of menopause and menopausal symptoms among urban women in Pune, Maharashtra. J. Obstet. Gynaecol. India 2011, 61, 323-326. [CrossRef]

71. Foster, N.E.; Bishop, A.; Bartlam, B.; Ogollah, R.; Barlas, P.; Holden, M.; Ismail, K.; Jowett, S.; Kettle, C.; Kigozi, J.; et al. Evaluating acupuncture and standard care for pregnant women with back pain (EASE Back): A feasibility study and pilot randomised trial. Health Technol. Assess. 2016, 20, 1-236. [CrossRef] [PubMed] 
72. Liddle, S.D.; Pennick, V. Interventions for preventing and treating low-back and pelvic pain during pregnancy. Cochrane Database Syst. Rev. 2015. [CrossRef] [PubMed]

73. Bhardwaj, A.; Nagandla, K. Musculoskeletal symptoms and orthopaedic complications in pregnancy: Pathophysiology, diagnostic approaches and modern management. Postgrad. Med. J. 2014, 90, 450-460. [CrossRef] [PubMed]

74. Chen, H.M.; Wang, H.H.; Chiu, M.H.; Hu, H.M. Effects of acupressure on menstrual distress and low back pain in dysmenorrheic young adult women: An experimental study. Pain Manag. Nurs. 2015, 16, 188-197. [CrossRef] [PubMed]

75. Katz, V.L.; Lentz, G.M.; Lobo, R.A.; Gershenson, D.M. Comprehensive Gynecology, 5th ed.; Mosby Elsevier: Philadelphia, PA, USA, 2007; Chapter 36.

76. Poomalar, G.K.; Arounassalame, B. The quality of life during and after menopause among rural women. J. Clin. Diagn Res. 2013, 7, 135-139.

77. Kozinoga, M.; Majchrzycki, M.; Piotrowska, S. Low back pain in women before and after menopause. Prz. Menopauzalny 2015, 14, 203-207. [CrossRef] [PubMed]

78. Wijnhoven, H.A.; de Vet, H.C.; Smit, H.A.; Picavet, H.S. Hormonal and reproductive factors are associated with chronic low back pain and chronic upper extremity pain in women-The MORGEN study. Spine 2006, 31, 1496-1502. [CrossRef] [PubMed]

79. Chou, Y.C.; Shih, C.C.; Lin, J.G.; Chen, T.L.; Liao, C.C. Low back pain associated with sociodemographic factors, lifestyle and osteoporosis: A population-based study. J. Rehabil. Med. 2013, 45, 76-80. [CrossRef] [PubMed]

80. Ahn, S.; Song, R. Bone mineral density and perceived menopausal symptoms: Factors influencing low back pain in postmenopausal women. J. Adv. Nurs. 2009, 65, 1228-1236. [CrossRef] [PubMed]

81. Yi, Y.; Hwang, B.; Son, H.; Cheong, I. Low bone mineral density, but not epidural steroid injection, is associated with fracture in postmenopausal women with low back pain. Pain Physician 2012, 15, 441-449. [PubMed]

82. Kitahara, H.; Ye, Z.; Aoyagi, K.; Ross, P.D.; Abe, Y.; Honda, S.; Kanagae, M.; Mizukami, S.; Kusano, Y.; Tomita, M.; et al. Associations of vertebral deformities and osteoarthritis with back pain among Japanese women: The Hizen-Oshima study. Osteoporos. Int. 2013, 24, 907-915. [CrossRef] [PubMed]

83. Heuch, I.; Heuch, I.; Hagen, K.; Zwart, J.A. Body mass index as a risk factor for developing chronic low back pain: A follow-up in the Nord-Trøndelag Health Study. Spine 2013, 38, 133-139. [CrossRef] [PubMed]

84. Kulie, T.; Slattengren, A.; Redmer, J.; Counts, H.; Eglash, A.; Schrager, S. Obesity and women's health: An evidence-based review. J. Am. Board Fam. Med. 2011, 24, 75-85. [CrossRef] [PubMed]

85. WHO. Obesity and Overweight. Available online: http://www.who.int/mediacentre/factsheets/fs $311 / \mathrm{en} /$ (accessed on 5 June 2018).

86. Bouchard, C.; Katzmarzyk, P.T. Physical Activity and Obesity, 2nd ed.; Human Kinetics: Champaign, IL, USA, 2010; Chapter 78.

87. Shemory, S.T.; Pfefferle, K.J.; Gradisar, I.M. Modifiable risk factors in patients with low back pain. Orthopedics 2016, 39, e413-e416. [CrossRef] [PubMed]

88. Kwon, M.A.; Shim, W.S.; Kim, M.H.; Gwak, M.S.; Hahm, T.S.; Kim, G.S.; Kim, C.S.; Choi, Y.H.; Park, J.H.; Cho, H.S.; et al. A correlation between low back pain and associated factors: A study involving 772 patients who had undergone general physical examination. J. Korean Med. Sci. 2006, 21, 1086-1091. [CrossRef] [PubMed]

89. Hayes, M.H.S.; Patterson, D.G. Experimental development of the graphic rating method. Psychol. Bull. 1921, 18, 98-99.

90. Siegfried, M.; Gerwin, R.D. Muscle Pain: Understanding the Mechanisms; Springer: Heiderberg, Germany, 2010; Chapter 1.

91. Merskey, H.; Bogduk, N. Classification of Chronic Pain, 2nd ed.; IASP Press: Seattle, WA, USA, 1994.

92. Sherrington, C. The Integrative Action of the Nervous System; Yale University Press: New Haven, CT, USA, 1906.

93. Melzack, R.; Wall, P.D. Pain mechanisms: A new theory. Science 1965, 150, 971-979. [CrossRef] [PubMed]

94. Khadilkar, A.; Odebiyi, D.O.; Brosseau, L.; Wells, G.A. Transcutaneous electrical nerve stimulation (TENS) versus placebo for chronic low-back pain. Cochrane Database Syst. Rev. 2008. [CrossRef] [PubMed]

95. Pert, C.B.; Snyder, S.H. Opiate receptor: Demonstration in nervous tissue. Science 1973, 179, 1011-1014. [CrossRef] [PubMed] 
96. Hughes, J.; Kosterlitz, H.W.; Smith, T.W.; Fothergill, L.A.; Morgan, B.A.; Morris, H.R. Identification of two related pentapeptides from the brain with potent opiate agonist activity. Nature 1975, 258, 577-580. [CrossRef] [PubMed]

97. Hughes, J.; Kosterlitz, H.W.; Smith, T.W. The distribution of methionine-enkephalin and leucine-enkephalin in the brain and peripheral tissues. Br. J. Pharmacol. 1977, 61, 639-647. [CrossRef] [PubMed]

98. Nicoll, R.A.; Siggins, G.R.; Ling, N.; Bloom, F.E.; Guillemin, R. Neuronal actions of endorphins and enkephalins among brain regions: A comparative microiontophoretic study. Proc. Natl. Acad. Sci. USA 1977, 74, 2584-2588. [CrossRef] [PubMed]

99. Simantov, R.; Kuhar, M.J.; Uhl, G.R.; Snyder, S.H. Opioid peptide enkephalin: Immunohistochemical mapping in rat central nervous system. Proc. Natl. Acad. Sci. USA 1977, 74, 2167-2171. [CrossRef] [PubMed]

100. Tran, V.T.; Chang, R.S.; Snyder, S.H. Histamine H1 receptors identified in mammalian brain membranes with [3H]mepyramine. Proc. Natl. Acad. Sci. USA 1978, 75, 6290-6294. [CrossRef] [PubMed]

101. Loeser, J.D.; Treede, R.D. The Kyoto protocol of IASP basic pain terminology. Pain 2008, 137, 473-477. [CrossRef] [PubMed]

102. Purves, D.; Augustine, G.J.; Fitzpatrick, D.; Hall, W.C.; LaMantia, A.S.; McNamara, J.O.; Williams, S.M. Neuroscience, 3rd ed.; Sinauer Associates, Inc.: Sunderland, MA, USA, 2004; Chapter 9.

103. Dobkin, B.H. The Clinical Science of Neurologic Rehabilitation, 2nd ed.; Oxford University Press: Oxford, UK, 2003; Chapter 8.

104. Usunoff, K.G.; Popratiloff, A.; Schmitt, O.; Wree, A. Functional Neuroanatomy of Pain; Springer: Berlin, Germany, 2006; Chapter 1.

105. Lautenbacher, S.; Fillingim, R.B. Pathophysiology of Pain Perception; Springer: New York, NY, USA, 2004; Chapter 1.

106. Macintyre, P.E.; Schug, S.A.; Scott, D.A.; Visser, E.J.; Walker, S.M. Acute Pain Management: Scientific Evidence, 3rd ed.; Working Group of the Australian and New Zealand College of Anaesthetists and Faculty of Pain Medicine, ANZCA \& FPM: Melbourne, Australia, 2010; Chapter 1.

107. Archer, P.; Nelson, L. Applied Anatomy \& Physiology for Manual Therapists; Lippincott, Williams \& Wilkins: Philadelphia, PA, USA, 2013; Chapter 7.

108. Livingston, W.K. Pain Mechanisms; Plenum Press: New York, NY, USA, 1976; Chapter 1.

109. Basbaum, A.I.; Bautista, D.M.; Scherrer, G.; Julius, D. Cellular and molecular mechanisms of pain. Cell 2009, 139, 267-284. [CrossRef] [PubMed]

110. Kagitani, F.; Uchida, S.; Hotta, H. Afferent nerve fibers and acupuncture. Auton. Neurosci. 2010, 157, $2-8$. [CrossRef] [PubMed]

111. Palastanga, N.; Soames, R. Anatomy and Human Movement, 6th ed.; Churchill Livingstone: Edinburg, UK, 2012; Chapter 1.

112. Zhao, Z.Q. Neural mechanism underlying acupuncture analgesia. Prog. Neurobiol. 2008, 85, 355-375. [CrossRef] [PubMed]

113. Qaseem, A.; Wilt, T.J.; McLean, R.M.; Forciea, M.A. Clinical Guidelines Committee of the American College of Physicians. Noninvasive treatments for acute, subacute, and chronic low back pain: A clinical practice guideline from the American College of Physicians. Ann. Intern Med. 2017, 166, 514-530. [CrossRef] [PubMed]

114. Bernstein, I.A.; Malik, Q.; Carville, S.; Ward, S. Low back pain and sciatica: Summary of NICE guidance. BMJ 2017, 356, i6748. [CrossRef] [PubMed]

115. Nunn, M.L.; Hayden, J.A.; Magee, K. Current management practices for patients presenting with low back pain to a large emergency department in Canada. BMC Musculoskelet. Disord. 2017, 18, 92. [CrossRef] [PubMed]

116. Australian Acute Musculoskeletal Pain Guidelines Group. Evidence-Based Management of Acute Musculoskeletal Pain; Australian Academic Press: Brisbane, Australia, 2003; Chapter 4. Available online: https://www.nhmrc.gov.au/_files_nhmrc/publications/attachments/cp94_evidence_based_ management_acute_musculoskeletal_pain_131223.pdf (accessed on 5 June 2018).

117. Kissin, I. The development of new analgesics over the past 50 years: A lack of real breakthrough drugs. Anesth. Analg. 2010, 110, 780-789. [CrossRef] [PubMed]

118. Marcus, D.A. Chronic Pain; Human Press: Totowa, NJ, USA, 2005; Chapter 2. 
119. Maoying, Q.; Mi, W. Acupuncture Analgesia in Clinical Practice. In Acupuncture Therapy for Neurological Diseases; Xia, Y., Cao, X.D., Wu, G.C., Cheng, J.S., Eds.; Tsinghua University Press: Beijing, China; Springer: Berlin, Germany, 2010; Chapter 7.

120. World Health Organization. WHO Global Atlas of Traditional, Complementary and Alternative Medicine. WHO Centre for Health Development: Kobe, Japan, 2005. Available online: http://apps.who.int/iris/ bitstream/10665/43108/1/9241562862_map.pdf (accessed on 5 June 2018).

121. Cui, J.; Wang, S.B.; Ren, J.H.; Zhang, J.; Jing, J. Use of acupuncture in the USA: Changes over a decade (2002-2012). Acupunct. Med. 2017, 35, 200-207. [CrossRef] [PubMed]

122. Von Ammon, K.; Frei-Erb, M.; Cardini, F.; Daig, U.; Dragan, S.; Hegyi, G.; Roberti di Sarsina, P.; Sörensen, J.; Lewith, G. Complementary and alternative medicine provision in Europe-First results approaching reality in an unclear field of practices. Forsch. Komplementmed. 2012, 19 (Suppl. 2), 37-43. [CrossRef] [PubMed]

123. Breuer, J.; Reinsperger, I.; Piso, B. Akupunktur. Einsatzgebiete, Evidenzlage und gesicherte Indikationen. HTA Projektbericht Nr. 78; Ludwig Boltzmann Institut für Health Technology Assessment: Wien, Austria, 2014.

124. Bundesgesetz über die Gesundheit Österreich GmbH (GÖGG) 132/2006. In Legal Status and Regulation of CAM in Europe. Available online: http:/ / www.cam-europe.eu/dms/files/CAMbrella_Reports/CAMbrellaWP2-part_1final.pdf (accessed on 5 June 2018).

125. World Health Organization. WHO Traditional Medicine Strategy: 2014-2023. World Health Organization, 2013. Available online: http://apps.who.int/iris/bitstream/10665/92455/1/9789241506090_eng.pdf (accessed on 5 June 2018).

126. Unschuld, P.U.; Tessenow, H.; Zheng, J. Huang Di Nei Jing Su Wen: An Annotated Translation of Huang Di's Inner Classic_Basic Questions; University of California Press: Berkeley, CA, USA, 2011.

127. Huang Di Nei Jing Ling Shu; Unschuld, P.U., Translator; University of California Press: Oakland, CA, USA, 2016.

128. Nan-Ching (The Classic of Difficult Issues); Translated and annotated by Unschuld, P.U.; University of California Press: Berkeley, CA, USA, 1986.

129. Zhen Jiu Jia Yi Jing (The Systematic Classic of Acupuncture and Moxibustion) by Huangfu Mi; Yang, S.; Chace, C., Translators; Blue Poppy Press: Boulder, CO, USA, 2004.

130. Unschuld, P.U. Approaches to Traditional Chinese Medical Literature: Proceedings of an International Symposium on Translation Methodologies and Terminologies; Kluwer Academic Publishers: Dordrecht, The Netherlands, 1989.

131. Kiple, K.F. The Cambridge World History of Human Disease; Cambridge University Press: Cambridge, UK, 1993; Chapter 1.

132. Ma, K.W. Acupuncture: Its place in the history of Chinese medicine. Acupunct. Med. 2000, 18, 88-99. [CrossRef]

133. White, A.; Ernst, E. A brief history of acupuncture. Rheumatology 2004, 43, 662-663. [CrossRef] [PubMed]

134. Bivins, R.E. Acupuncture, Expertise and Cross-Cultural Medicine; Palgrave Macmillan: Basingstoke, UK, 2000.

135. Reston, J. Now, About My Operation in Peking; New York Times: New York, NY, USA, 1971; Volume 1, p. 6. Available online: http://www.nytimes.com/1971/07/26/archives/now-about-my-operation-in-pekingnow-let-me-tell-you-about-my.html (accessed on 5 June 2018).

136. Chaves, J.F.; Barber, T.X. Acupuncture Analgesia: A Six-Factor Theory. In Pain; Weisenberg, M., Tursky, B., Eds.; Plenum Press: New York, NY, USA, 1976; Chapter 4.

137. Dimond, E.G. Acupuncture anesthesia. Western medicine and Chinese traditional medicine. JAMA 1971, 218, 1558-1563. [CrossRef] [PubMed]

138. SpoereL, W.E. Acupuncture: Canadian anesthetists report on visit to China. Can. Med. Assoc. J. 1974, 111, 1123.

139. Bonica, J.J. Acupuncture anesthesia in the People's Republic of China. Implications for American medicine. JAMA 1974, 229, 1317-1325. [CrossRef] [PubMed]

140. Hamilton, S.G. Anesthesia by acupuncture. Br. Med. J. 1972, 4, 232-233. [CrossRef] [PubMed]

141. World Health Organization. The Contribution of Traditional Chinese Medicine to Sustainable Development: Keynote Address at the International Conference on the Modernization of Traditional Chinese Medicine. WHO: Singapore, October 2016. Available online: http://www.who.int/dg/speeches/2016/chinesemedicine-sustainable/en/ (accessed on 5 June 2018).

142. Lozano, F. Basic Theories of Traditional Chinese Medicine. In Acupuncture for Pain Management; Lin, Y., Hsu, E.S., Eds.; Springer: Heidelberg, Germany, 2014; Chapter 2. 
143. Sun, P. The Treatment of Pain with Chinese Herbs and Acupuncture, 2nd ed.; Churchill Livingstone: Edinburg, UK, 2011; Chapter 1.

144. Maciocia, G. The Practice of Chinese Medicine: The Treatment of Diseases with Acupuncture and Chinese Herbs, 2nd ed.; Churchill Livingstone: Edinburg, UK, 2008; Chapter 39.

145. Du, G.H.; Yuan, T.Y.; Du, L.D.; Zhang, Y.X. The potential of traditional Chinese medicine in the treatment and modulation of pain. Adv. Pharmacol. 2016, 75, 325-361. [PubMed]

146. Newberg, A.B.; Lee, B.Y.; LaRiccia, P.J. Acupuncture in theory and practice part I: Theoretical basis and physiologic effects. Hosp. Physician 2004, 40, 11-18.

147. British Medical Association. Acupuncture: Efficacy, Safety and Practice; Harwood Academic Publishers: Amsterdam, The Netherlands, 2005; Chapter 2.

148. Beijing College of Traditional Chinese Medicine. Essentials of Chinese Acupuncture; Foreign Languages Press: Beijing, China, 1980.

149. World Health Organization. WHO Standard Acupuncture Point Locations; World Health Organization: Geneva, Switzerland, 2009.

150. Focks, C. Atlas of Acupuncture; Churchill Livingstone: Munich, Germany, 2008.

151. Deadman, P.; Al-Khafaji, M.; Baker, K. A Manual of Acupuncture. J. Chin. Med. Publ. 2001. Available online: https: / www.naturmed.de/produkt/a-manual-of-acupuncture-deadman-p-al-khafaji-m-baker-k/ (accessed on 5 June 2018).

152. Kim, B.H. On the Kyungrak System. J. Acad. Med. Sci. DPR Korea 1963, 90, 1-35.

153. Soh, K.S.; Kang, K.A.; Ryu, Y.H. 50 years of Bong-Han theory and 10 years of primo vascular system. Evid. Based Complement. Alternat. Med. 2013, 2013, 587827. [CrossRef] [PubMed]

154. Shin, H.S.; Soh, K.S. Electrical method to detect a Bonghan duct inside blood vessels. New Phys. 2002, 45, 376-378.

155. Stefanov, M.; Potroz, M.; Kim, J.; Lim, J.; Cha, R.; Nam, M.H. The primo vascular system as a new anatomical system. J. Acupunct. Meridian Stud. 2013, 6, 331-338. [CrossRef] [PubMed]

156. Ciszek, M.; Szopinski, J.; Skrzypulec, V. Investigations of morphological structure of acupuncture points and meridians. J. Tradit. Chin. Med. 1985, 5, 289-292. [PubMed]

157. Lazorthes, Y.; Esquerré, J.P.; Simon, J.; Guiraud, G.; Guiraud, R. Acupuncture meridians and radiotracers. Pain 1990, 40, 109-112. [CrossRef]

158. Darras, J.; Albarède, P.; de Vernejoul, P. Nuclear medicine investigation of transmission of acupuncture information. Acupunct. Med. 1993, 11, 22-28. [CrossRef]

159. Langevin, H.M.; Yandow, J.A. Relationship of acupuncture points and meridians to connective tissue planes. Anat. Rec. 2002, 269, 257-265. [CrossRef] [PubMed]

160. Heine, H. Anatomical structure of acupoints. J. Tradit. Chin. Med. 1988, 8, 207-212. [PubMed]

161. Li, A.H.; Zhang, J.M.; Xie, Y.K. Human acupuncture points mapped in rats are associated with excitable muscle/skin-nerve complexes with enriched nerve endings. Brain Res. 2004, 1012, 154-159. [CrossRef] [PubMed]

162. Ahn, A.C.; Wu, J.; Badger, G.J.; Hammerschlag, R.; Langevin, H.M. Electrical impedance along connective tissue planes associated with acupuncture meridians. BMC Complement. Altern. Med. 2005, 5, 10. [CrossRef] [PubMed]

163. Ahn, A.C.; Park, M.; Shaw, J.R.; McManus, C.A.; Kaptchuk, T.J.; Langevin, H.M. Electrical impedance of acupuncture meridians: The relevance of subcutaneous collagenous bands. PLoS ONE 2010, 5, e11907. [CrossRef] [PubMed]

164. Litscher, G.; Wang, L. Biomedical engineering meets acupuncture-Development of a miniaturized 48-channel skin impedance measurement system for needle and laser acupuncture. Biomed. Eng. Online 2010, 9, 78. [CrossRef] [PubMed]

165. Stux, G.; Pomeranz, B. Acupuncture: Textbook and Atlas; Springer: Berlin, Germany, 1987; Chapter 1.

166. Kramer, S.; Winterhalter, K.; Schober, G.; Becker, U.; Wiegele, B.; Kutz, D.F.; Kolb, F.P.; Zaps, D.; Lang, P.M.; Irnich, D. Characteristics of electrical skin resistance at acupuncture points in healthy humans. J. Altern. Complement. Med. 2009, 15, 495-500. [CrossRef] [PubMed]

167. Litscher, G.; Wang, L.; Gao, X.Y.; Gaischek, I. Electrodermal mapping: A new technology. World J. Methodol. 2011, 1, 22-26. [CrossRef] [PubMed] 
168. Zhou, F.; Huang, D.K.; Xia, Y. Neuroanatomic Basis of Acupuncture Points. In Acupuncture Therapy for Neurological Diseases; Tsinghua University Press: Beijing, China; Springer: Berlin, Germany, 2010; Chapter 2.

169. Yao, W.; Yang, H.W.; Yin, N.; Ding, G.H. Mast cell-nerve cell interaction at acupoint: Modeling mechanotransduction pathway induced by acupuncture. Int. J. Biol. Sci. 2014, 10, 511-519. [CrossRef] [PubMed]

170. Zhang, D.; Ding, G.; Shen, X.; Yao, W.; Zhang, Z.; Zhang, Y.; Lin, J.; Gu, Q. Role of mast cells in acupuncture effect: A pilot study. Explore 2008, 4, 170-177. [CrossRef] [PubMed]

171. Marcelli, S. Gross anatomy and acupuncture: A comparative approach to reappraise the meridian system. Med. Acupunct. 2013, 25, 5-22. [CrossRef]

172. Peuker, E.; Cummings, M. Anatomy for the acupuncturist-Facts \& fiction 1: The head and neck region. Acupunct. Med. 2003, 21, 2-8. [PubMed]

173. Peuker, E.; Cummings, M. Anatomy for the acupuncturist-Facts \& fiction 2: The chest, abdomen, and back. Acupunct. Med. 2003, 21, 72-79. [PubMed]

174. Cheng, K.J. Neuroanatomical characteristics of acupuncture points: Relationship between their anatomical locations and traditional clinical indications. Acupunct. Med. 2011, 29, 289-294. [CrossRef] [PubMed]

175. Shaw, V.; McLennan, A.K. Was acupuncture developed by Han Dynasty Chinese anatomists? Anat. Rec. 2016, 299, 643-659. [CrossRef] [PubMed]

176. Robinson, N.G. Interactive Medical Acupuncture Anatomy; Tenton NewMedia: Jackson, MS, USA, 2016; Section 3, Channel 1 .

177. Zhang, W.; Tao, Q.; Guo, Z.; Fu, Y.; Chen, X.; Shar, P.A.; Shahen, M.; Zhu, J.; Xue, J.; Bai, Y.; et al. Systems pharmacology dissection of the integrated treatment for cardiovascular and gastrointestinal disorders by Traditional Chinese Medicine. Sci. Rep. 2016, 6, 32400. [CrossRef] [PubMed]

178. Myers, T. Anatomy Trains, 2nd ed.; Churchill Livingstone: Edinburg, UK, 2009.

179. Finando, S.; Finando, D. Fascia and the mechanism of acupuncture. J. Bodyw. Mov. Ther. 2011, 15, 168-176. [CrossRef] [PubMed]

180. Kellgren, J.H. A preliminary account of referred pains arising from muscle. Br. Med. J. 1938, 1, 325-327. [CrossRef] [PubMed]

181. Travell, J.; Rinzler, S.; Herman, M. Pain and disability of the shoulder and arm: Treatment by intramuscular infiltration with procaine hydrochloride. J. Am. Med. Assoc. 1942, 120, 417-422. [CrossRef]

182. Travell, J.; Simons, D. Myofascial Pain and Dysfunction: The Trigger Point Manual (Volume 1: Upper Extremities), 2nd ed.; Williams \& Wilkins: Baltimore, MD, USA, 1998.

183. Travell, J.; Simons, D. Myofascial Pain and Dysfunction: The Trigger Point Manual (Volume 2: Lower Extremities); Lippincott Williams \& Wilkins: Philadelphia, PA, USA, 1983.

184. Dorsher, P.T. Myofascial referred-pain data provide physiologic evidence of acupuncture meridians. J. Pain 2009, 10, 723-731. [CrossRef] [PubMed]

185. Jiang, S.; Zhao, J.S. The historical source of "Trigger Points": Classical ashi points. World J. Acupunct. Moxibustion 2016, 26, 11-14. [CrossRef]

186. Nugent-Head, A. Ashi points in clinical practice. J. Chin. Med. 2013, 101, 5-12.

187. Focks, C.; Hosbach, I.; März, U. Leitfaden Akupunktur, 2. Auflage; Elsevier: München, Germany, 2014.

188. Tortora, G.J.; Derrickson, B. Principles of Anatomy \& Physiology, 14th ed.; Wiley: Hoboken, NJ, USA, 2014.

189. Wilson-Pauwels, L.; Stewart, P.; Akesson, E. Autonomic Nerves; BC Decker: London, UK, 1997; Chapter 3.

190. Rong, P.; Zhu, B. Mechanism of relation among heart meridian, referred cardiac pain and heart. Sci. China C Life Sci. 2002, 45, 538-545. [CrossRef] [PubMed]

191. Cheng, J. Anatomical Atlas of Chinese Acupuncture Points; Shandong Science and Technology Press: Jinan China, 1982.

192. Maciocia, G. The Foundations of Chinese Medicine, 3rd ed.; Elsevier: Edinburg, UK, 2015; Chapter 32.

193. Liu, Z.; Liu, L. Essential of Chinese Medicine; Springer: Heidelberg, Germany, 2009; Chapter 5; Volume 2.

194. O'Brien, K.A. Alternative perspectives: How Chinese medicine understands hypercholesterolemia. Cholesterol 2010, 2010, 723289. [CrossRef] [PubMed]

195. Goldman, N.; Chen, M.; Fujita, T.; Xu, Q.; Peng, W.; Liu, W.; Jebsebm, T.K.; Pei, Y.; Wang, F.; Han, X.; et al. Adenosine A1 receptors mediate local anti-nociceptive effects of acupuncture. Nat. Neurosci. 2010, 13, 883-888. [CrossRef] [PubMed] 
196. Takano, T.; Chen, X.; Luo, F.; Goldman, N.; Zhao, Y.; Markman, J.D.; Nedergaard, M. Traditional acupuncture triggers a local increase in adenosine in human subjects. J. Pain 2012, 13, 1215-1223. [CrossRef] [PubMed]

197. Goldman, N.; Chandler-Militello, D.; Langevin, H.M.; Nedergaard, M.; Takano, T. Purine receptor mediated actin cytoskeleton remodeling of human fibroblasts. Cell Calcium 2013, 53, 297-301. [CrossRef] [PubMed]

198. Ren, W.; Tu, W.Z.; Jiang, S.H.; Cheng, R.D.; Du, Y.P. Electroacupuncture improves neuropathic pain: Adenosine, adenosine 5'-triphosphate disodium and their receptors perhaps change simultaneously. Neural Regen Res. 2012, 7, 2618-2623. [PubMed]

199. Zylka, M.J. Needling adenosine receptors for pain relief. Nat. Neurosci. 2010, 13, 783-784. [CrossRef] [PubMed]

200. Wang, L.; Sikora, J.; Hu, L.; Shen, X.Y.; Grygorczyk, R.; Schwarz, W. ATP release from mast cells by physical stimulation: A putative early step in activation of acupuncture points. Evid. Based Complement. Alternat. Med. 2013, 2013, 350949. [CrossRef] [PubMed]

201. Lin, D.; De La Pena, I.; Lin, L.L.; Zhou, S.F.; Borlongan, C.V.; Cao, C.H. The neuroprotective role of acupuncture and activation of the BDNF signalling pathway. Int. J. Mol. Sci. 2014, 15, 3234-3252. [CrossRef] [PubMed]

202. Szent-Györgyi, A. Introduction to a Submolecular Biology; Academic Press: New York, NY, USA, 1960.

203. Szent-Györgyi, A. The Development of Bioenergetics. In Membrane Structure and Mechanisms of Biological Energy Transduction; Plenum Press: London, UK, 1973.

204. Szent-Györgyi, A. Bioenergetics; Academic Press: New York, NY, USA, 1957.

205. Szent-Györgyi, A. Bioelectronics; Academic Press: New York, NY, USA, 1968.

206. Drury, A.N.; Szent-Györgyi, A. The physiological activity of adenine compounds with special reference to their action upon mammalian heart. J. Physiol. 1929, 68, 213-237. [CrossRef] [PubMed]

207. Oschman, J.L. Energy Medicine: The Scientific Basis, 2nd ed.; Elsevier: Edinburg, UK, 2016.

208. Sengupta, B.; Stemmler, M.; Laughlin, S.B.; Niven, J.E. Action potential energy efficiency varies among neuron types in vertebrates and invertebrates. PLoS Comput. Biol. 2010, 6, E1000840. [CrossRef] [PubMed]

209. Yi, G.S.; Wang, J.; Deng, B.; Hong, S.H.; Wei, X.L.; Chen, Y.Y. Action potential threshold of wide dynamic range neurons in rat spinal dorsal horn evoked by manual acupuncture at ST36. Neurocomputing 2015, 166, 201-209. [CrossRef]

210. Becker, R.; Selden, G. The Body Electric; William Marrow: New York, NY, USA, 1985; Chapter 13.

211. Nordenström, B. Biologically Closed Electric Circuits; Nordic Medical Publications: Stockholm, Sweden, 1983; Chapter 18.

212. Cohen, D.; Palti, Y.; Cuffin, B.N.; Schmid, S.J. Magnetic fields produced by steady currents in the body. Proc. Natl. Acad. Sci. USA 1980, 77, 1447-1451. [CrossRef] [PubMed]

213. McCraty, R. Science of the Heart; HeartMath Institute: Boulder Creek, CA, USA, 2015; Volume 2, Chapter 6.

214. Russek, L.; Schwartz, G. Energy cardiology: A dynamical energy systems approach for integrating conventional and alternative medicine. Advances 1996, 12, 4-24.

215. Adams, J.; Parker, K. Extracellular and Intracellular Signalling; Royal Society of Chemistry: Cambridge, UK, 2011; Chapter 1.

216. Adams, J.; Lien, E. Traditional Chinese Medicine: Scientific Basis for Its Use; Royal Society of Chemistry: Cambridge, UK, 2013; Chapter 1.

217. Deng, S.; Zhao, X.; Du, R.; He, S.; Wen, Y.; Huang, L.; Tian, G.; Zhang, C.; Meng, Z.; Shi, X. Is acupuncture no more than a placebo? Extensive discussion required about possible bias. Exp. Ther. Med. 2015, 10, 1247-1252. [CrossRef] [PubMed]

218. Pach, D.; Yang-Strobel, X.; Lüdtke, R.; Roll, S.; Icke, K.; Brinkhaus, B.; Witt, C.M. Standardized versus individualized acupuncture for chronic low back pain: A randomized controlled trial. Evid. Based Complement. Alternat. Med. 2013, 2013, 125937. [CrossRef] [PubMed]

219. Molsberger, A.F.; Mau, J.; Pawelec, D.B.; Winkler, J. Does acupuncture improve the orthopedic management of chronic low back pain-A randomized, blinded, controlled trial with 3 months follow up. Pain 2002, 99, 579-587. [CrossRef]

220. Weiss, J.; Quante, S.; Xue, F.; Muche, R.; Reuss-Borst, M. Effectiveness and acceptance of acupuncture in patients with chronic low back pain: Results of a prospective, randomized, controlled trial. J. Altern. Complement. Med. 2013, 19, 935-941. [CrossRef] [PubMed] 
221. Inoue, M.; Kitakoji, H.; Ishizaki, N.; Tawa, M.; Yano, T.; Katsumi, Y.; Kawakita, K. Relief of low back pain immediately after acupuncture treatment-A randomised, placebo controlled trial. Acupunct. Med. 2006, 24, 103-108. [CrossRef] [PubMed]

222. Giles, L.; Muller, R. Chronic spinal pain: A randomized clinical trial comparing medication, acupuncture, and spinal manipulation. Spine 2003, 28, 1490-1502. [CrossRef] [PubMed]

223. Haake, M.; Müller, H.H.; Schade-Brittinger, C.; Basler, H.D.; Schäfer, H.; Maier, C.; Endres, H.G.; Trampisch, H.J.; Wolsberger, A. German Acupuncture Trials (GERAC) for chronic low back pain: Randomized, multicenter, blinded, parallel-group trial with 3 groups. Arch. Intern Med. 2007, 167, 1892-1898. [CrossRef] [PubMed]

224. Brinkhaus, B.; Witt, C.M.; Jena, S.; Linde, K.; Streng, A.; Wagenpfeil, S.; Irnich, D.; Walther, H.-U.; Melchart, D.; Willich, S.N. Acupuncture in patients with chronic low back pain: A randomized controlled trial. Arch. Intern Med. 2006, 166, 450-457. [CrossRef] [PubMed]

225. Cho, Y.J.; Song, Y.K.; Cha, Y.Y.; Shin, B.C.; Shin, I.H.; Park, H.J.; Lee, H.-S.; Kim, K.-W.; Cho, J.-H.; Chuang, W.S.; et al. Acupuncture for chronic low back pain: A multicenter, randomized, patient-assessor blind, sham-controlled clinical trial. Spine 2013, 38, 549-557. [CrossRef] [PubMed]

226. Cherkin, D.C.; Eisenberg, D.; Sherman, K.J.; Barlow, W.; Kaptchuk, T.J.; Street, J.; Deyo, R.A. Randomized trial comparing traditional Chinese medical acupuncture, therapeutic massage, and self-care education for chronic low back pain. Arch. Intern Med. 2001, 161, 1081-1088. [CrossRef] [PubMed]

227. Cherkin, D.C.; Sherman, K.J.; Avins, A.L.; Erro, J.H.; Ichikawa, L.; Barlow, W.E.; Delney, K.; Hawkes, R.; Hamilton, L.; Pressman, A.; et al. A randomized trial comparing acupuncture, simulated acupuncture, and usual care for chronic low back pain. Arch. Intern Med. 2009, 169, 858-866. [CrossRef] [PubMed]

228. Mingdong, Y.; Na, X.; Mingyang, G.; Jun, Z.; Defang, L.; Yong, L.; Lingling, G.; Jiao, Y. Acupuncture at the back-pain-acupoints for chronic low back pain of peacekeepers in Lebanon: A randomized controlled trial. J. Muscoskelet. Pain 2012, 20,107-115. [CrossRef]

229. Zhang, X.; Wang, Y.; Wang, Z.; Wang, C.; Ding, W.; Liu, Z. A randomized clinical trial comparing the effectiveness of electroacupuncture versus medium-frequency electrotherapy for discogenic sciatica. Evid. Based Complement. Alternat. Med. 2017, 2017, 9502718. [CrossRef] [PubMed]

230. Thomas, M.; Lundberg, T. Importance of modes of acupuncture in the treatment of chronic nociceptive low back pain. Acta Anaesthesiol. Scand. 1994, 38, 63-69. [CrossRef] [PubMed]

231. Glazov, G.; Yelland, M.; Emery, J. Low-dose laser acupuncture for non-specific chronic low back pain: A double-blind randomised controlled trial. Acupunct. Med. 2014, 32, 116-123. [CrossRef] [PubMed]

232. Shin, J.Y.; Ku, B.; Kim, J.U.; Lee, Y.J.; Kang, J.H.; Heo, H.; Choi, H.-J.; Lee, J-H. Short-term effect of laser acupuncture on lower back pain: A randomized, placebo-controlled, double-blind trial. Evid. Based Complement. Alternat Med. 2015, 2015, 808425. [CrossRef] [PubMed]

233. Bothwell, L.E.; Greene, J.A.; Podolsky, S.H.; Jones, D.S. Assessing the gold standard-Lessons from the history of RCTs. N. Engl. J. Med. 2016, 374, 2175-2181. [CrossRef] [PubMed]

234. Hill, A.B. Principles of Medical Statistics, 6th ed.; Oxford University Press: New York, NY, USA, 1955; Chapter 1.

235. Brown, W. The Placebo Effect in Clinical Practice; Oxford University Press: Oxford, UK, 2013; Chapters 2-4.

236. Kaptchuk, T.J. The double-blind, randomized, placebo-controlled trial: Gold standard or golden calf? J. Clin. Epidemiol. 2001, 54, 541-549. [CrossRef]

237. Moerman, D. Meaning, Medicine, and the "Placebo Effect"; Cambridge University Press: Cambridge, UK, 2002; Chapter 1.

238. Benedetti, F.; Mayberg, H.S.; Wager, T.D.; Stohler, C.S.; Zubieta, J.K. Neurobiological mechanisms of the placebo effect. J. Neurosci. 2005, 25, 10390-10402. [CrossRef] [PubMed]

239. Price, D.D.; Finniss, D.G.; Benedetti, F. A comprehensive review of the placebo effect: Recent advances and current thought. Annu. Rev. Psychol. 2008, 59, 565-590. [CrossRef] [PubMed]

240. Finniss, D.G.; Kaptchuk, T.J.; Miller, F.; Benedetti, F. Biological, clinical, and ethical advances of placebo effects. Lancet 2010, 375, 686-695. [CrossRef]

241. Bausell, R.B.; Lao, L.; Bergman, S.; Lee, W.L.; Berman, B.M. Is acupuncture analgesia an expectancy effect? Preliminary evidence based on participants' perceived assignments in two placebo-controlled trials. Eval. Health Prof. 2005, 28, 9-26. [CrossRef] [PubMed]

242. Benedetti, F. What do you expect from this treatment? Changing our mind about clinical trials. Pain 2007, 128, 193-194. [CrossRef] [PubMed] 
243. Linde, K.; Witt, C.M.; Streng, A.; Weidenhammer, W.; Wagenpfeil, S.; Brinkhaus, B.; Willich, S.N.; Melchart, D. The impact of patient expectations on outcomes in four randomized controlled trials of acupuncture in patients with chronic pain. Pain 2007, 128, 264-271. [CrossRef] [PubMed]

244. Myers, S.S.; Phillips, R.S.; Davis, R.B.; Cherkin, D.C.; Legedza, A.; Kaptchuk, T.J.; Hrbek, A.; Buring, J.E.; Post, D.; Connelly, M.T.; et al. Patient expectations as predictors of outcome in patients with acute low back pain. J. Gen. Intern Med. 2008, 23, 148-153. [CrossRef] [PubMed]

245. Pariente, J.; White, P.; Frackowiak, R.S.; Lewith, G. Expectancy and belief modulate the neuronal substrates of pain treated by acupuncture. Neuroimage 2005, 25, 1161-1167. [CrossRef] [PubMed]

246. Colagiuri, B. Participant expectancies in double-blind randomized placebo-controlled trials: Potential limitations to trial validity. Clin. Trials 2010, 7, 246-255. [CrossRef] [PubMed]

247. Perlis, R.H.; Ostacher, M.; Fava, M.; Nierenberg, A.A.; Sachs, G.S.; Rosenbaum, J.F. Assuring that double-blind is blind. Am. J. Psychiatry 2010, 167, 250-252. [CrossRef] [PubMed]

248. Hertzman, M.; Adler, L. Clinical Trials in Psychopharmacology, 2nd ed.; Wiley-Blackwell: Oxford, UK, 2010; Chapter 18.

249. Hertzman, M.; Feltner, D. The Handbook of Psychopharmacology Trial; New York University Press: New York, NY, USA, 1997; Chapter 6.

250. Vickers, A.; Goyal, N.; Harland, R.; Rees, R. Do certain countries produce only positive results? A systematic review of controlled trials. Control Clin. Trials 1998, 19, 159-166. [CrossRef]

251. Molsberger, A.; Zhou, J.; Boewing, L.; Arndt, D.; Karst, M.; Teske, W.; Drabik, A. An international expert survey on acupuncture in randomized controlled trials for low back pain and a validation of the low back pain acupuncture score. Eur. J. Med. Res. 2011, 16, 133-138. [CrossRef] [PubMed]

252. Shapiro, A.K. Etiological factors in placebo effect. JAMA 1964, 187, 712-714. [CrossRef] [PubMed]

253. Miller, F.G.; Kaptchuk, T.J. The power of context: Reconceptualizing the placebo effect. J. R. Soc. Med. 2008, 101, 222-225. [CrossRef] [PubMed]

254. Katz, J. The Silent World of Doctor and Patient; The Free Press: New York, NY, USA, 1984; Chapter 8.

255. Kerr, C.E.; Shaw, J.R.; Conboy, L.A.; Kelley, J.M.; Jacobson, E.; Kaptchuk, T.J. Placebo acupuncture as a form of ritual touch healing: A neurophenomenological model. Conscious. Cogn. 2011, 20, 784-791. [CrossRef] [PubMed]

256. Beecher, H.K. The powerful placebo. JAMA 1955, 159, 1602-1606. [CrossRef]

257. Tragende Gründe zum Beschluss des Gemeinsamen Bundesausschusses zur Akupunktur. Press Release by Gemeinsamen Bundesausschusses, Dated 18.04.2006. Available online: https://www.g-ba.de/ informationen/beschluesse/295/ (accessed on 5 June 2018).

258. Lee, I.S.; Lee, S.H.; Kim, S.Y.; Lee, H.J.; Park, H.J.; Chae, Y.Y. Visualization of the meridian system based on biomedical information about acupuncture treatment. Evid. Based Complement. Alternat. Med. 2013, 2013, 872142. [CrossRef] [PubMed]

259. Early Acupuncture, by Mark Parisi. Available online: https://www.offthemark.com/search/?q=early\% 20acupuncture (accessed on 5 June 2018).

260. Dellon, A.L.; Höke, A.; Williams, E.H.; Williams, C.G.; Zhang, Z.; Rosson, G.D. The sympathetic innervation of the human foot. Plast. Reconstr. Surg. 2012, 129, 905-909. [CrossRef] [PubMed]

261. Langevin, H.M.; Konofagou, E.E.; Badger, G.J.; Churchill, D.L.; Fox, J.R.; Ophir, J.; Garra, B.S. Tissue displacements during acupuncture using ultrasound elastography techniques. Ultrasound Med. Biol. 2004, 30, 1173-1183. [CrossRef] [PubMed]

262. Langevin, H.M.; Bouffard, N.A.; Badger, G.J.; Churchill, D.L.; Howe, A.K. Subcutaneous tissue fibroblast cytoskeletal remodeling induced by acupuncture: Evidence for a mechanotransduction-based mechanism. J. Cell Physiol. 2006, 207, 767-774. [CrossRef] [PubMed]

263. Langevin, H.M.; Bouffard, N.A.; Churchill, D.L.; Badger, G.J. Connective tissue fibroblast response to acupuncture: Dose-dependent effect of bidirectional needle rotation. J. Altern. Complement. Med. 2007, 13, 355-360. [CrossRef] [PubMed]

264. Fox, J.R.; Gray, W.; Koptiuch, C.; Badger, G.J.; Langevin, H.M. Anisotropic tissue motion induced by acupuncture needling along intermuscular connective tissue planes. J. Altern. Complement. Med. 2014, 20, 290-294. [CrossRef] [PubMed]

265. Burnstock, G. Physiology and pathophysiology of purinergic neurotransmission. Physiol. Rev. 2007, 87, 659-797. [CrossRef] [PubMed] 
266. Abbracchio, M.P.; Burnstock, G.; Verkhratsky, A.; Zimmermann, H. Purinergic signalling in the nervous system: An overview. Trends Neurosci. 2009, 32, 19-29. [CrossRef] [PubMed]

267. Yu, J.; Zhao, C.; Luo, X. The effects of electroacupuncture on the extracellular signal-regulated kinase 1/2/P2X3 signal pathway in the spinal cord of rats with chronic constriction injury. Anesth. Analg. 2013, 116, 239-246. [CrossRef] [PubMed]

268. Tang, Y.; Yin, H.Y.; Rubini, P.; Illes, P. Acupuncture-induced analgesia: A neurobiological basis in purinergic signaling. Neuroscientist 2016, 22, 563-578. [CrossRef] [PubMed]

269. Zylka, M.J. Pain-relieving prospects for adenosine receptors and ectonucleotidases. Trends Mol. Med. 2011, 17, 188-196. [CrossRef] [PubMed]

270. Zhou, W.; Benharash, P. Significance of "Deqi" response in acupuncture treatment: Myth or reality. J. Acupunct. Meridian Stud. 2014, 7, 186-189. [CrossRef] [PubMed]

271. Kong, J.; Gollub, R.; Huang, T.; Polich, G.; Napadow, V.; Hui, K.; Vangel, M.; Rosen, B.; Kaptchuk, T.J. Acupuncture de qi, from qualitative history to quantitative measurement. J. Altern. Complement. Med. 2007, 13, 1059-1070. [CrossRef] [PubMed]

272. Cheng, X. Chinese Acupuncture and Moxibustion, revised ed.; Foreign Languages Press: Beijing, China, 1999; Chapter 14.

273. Essentials of Chinese Acupuncture; Beijing College of Traditional Chinese Medicine; Shanghai College of Traditional Chinese Medicine; Nanjing College of Traditional Chinese Medicine; The Acupuncture Institute of the Academy of Traditional Chinese Medicine. (Compiler) Foreign Languages Press: Beijing, China, 1980; Part 3, Chapter 1.

274. Stux, G.; Berman, B.; Pomeranz, B. Basics of Acupuncture, 5th ed.; Springer: Berlin, Germany, 2003; Chapter 5.

275. Napadow, V.; Dhond, R.P.; Kim, J.; LaCount, L.; Vangel, M.; Harris, R.E.; Kettner, N.; Park, K. Brain encoding of acupuncture sensation-Coupling on-line rating with fMRI. Neuroimage 2009, 47, 1055-1065. [CrossRef] [PubMed]

276. Kong, J.; Fufa, D.T.; Gerber, A.J.; Rosman, I.S.; Vangel, M.G.; Gracely, R.H.; Gollub, R.L. Psychophysical outcomes from a randomized pilot study of manual, electro, and sham acupuncture treatment on experimentally induced thermal pain. J. Pain 2005, 6, 55-64. [CrossRef] [PubMed]

277. Spaeth, R.B.; Camhi, S.; Hashmi, J.A.; Vangel, M.; Wasan, A.D.; Kong, J.; Edwards, R.R.; Gollub, R.L.; Kong, J. A longitudinal study of the reliability of acupuncture deqi sensations in knee osteoarthritis. Evid. Based Complement. Alternat. Med. 2013, 2013, 204259. [CrossRef] [PubMed]

278. White, P.; Prescott, P.; Lewith, G. Does needling sensation (de qi) affect treatment outcome in pain? Analysis of data from a larger single-blind, randomised controlled trial. Acupunct. Med. 2010, 28, 120-125. [CrossRef] [PubMed]

279. Langevin, H.M.; Churchill, D.L.; Cipolla, M.J. Mechanical signaling through connective tissue: A mechanism for the therapeutic effect of acupuncture. FASEB J. 2001, 15, 2275-2282. [CrossRef] [PubMed]

280. Langevin, H.M.; Churchill, D.L.; Fox, J.R.; Badger, G.J.; Garra, B.S.; Krag, M.H. Biomechanical response to acupuncture needling in humans. J. Appl. Physiol. 2001, 91, 2471-2478. [CrossRef] [PubMed]

281. Langevin, H.M.; Churchill, D.L.; Wu, J.; Badger, G.J.; Yandow, J.A.; Fox, J.R.; Krag, M.H. Evidence of connective tissue involvement in acupuncture. FASEB J. 2002, 16, 872-874. [CrossRef] [PubMed]

282. Zhu, J.; Kennedy, D.N.; Cao, X. Neural Transmission of Acupuncture Signal. In Acupuncture Therapy for Neurological Diseases; Xia, Y., Cao, X.D., Wu, G.C., Cheng, J.S., Eds.; Tsinghua University Press: Beijing, China; Springer: Berlin, Germany, 2010; Chapter 3.

283. Hui, K.K.; Liu, J.; Marina, O.; Napadow, V.; Haselgrove, C.; Kwong, K.K.; Kennedy, D.N.; Markris, N. The integrated response of the human cerebro-cerebellar and limbic systems to acupuncture stimulation at ST 36 as evidenced by fMRI. Neuroimage 2005, 27, 479-496. [CrossRef] [PubMed]

284. Tang, W.J.; Li, J.; Zhang, J.H.; Yi, T.; Wang, S.W.; Dong, J.C. Acupuncture treatment of chronic low back pain reverses an abnormal brain default mode network in correlation with clinical pain relief. Acupunct. Med. 2013, 1-7. [CrossRef]

285. Chen, X.; Spaeth, R.B.; Retzepi, K.; Ott, D.; Kong, J. Acupuncture modulates cortical thickness and functional connectivity in knee osteoarthritis patients. Sci. Rep. 2014, 4, 6482. [CrossRef] [PubMed]

286. Shi, Y.; Liu, Z.; Zhang, S.; Li, Q.; Guo, S.; Yang, J.; Wu, W. Brain network response to acupuncture stimuli in experimental acute low back pain: An fMRI study. Evid. Based Complement. Alternat. Med. 2015, 2015, 210120. [CrossRef] [PubMed] 
287. Kandel, E.; Schwartz, J.; Jessel, T.; Siegelbaum, S.; Hudspeth, A.J. Principles of Neural Science, 5th ed.; McGraw-Hill: New York, NY, USA, 2013; Chapter 22.

288. Pomeranz, B.; Chiu, D. Naloxone blockade of acupuncture analgesia: Endorphin implicated. Life Sci. 1976, 19, 1757-1762. [CrossRef]

289. Lee, A.D.; Hsu, E.S. Mechanisms of Acupuncture Analgesia. In Acupuncture for Pain Management; Lin, Y., Hsu, E.S., Eds.; Springer: Heidelberg, Germany, 2014; Chapter 4.

290. Li, P.; Chiang, C.Y. The Analgesic Effects of Acupuncture. In The Mechanism of Acupuncture Therapy and Clinical Case Studies; Cheung, L., Li, P., Wong, C., Eds.; Taylor \& Francis: London, UK, 2001; Chapter 4.

291. Melzack, R. Akupunktur und Schmerzbeeinflussung. Anaesthesist 1976, 25, 204-207. [PubMed]

292. Pomeranz, B.; Berman, B. Scientific Basis of Acupuncture. In Basics of Acupuncture, 5th ed.; Stux, G., Berman, B., Pomeranz, B., Eds.; Springer: Berlin, Germany, 2003; Chapter 2.

293. Dung, H. Acupuncture: An Anatomical Approach, 2nd ed.; CRC Press: London, UK, 2014; Chapter 9.

294. Grissa, M.H.; Baccouche, H.; Boubaker, H.; Beltaief, K.; Bzeouich, N.; Fredj, N.; Msolli, M.A.; Boukef, R.; Bouida, W.; et al. Acupuncture vs intravenous morphine in the management of acute pain in the, ED. Am. J. Emerg. Med. 2016, 34, 2112-2116. [CrossRef] [PubMed]

295. Lohmann, K. Über die Pyrophosphatfraktion im Muskel. Naturwissenschaften 1929, 17, 624-625.

296. Holton, F.A.; Holton, P. The capillary dilator substances in dry powders of spinal roots; a possible role of adenosine triphosphate in chemical transmission from nerve endings. J. Physiol. 1954, 126, 124-140. [CrossRef] [PubMed]

297. Burnstock, G. Purinergic nerves. Pharmacol. Rev. 1972, 24, 509-581. [PubMed]

298. Burnstock, G. Acupuncture: A novel hypothesis for the involvement of purinergic signalling. Med. Hypotheses 2009, 73, 470-472. [CrossRef] [PubMed]

299. Burnstock, G. P2X receptors in sensory neurones. Br. J. Anaesth. 2000, 84, 476-488. [CrossRef] [PubMed]

300. Burnstock, G. Pathophysiology and therapeutic potential of purinergic signaling. Pharmacol. Rev. 2006, 58, 58-86. [CrossRef] [PubMed]

301. Burnstock, G.; Verkhratsky, A. Purinergic Signalling and the Nervous System; Springer: Berlin, Germany, 2012; Chapter 8.

302. Masino, S.; Boison, D. Adenosine: A Key Link between Metabolism and Brain Activity; Springer: Heidelberg, Germany, 2013.

303. Sawynok, J.; Liu, X.J. Adenosine in the spinal cord and periphery: Release and regulation of pain. Prog. Neurobiol. 2003, 69, 313-340. [CrossRef]

304. Bours, M.J.; Swennen, E.L.; Di Virgilio, F.; Cronstein, B.N.; Dagnelie, P.C. Adenosine 5'-triphosphate and adenosine as endogenous signaling molecules in immunity and inflammation. Pharmacol. Ther. 2006, 112, 358-404. [CrossRef] [PubMed]

305. Hurt, J.K.; Zylka, M.J. PAPupuncture has localized and long-lasting antinociceptive effects in mouse models of acute and chronic pain. Mol. Pain 2012, 8, 28. [CrossRef] [PubMed]

306. Fujita, T.; Feng, C.; Takano, T. Presence of caffeine reversibly interferes with efficacy of acupuncture-induced analgesia. Sci. Rep. 2017, 7, 3397. [CrossRef] [PubMed]

307. Montes, L.A.; Valenzuela, M.J. Effectiveness of low back pain treatment with acupuncture. Biomedica 2017, 38, 54-60. [CrossRef] [PubMed]

308. Leem, J.; Kim, H.; Jo, H.G.; Jeon, S.R.; Hong, Y.; Park, Y.; Seo, B.; Cho, Y.; Kang, J.W.; Kim, E.J.; et al. Efficacy and safety of thread embedding acupuncture combined with conventional acupuncture for chronic low back pain: A study protocol for a randomized, controlled, assessor-blinded, multicenter clinical trial. Medicine 2018, 97, e10790. [CrossRef] [PubMed]

309. Vitoula, K.; Venneri, A.; Varrassi, G.; Paladini, A.; Sykioti, P.; Adewusi, J.; Zis, P. Behavioral therapy approaches for the management of low back pain: An up-to-date systematic review. Pain Ther. 2018, 16. [CrossRef] [PubMed]

310. Zhang, X. Acupuncture: Review and Analysis of Controlled Clinical Trials; World Health Organization: Geneva, Switzerland, 2002. Available online: http:www.iama.edu/OtherArticles/acupunctureWHOfullreport.pdf (accessed on 5 June 2018).

311. Manheimer, E.; White, A.; Berman, B.; Forys, K.; Ernst, E. Meta-analysis: Acupuncture for low back pain. Ann. Intern Med. 2005, 142, 651-663. [CrossRef] [PubMed] 
312. Taylor, P.; Pezzullo, L.; Grant, S.J.; Bensoussan, A. Cost-effectiveness of acupuncture for chronic nonspecific low back pain. Pain Pract. 2014, 14, 599-606. [CrossRef] [PubMed]

313. Wu, J.; Hu, Y.; Zhu, Y.; Yin, P.; Litscher, G.; Xu, S. Systematic review of adverse effects: A further step towards modernization of acupuncture in China. Evid. Based Complement. Alternat. Med. 2015, 432467. [CrossRef] [PubMed]

(C) 2018 by the authors. Licensee MDPI, Basel, Switzerland. This article is an open access article distributed under the terms and conditions of the Creative Commons Attribution (CC BY) license (http:/ / creativecommons.org/licenses/by/4.0/). 
Review

\title{
The Effects of Yin, Yang and Qi in the Skin on Pain
}

\author{
James David Adams, Jr. \\ University of Southern California, School of Pharmacy, 1985 Zonal Avenue, Los Angeles, CA, 90089-9121, USA; \\ jadams@usc.edu; Tel.: +1-323-442-1362; Fax: +1-323-442-1681
}

Academic Editors: Gerhard Litscher and William Chi-shing Cho

Received: 30 November 2015; Accepted: 26 January 2016; Published: 29 January 2016

\begin{abstract}
The most effective and safe treatment site for pain is in the skin. This chapter discusses the reasons to treat pain in the skin. Pain is sensed in the skin through transient receptor potential cation channels and other receptors. These receptors have endogenous agonists (yang) and antagonists (yin) that help the body control pain. Acupuncture works through modulation of these receptor activities (qi) in the skin; as do moxibustion and liniments. The treatment of pain in the skin has the potential to save many lives and improve pain therapy in most patients.
\end{abstract}

Keywords: pain; skin; topical; liniment; acupuncture; transient receptor potential cation channels

\section{Introduction}

The ancient Chinese concepts of yin, yang and qi have been explained in modern scientific terms [1]. Yin is cold, wet and diminishes blood flow. Yang is hot, dry and increases blood flow. Yin can also be represented by an antagonist that decreases pain and inflammation by inhibiting a receptor, such as a transient receptor potential cation channel (TRP). Yang can be represented by an agonist that decreases pain and inflammation by increasing the activity of a receptor, such as an opioid receptor. Qi is the flow of signal transduction mechanisms that occurs in cells because of the actions of agonists and antagonists. When qi flows well, these signal transduction mechanisms result in less pain and inflammation. A balance of yin and yang is necessary for qi to flow well. Signal transduction mechanisms may influence yin and yang by altering the transcription or activation of TRP or other receptors. There is a pain cycle that starts in the skin, travels to the brainstem and brain, and returns to the skin [2]. This pain cycle can magnify pain if left unchecked. The pain cycle is caused when yin and yang are not in balance and qi does not flow correctly in the skin.

The gate control theory of pain presents the pain cycle in terms of the brainstem rather than the skin [3]. In this theory, pain is sensed in the brain not the skin, and can be modified by non-painful sensations in the skin, such as rubbing the skin after a painful incident. This theory contends that inhibitory interneurons in the brainstem can suppress the transmission of pain signals into the brain. The gate control theory is useful, but does not take into account the many pain sensors in the skin and the fact that the signals from these pain sensors can be modified in the skin [2]. The fact that the skin is involved in pain sensation is obvious, since injection of a local anesthetic into the skin causes analgesia near the site of injection. The current paper proposes a modification of the gate control theory in which the skin is involved in sensing and modifying pain signals. The brainstem can modify pain signals. The brain is responsible for processing and modifying pain signals.

It is well known that ice packs decrease pain and swelling soon after an injury. Later, heat packs may be applied in order to decrease pain and swelling. How do ice and heat work? They work through TRPs that are sensitive to cold and heat. Initial TRP activation by cold or heat results in TRP deactivation that causes pain relief and decreases inflammation. TRPs are the most abundant pain receptors in the body. They are located in the plasma membranes of many cells of the body and are sensitive to heat, cold, pain, mechanical stimulation and other stimuli. They are abundant in the skin 
where they are located in the terminals of sensory afferent neurons [2]. TRP activation causes pain. TRPs are unusual receptors in that activation by an agonist may cause them to deactivate. This can lead to pain relief for much longer than expected. TRPs are channels that allow calcium and other positive ions to enter sensory neurons. Excessive calcium permeability can cause apoptosis of sensory terminals. This causes long term pain relief until nerve terminals can be regenerated [4]. TRPs are also involved in inflammation in the skin and other sites in the body [2].

\section{TRP Diversity and Neuronal Populations}

There are at least 28 different TRPs in the skin (Table 1), most of which are pain receptors [5]. In other words, these receptors are activated by painful stimuli and transmit these pain stimuli to the brain. There is no evidence of tolerance to the analgesia produced by inhibiting or deactivating TRPs. The body makes agonists and antagonists for these receptors which are derived from arachidonic acid and other fats. There are transient receptor potential cation channel vanilloid receptors, TRPV1-6, that can be inhibited by plant derived compounds such as capsaicin and some monoterpenoids [5]. Several TRPV receptor subtypes are activated by heat. As heat is applied, the receptors are initially activated, then deactivated resulting in channel closing and analgesia. TRPV receptors respond to endocannabinoids, endovanilloids, cannabinoids, hydroperoxyeicosatetraenoic acid (HPETE) and hydroxyeicosatetraenoic acid (HETE) [5]. Mechanical stimuli, such as pressure on the skin, can also activate some vanilloid channels such as TRPV4. There is one transient receptor potential cation channel ankyrin receptor, TRPA1, which can be inhibited by some monoterpenoids, other plant derived compounds, arachidonic acid and some prostaglandins. TRPA1 also responds to cold and mechanical stimuli. There are transient receptor potential cation channel canonical receptors, TRPC1-7, that are inhibited by hyperforin and other compounds. TRPC 5 is activated by low temperature. TRPC 1 and 6 are activated by mechanical stretch. Transient receptor potential cation channel melastatin receptors, TRPM1-8, are inhibited by monoterpenoids such as menthol and by fats such as sphingosine. TRPM1, 2, 3, 4 and 5 are activated by heat. TRPM8 is activated by cold. The transient receptor potential cation channel polycystin receptors, TRPP1-3, may be inhibited by diterpenes such as triptolide. TRPP1 and 2 are mechanosensitive channels. The transient receptor potential cation channel mucolipin receptors, TRPML1-3, respond to protons. 
Table 1. Skin Pain Receptors.

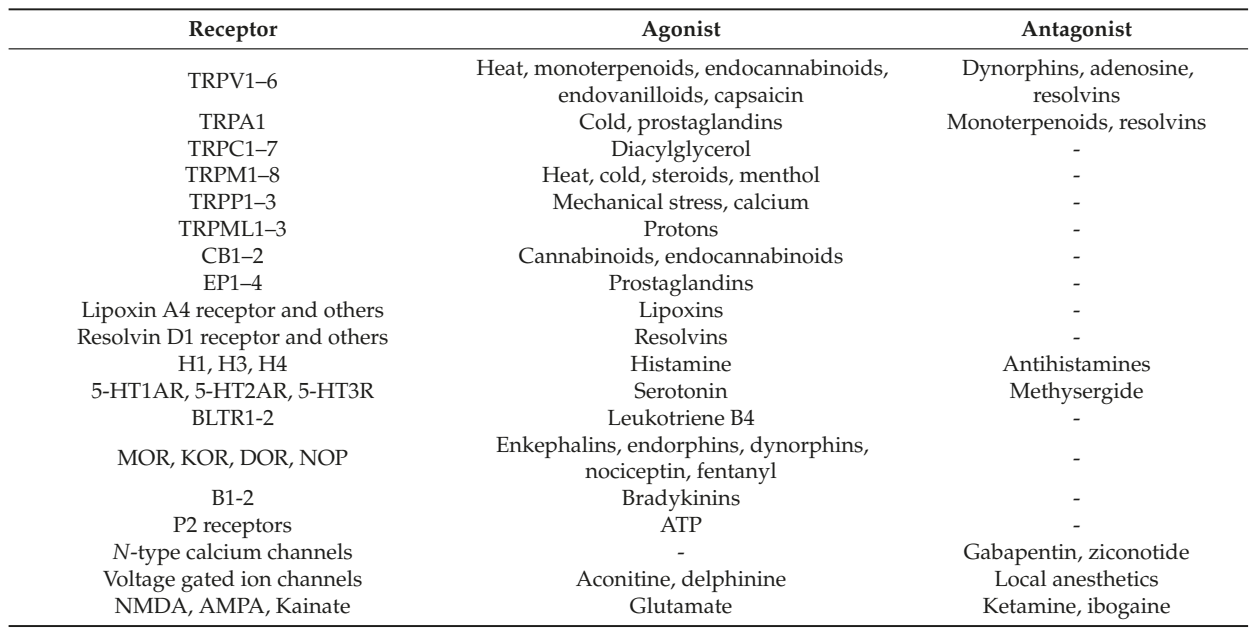

TRPV-transient receptor potential cation channel vanilloid, TRPA-transient receptor potential cation channel ankyrin, TRPC — transient receptor potential cation channel canonical, TRPM-transient receptor potential cation channel melastatin, TRPP-transient receptor potential cation channel polycystin, TRPML - transient receptor potential cation channel mucolipin, $\mathrm{CB}$ - cannabinoid receptor, EP — prostaglandin receptor, H-histamine receptor, 5-HTR-serotonin receptor, BLTR-leukotriene receptor, MOR-mu opioid receptor, KOR—kappa opioid receptor, DOR—delta opioid receptor, NOP-nociception receptor, $\mathrm{B}$-bradykinin receptor, $\mathrm{P} 2$ - adenosine triphosphate (ATP) receptor, NMDA-N-methyl-D-aspartate receptor, AMPA-alpha-amino-3-hydroxy-5-methyl-4-isoxazolepropionic acid receptor.

TRPs are found in non-overlapping populations of nerve terminals in the skin [6]. Many of these receptors also are found in endothelial and dendritic cells and are involved in dermatitis. Since these receptors are found in non-overlapping neuron populations, this makes pain treatment complex. For instance, if a menthol liniment is applied to the skin, it may not inhibit all of the neuronal terminals in the area, and may not adequately relieve pain. It is important to use a liniment that inhibits as many skin TRPs as possible in order to get pain relief, which may involve multiple monoterpenoids [7-9].

\section{Other Skin Receptors Involved in Pain}

The skin contains a variety of receptors involved in pain [10]. TRP receptors are the most abundant and varied. There are cannabinoid receptors, $\mathrm{CB} 1$ and CB2, which are involved in inflammation and pain sensation in the skin [11]. Cannabinoids are also agonists for several TRPs and cause an initial activation of the receptors followed by deactivation. There are skin lipoxin receptors that cause pain [12]. There are skin resolvin receptors that decrease pain [12]. Resolvins also inhibit TRPA1, TRPV3 and TRPV4. There are opioid receptors in the skin [13]. Opioid peptides such as the enkephalins are also made in the skin [13]. Fentanyl patches are used to treat pain and stimulate opioid receptors by direct application to the skin. Other pain receptors in the skin include bradykinin receptors, histamine receptors, serotonin receptors, adenosine triphosphate (ATP) receptors, prostaglandin receptors, $\mathrm{N}$-type calcium channels, voltage gated sodium channels and glutamate receptors [10]. Voltage gated sodium channels are inhibited by local anesthetics and result in pain inhibition in the skin [10]. All of these receptors are involved in causing and relieving pain. All of these receptors have endogenous agonists and antagonists that are involved in pain and analgesia. Pain occurs when the production of these endogenous compounds is out of balance and causes too much stimulation of pain receptors. 


\section{Interactions of Pain Receptor Responses}

The activation of one pain receptor can potentiate the activity of other pain receptors in the skin. This interaction greatly increases pain, in other words increases the improper flow of qi in the skin. TRPC 5 activity is potentiated by Gq coupled G-protein coupled receptor (GPCR) activation [2], such as by glutamate, serotonin, histamine, muscarine and angtiotensin II receptors. TRPM2 is potentiated by receptor activation that involves the formation of cyclic-adenosine diphosphate (ADP) ribose, such as by muscarinic receptors [2]. Bradykinin receptor activation potentiates TRPA1 activity [2]. TRPC channels are activated by phospholipase C [14]. Several receptors activate phospholipase C, such as muscarinic, histaminergic, serotonergic, glutamatergic and muscarinic. Interactions of these pain receptors alter qi in the skin such that pain is magnified.

\section{Skin Cyclooxygenase-2}

Cyclooxygense-2 (COX2) is the main source of prostaglandins. As mentioned before, prostaglandins cause pain by interacting with prostaglandin receptors and TRPs. They also potentiate TRPV1 activity by increasing protein kinase A and C activity [2]. COX2 activity increases in the skin in chronic pain conditions [15]. This induction of skin COX2 makes pain worse and ensures that pain will continue until COX2 activity decreases. It is not known how skin COX2 is induced in chronic pain. Nonsteroidal anti-inflammatory agents (NSAIDS) are used to inhibit both COX1 and COX2 in the treatment of pain. These oral or injected agents do not penetrate adequately into the skin to inhibit skin COX2 [2]. On the other hand, topical sesquiterpenes are known to penetrate the skin and may inhibit COX2 or decrease the expression of COX2 in the skin $[7,8]$. Topical preparations can be superior to oral or injected preparations for pain treatment.

\section{Moxibustion and Skin Yin, Yang and Qi}

Moxibustion involves heating the skin at specific acupuncture points to relieve pain [16]. Application of heat for several seconds causes the deactivation of some TRPs [5]. This diminishes pain by decreasing the activity of skin sensory neurons. The heat sensitive TRPs are discussed above. By using a yang influence, heat, moxibustion reestablishes the proper flow of qi that comes from TRPs in sensory neurons and decreases pain.

\section{Acupuncture and Skin Yin, Yang and Qi}

Acupuncture causes an initial activation of several different TRPs by causing an initial pain sensation and a mechanical stimulation. Several TRPs are activated by pain and mechanical stimuli as discussed above. The continued application of the acupuncture needle for more than several seconds, may cause these channels to deactivate and relieve pain. As discussed before, the application of too much yin (antagonist) or yang (agonist) to TRPs, causes them to shut down. This relieves pain by allowing qi (signal transduction) to flow correctly. It has been suggested that mast cell degranulation involves TRPV2 activation and that acupuncture may increase this process [17]. Mast cell degranulation is important in skin inflammation, irritation and pain. In addition, electroacupuncture was shown to decrease the expression of TRPV1 [13]. COX2 expression can also be diminished by acupuncture [18-21], which is important in the treatment of chronic pain conditions. Since acupuncture is applied to the skin, it inhibits the expression of skin COX2 [21]. It has been known for centuries that acupuncture is useful in the treatment of acute and chronic pain. TRP inhibition and decreased COX2 expression may be involved in this pain relief.

\section{The Superiority Pain Treatment in the Skin}

The most popular treatments for pain are oral medications such as NSAIDS and opioids. These agents are given in large doses and cause many toxic reactions. NSAIDS cause 100,000 ulcers in the US every year that result in 10,000 deaths. NSAIDS also cause kidney damage and clotting problems 
that lead to stroke and heart attack. COX1 is the major source of thromboxane. COX2 is the major source of prostaglandins. The prostaglandin, prostacyclin (PGI2) can inhibit clotting. It is possible that inhibition of COX2 in platelets leads to excess thromboxane, inadequate PGI2 and clotting. NSAIDS alter the balance of arachidonic acid metabolites, including prostaglandins and lipoxins, such that drug toxicity occurs. Opioids cause tolerance, addiction and toxicity that leads to 14,000 deaths in the US every year. Opioid medicines alter the balance of natural opioid proteins in the body, including enkephalins and dynorphins, preventing the ability of the body to stop pain.

The gate control theory of pain supports the use of oral medications to treat pain, since the theory contends that pain is sensed in the brain and can be modified in the brainstem. The gate control theory has led to the overuse of oral pain medications and the many deaths discussed above.

In contrast, acupuncture is a safe treatment. Various liniments are available to treat pain by topical application [7-9]. These liniments are applied where they are needed, work quickly, and are very effective and safe.

\section{Endovanilloids, Endocannabinoids and Arachidonic Acid Metabolites}

The body has the ability to stop pain through a number of mechanisms (Table 1). The opioid peptides are important, including endorphins, enkephalins and dynorphins. They are produced in the brain and skin, work at opioid receptors in the brain and skin and are effective [10]. Several other compounds are made in the skin to either cause or inhibit pain sensed in the skin.

Endovanilloids work through deactivation of vanilloid receptors, the TRPV channels [22]. Several endovanilloids are made from arachidonic acid such as 15-hydroperoxyeicosatetraenoic acid (15-HPETE) made by 15-lipoxygenase, 12-HPETE made by 12-lipoxygenase, anandamide, and $\mathrm{N}$-arachidonoyldopamine. 5-Lipoxygenase makes 5-HPETE, and leukotriene B4 that are both endovanilloids [23,24]. Other endovanilloids are not made from arachidonic acid and include $\mathrm{N}$-oleoyldopamine, palmitoylethanolamide and the resolvins.

Lipoxins are trihydroxy-eicosatetraenoic acids made from arachidonic acid by 15-lipoxygenase and cause pain. They bind to several receptors such as, lipoxin $\mathrm{A}_{4}$ receptor, ALX/formyl peptide receptor 2, and resolvin D1 receptor [10]. Lipoxins also may act through stimulation of TRPV1 to cause pain [12]. They are made in very small amounts, where they are needed and are cleared quickly. They are balanced by the resolvins that inhibit pain.

Resolvins are trihydroxy-eicosapentaenoic acids made from omega-3 fatty acids by 15-lipoxygenase and COX2 [25]. Resolvins interact with several receptors, at least one of which is responsible for relieving pain. These receptors are resolvin D1 receptor, resolvin E1 receptor, G protein coupled receptor 32 , lipoxin $\mathrm{A}_{4}$ receptor, chemokine like receptor 1 (also called chemerin receptor 23, ChemR23) and leukotriene B4 receptor [10]. Resolvins inhibit TRPA1, TRPV3 and TRPV4 which also relieves pain. One of the consequences of COX2 inhibition is that resolvin synthesis is inhibited, which alters the ability of the body to decrease pain.

Endocannabinoids include anadamide (made by phospholipase D), $\mathrm{N}$-arachidonoyldopamine and 2-arachidonoylglycerol and interact with CB1 and CB2. Both of these receptors are found on sensory neurons in the skin and are involved in pain relief induced by cannabinoids and endocannabinoids [26]. It should be pointed out that although the endocannabinoids appear to be agonists for TRPV1, plant derived cannabinoids also interact with TRPV2, TRPV3, TRPV4, TRPA1 and TRPM8. It has been proposed that TRPV1 activity can be modulated through CB1 or CB2 activation by endocannabinoids [26].

All of these yin and yang influences alter the flow of qi. When qi flows correctly, pain is relieved. When qi flows incorrectly, pain occurs and may be magnified. Pain treatment should reestablish the proper balance of yin and yang. When the body is in balance, the body can heal itself $[27,28]$. 


\section{Conclusions}

In general, the inhibition of COX enzymes decreases prostaglandin and resolvin synthesis and shifts the metabolism of arachidonic acid to the lipoxygenase pathways. The synthesis of lipoxins and hepoxilins, mediators of pain and inflammation, may increase. Hepoxilins are made by 12-lipoxygenase [29]. However, the synthesis of several endocannabinoids and endovanilloids may increase, which decreases pain and inflammation.

There are several endogenous compounds that that come from omega- 3 fatty acids through docosahexaenoic acid such as protectins and maresins. Protectins are antiapoptotic and anti-inflammatory [30]. Protectins are made by 17-lipoxygnease. Maresins are anti-inflammatory, analgesic and are made by macrophage 12-lipoxygenase [31]. The effects of COX inhibition on these compounds is not known.

The consequences of systemic inhibition of COX2 in the body are only now being understood. When orally active COX2 inhibitors, such as valdecoxib, were first released, thousands of patients experienced angina, heart attacks and other clotting issues. This may be due to inhibition of platelet COX2 that throws off the balance of $\mathrm{PGI}_{2}$ and thromboxanes, leading to clotting. Valdecoxib was removed from the US market in April of 2005. Since that time, clinical trials and meta-analyses have shown that all orally active or injected COX2 or nonselective COX inhibitors cause strokes, heart attacks and other clotting issues. Since July of 2015, the FDA requires the labels of all NSAIDS to indicate the increased risk of excess clotting. It is not known if inhibition of skin COX2 increases the risk of clotting. However, acupuncture inhibits skin COX2 and has been shown to not alter blood clotting [32].

TRP inhibition provides analgesia. Many TRP receptors are involved in this analgesia. It is important to inhibit as many types of TRP receptors as possible to provide effective pain relief, such as by using several monoterpenoids at the same time. Acupuncture and moxibustion provide pain relief, at least in part, through inhibition of TRP receptors.

The skin is a complex organ and is the major pain sensing organ. Many receptors that sense pain are found in the skin and are involved in the pain cycle that can magnify pain. These receptors interact with each other through signal transduction pathways. These pathways can be used to decrease sensitivity to pain such as by acupuncture, the application of cold, heat or topical preparations. This approach to pain treatment is safer and can be more effective than the use of oral or injected drugs.

Acknowledgments: The author is grateful to Gerhard Litscher for the invitation to write this review.

Author Contributions: All of this work was performed solely by James David Adams, Jr.

Conflicts of Interest: The author declares no conflict of interest.

\section{References}

1. Adams, J.; Lien, E. The traditional and scientific bases for traditional Chinese medicine: Communication between traditional practitioners, physicians and scientists. In Traditional Chinese Medicine Scientific Basis for Its Use; Adams, J., Lien, E., Eds.; The Royal Society of Chemistry: Cambridge, UK, 2013; pp. 1-10.

2. Moran, M.M.; McAlexander, M.A.; Bíró, T.; Szallasi, A. Transient receptor potential channels as therapeutic targets. Nat. Rev. Drug Discov. 2011, 10, 601-620. [CrossRef] [PubMed]

3. Melzack, R.; Wall, P. Pain mechanisms: A new theory. Science 1965, 150, 971-979. [CrossRef] [PubMed]

4. Adams, J. Apoptosis is critical to pain control. Open J. Apoptosis 2013, 2, 23-24. [CrossRef]

5. Premkumar, L. Transient receptor potential channels as targets for phytochemicals. ACS Chem. Neurosci. 2014, 5, 1117-1130. [CrossRef] [PubMed]

6. Basbaum, A.I.; Bautista, D.M.; Scherrer, G.; Julius, D. Cellular and molecular mechanisms of pain. Cell 2009, 139, 267-284. [CrossRef] [PubMed]

7. Adams, J. The use of California sagebrush (Artemisia californica) liniment to control pain. Pharmaceuticals (Basel) 2012, 5, 1045-1053. [CrossRef] [PubMed] 
8. Fontaine, P.; Wong, V.; Williams, T.J.; Garcia, C.; Adams, J. Chemical composition and antinociceptive activity of California sagebrush (Artemisia californica). J. Pharmacogn. Phytother. 2013, 5, 1-11.

9. Garcia, C.; Adams, J. Healing with Medicinal Plants of the West-Cultural and Scientific Basis for Their Use; Abedus Press: La Crescenta, CA, USA, 2012.

10. Adams, J.; Wang, X. Control of pain with topical plant medicines. Asian Pac. J. Trop. Biomed. 2015, 5, 930-935. [CrossRef]

11. Rani Sagar, D.; Burston, J.; Woodhams, S.; Chapman, V. Dynamic changes to the endocannabinoid system in models of chronic pain. Philos. Trans. R. Soc. Lond. B Biol. Sci. 2012, 367, 3300-3311. [CrossRef] [PubMed]

12. Serhan, C. Pro-resolvin lipid mediators are leads for resolution physiology. Nature 2014, 510, 92-101. [CrossRef] [PubMed]

13. Bigliardi, P.; Tobin, D.; Gaveriaux-Ruff, C.; Bigliardi-Qi, M. Opioids and the skin-where do we stand? Exp. Dermatol. 2009, 18, 424-430. [CrossRef] [PubMed]

14. Yue, Z.; Xie, J.; Yu, A.; Stock, J.; Du, J.; Yue, L. Role of TRP channels in the cardiovascular system. Am. J. Physiol. Heart Circ. Physiol. 2015, 308, H157-H182. [CrossRef] [PubMed]

15. Ma, W.; Quirion, R. Does COX2 dependent PGE2 play a role in neuropathic pain? Neurosci. Lett. 2008, 437, 165-169. [CrossRef] [PubMed]

16. Wang, M. Huang di nei jing and the treatment of low back pain. In Traditional Chinese Medicine Scientific Basis for Its Use; Adams, J., Lien, E., Eds.; The Royal Society of Chemistry: Cambridge, UK, 2013; pp. 17-47.

17. Zhang, D.; Spielmann, A.; Wang, L.; Ding, G.; Huang, F.; Gu, Q.; Schwarz, W. Mast cell degranulation induced by physical stimuli involves the activation of transient receptor potential channel TRPV2. Physiol. Res. 2012, 61, 113-124. [PubMed]

18. Zhang, Z.; Wang, C.; Gu, G.; Li, H.; Zhao, H.; Wang, K.; Han, F.; Wang, G. The effects of electroacupuncture at the ST36 (Zusanli) acupoint on cancer pain and transient receptor potential vanilloid subfamily 1 expression in Walker 256 tumor bearing rats. Anesth. Analg. 2012, 114, 879-885. [CrossRef] [PubMed]

19. Kim, J.; Shin, K.; Na, C. Effect of acupuncture treatment on uterine motility and cyclooxygenase-2 expression in pregnant rats. Gynecol. Obstet. Investig. 2000, 50, 225-230. [CrossRef]

20. Kim, J.; Na, C.; Hwang, W.; Lee, B.; Shin, K.; Pak, S. Immunohistochemical localization of cyclooxygenase-2 in pregnant rat uterus by Sp-6 acupuncture. Am. J. Chin. Med. 2003, 31, 481-488. [CrossRef] [PubMed]

21. Lee, J.; Jang, K.; Lee, Y.; Choi, Y.; Choi, B. Electroacupuncture inhibits inflammatory edema and hyperalgesia through regulation of cyclooxygenase synthesis in both peripheral and central nociceptive sites. Am. J. Chin. Med. 2006, 34, 981-988. [CrossRef] [PubMed]

22. Van der Stelt, M.; Di Marzo, V. Endovanilloids putative ligands of transient receptor potential vanilloid 1 channels. Eur. J. Biochem. 2004, 271, 1827-1834. [CrossRef] [PubMed]

23. Meves, H. Arachidonic acid and ion channels: An update. Br. J. Pharmacol. 2008, 155, 4-16. [CrossRef] [PubMed]

24. Mazini, S.; Meini, S. Involvement of capsaicin sensitive nerves in the bronchomotor effects of arachidonic acid and melittin: A possible role for lipoxin A4. Br. J. Pharmacol. 1991, 103, 1027-1032. [CrossRef]

25. Serhan, C.; Hong, S.; Gronert, K.; Colgan, S.; Devchand, P.; Mirick, G.; Moussignac, R. Resolvins a family of bioactive products of omega- 3 fatty acid transformation circuits initiated by aspirin treatment that counter proinflammation signals. J. Exp. Med. 2002, 196, 1025-1037. [CrossRef] [PubMed]

26. Caterina, M. TRP channel cannabinoid receptors in skin sensation, homeostasis and inflammation. ACS Chem. Neurosci. 2014, 5, 1107-1116. [CrossRef] [PubMed]

27. Adams, J. Preventive medicine and the traditional concept of living in balance. World J. Pharmacol. 2013, 2, 73-77. [CrossRef]

28. Adams, J. The Balanced Diet for You and the Planet; Abedus Press: La Crescenta, CA, USA, 2014.

29. Mrsny, R.; Gewirtz, A.; Siccardi, D.; Savidge, T.; Hurley, B.; Madara, J.; McCormick, B. Identification of hepoxilin A3 in inflammatory events: A required role in neutrophil migration across intestinal epithelium. Proc. Natl. Acad. Sci. USA 2004, 101, 7421-7426. [CrossRef] [PubMed]

30. Serhan, C.; Gotlinger, K.; Hong, S.; Lu, Y.; Siegelman, J.; Baer, T.; Yang, R.; Colgan, S.; Petasis, N. Anti-inflammatory actions of neuroprotection D1/protectin D1 and its natural stereoisomers: Assignments of dihydroxy containing docosatrienes. J. Immunol. 2006, 176, 1848-1859. [CrossRef] [PubMed] 
31. Serhan, C.; Dalli, J.; Karamnov, S.; Choi, A.; Park, C.; Xu, Z.; Ji, R.; Zhu, M.; Petasis, N. Macrophage proresolving mediator maresin 1 stimulates tissue regeneration and controls pain. FASEB J. 2012, 26, 1755-1765. [CrossRef] [PubMed]

32. Berqqvist, D. Vascular injuries caused by acupuncture: A systematic review. Int. Angiol. 2013, 32, 1-8.

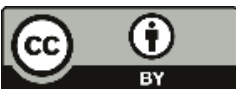

(C) 2016 by the author. Licensee MDPI, Basel, Switzerland. This article is an open access article distributed under the terms and conditions of the Creative Commons Attribution (CC BY) license (http:/ / creativecommons.org/licenses/by/4.0/). 


\title{
Case Report \\ Evaluation of the Effectiveness of Acupuncture in the Treatment of Knee Osteoarthritis: A Case Study
}

\author{
Joana Teixeira ${ }^{1}$, Maria João Santos ${ }^{1}$, Luís Carlos Matos ${ }^{2}$ and Jorge Pereira Machado ${ }^{1,3, *}$ \\ 1 ICBAS- Institute of Biomedical Sciences Abel Salazar, University of Porto, 4050-313 Porto, Portugal; \\ joanabcteixeira@gmail.com (J.T.); mjrs.mtc@gmail.com (M.J.S.) \\ 2 Faculdade de Engenharia da Universidade do Porto, Rua Dr. Roberto Frias, s/n 4200-465 Porto, Portugal; \\ lcmatos@fe.up.pt \\ 3 LABIOMEP-Porto Biomechanics Laboratory, University of Porto, 4200-450 Porto, Portugal \\ * Correspondence: jmachado@icbas.up.pt; Tel.: +351-220-428-304
}

Received: 11 December 2017; Accepted: 1 February 2018; Published: 5 February 2018

\begin{abstract}
Background: Osteoarthritis is a widespread chronic disease seen as a continuum of clinical occurrences within several phases, which go from synovial inflammation and microscopic changes of bone and cartilage to painful destructive changes of all the joint structures. Being the most common joint disease, it is the leading cause of disability in working individuals above 50 years of age. In some cases, conventional treatments produce just a mild and brief pain reduction and have considerable side-effects. Contemporary Traditional Chinese Medicine (TCM) is a model of systems biology based on a logically accessible theoretical background. It integrates several therapeutic approaches, among them acupuncture, which has shown effective results in the treatment of knee and hip osteoarthritis, minimizing pain, improving functionality and consequently leading to a better quality of life. Methods: The present case study included two patients with clinical signs of osteoarthritis and diagnosis of medial pain, as defined by the Heidelberg Model of TCM. Over 6 weeks, those patients were treated with acupuncture, with a frequency of one session a week. The sessions lasted for thirty minutes and were based on the needling of 4 local acupoints. Before and after each session, pain and mobility assessments were performed. Results: The results were positive, with significant reduction of pain and increased knee joint flexion amplitude and mobility. Conclusion: Acupuncture was effective as an alternative or complementary treatment of knee osteoarthritis, with high levels of improvement within a modest intervention period.
\end{abstract}

Keywords: osteoarthritis; acupuncture; Heidelberg Model of Traditional Chinese Medicine

\section{Introduction}

Osteoarthritis is a chronic degenerative joint disease demonstrating articular cartilage damage and leading to disabling pain and joint dysfunction [1]. Clinically, osteoarthritis is characterized by pain, typically with gradual onset that worsens over time, swollen joint caused by synovitis, morning stiffness, crackling bone, muscle atrophy, narrowing of the intra-articular space, osteophyte formation, subchondral bone sclerosis and cyst formation [2].

Osteoarthritis of the knee is a multifactorial disease, whose etiology includes generalized systemic disease (e.g., gout, rheumatoid arthritis), constitutional factors (e.g., age, gender and genetics) and also biomechanical factors (e.g., joint damage, muscle weakness, overweight and obesity) [3]. The higher incidence and severity in females is related to hormonal status. Fluctuations of sex hormone levels in young females and loss of ovarian sex hormone production due to menopause in older ones contribute to the observed differences in gender prevalence $[4,5]$.

The treatment of knee osteoarthritis may be categorized as either conservative or surgical. Conservative treatment may include medication, manual and physical therapies, medially directed 
patellar taping, walking aids, thermal agents, weight loss, Tai Chi practice, swimming, water aerobics, and resistance exercises. The American College of Rheumatology recommends most of the previous non-pharmacological approaches in the initial treatment of this disease [6]. Nevertheless, common interventions involve the use of analgesics, anti-inflammatories and infiltrations with corticosteroids. Pharmacological intervention may include the use of glucosamine, glucosamine with chondroitin, chondroitin, acetaminophen, oral and topical NSAIDs, tramadol, and intraarticular corticosteroid injections, intraarticular hyaluronate injections, duloxetine, and opioids [7]. Physiotherapy, occupational therapy and psychomotor rehabilitation may help controlling pain and improving joint function, restoring quality of life [6,8]. Surgical treatment, which can be divided into joint-preserving, such as arthroscopy and osteotomy (femoral or tibial), and joint-replacing procedures, such as partial and total arthroplasties, should be indicated in cases without symptom relief after conservative approaches [9].

Although conventional approaches, either pharmacological and surgical have been reported as successful, side effects such as toxicity manifestations, complications involving anesthesia, infection, osteoligamentous surgery-induced injuries are issues that cannot be ignored [1]. In this scenario, acupuncture comes as an alternative therapeutic approach in knee osteoarthritis conditions, showing good results in pain reduction and rehabilitation of motor abilities, improving functionality and quality of life, either when used as a stand-alone therapy or together with other procedures [7,10-19].

Nowadays, acupuncture is accepted among the Portuguese medical community with regard to its mechanisms of action as a medical procedure, with its analgesic and anti-inflammatory effects recognized a long time ago by the World Health Organization, and is considered superior to placebo in published randomized controlled trials [20]. Indeed, this integration requires a science-based approach supported by controlled research. Nevertheless, even with studies corroborating its benefits, there is still a great debate within the scientific community with regard to its mechanisms of action and therapeutic methodology [21-23].

Eastern and Western therapeutic approaches and anatomical and physiological views of the knee region are considerably different. In TCM, the knee is sustained by the liver (hepatic) and by the conduits that pass through this region; namely, the stomach, gallbladder and bladder, known as the yang conduits, and the liver, kidney and Spleen, known as the yin conduits [24-26]. These conduits are involved in the neurovegetative patterns of that anatomical region acting on the knee joint, nerves, and being responsible for the normal functioning of the knee processes [25]. The most common form of knee pain, known in TCM as center or medial pain, is characterized by a localized pain in the medial part of the knee that the Spleen conduit passes through [27]. Although many other acupoints could be used in the treatment of this condition [17], the approach based on the Heidelberg Model of TCM involves supporting the Centre by the simultaneous stimulation of specific acupoints from the Spleen and Stomach conduits, which belong to the Phase Earth, in order to promote orthopathy [26].

In this case study, conducted with two patients suffering from knee osteoarthritis with constant pain, the research team aimed to evaluate the effectiveness of acupuncture as a treatment procedure, using a protocol based on the needling of just 4 local acupoints to treat pain and increase joint mobility.

\section{Materials and Methods}

The patients considered in this study were selected according to the following inclusion and exclusion criteria.

Inclusion criteria: clinical signs of osteoarthritis and diagnosis of medial pain, as defined by Heidelberg Model of TCM, knee pain, mobility commitment and impairment in daily living activities, such as going up and down stairs.

Exclusion criteria: pregnancy and lactation, psychiatric or neurological disorders, presence of inflammatory autoimmune disease, history of substance abuse. 


\subsection{Sample Characterization}

Subject A-A female of 46 years old, formerly a cook in a private hospital, currently unemployed, with acute pain in the knee and signs of osteoarthritis detected by imaging tests. Acupuncture was performed after a month of intense pain and loss of mobility. The patient used crutches during the rehabilitation period.

Subject B-A female of 56 years old, formerly a secretary, currently unemployed, suffering from internal and femoro-patellar gonarthrosis, was victim of a stairs accident in December 2010 and submitted to two surgical interventions in 2010 and 2012. The patient took medication and decided to start acupuncture after two years of constant pain and mobility problems.

A written informed consent from patients was required to proceed with the intervention.

\subsection{Materials}

Single-use sterilized acupuncture needles ( $25 \mathrm{~mm}$ length and $0.25 \mathrm{~mm}$ diameter) brand Tewa, Goniometer, and Portuguese pain assessment scale.

\subsection{Methodology}

The intervention consisted of 6 thirty-minute acupuncture sessions with a frequency of one session a week. The degree of pain was evaluated before and after the treatment by using the numeric pain rating scale, which is a single-dimensional instrument to assess pain intensity at rest or with activity. This scale is frequently used in adults with chronic pain due to rheumatic diseases, and is scored by choosing a number between 0 (no pain) and 10 (extreme pain or other label) to rate current pain intensity [28]. The mobility range tests were performed with a Goniometer at the beginning and $10 \mathrm{~min}$ after each session.

The acupuncture treatments were performed by a qualified TCM practitioner and the points used in this study were: St34 Liang Qiu (S34 Monticulus Septi), St36 Zu San Li (S36 Vicus Tertius Pedis), Sp9 Yin Ling Quan (L9 Fons Tumuli Yin) and Sp10 Xue Hai (L10 Mare xue) (acupoints denomination according to the Heidelberg Model of TCM is quoted between bracelets).

\section{Results}

As shown in Figures 1 and 2, subjects A and B reported clear improvements in their condition, with pain reduction along the acupuncture treatment (pain scores dropped from 9.5 to 2 and from 9 to 1 in subjects A and B, respectively). These good results allowed them to stop taking conventional medication for pain. The analgesic effect of acupuncture has been often reported by other authors. This effect can be induced both by a local stimulation of the tissue, thus resulting in the release of inflammatory related substances, vasodilatation and the increase of serotonin and immune cells, as well as by a hypothalamus activation and related endorphins release [29].

Although some studies point to pain relief in patients suffering from osteoarthrosis, the effects on articular mobility are unclear, probably due to different types of therapeutic methodologies [16,30]. As standardization is a key issue in research, protocols must control a wide range of variables, such as the acupuncture technique, the intervention protocol, the duration of the treatment, the selected acupoints, just to mention a few. It is easy to find studies in which a vast selection of acupoints and different stimulations were used in the treatment of knee osteoarthritis. Some used a combination of 9 to 10 local and distal points from several conduits such as Stomach, Spleen, Gall Bladder, Kidney, Urinary Bladder, Liver, Large Intestine, and the xiyan extraordinary acupoint, as well as a combination of manual and electrical stimulation [19,31-35]. In these studies, the duration of the intervention and the frequency of the sessions also varied between 2 and 12 weeks with one or two sessions a week. In fact, methodological standardization is a hard task, not only because, in some cases, there is no consensus between practitioners and their diagnosis, but also because each patient has a specific homeostatic imbalance and physiological compensation when submitted to the same stimulus [36]. 


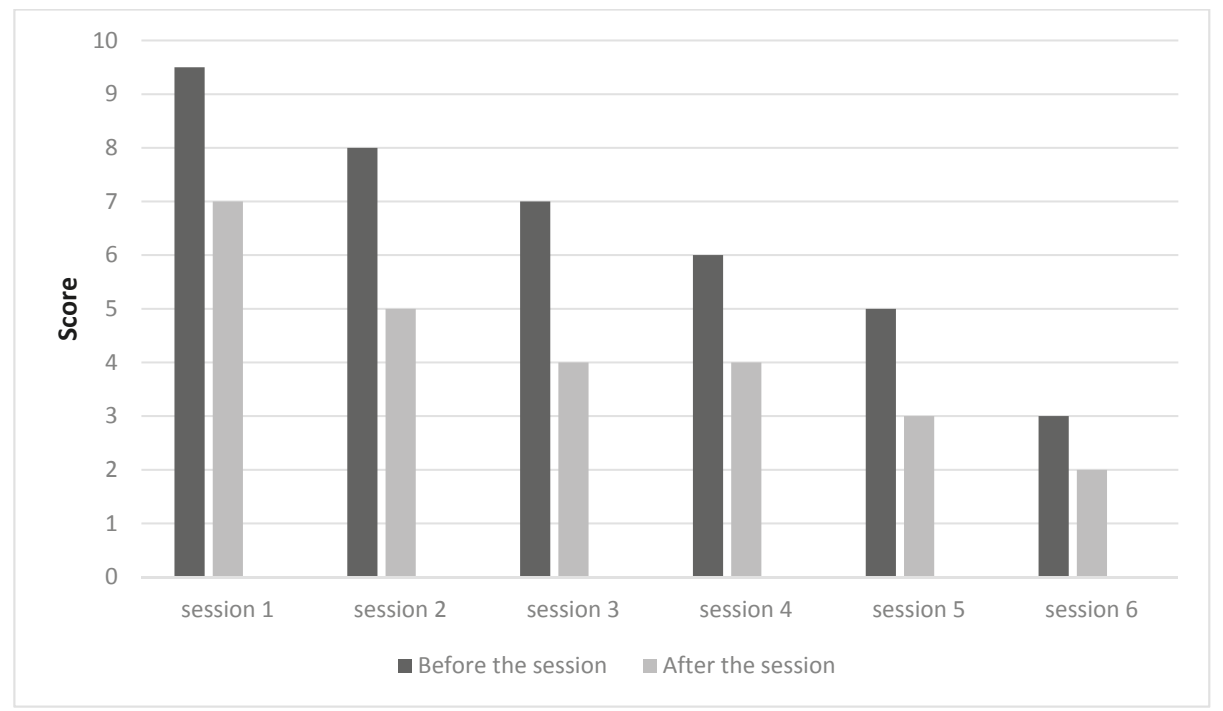

Figure 1. Assessment of pain per session, subject A.

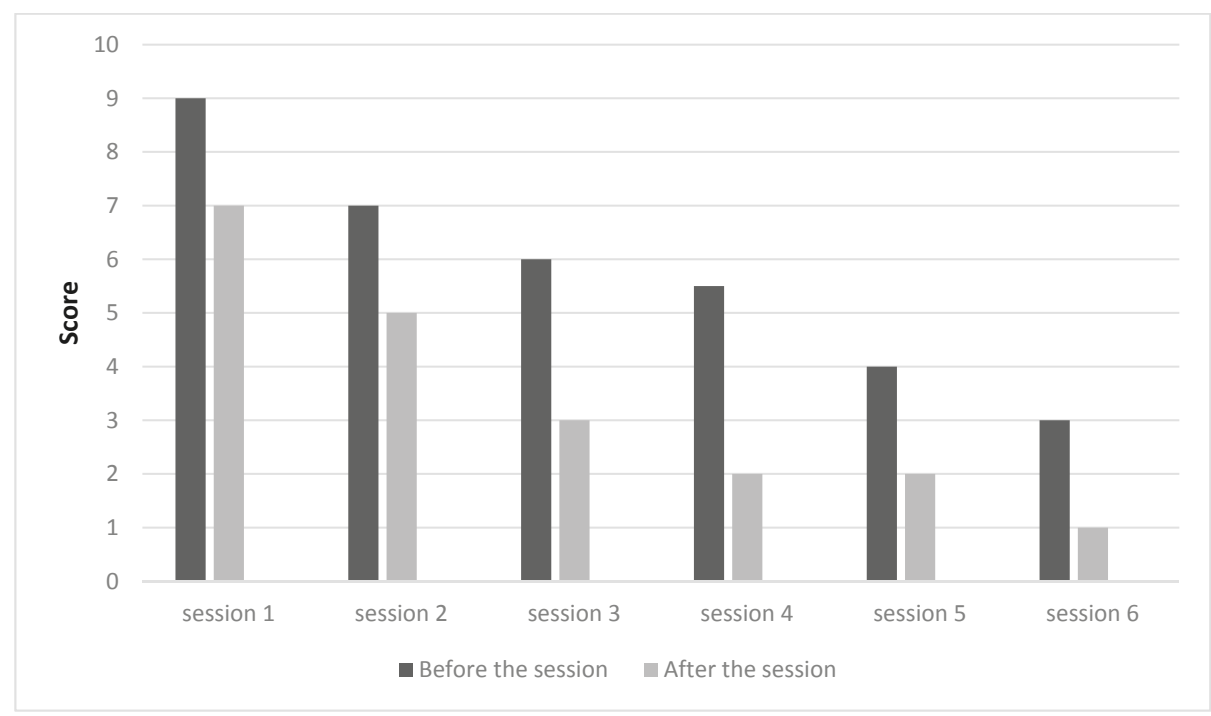

Figure 2. Assessment of pain per session, subject B.

In our study, Subjects A and B presented an increase in mobility and range of motion following treatment. The degree of knee flexion raised up from $45^{\circ}$ with pain to $160^{\circ}$ without pain to subject $\mathrm{A}$ and from $90^{\circ}$ to $160^{\circ}$ to subject $\mathrm{B}$ (Table 1). In this process, subject A abandoned the use of crutches. 
Table 1. Knee joint flexion amplitude before and after acupuncture sessions.

\begin{tabular}{ccccc}
\hline \multirow{2}{*}{ Session } & \multicolumn{2}{c}{ Subject A } & \multicolumn{2}{c}{ Subject B } \\
\cline { 2 - 5 } & Before & After & Before & After \\
\hline 1st & $45^{\circ}$ & $90^{\circ}$ & $90^{\circ}$ & $110^{\circ}$ \\
2nd & $60^{\circ}$ & $110^{\circ}$ & $110^{\circ}$ & $120^{\circ}$ \\
3rd & $90^{\circ}$ & $140^{\circ}$ & $110^{\circ}$ & $130^{\circ}$ \\
4th & $110^{\circ}$ & $155^{\circ}$ & $125^{\circ}$ & $140^{\circ}$ \\
5th & $140^{\circ}$ & $160^{\circ}$ & $130^{\circ}$ & $155^{\circ}$ \\
6th & $155^{\circ}$ & $160^{\circ}$ & $140^{\circ}$ & $155^{\circ}$ \\
\hline
\end{tabular}

The improvement percentages for pain and knee joint flexion amplitude per session, considering each session initial and final scores, along the experimental period are shown in Figure 3.

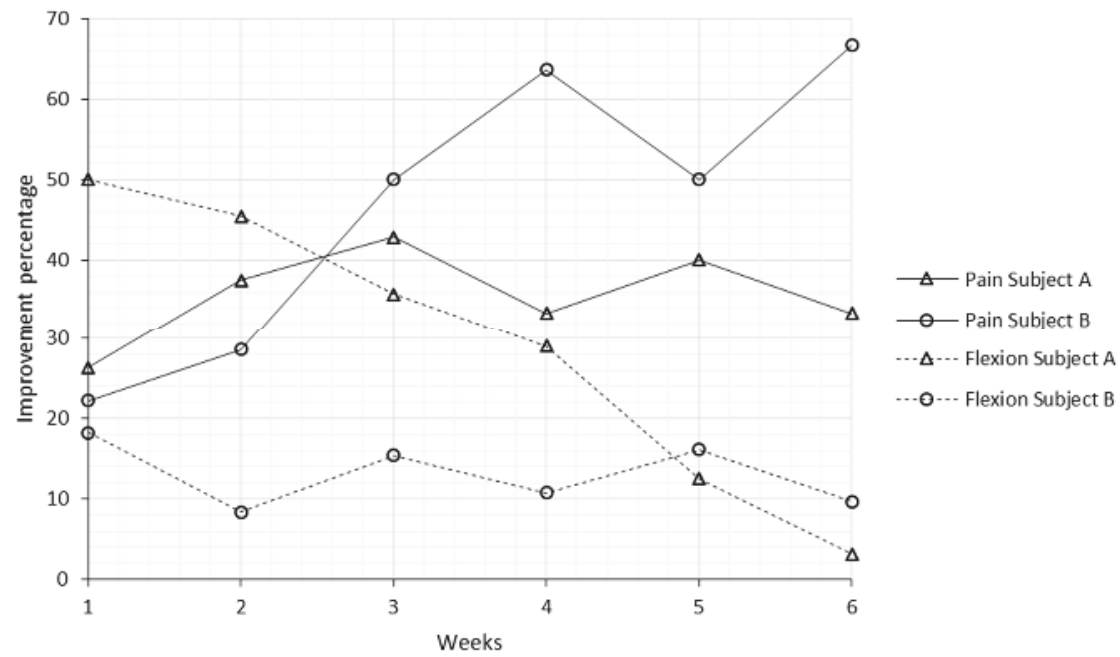

Figure 3. Improvement percentages for pain and knee joint flexion amplitude per session, considering each session initial and final scores, along the experimental period.

Regarding pain, Subject A experienced an increasing tendency in the improvement percentage per session from week 1 to 3 , and from this point on, this tendency stopped rising. The average improvement percentage per session for Subject A was 36\%, and the overall improvement at the end of the experimental period reflecting the initial to final evaluation, was $79 \%$. In the case of Subject B, with the exception of week 5 , the improvement per session was always higher than the week before, with an average of $47 \%$ and overall improvement of $89 \%$. One week after each treatment, Subjects A and B had average regressions on pain of $19 \%$ and $29 \%$, respectively, taking into account the previous evaluation and the evaluation before the acupuncture session.

With regard to knee joint flexion, the condition of Subject A in the beginning of the experimental period was worse than Subject B. Subject A experienced an improvement of 50\% immediately after the first session. The following weeks, a decreasing tendency was noticed as knee flexion, before each session, tended to be higher as a result of the patient's response to the treatment. The average per-session and overall improvement percentages were $29 \%$ and $72 \%$ for Subject A and $13 \%$ and $42 \%$ for Subject B. Considering that Subject B's condition was better, the improvements per session were not as high as Subject $\mathrm{A}$, and remained almost stable along the experimental period. Regressions one 
week after each session were also noticed in knee flexion amplitude, with scores falling on average $17 \%$ and $6 \%$, for Subjects $\mathrm{A}$ and B, respectively.

The overall analysis of pain and knee flexion improvements presented in this case study is highly satisfactory. High improvement percentages, an average of $84 \%$ for pain and $57 \%$ for join flexion mobility, were achieved within a modest intervention period, 6 weeks, with just one session a week, and with a reduced number of needled acupoints, compared to most of the treatment protocols used in other studies. Knee flexion mobility per session (an average of 21\%) was higher than the outcomes reported in similar studies (9\% [30] and 16\% [37]). Although the beneficial effects of acupuncture are shown here in just two patients, and the small sample can skew results, our study supports the thesis that acupuncture can be used as an effective therapeutic tool in the treatment of knee osteoarthritis.

\section{Conclusions}

Contemporary understanding of TCM considers it as a model of systems biology with a holistic therapeutic approach, in which the diagnosis is key to achieving positive results. Thus, systematized science-based analysis and decisions, both of the pathological condition and therapeutic intervention, are required to validate the results obtained by the use of acupuncture as a therapeutic tool. In our study, within the framework of the Heidelberg Model of TCM, we found that acupuncture was effective in the treatment of knee osteoarthritis with significant pain relief and improvement in knee joint mobility and range in 2 subjects whose initial presentation was characterized by extreme pain, scored 9.5 and 9 , as well as reduced joint flexion amplitude, $45^{\circ}$ and $90^{\circ}$. The overall pain relief, considering the whole intervention period, was $79 \%$ and $89 \%$ for subject $\mathrm{A}$ and $\mathrm{B}$, respectively. With regard to mobility and range of motion, positive results were also found with considerable improvements in the knee flexion angle from $45^{\circ}$ to $160^{\circ}$ in subject $\mathrm{A}$ (an improvement of $72 \%$ ), and $90^{\circ}$ to $155^{\circ}$ in subject B (an improvement of $42 \%$ ). Although regressions, both in pain and joint flexion mobility, were noticed one week after each treatment, the improvements in each session were high enough to overcome this issue, allowing for maintenance of the recovery with increasing tendency along the experimental period.

In addition to concluding that acupuncture was effective as a therapeutic tool with high levels of recovery when compared with similar published studies, it is important to mention that these results were achieved within a modest intervention period, 6 weeks, with just one session a week, and with a reduced number of needled acupoints, compared to most of the treatment protocols used in other studies, and doesn't require electrical stimulation. Our outcomes are a good example of a successful intervention that can contribute to the debate about methodological standardization of acupuncture in the treatment of knee osteoarthrosis.

We are aware of the limitations of this study and suggest a follow up study with a statistically representative sample.

Acknowledgments: We would like to thank to everyone that somehow contributed to this study.

Author Contributions: J.T. conceived, designed and performed the experiments, analyzed the data, and wrote the first version of the paper. M.J.S. oversaw the experimental process and revised the paper. L.C.M. and J.P.M. participated in conceiving the study, interpreting data and revising the paper.

Conflicts of Interest: The authors declare no conflict of interest.

\section{References}

1. Crawford, D.C.; Miller, L.E.; Block, J.E. Conservative management of symptomatic knee osteoarthritis: A flawed strategy? Orthop. Rev. 2013, 5, e2. [CrossRef] [PubMed]

2. Langworthy, M.J.; Saad, A.; Langworthy, N.M. Conservative treatment modalities and outcomes for osteoarthritis: The concomitant pyramid of treatment. Phys. Sportsmed. 2010, 38, 133-145. [CrossRef] [PubMed] 
3. Silverwood, V.; Blagojevic-Bucknall, M.; Jinks, C.; Jordan, J.; Protheroe, J.; Jordan, K. Current evidence on risk factors for knee osteoarthritis in older adults: A systematic review and meta-analysis. Osteoarthr. Cartil. 2015, 23, 507-515. [CrossRef] [PubMed]

4. Boyan, B.D.; Hart, D.A.; Enoka, R.M.; Nicolella, D.P.; Resnick, E.; Berkley, K.J.; Sluka, K.A.; Kwoh, C.K.; Tosi, L.L.; O'Connor, M.I.; et al. Hormonal modulation of connective tissue homeostasis and sex differences in risk for osteoarthritis of the knee. Biol. Sex Differ. 2013, 4, 3. [CrossRef] [PubMed]

5. Pereira, D.; Peleteiro, B.; Araujo, J.; Branco, J.; Santos, R.; Ramos, E. The effect of osteoarthritis definition on prevalence and incidence estimates: A systematic review. Osteoarthr. Cartil. 2011, 19, 1270-1285. [CrossRef] [PubMed]

6. Hochberg, M.C.; Altman, R.D.; April, K.T.; Benkhalti, M.; Guyatt, G.; McGowan, J.; Towheed, T.; Welch, V.; Wells, G.; Tugwell, P. American college of rheumatology 2012 recommendations for the use of nonpharmacologic and pharmacologic therapies in osteoarthritis of the hand, hip, and knee. Arthritis Care Res. 2012, 64, 465-474. [CrossRef]

7. Newberry, S.J.; FitzGerald, J.; SooHoo, N.F.; Booth, M.; Marks, J.; Motala, A.; Apaydin, E.; Chen, C.; Raaen, L.; Shanman, R. Treatment of Osteoarthritis of the Knee: An Update Review; Report No. 17-EHC011-EF; AHRQ (US Agency for Healthcare Research and Quality): Rockville, MD, USA, 2017.

8. Alshami, A.M. Knee osteoarthritis related pain: A narrative review of diagnosis and treatment. Int. J. Health Sci. 2014, 8, 85-104. [CrossRef]

9. Hussain, S.; Neilly, D.; Baliga, S.; Patil, S.; Meek, R. Knee osteoarthritis: A review of management options. Scott. Med. J. 2016, 61, 7-16. [CrossRef] [PubMed]

10. Yue, J. Treatment of 78 patients with knee osteoarthritis by acupuncture, moxibustion, and tuina. World J. Acupunct. Moxibustion 2015, 25, 53-56. [CrossRef]

11. Mavrommatis, C.I.; Argyra, E.; Vadalouka, A.; Vasilakos, D.G. Acupuncture as an adjunctive therapy to pharmacological treatment in patients with chronic pain due to osteoarthritis of the knee: A 3-armed, randomized, placebo-controlled trial. Pain 2012, 153, 1720-1726. [CrossRef] [PubMed]

12. Fu, M.; Zhang, Z. Knee osteoarthritis treated with acupuncture based on syndrome differentiation: A randomized controlled trial. World J. Acupunct. Moxibustion 2012, 22, 11-17. [CrossRef]

13. Corbett, M.S.; Rice, S.J.C.; Madurasinghe, V.; Slack, R.; Fayter, D.A.; Harden, M.; Sutton, A.J.; MacPherson, H.; Woolacott, N.F. Acupuncture and other physical treatments for the relief of pain due to osteoarthritis of the knee: Network meta-analysis. Osteoarthr. Cartil. 2013, 21, 1290-1298. [CrossRef] [PubMed]

14. Hou, P.-W.; Fu, P.-K.; Hsu, H.-C.; Hsieh, C.-L. Traditional chinese medicine in patients with osteoarthritis of the knee. J. Tradit. Complement. Med. 2015, 5, 182-196. [CrossRef] [PubMed]

15. Selfe, T.K.; Taylor, A.G. Acupuncture and osteoarthritis of the knee: A review of randomized, controlled trials. Fam. Community Health 2008, 31, 247-254. [CrossRef] [PubMed]

16. Ezzo, J.; Hadhazy, V.; Birch, S.; Lao, L.; Kaplan, G.; Hochberg, M.; Berman, B. Acupuncture for osteoarthritis of the knee: A systematic review. Arthritis Rheumatol. 2001, 44, 819-825. [CrossRef]

17. Mc Neill, S.; Fullen, B.M. Acupuncture for osteoarthritis of the knee: Common points and treatment parameters used. Physiotherapy 2015, 101, e968-e969. [CrossRef]

18. Witt, C.M.; Jena, S.; Brinkhaus, B.; Liecker, B.; Wegscheider, K.; Willich, S.N. Acupuncture in patients with osteoarthritis of the knee or hip: A randomized, controlled trial with an additional nonrandomized arm. Arthritis Rheumatol. 2006, 54, 3485-3493. [CrossRef] [PubMed]

19. Manyanga, T.; Froese, M.; Zarychanski, R.; Abou-Setta, A.; Friesen, C.; Tennenhouse, M.; Shay, B.L. Pain management with acupuncture in osteoarthritis: A systematic review and meta-analysis. BMC Complement. Altern. Med. 2014, 14, 312. [CrossRef] [PubMed]

20. World Health Organization. Acupuncture: Review and Analysis of Reports on Controlled Clinical Trials; World Health Organization: Geneva, Switzerland, 2002.

21. Soh, K.-S. Bonghan circulatory system as an extension of acupuncture meridians. J. Acupunct. Meridian Stud. 2009, 2, 93-106. [CrossRef]

22. Zhou, W.; Benharash, P. Effects and mechanisms of acupuncture based on the principle of meridians. J. Acupunct. Meridian Stud. 2014, 7, 190-193. [CrossRef] [PubMed]

23. Cheng, K.J. Neurobiological mechanisms of acupuncture for some common illnesses: A clinician's perspective. J. Acupunct. Meridian Stud. 2014, 7, 105-114. [CrossRef] [PubMed] 
24. Frank Brazkiewicz, H.J.G. Conduit-(Channel) System, Acupuncture Points, Basic; Heidelberg School of Chinese Medicine: Heidelberg, Germany, 2009.

25. Greten, H. Understanding Tcm-Scientific Chinese Medicine-The Heidelberg Model; Heidelberg School of Chinese Medicine: Heidelberg, Germany, 2008.

26. Greten, H.J. Clinical Subjects, Scientific Chinese Medicine, the Heidelberg Model; Heidelberg School of Chinese Medicine: Heidelberg, Germany, 2008.

27. Sousa, C.; Gonçalves, M.; Machado, J.; Greten, H. Treating musculoskeletal pain with traditional chinese medicine techniques-A short review. Exp. Pathol. Health Sci. 2016, 8, 25-28.

28. Hawker, G.A.; Mian, S.; Kendzerska, T.; French, M. Measures of adult pain: Visual analog scale for pain (vas pain), numeric rating scale for pain (nrs pain), mcgill pain questionnaire (mpq), short-form mcgill pain questionnaire (sf-mpq), chronic pain grade scale (cpgs), short form-36 bodily pain scale (sf-36 bps), and measure of intermittent and constant osteoarthritis pain (icoap). Arthritis Care Res. 2011, 63, S240-S252.

29. Audette, J.F.; Bailey, A. Integrative Pain Medicine: The Science and Practice of Complementary and Alternative Medicine in Pain Management; Springer: Berlin/Heidelberg, Germany, 2008.

30. Karner, M.; Brazkiewicz, F.; Remppis, A.; Fischer, J.; Gerlach, O.; Stremmel, W.; Subramanian, S.V.; Greten, H.J. Objectifying specific and nonspecific effects of acupuncture: A double-blinded randomised trial in osteoarthritis of the knee. Evid. Based Complement. Altern. Med. eCAM 2013, 2013, 427265. [CrossRef] [PubMed]

31. Berman, B.M.; Lao, L.; Langenberg, P.; Lee, W.L.; Gilpin, A.M.; Hochberg, M.C. Effectiveness of acupuncture as adjunctive therapy in osteoarthritis of the kneea randomized, controlled trial. Ann. Intern. Med. 2004, 141, 901-910. [CrossRef] [PubMed]

32. Tukmachi, E.; Jubb, R.; Dempsey, E.; Jones, P. The effect of acupuncture on the symptoms of knee osteoarthritis-an open randomised controlled study. Acupunct. Med. 2004, 22, 14-22. [CrossRef] [PubMed]

33. Vas, J.; Méndez, C.; Perea-Milla, E.; Vega, E.; Panadero, M.D.; León, J.M.; Borge, M.Á.; Gaspar, O.; Sánchez-Rodríguez, F; Aguilar, I. Acupuncture as a complementary therapy to the pharmacological treatment of osteoarthritis of the knee: Randomised controlled trial. BMJ 2004, 329, 1216. [CrossRef] [PubMed]

34. Witt, C.; Brinkhaus, B.; Jena, S.; Linde, K.; Streng, A.; Wagenpfeil, S.; Hummelsberger, J.; Walther, H.; Melchart, D.; Willich, S. Acupuncture in patients with osteoarthritis of the knee: A randomised trial. Lancet 2005, 366, 136-143. [CrossRef]

35. White, A.; Tough, L.; Eyre, V.; Vickery, J.; Asprey, A.; Quinn, C.; Warren, F.; Pritchard, C.; Foster, N.E.; Taylor, R.S.; et al. Western medical acupuncture in a group setting for knee osteoarthritis: Results of a pilot randomised controlled trial. Pilot Feasibility Stud. 2016, 2, 10. [CrossRef] [PubMed]

36. Cardoso, R.; Lumini-Oliveira, J.; Santos, M.J.; Ramos, B.; Machado, J.; Greten, H. Effect of acupuncture on delayed onset muscle soreness: Series of case studies. Exp. Pathol. Health Sci. 2016, 8, 85-92.

37. Liu, Y.-H.; Wei, I.-P.; Wang, T.-M.; Lu, T.-W.; Lin, J.-G. Immediate effects of acupuncture treatment on intra-and inter-limb contributions to body support during gait in patients with bilateral medial knee osteoarthritis. Am. J. Chin. Med. 2017, 45, 23-35. [CrossRef] [PubMed]

(C) 2018 by the authors. Licensee MDPI, Basel, Switzerland. This article is an open access article distributed under the terms and conditions of the Creative Commons Attribution (CC BY) license (http:/ / creativecommons.org/licenses/by/4.0/). 


\title{
Brief Report \\ Treatment of Sciatica Following Uterine Cancer with Acupuncture: A Case Report
}

\author{
Henry Xiao ${ }^{1, *}$, Christopher Zaslawski ${ }^{1}$, Janette Vardy ${ }^{2,3}$ and Byeongsang Oh ${ }^{1,2,4}$ \\ 1 School of Life Sciences, University of Technology Sydney, Ultimo, NSW 2007, Australia; \\ chris.Zaslawski@uts.edu.au (C.Z.); byeong.oh@sydney.edu.au (B.O.) \\ 2 Sydney Medical School, University of Sydney, Camperdown, NSW 2006, Australia; \\ janette.vardy@sydney.edu.au \\ 3 Concord Cancer Centre, Concord Repatriation General Hospital, Concord, NSW 2137, Australia \\ 4 Northern Sydney Cancer Centre, Royal North Shore Hospital, St Leonards, NSW 2065, Australia \\ * Correspondence: henry-xiao@outlook.com; Tel.: +61-429-389-616
}

Received: 5 December 2017; Accepted: 7 January 2018; Published: 15 January 2018

\begin{abstract}
For women, gynaecological or obstetrical disorders are second to disc prolapse as the most common cause of sciatica. As not many effective conventional treatments can be found for sciatica following uterine cancer, patients may seek assistance from complementary and alternative medicine. Here, we present a case of a woman with severe and chronic sciatica secondary to uterine cancer who experienced temporary relief from acupuncture.
\end{abstract}

Keywords: uterine cancer; sciatica; acupuncture

\section{Introduction}

Uterine cancer (UC), also known as endometrial cancer, arises from the epithelium lining of the uterus [1]. The most common symptoms in women are abnormal uterine bleeding, vaginal discharge and nonspecific gastrointestinal symptoms [1]. On the other hand, the observed symptoms of the sciatica could be due to a number of factors, which we are unfortunately unable to confirm. However from a neuro-anatomical perspective, sciatica is generally caused by a disc herniation or spinal epidural abscess along the sciatic nerve, which anatomically contains fibres originating in the L4-S2 roots [1]. It is not uncommon for sciatica to result from the uterine tumour compressing the lumbosacral plexus, in particular the L4-L5 nerve roots [2]. The first reported case of this was in 1992 when a calcified degenerated myoma, suspected to be an ovarian tumour, induced sciatica by compressing the sciatic nerve in the lumbosacral plexus [3]. Uterine fibroids are another diagnostic consideration [4], and after pregnancy endometriosis is the most common cause of sciatica [2].

Acupuncture has been utilised to treat sciatic symptoms in China and in Western countries. Clinical trials have documented the effects of acupuncture on multiple cancer-related symptoms including pain, but the efficacy of acupuncture for managing cancer-related sciatic symptoms remains unclear [5]. Here, we report a case of acupuncture treating sciatica following uterine cancer.

\section{Case Description}

The patient was a 66-year-old female diagnosed with a stage III, type 2 endometrial cancer in late 2013. Her past medical history included type 2 diabetes diagnosed in 2012 (treated with oral hypoglycaemics), asthma (managed with inhalers), and arthritis in her foot (treated with Glucosamine hydrochloride/Chondroitin sulphate $500 \mathrm{mg} / 400 \mathrm{mg}$ and Paracetamol $665 \mathrm{mg}$ as required). In addition she described her difficulties with concentrating and memory for which she took ginkgo biloba $2000 \mathrm{mg}$ (1-2 tablets a day). 
The tumour was a serous, poorly differentiated, uterine adenocarcinoma that invaded more than $50 \%$ of the myometrial thickness, and involved the uterus and cervix. She was treated with a total abdominal hysterectomy and bilateral salpingo-oophorectomy. Post-operatively, she had 5 cycles of chemotherapy (Paclitaxel and Carboplatin), which was complicated by neutropenia and peripheral neuropathy. This was followed by 25 fractions of pelvic radiotherapy.

After surgery, although there were no recurrent symptoms of UC, the patient developed a dull pain down the left leg, radiating from the L5-S1 segments to the second toe. Standing and sitting exacerbated the pain. Before the tumour diagnosis, there were no sciatic symptoms. The sciatica therefore considerably impacted her quality of life.

In 2016, she was referred to the acupuncture clinic for individualised acupuncture treatments of her back and leg pain. The pain was described as a dull and radiating from the L5-S1 segments to her second toe, and had been present for three years. The patient attended 6 weekly sessions to have the acupuncture administered by a final year intern (HX) at a university-affiliated cancer centre that was supervised by a professional acupuncturist (BO). At each visit, the patient rated her pain from 0 to 10 , with 0 being no pain and 10 being the worst conceivable pain. The patient initially reported a $3 / 10$ pain at rest, worsening to $8 / 10$ when she stood up or sat down.

The style of acupuncture conducted was Traditional Chinese Medicine. During the acupuncture treatment, a combination of local and distal points were needled to address the sciatica, as shown in Figure 1. Apart than the acupuncture, there were no other interventions. The Traditional Chinese Medicine (TCM) diagnosis was Qi Stagnation in the Gall Bladder Channel.

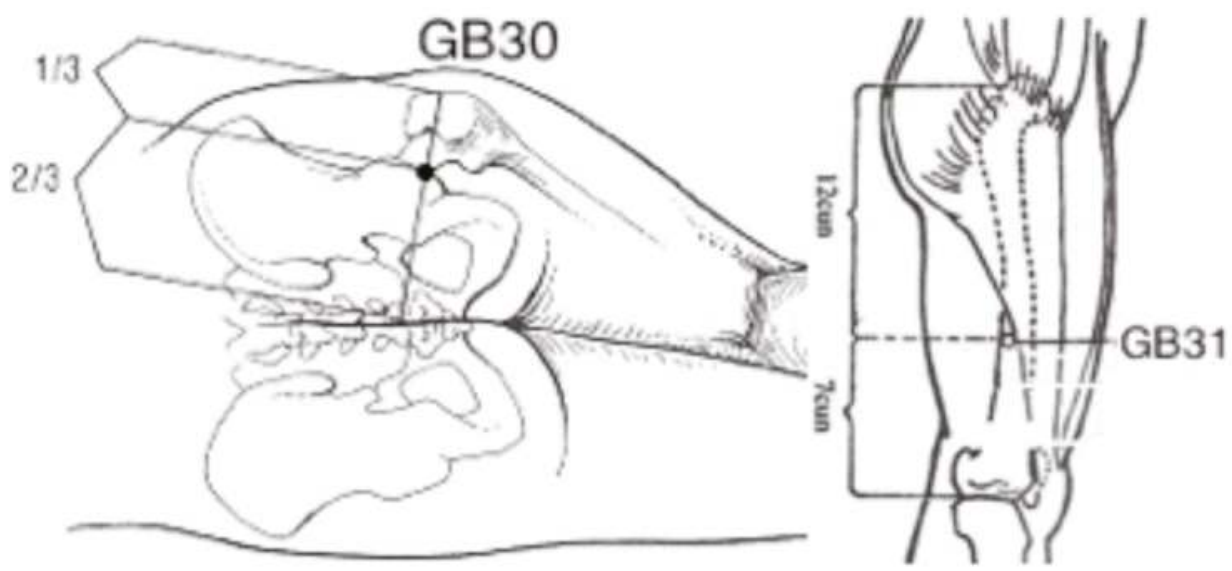

Figure 1. Acupuncture points GB30 and GB31.

With the patient lying on one side, the area was sterilised with an alcohol swab, the needles (30 and $0.12 \mathrm{~mm}$ gauge, Tempo J-Type Acupuncture Needles) were inserted at $90^{\circ}$ until the patient experienced De Qi (a dull pressing and radiating sensation). The insertion for GB30 and GB31 for sciatica was 4-6 cm and 2-3 cm respectively [6] in the left hand side. The acupuncture points administered for her other signs and symptoms (e.g., shoulder pain, arthritis in her feet, poor concentration) were GB21, LI14, BL60, SP6, KD3 (first treatment), BL60, BL28, KD7, GB34, GB21 (second treatment), GB21, LU3, Yintang, LR3, Erjian, TE5 (third treatment), LI4, LI10, GB34, ST41, BL13, BL15, BL23 (fourth treatment), SP3, BL65, GB34, GV24, Anmian (fifth treatment), and GV20, LU7, GB34, LR3, KD6 (sixth treatment). The patient was left to rest for $30 \mathrm{~min}$ before the needles were removed.

After one treatment, the patient reported a decrease in pain intensity, rating her pain as 1/10 at rest and 5/10 when she stood up or sat down. After the second treatment, she reported further improvement in pain and she was able to perform most of her daily activities, including sitting 
and standing. She was able to perform stretching exercises such as Qigong without experiencing severe sciatic pain. The patient expressed improved mood and an interest in continuing acupuncture to address her other pain symptoms such as her arthritis in her feet, so that she would be able to participate in low impact exercises. Treatments in weeks 3-5 focused on her right shoulder pain and arthritis in her feet. The patient experienced little to no sciatica during this time. During the follow-up assessment at week 12 , she presented with sciatica again, and rated the pain to be 2/10 at rest, worsening to $5 / 10$ when she stood up or sat down.

\section{Discussion}

Sciatica is usually treated with non-steroidal anti-inflammatory drugs, but there is a lack of consensus regarding the efficacy of these drugs [7]. As a result, some patients turn to acupuncture for which there is some evidence of efficacy in treating painful symptoms associated with sciatica [8]. Acupuncture has been shown to be minimally invasive [9] and safe [10]. The treatment modality of acupuncture is based on the principles of TCM. The classic text, 'Song of Points for Miscellaneous Diseases' from 'The Glorious Anthology of Acupuncture and Moxibustion' written during the Ming Dynasty, in China, indicates that the acupuncture points of GB30, GB31 and LR2 were used for lumbar pain radiating down the leg [11].

In this report, we document the earliest case, to our knowledge, of potentially decreasing the intensity of sciatica following uterine cancer with acupuncture. After two treatment sessions, our patient provided feedback that her pain had improved. She reported that not only did she experience less sciatic pain, but the acupuncture also greatly improved her mood, contributing to better quality of life with family and friends. Furthermore, her newly managed pain opened her up to consider acupuncture for addressing other symptoms such as foot arthritis, which had been a secondary complaint. Nevertheless, she did not have complete relief from her sciatic pain at the sixth treatment, suggesting that chronic conditions may require a longer-term pain-management plan.

There are limitations to our case report. Firstly, there is a possibility of the synergistic effect of acupuncture with her pharmaceutical intervention; however, this had been stable and long term. The pharmaceutical intervention in this case refers to the patient's ongoing medications for type 2 diabetes, asthma, and foot arthritis. Furthermore, it may be that acupuncture plus lifestyle change could have improved the treatment efficacy. The very nature of a case report is that the clinical experience of only a single patient is presented; however, a testable hypothesis can be generated for future studies to investigate. Furthermore, the proximity between the tumour and sciatica events in the timeline leads to the conclusion that there could be a connection between the two. There exists the possibility that the patient's sciatic pain originated partially from a problem that was musculoskeletal in nature. To confirm the effect of acupuncture on sciatica following uterine cancer would require a much larger study, controlling for confounding factors and bias, including the placebo effect.

\section{Conclusions}

Sciatica following uterine cancer can be a debilitating condition with few successful treatments. Our case report documents how a woman with severe and persistent sciatica pain that could have been a result of her uterine cancer experienced considerable relief from acupuncture. This warrants further evaluation to determine the efficacy of acupuncture for sciatica following uterine cancer.

Author Contributions: H.X. drafted the article, J.V., C.Z. and B.O. revised it critically for important intellectual content. B.O. supervised the acupuncture clinic and all authors approved the final version to be published.

Conflicts of Interest: The authors declare no conflict of interest.

\section{References}

1. Goldman, L.; Schafer, A. Goldman-Cecil Medicine, 25th ed.; Elsevier Saunders: Philadelphia, PA, USA, 2016. 
2. Al-Khodairy, A.W.; Bovay, P.; Gobelet, C. Sciatica in the female patient: Anatomical considerations, aetiology and review of the literature. Eur. Spine J. 2007, 16, 721-731. [CrossRef] [PubMed]

3. Acar, B.; Kadanali, S.; Acar, U. Rare gynecological condition causing sciatic pain. Int. J. Gynecol. Obstet. 1993, 42, 50-51. [CrossRef]

4. Bodack, M.P.; Cole, J.C.; Nagler, W. Sciatic neuropathy secondary to a uterine fibroid: A Case Report. Am. J. Phys. Med. Rehabil. 1999, 78, 157-159. [CrossRef] [PubMed]

5. Posadzki, P.; Moon, T.W.; Choi, T.Y.; Park, T.Y.; Lee, M.S.; Ernst, E. Acupuncture for cancer-related fatigue: A systematic review of randomized clinical trials. Support. Care Cancer 2013, 21, 2067-2073. [CrossRef] [PubMed]

6. Deadman, P.; Al-Khafaji, M.; Baker, K. A Manual of Acupuncture, 1st ed.; Journal of Chinese Medicine Publications: Hove, UK, 2001.

7. Machado, G.C.; Maher, C.G.; Ferreira, P.H.; Day, R.O.; Pinheiro, M.B.; Ferreira, M.L. Non-steroidal anti-inflammatory drugs for spinal pain: A systematic review and meta-analysis. Ann. Rheum. Dis. 2017, 76, 1269-1278. [CrossRef] [PubMed]

8. Fernandez, M.; Ferreira, P.H. Acupuncture for sciatica and a comparison with Western Medicine. Br. J. Sports Med. 2016. [CrossRef]

9. Davison, B. Advanced techniques in musculoskeletal medicine \& physiotherapy using minimally invasive therapies in practice. Phys. Ther. Sport 2016, 21, 94.

10. Patil, S.; Sen, S.; Bral, M.; Reddy, S.; Bradley, K.K.; Cornett, E.M.; Fox, C.J.; Kaye, A.D. The Role of Acupuncture in Pain Management. Curr. Pain Headache Rep. 2016, 20, 1-8. [CrossRef] [PubMed]

11. Gao, W. The Glorious Anthology of Acupuncture and Moxibustion, 1st ed.; Ming Dynasty; 1529.

(C) 2018 by the authors. Licensee MDPI, Basel, Switzerland. This article is an open access article distributed under the terms and conditions of the Creative Commons Attribution (CC BY) license (http:/ / creativecommons.org/licenses/by/4.0/). 
Opinion

\title{
Why We Need Minimum Basic Requirements in Science for Acupuncture Education
}

\author{
Narda G. Robinson \\ Department of Clinical Sciences, Colorado State University, Fort Collins, CO 80526, USA; \\ narda@onehealthsim.org; Tel.: +1-970-443-3588
}

Academic Editors: Gerhard Litscher and William Chi-shing Cho

Received: 21 June 2016; Accepted: 1 August 2016; Published: 5 August 2016

\begin{abstract}
As enthusiasm for alternatives to pharmaceuticals and surgery grows, healthcare consumers are turning increasingly to physical medicine modalities such as acupuncture. However, they may encounter obstacles in accessing acupuncture due to several reasons, such as the inability to locate a suitable practitioner, insufficient reimbursement for treatment, or difficulty gaining a referral due to perceived lack of evidence or scientific rigor by specialists. Claims made about a range of treatment paradigms outstrip evidence and students in acupuncture courses are thus led to believe that the approaches they learn are effective and clinically meaningful. Critical inquiry and critical analysis of techniques taught are often omitted, leading to unquestioning acceptance, adoption, and implementation into practice of approaches that may or may not be rational and effective. Acupuncture education for both licensed physicians (DOs and MDs) and non-physicians needs to include science (i.e., explanation of its effects based on contemporary explanations of biological processes), evidence, and critical thinking. Erroneous notions concerning its mechanisms such as moving "stuck Qi (Chi)" or "energy" with needles and that this energy stagnates at specific, tiny locations on the body called acupuncture points invite errors in methodologic design. For example, researchers may select sham and verum point locations that overlap considerably in their neural connections, leading to nonsignificant differences between the two interventions. Furthermore, attributing the effects of acupuncture to metaphorical and arcane views of physiology limits both acceptance and validation of acupuncture in both research and clinical settings. Finally, the content and quality of education and clinical exposure across acupuncture programs varies widely, with currently no minimum basic educational requirements in a scientific methodology. Considering the pressures mounting on clinicians to practice in an evidence-based and scientific manner that also demonstrates cost-effectiveness, acupuncture schools and continuing medical education (CME) courses should provide their students a strong foundation in rational approaches supported by research.
\end{abstract}

Keywords: acupuncture; education; evidence-based

\section{Introduction}

Today, acupuncture, especially in the West, spans a broad continuum [1]. At one pole sit the strictly scientific practitioners, i.e., those that eschew the myriad metaphors and metaphysical, mystical mechanisms so long associated with this form of medicine. At the other end reside acupuncturists content to view their practice as the manipulation and management of subtle energy circuits, relying on subjective observations of the patient that then determine both diagnosis and treatment.

The majority of physician acupuncturists likely land somewhere between these two ends of the spectrum, practicing a panoply of techniques that have greater and lesser degrees of scientific backing. Acupuncture coursework may focus more fully on one or a few approaches, whether 
neuroanatomic or myofascial trigger point therapy (i.e., the scientific methods) or Traditional Chinese Medicine, microsystems, Five Phases (or Five Elements), and more (largely abstract, metaphorical, irrational, or otherwise unscientific approaches). What physician acupuncturists learn in a given course stems more from the intellectual and philosophical proclivities of the course director(s) rather than agreed-upon standards profession-wide. Thus, in North America, acupuncture education for physicians has existed, for the most part, on its own in CME programs [2] or acupuncture schools [3] apart from coursework consisting of the "mainstream" of medicine, leading to, in some cases, markedly different standards and expectations for curricula and graduates.

With course content depending solely on the determination of each individual course director, students in that program sign up not only to learn "acupuncture" but in effect are brought into the fold of one or more systems with premises they may or may not agree. That is, should a medical practitioner find the approaches of neuroanatomic acupuncture and trigger point therapy more attractive because they rest on biomedical principles, that individual needs to select carefully a course of study that aligns with those ideals. Otherwise, one could find oneself in a program that espouses what he or she might consider pseudoscience, i.e., explaining acupuncture mechanisms metaphysically rather than through analysis of the actual, tangible, readily identifiable structures involved $[4,5]$. This divergence sets up a dichotomy within the profession: some practice in accordance with scientific principles and others based on abstract explanations. However, even if a physician seeks a purely scientific acupuncture education, s/he must learn a broad array of philosophies and techniques, some based on abstract and metaphorical approaches, in order to become board certified in medical acupuncture, as reflected in the recommended readings for the American Board of Medical Acupuncture board certification examination [6].

Whereas physicians typically spend years in medical school and postgraduate programs and then add acupuncture as CME, certified acupuncturists typically spend years in school learning acupuncture and herbal treatment medicine [7]. However, most programs that train certified or licensed acupuncturists (L.Ac.'s) teach that acupuncture works, at least in part, by moving energies and eliminating "pathogenic factors" such as metaphorical wind, damp, heat, and cold. Their qualifying examination (i.e., that offered by the National Certification Commission for Acupuncture and Oriental Medicine or NCCAOM) reflects this. It also includes testing on clinical examination methods [8] such as tongue and pulse diagnosis that have low interrater reliability and little proven validity as diagnostic tools $[9,10]$. Considering that healthcare decisions made by acupuncturists rely heavily on the subjective assessment by the practitioner, relying on arcane and unproven methods to differentiate between health and disease puts patients at risk medically and financially if limited resources lead to ineffective or harmful treatments.

While current medical diagnostic approaches can also have some subjectivity and inter-rater differences, the assessments made involve actual anatomical structures such as trigger points [11] that are palpated or otherwise analyzed, not abstract inferences concerning organ function based on the appearance of the tongue or the quality of the pulse.

\section{Overview}

In postgraduate medicine programs, one assumes that academic educators regularly undergo self-examination and question whether requirements for postgraduate training, licensure, and specialty education are meeting the intended objectives [12]. As techniques develop and evidence accrues, needs for certain types of knowledge or skills may change. Furthermore, in most other courses of study, a student may safely assume that the premises and content within a CME course are valid, tested, and reliable. This does not necessarily apply to acupuncture, given the wide variation in content one might find, ranging from a discussion of the neuroanatomy and neurophysiology of acupuncture to what some might call "superstition", i.e., processes that contradict natural science.

In such instances, uncertainty about the veracity of the techniques taught put the learner, no matter how earnest, at a clear disadvantage. She or he may have mistakenly assumed that by definition 
a continuing medical education program, especially one approved for CME credits, would be quality controlled for rational content and substantiation. While it is wise to think critically about any course content, most physicians attending conventional CME courses do not find themselves needing to do further research on their own in order to determine whether what they learned defied rational explanation and evidential support. With acupuncture, they do, at least for now where training programs offer such widely divergent methodologies.

Currently, patients seeking care even from board-certified physician acupuncturists could receive treatment ranging from rational and evidence-informed methodologies (such as neuroanatomic acupuncture or trigger point therapy) or approaches that have no scientific basis and little to no evidence of effectiveness. This uncertainty places them in a vulnerable position, i.e., assuming and expecting a level of care in accordance with contemporary biomedicine as well as a fair expectation of a beneficial clinical outcome. Approaches practiced by certified acupuncturists typically involve Traditional Chinese Medicine (TCM) philosophies and practices-also unscientific. Remaining unaware and, in some cases, uninterested in the actual anatomy of acupuncture and its underlying physiologic mechanisms of needling and related techniques hinders one's ability justify point selection and defend treatment techniques, even though this information is available [4].

Even if the practitioner believes that she or he is moving mysterious energies, acupuncture often has physiologic effects, thereby reaffirming his or her belief that what was taught was real, but that faith is misplaced. For example, microsystems approaches such as scalp, hand, and ear acupuncture have many followers and some research, but the premises upon which they rest are fundamentally flawed and unsupported by evidence. No matter what one believes in terms of special "maps" of the body on the surface of the head, hand, or ear, acupuncture stimulation leads to physiologic changes that can be therapeutic. Does that mean that the topography of the ear actually contains an implied inverted fetus somewhere encoded into its tissue? No. It merely indicates that the cranial and upper cervical nerves that supply the ear cause myriad physiologic changes when stimulated.

Despite there being a clear, neuroanatomic description of the neural supply of the ear and reflex connections through the brainstem that explain how auricular point stimulation neuromodulates vagal pathways as well as evidence that does not support the theory of a highly specific functional map on the ear [13], the majority of practitioners of auricular acupuncture cling to unfounded notions that the auricular acupuncture diagrams are accurate and reliable [14]. This leads to inconsistent results in research and in the practice of auricular acupuncture [13]. Unless and until a standardized auricular acupuncture map [15] becomes available and is based on systematic analysis of the physiologic and anatomic outcomes of point stimulation rather than opinion and voting [16], current "ear maps" are no more reliable than other fanciful, imagined maps as in scalp acupuncture [17-19], Korean hand acupuncture [20], foot reflexology, and iridology.

Problems plaguing auricular acupuncture, if resolved, could facilitate its integration into conventional settings such as the emergency department [21,22] and drug detoxification settings [23].

\subsection{Is There a Better Way?}

There is another option. Insights into the anatomy and physiology of acupuncture have grown to where there is no longer any need to rely on metaphysical ideations regarding how acupuncture works. Having certification programs institute a minimum basic requirement for scientific content and critical thinking skills, all would ensure that practitioners certified by that group could describe and defend their scientific acupuncture techniques to colleagues, insurers, and institutions. They would also become better researchers and advocates for the profession. As stated by Ning and Lao, "The most critical challenge in acupuncture research is the selection of controls and the design of appropriate sham needling [24]." Designing higher quality studies mandates that the researchers have a clear picture of what constitutes an acupuncture point and how the structures affiliated with that site produce the physiologic effects classically attributed to that site's activation. 


\subsection{Proposed Curricular Content}

In which ways, specifically, could acupuncture schools and CME programs ensure that training protects the public by graduating highly qualified acupuncturists with a strong background in science and evidence that can provide safe, efficacious, and cost-effective health care [25]? What information and strategies should acupuncture providers learn that would give them the ability to discern between rational and irrational approaches, whether in their work as clinicians, researchers, or educators? How can acupuncture education evolve so that training is "based on rigorous scientific evidence and a robust system of quality assurance [25]"?

To begin with, acupuncture students should learn about acupuncture history, become familiar with research milestones, and develop critical thinking skills that will show them how to assess the veracity and validity of acupuncture principles and practices. For example, instead of learning how to perform tongue and pulse "diagnosis" in preparation for determining the diagnosis and treatment approach as in Traditional Chinese Medicine (TCM), students should first learn to how to appropriately question and critique research on these highly unreliable measures. Before moving forward with adopting these skills, they need to understand that neither pulse nor tongue diagnosis has been validated as a reliable method by which to determine health or pathology in a patient [26,27]. At least by recognizing the high level of subjectivity in these tools, acupuncturists have the opportunity to introduce caution in the judgments they make. Treatment follows diagnosis. As such, if the diagnostic techniques are neither reliable nor valid, the veracity of a patient assessment and the effectiveness of treatment come into question.

Acupuncturists also need to become acquainted with Western (scientific) medical acupuncture [26], its rational premise, and methods of diagnosis and treatment that include and rely heavily upon appropriate, well established analyses as well as myofascial palpation.

The anatomical segment of the minimum basic requirement in science would include in-depth study of point anatomy as well as discussions about how the structures at each point relate to the physiologic effects one expects to see based on clinical experience and/or research-based evidence.

For clinical applications, students would learn the central tenets of neuromodulation [28,29] and connective tissue effects [30] as the basis of acupuncture, continue with a critical examination of acupuncture research methodologies and flaws, and proceed into a science-based, evidence-informed review of a scientific approach to the gamut of medical conditions and clinical challenges effectively treated by acupuncture. They would be able to differentiate scientific medical acupuncture from other forms of acupuncture [26].

\subsection{Encouraging Better-Designed Acupuncture Research}

In order to best serve patients and make the best use of healthcare dollars and resources [31], acupuncture practitioners need factual and reliable information on which to base their care and inform their patients or clients of the relative merit of various options. This information comes from rigorous, scientific research. However, the same problems that plague acupuncture practice (i.e., outmoded or imagined mechanisms of action, methods of diagnosis that lack validity and reliability, unsubstantiated premises of treatment) also plague acupuncture research. New standards have been developed [32], but problems remain.

Furthermore, the lack of distance between verum and sham input effects and the inclusion of primitive, folkloric diagnostic methods, lay the acupuncture profession open to criticism from skeptical observers who claim that acupuncture is a "theatrical placebo" [33,34]. Graduates of acupuncture educational programs should be well-equipped to respond to critics that dismiss acupuncture as nothing more than placebo with facts from the latest research [35,36]. Most practitioners of acupuncture, whether MDs, DOs, or LAcs, would not feel confident building a strong, science based defense at this time. 


\section{Conclusions}

Requiring a solid foundation in the science and evidence of acupuncture does not make the approach any less of an art. Rather, a clinician who recognizes and addresses the multifaceted nature of neural and connective tissue interrelationships is working with active and anatomically identifiable structures rather than ethereal energies that may not even exist.

Conflicts of Interest: The author declares no conflict of interest.

\section{References}

1. Kalauokalani, D.; Cherkin, D.C.; Sherman, K.J. A comparison of physician and nonphysician acupuncture treatment for chronic low back pain. Clin. J. Pain. 2005, 21, 406-411. [CrossRef] [PubMed]

2. American Board of Medical Acupuncture. ABMA Approved Training Programs. Available online: http:/ /dabma.org/programs (accessed on 6 September 2016).

3. Acupuncture Today. Acupuncture Schools. Available online: http://www.acupuncturetoday.com/schools / (accessed on 6 September 2016).

4. Robinson, N.G. Interactive Medical Acupuncture Anatomy; Teton NewMedia: Jackson, WY, USA, 2016.

5. Cheng, K.J. Neuroanatomical characteristics of acupuncture points: Relationship between their anatomical locations and traditional clinical indications. Acupunct. Med. 2011, 29, 289-294. [CrossRef] [PubMed]

6. American Board of Medical Acupuncture Website. Recommended Readings for the ABMA Board Certification Examination. Available online: http://dabma.org/documents/EXAM_RECOMMENDED.pdf (accessed on 25 July 2016).

7. Council of Colleges of Acupuncture and Oriental Medicine. Know Your Acupuncturist. Available online: http://www.ccaom.org/downloads/CCAOM_KnowYourAcu.pdf (accessed on 25 July 2016).

8. $\quad$ NCCAOM $^{\circledR}$ Study Guide for Diplomate in Acupuncture Certification, 2016. Available online: http://www. nccaom.org/forms-and-applications/ (accessed on 25 July 2016).

9. O’Brien, K.A.; Abbas, E.; Zhang, J.; Guo, Z.-X.; Luo, R.; Bensoussan, A.; Komesaroff, P.A. Understanding the reliability of diagnostic variables in a Chinese Medicine examination. J. Altern. Complement. Med. 2009, 15, 727-734.

10. Zhang, G.G.; Lee, W.L.; Lao, L.; Lee, W.L.; Handwerger, B.; Berman, B. The variability of TCM pattern diagnosis and herbal prescription on rheumatoid arthritis patients. Altern. Ther. Health Med. 2004, 10, 58-63. [PubMed]

11. Gerwin, R.D. Diagnosis of myofascial pain syndrome. Phys. Med. Rehabil. Clin. N. Am. 2014, 25, 341-355. [CrossRef] [PubMed]

12. Freeman, B.D. Is it time to rethink postgraduate training requirements for licensure? Acad. Med. 2016, 91, 20-22. [CrossRef] [PubMed]

13. He, W.; Want, X.; Shi, H.; Shang, H.; Li, L.; Jing, X.; Zhu, B. Auricular acupuncture and vagal regulation. Evid.-Based Complement. Altern. Med. 2012. [CrossRef] [PubMed]

14. Robinson, N.G. Personal communication with medical acupuncturists at the 2016 American Academy of Medical Acupuncture Annual Symposium during Dr. Robinson's afternoon neuroanatomic acupuncture workshop presentation. Unpublished work, 2016.

15. Litscher, G.; Rong, P.J. Auricular acupuncture. Evid.-Based Complement. Altern. Med. 2016. [CrossRef] [PubMed]

16. Rong, P.J.; Zhao, J.J.; Wang, L.; Zhou, L.Q. Analysis of advantages and disadvantages of the location methods of international auricular acupuncture points. Evid.-Based Complement. Altern. Med. 2016. [CrossRef] [PubMed]

17. Liu, Z.; Guan, L.; Wang, Y.; Xie, C.L.; Lin, X.M.; Zheng, G.Q. History and mechanism for treatment of intracerebral hemorrhage with scalp acupuncture. Evid.-Based Complement. Altern. Med. 2012. [CrossRef] [PubMed]

18. Rezvani, M.; Yaraghi, A.; Mohseni, M.; Fathimoghadam, F. Efficacy of Yamamoto New Scalp Acupuncture versus Traditional Chinese acupuncture for migraine treatment. J. Altern. Complement. Med. 2014, 20, 371-374. [CrossRef] [PubMed] 
19. Zheng, G.Q.; Zhao, Z.M.; Wang, Y.; Gu, Y.; Li, Y.; Chen, X.M.; Fu, S.P.; Shen, J. Meta-analysis of scalp acupuncture for acute hypertensive intracerebral hemorrhage. J. Altern. Complement. Med. 2011, 17, 293-299. [CrossRef] [PubMed]

20. Ochi, J.W. Korean hand therapy for tonsillectomy pain in children. Int. J. Pediatr. Otorhinolaryngol. 2015, 79, 1263-1267. [CrossRef] [PubMed]

21. Tsai, S.L.; Fox, L.M.; Murakami, M.; Tsung, J.W. Auricular acupuncture in emergency department treatment of acute pain. Ann. Emerg. Med. 2016. [CrossRef] [PubMed]

22. Ushinohama, A.; Cunha, B.P.; Costa, L.O.; Barela, A.M.; Freitas, P.B. Effect of a single session of ear acupuncture on pain intensity and postural control in individuals with chronic low back pain: A randomized controlled trial. Braz. J. Phys. Therapy 2016. [CrossRef] [PubMed]

23. Wu, S.L.Y.; Leung, A.W.N.; Yew, D.T.W. Acupuncture for detoxification in treatment of opioid addiction. East Asian Arch. Psychiatry 2016, 26, 70-76. [PubMed]

24. Ning, Z.; Lao, L. Acupuncture for pain management in evidence-based medicine. J. Acupunct. Meridian Stud. 2015, 8, 270-273. [CrossRef] [PubMed]

25. Jiang, J.; Peng, W.; Gu, T.; King, C.; Yin, J.K. Critical review of data evaluation in teaching clinics of Traditional Chinese Medicine outside China: Implications for education. Explore 2016, 12, 188-195. [CrossRef] [PubMed]

26. White, A.; Editorial board of acupuncture in medicine. Western medical acupuncture: A definition. Acupunct. Med. 2009, 27, 33-35. [PubMed]

27. Hua, B.; Abbas, E.; Hayes, A.; Ryan, P.; Nelson, L.; O’Brien, K. Reliability of Chinese medicine diagnostic variables in the examination of patients with osteoarthritis of the knee. J. Altern. Complement. Med. 2012, 18, 1028-1037. [CrossRef] [PubMed]

28. Da Silva, M.A.; Dorsher, P.T. Neuroanatomic and clinical correspondences: acupuncture and vagus nerve stimulation. J. Altern. Complement. Med. 2014, 20, 233-240. [CrossRef] [PubMed]

29. Takahashi, T. Mechanism of acupuncture on neuromodulation in the gut-A review. Neuromodulation 2011, 14, 8-12. [CrossRef] [PubMed]

30. Langevin, H.M.; Churchill, D.L.; Cipolla, M.J. Mechanical signaling through connective tissue: A mechanism for the therapeutic effect of acupuncture. FASEB J. 2001, 15, 2275-2282. [CrossRef] [PubMed]

31. Zhang, F.; Kong, L.L.; Zhang, Y.Y.; Li, S.C. Evaluation of impact on health-related quality of life and cost effectiveness of Traditional Chinese Medicine: A systematic review of randomized clinical trials. J. Altern. Complement. Med. 2012, 18, 1108-1120. [CrossRef] [PubMed]

32. STRICTA. Standards for Reporting Interventions in Controlled Trials of Acupuncture. Available online: http:/ / www.stricta.info/ (accessed on 25 July 2016).

33. DC's Improbable Science Blog. Acupuncture Is a Theatrical Placebo: The End of a Myth. 30 May 2013. Available online: http:/ /www.dcscience.net/2013/05/30/acupuncture-is-a-theatrical-placebo-the-end-ofa-myth/ (accessed on 17 June 2016).

34. Want, S.M.; Harris, R.E.; Lin, Y.C.; Gan, T.J. Acupuncture in 21st century anesthesia: Is there a needle in the haystack? Anesth. Analg. 2013, 116, 1356-1359.

35. Deng, S.; Zhao, X.; Du, R.; He, S.; Wen, Y.; Huang, L.; Tian, G.; Zhang, C.; Meng, Z.; Shi, X. Is acupuncture no more than a placebo? Extensive discussion required about possible bias. Exp. Ther. Med. 2015, 10, 1247-1252. [CrossRef] [PubMed]

36. Lundeberg, T.; Lund, I.; Naslund, J.; Thomas, M. The Emperor's sham-Wrong assumption that sham needling is sham. Acupunct. Med. 2008, 26, 239-242. [CrossRef] [PubMed]

(C) 2016 by the author. Licensee MDPI, Basel, Switzerland. This article is an open access article distributed under the terms and conditions of the Creative Commons Attribution (CC BY) license (http:/ / creativecommons.org/licenses/by/4.0/). 

MDPI

St. Alban-Anlage 66

4052 Basel

Switzerland

Tel. +41616837734

Fax +41 613028918

www.mdpi.com

Medicines Editorial Office

E-mail: medicines@mdpi.com

www.mdpi.com/journal/medicines

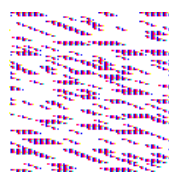



MDPI

St. Alban-Anlage 66

4052 Basel

Switzerland

Tel: +41 616837734

Fax: +41 613028918 